NIST Technical Note 2065

\title{
Room Temperature Fracture Toughness Characterization of Additively Manufactured Ti-6Al-4V
}

Enrico Lucon

Jake Benzing

Nik Hrabe

This publication is available free of charge from: https://doi.org/10.6028/NIST.TN.2065

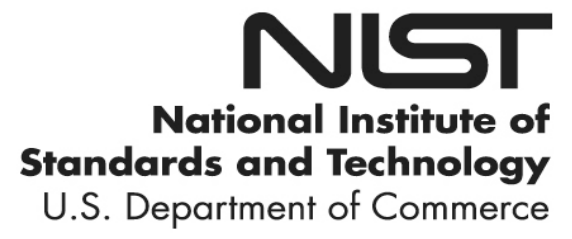


NIST Technical Note 2065

\title{
Room Temperature Fracture Toughness Characterization of Additively Manufactured Ti-6Al-4V
}

\author{
Enrico Lucon \\ Jake Benzing \\ Nik Hrabe \\ Applied Chemicals and Materials Division \\ Material Measurement Laboratory
}

This publication is available free of charge from:

https://doi.org/10.6028/NIST.TN.2065

September 2019

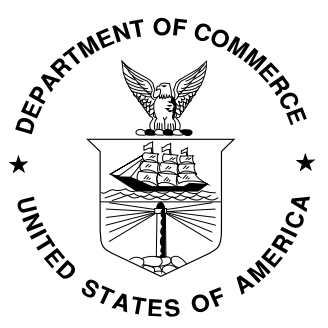

U.S. Department of Commerce Wilbur L. Ross, Jr., Secretary

National Institute of Standards and Technology Walter Copan, NIST Director and Undersecretary of Commerce for Standards and Technology 
Certain commercial entities, equipment, or materials may be identified in this document in order to describe an experimental procedure or concept adequately. Such identification is not intended to imply recommendation or endorsement by the National Institute of Standards and Technology, nor is it intended to imply that the entities, materials, or equipment are necessarily the best available for the purpose.

National Institute of Standards and Technology Technical Note 2065

Natl. Inst. Stand. Technol. Tech. Note 2065, 203 (September 2019) CODEN: NTNOEF

This publication is available free of charge from:

https://doi.org/10.6028/NIST.TN.2065 


\begin{abstract}
The room temperature elastic-plastic fracture toughness of additively manufactured (AM) Ti-6Al-4V was characterized by means of Elastic Compliance (EC) tests on Charpy-type fatigue precracked and side-grooved specimens. Various fabrication and material conditions were investigated: as-built parameters (effects of scan length and use of supports) and hot isostatic pressing parameters (effects of temperature and cooling rate). The results, although strictly not fully compliant with ASTM E1820-18 $\mathrm{a}^{\mathrm{e}}$, can be considered representative of the fracture toughness of the material in the different conditions, and compare favorably with literature data for both non-AM and AM Ti-6Al-4V. Additional analyses were conducted with another single-specimen approach (Normalization Data Reduction) and were compared with EC results.
\end{abstract}

\title{
Key words
}

Additive manufacturing; elastic compliance; fracture toughness; normalization data reduction; scan length; Ti-6Al-4V. 


\section{Table of Contents}

1. Introduction ................................................................................................................................ 1

2. Material and processing parameters ........................................................................ 2

3. Experimental setup and analysis procedures.............................................................. 3

4. Test Results - As Built Condition ............................................................................... 6

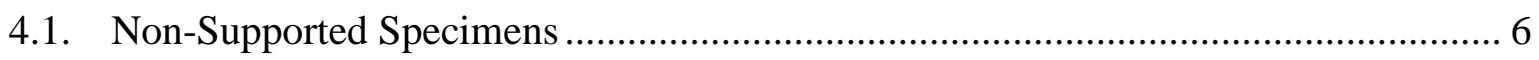

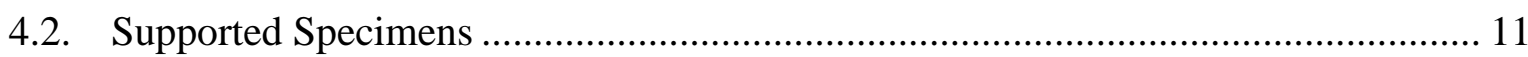

5. Test Results - Classic HIP Condition ........................................................................ 16

5.1. Non-Supported Specimens ............................................................................... 16

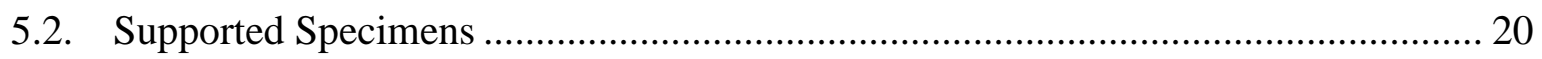

6. Test Results - Super- $\beta$ Transus HIP, Non-Supported Condition ................................. 21

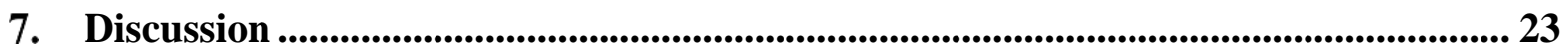

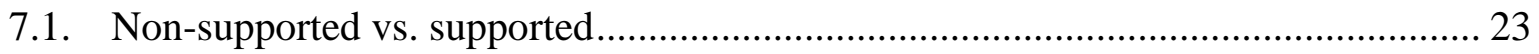

7.2. Influence of scan length .............................................................................. 25

7.3. As-built vs. HIP (classic and super- $\beta$ transus) …………………......................... 27

7.4. Crack jumps and lack-of-fusion (LoF) pores ……................................................ 29

7.5. Validity of the measured fracture toughness parameters ........................................... 31

7.6. Elastic Compliance vs. Normalization Data Reduction .............................................. 33

7.7. Comparison with literature fracture toughness values ............................................ 36

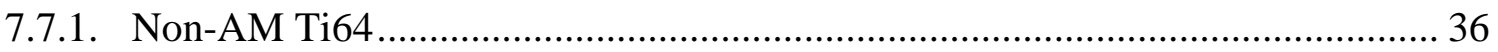

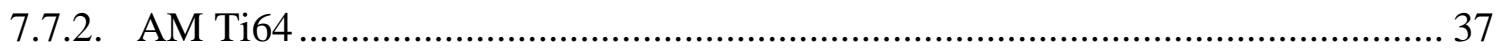

8. Conclusions........................................................................................................................ 38

Acknowledgements ............................................................................................................................. 39

References ....................................................................................................................................... 39

\section{List of Tables}

Table 1 - Overall test matrix for the investigation of the room temperature fracture toughness properties of AM Ti64 .......................................................................... 3

Table 2 - AM Ti64 room temperature tensile properties used in the analysis of the fracture toughness tests.

Table 3 - Results obtained on as-built (A), non-supported (N) specimens. ............................. 6

Table 4 - Results obtained on as-built (A), supported (S) specimens. ................................... 11

Table 5 - Results obtained on classically HIPed (C), non-supported (N) specimens............ 16

Table 6 - Results obtained on classically HIPed (C), supported (S) specimens..................... 20

Table 7 - Results obtained on super- $\beta$ transus HIPed, non-supported specimens................. 22

Table 8 - Comparison between fracture toughness of non-supported and supported specimens. 
Table 9 - Results of unpaired t-tests on the differences between non-supported and supported mean values (significance level $=0.05$ ). $p$-values $<0.05$ (green) indicate that differences are not statistically significant; $p$-values $>0.05$ (red) indicate that differences are statistically significant.

Table 10 - Literature fracture toughness values for non-AM Ti64, and results obtained on AM Ti64 in this investigation. 36

Table 11 - Literature fracture toughness values for AM Ti64 reported in [37] and results obtained in this investigation.

Table 12 - Literature fracture toughness values for AM Ti64 reported in [38] and results obtained in this investigation.

\section{List of Figures}

Fig. 1 - Drawing of the Charpy-type specimen before side-grooving. ................................. 4

Fig. 2 - Drawing of the Charpy-type specimen after side-grooving. ................................... 4

Fig. 3 - Data points and $J-R$ curves for as-built, non-supported specimens (scan length $=28$ $\mathrm{mm}) . J-R$ curves were obtained by fitting data points lying between dashed lines. ............... 7 Fig. 4 - Data points and $J-R$ curves for as-built, non-supported specimens (scan length $=56$ $\mathrm{mm}) . J-R$ curves were obtained by fitting data points lying between the dashed lines. .......... 8 Fig. 5 - Data points and $J-R$ curves for as-built, non-supported specimens (scan length $=70$ $\mathrm{mm}) . J-R$ curves were obtained by fitting data points lying between the dashed lines.......... 8 Fig. 6 - Data points and $J-R$ curves for as-built, non-supported specimens (scan length $=84$ $\mathrm{mm}$ ). $J-R$ curves were obtained by fitting data points lying between the dashed lines.......... 9 Fig. 7 - Individual $J-R$ curves for as-built, non-supported specimens. .............................. 9

Fig. 8 - Mean $J-R$ curves with $\pm 1 \sigma$ error bars for as-built, non-supported specimens. ........ 10 Fig. 9 - Mean values of $J_{Q}$ and $T_{M \text {,mean }}$ as a function of scan length for as-built, non-supported specimens. NOTE: points corresponding to scan length $=84 \mathrm{~mm}$ are slightly staggered for visual clarity.

Fig. 10 - Data points and $J-R$ curves for as-built, supported specimens (scan length $=$ $28 \mathrm{~mm}$ ). $J-R$ curves were obtained by fitting data points lying between dashed lines.

Fig. 11 - Data points and $J-R$ curves for as-built, supported specimens (scan length = $56 \mathrm{~mm}$ ). $J-R$ curves were obtained by fitting data points lying between the dashed lines. .... 13

Fig. 12 - Data points and $J-R$ curves for as-built, supported specimens (scan length $=$ $70 \mathrm{~mm}$ ). $J-R$ curves were obtained by fitting data points lying between the dashed lines.... 13

Fig. 13 - Data points and $J-R$ curves for as-built, supported specimens (scan length = $84 \mathrm{~mm}) . J-R$ curves were obtained by fitting data points lying between the dashed lines. .... 14

Fig. 14 - Individual $J-R$ curves for as-built, supported specimens. ................................... 14

Fig. 15 - Mean $J-R$ curves with errors $( \pm 1 \sigma)$ for as-built, supported specimens. ................ 15

Fig. 16 - Mean values of $J_{Q}$ and $T_{M, \text { mean }}$ as a function of scan length for as-built, supported specimens. NOTE: scan lengths are slightly staggered for visual clarity.....

Fig. 17 - Data points and $J-R$ curves for classically HIPed, non-supported specimens (scan length $=28 \mathrm{~mm}) . J-R$ curves were obtained by fitting points lying between dashed lines. ... 17 Fig. 18 - Data points and $J-R$ curves for classically HIPed, non-supported specimens (scan length $=70 \mathrm{~mm}) . J-R$ curves were obtained by fitting points lying between the dashed lines. 
Fig. 19 - Data points and $J-R$ curves for classically HIPed, non-supported specimens (scan length $=84 \mathrm{~mm}$ ). $J-R$ curves were obtained by fitting points lying between the dashed lines.

Fig. 20 - Individual $J-R$ curves for classically HIPed, non-supported specimens. ................ 18

Fig. 21 - Mean $J-R$ curves with $\pm 1 \sigma$ errors for classically HIPed, non-supported specimens.

Fig. 22 - Mean values of $J_{Q}$ and $T_{M, \text { mean }}$ as a function of scan length for as-built and supported specimens. NOTE: scan lengths are slightly staggered for visual clarity......

Fig 23 - Data points and $J-R$ curves for classically HIPed, supported specimens (scan length $=84 \mathrm{~mm}) . J-R$ curves were obtained by fitting points lying between the dashed lines........... 21

Fig. 24 - Data points obtained from the EC analyses for super- $\beta$ transus HIPed, non-supported specimens (scan length $=70 \mathrm{~mm}$ ).

Fig. 25 - Critical toughness values for non-supported and supported specimens, with $\pm 1 \sigma$

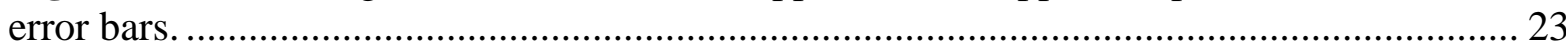

Fig. 26 - Tearing moduli at initiation for non-supported and supported specimens.............. 24

Fig. 27 - Mean values of tearing modulus for non-supported and supported specimens. .... 24

Fig. 28 - Mean values of $J_{Q}$ as a function of scan length. NOTE: scan lengths for as-built specimens are slightly staggered for clarity.

Fig. 29 - Mean values of $T_{M, J Q}$ as a function of scan length. NOTE: scan lengths are slightly staggered for clarity. 26

Fig. 30 - Mean values of $T_{M \text {, mean }}$ as a function of scan length. NOTE: scan lengths are slightly staggered for clarity. 26

Fig. 31 - Mean values of $J_{Q}$ with $\pm 1 \sigma$ error bars for non-supported specimens with scan length $=70 \mathrm{~mm}$. NOTE: the value for super- $\beta$ transus HIP is a rough engineering estimate. 27 Fig. 32 - Mean values of $J_{Q}$ with $\pm 1 \sigma$ error bars for non-supported specimens with $28 \mathrm{~mm}$, $70 \mathrm{~mm}$, and $84 \mathrm{~mm}$ scan lengths. 28

Fig. 33 - Mean values of $T_{M, J Q}$ with $\pm 1 \sigma$ error bars for non-supported specimens with 28 $\mathrm{mm}, 70 \mathrm{~mm}$, and $84 \mathrm{~mm}$ scan lengths.

Fig. 34 - Mean values of $T_{M, \text { mean }}$ with $\pm 1 \sigma$ error bars for non-supported specimens with 28 $\mathrm{mm}, 70 \mathrm{~mm}$, and $84 \mathrm{~mm}$ scan lengths.

Fig. 35 - Force and crack size vs. CMOD for specimen BN-5-1. NOTE: unloading/reloading cycles have been removed from the force/CMOD plot for clarity. 30

Fig. 36 - Fracture surfaces of specimens AS-4-2 (high density of LoF pores) and AS-4-3 (low density of LoF pores). Material condition: as-built, supported, scan length $=84 \mathrm{~mm}$. . 30 Fig. 37 - Comparison between values of critical fracture toughness, $J_{Q}$, obtained from EC and NDR analyses. 33

Fig. 38 - Comparison between values of tearing modulus at initiation, $T_{M, J Q}$, obtained from EC and NDR analyses.

Fig. 39 - Comparison between values of mean tearing modulus, $T_{M, \text { mean }}$, obtained from EC and NDR analyses. 


\section{Introduction}

Additive Manufacturing (AM), previously known as 3D printing, is a process in which material is joined or solidified under computer control to create a threedimensional object, with material being added together (such as liquid molecules or powder grains being fused together), typically layer by layer. In the 1990s, 3D printing was considered only suitable to produce functional or aesthetical prototypes. Nowadays, the precision, repeatability, and material range have increased to the point that $3 \mathrm{D}$ printing, or $\mathrm{AM}$, is considered as an industrial production technology.

The sale of AM products and services is projected to exceed $\$ 6.5$ billion worldwide by 2019 [1]. To enable use of metal AM in fatigue and fracture applications, a recent NIST/ASTM workshop [2] identified the need for a deeper understanding of fatigue and fracture behavior of these materials through detailed investigations of processing-structure-propertyperformance relationships. twofold:

The objective of the Additive Manufacturing Fatigue and Fracture Project at NIST is

- Develop appropriate measurement science for fatigue and fracture behavior of additively manufactured metals, to underpin a rapid qualification framework.

- Determine the effect of processing (including post-processing) and structure (e.g. internal defects, external defects, residual stress, crystallographic microstructure, and chemistry) on fatigue and fracture properties of additively manufactured metals.

The first fracture measurements published in the framework of this project characterized the impact properties of electron-beam melted (EBM) Ti-6Al-4V by means of instrumented tests on miniaturized Charpy specimens [3,4]. Tests were performed in two different orientations with respect to the build direction (horizontal and vertical), as well as in the as-built and Hot Isostatic Pressed (HIPed) conditions. The results showed a deleterious effect of internal porosity and a significant influence of texture variations on absorbed energy.

Ti-6Al-4V (commonly, and hereinafter, referred to as Ti64) is the most widely used titanium alloy, featuring good machinability and excellent mechanical properties. It offers the best all-round performance for a variety of weight reduction applications in aerospace, automotive, and marine equipment. Its high strength, low weight, and outstanding corrosion resistance has led to a wide range of successful applications that demand high levels of reliable performance in surgery and medicine (e.g. implants and prosthesis), aerospace, automotive, chemical plants, power generation, oil and gas extraction, sports, and other major industries.

This Technical Note reports on an extensive fracture toughness test campaign on AM Ti64, consisting of 50 tests on Charpy-type specimens performed at room temperature by means of the single-specimen elastic compliance (EC) technique, which allowed determining both critical toughness values of $J$-integral at crack initiation $\left(J_{Q}\right)$ and crack resistance $(J-R)$ curves. The following manufacturing parameters were investigated in this campaign:

- As-built versus two types of HIPing (classic and super- $\beta$ transus).

- Non-supported versus supported specimens ${ }^{1}$.

\footnotetext{
${ }^{1}$ Specimens directly attached to the build plate were identified as "non-supported", while "supported" specimens were connected to the build plate by means of standard thin wafer supports.
} 
- Different scan lengths ${ }^{2}$.

A preliminary fracture toughness study was also performed [6] on non-supported and supported specimens, all in classic HIP condition, for a specific scan length ( $84 \mathrm{~mm})$. The main objective of this activity (besides developing and fine-tuning the experimental procedure) was to determine whether very sharp Electrically Discharge Machined (EDM) notches could be a reliable alternative to fatigue precracks for AM Ti-6Al-4V Charpy-type specimens. This was found to be case for several steels in a previous investigation [7]. The results of the preliminary study [6] showed that fatigue precracking had to be used for further testing, in order to avoid fracture toughness overestimation caused by the finite root radius of an EDM notch. Based on the outcome of this preliminary campaign, only fatigue precracked specimens were used for the investigation described herein.

\section{Material and processing parameters}

The AM Ti64 parts used in this study were fabricated using an Arcam ${ }^{3}$ A1 EBM machine (accelerating voltage $60 \mathrm{kV}$, layer thickness $50 \mu \mathrm{m}$, speed factor 35, and software version 3.2.132) and standard Arcam Ti-6Al-4V gas atomized powder (particle size range approximately $40 \mu \mathrm{m}$ to $100 \mu \mathrm{m}$, average approximately $70 \mu \mathrm{m}$ ).

Parts on the build plate were organized in such a way that the $\mathrm{X}$ and $\mathrm{Y}$ scan lengths (distance the electron beam travels on a single track before turning around) were the same for a given melt model. Melt models were designed to have different overall scan lengths $(28 \mathrm{~mm}$, $56 \mathrm{~mm}, 70 \mathrm{~mm}$, and $84 \mathrm{~mm}$ ). In some cases, $5 \mathrm{~mm}$ tall support structures were used, while other parts were not supported (directly attached to the build plate). All parts were manufactured to have the same total build height of $58 \mathrm{~mm}$ (including the height of the support structures when applicable).

Parts were subjected to two different HIP treatments:

(a) "Classic" sub- $\beta$ transus HIP $\left(900{ }^{\circ} \mathrm{C}, 100 \mathrm{MPa}, 2 \mathrm{~h}\right.$, Ar environment, standard heating and cooling rates) [8].

(b) Super- $\beta$ transus HIP $\left(1050{ }^{\circ} \mathrm{C}, 100 \mathrm{MPa}, 2 \mathrm{~h}\right.$, rapid cooling in Ar) with an additional HIP $\left(800{ }^{\circ} \mathrm{C}, 30 \mathrm{MPa}, 2 \mathrm{~h}\right.$, slow cooling in $\mathrm{Ar}$ - meant for martensite tempering), which however requires further analysis and optimization.

The processing parameters whose influence was investigated in this study (and in the preliminary campaign that investigated the $84 \mathrm{~mm}$ scan length documented in [6]) were the following:

- As built vs. HIPed.

- Different scan lengths: $28 \mathrm{~mm}, 56 \mathrm{~mm}, 70 \mathrm{~mm}$, and $84 \mathrm{~mm}$ for as-built specimens; $28 \mathrm{~mm}$ and $70 \mathrm{~mm}$ for classic HIP; $70 \mathrm{~mm}$ for super- $\beta$ transus HIP.

- Non-supported vs. supported specimens.

\footnotetext{
${ }^{2}$ Scan length is a manufacturer-specific parameter that corresponds to the distance the electron beam travels on a single track before turning around to begin the next track. It has been shown to determine energy density and affect texture [5].

${ }^{3}$ Certain commercial software, equipment, instruments or materials are identified in this paper in order to adequately specify the experimental procedure. Such identification is not intended to imply recommendation or endorsement by the National Institute of Standards and Technology, nor is it intended to imply that the equipment or materials identified are necessarily the best available for the purpose.
} 
The overall test matrix is presented in Table 1. The total number of tests performed (including the preliminary study) was 50 .

Table 1 - Overall test matrix for the investigation of the room temperature fracture toughness properties of AM Ti64.

\begin{tabular}{|c|c|c|c|}
\hline $\begin{array}{l}\text { Material } \\
\text { condition }\end{array}$ & $\begin{array}{l}\text { Non-supported } \\
\text { vs. supported }\end{array}$ & $\begin{array}{l}\text { Scan length } \\
(\mathrm{mm})\end{array}$ & $\begin{array}{l}\text { Number } \\
\text { of tests }\end{array}$ \\
\hline \multirow{2}{*}{ As-built } & Non-supported & $\begin{array}{l}28 \\
56 \\
70 \\
84\end{array}$ & $\begin{array}{l}4 \\
4 \\
4 \\
4\end{array}$ \\
\hline & \multirow[t]{2}{*}{ Supported } & $\begin{array}{l}28 \\
56 \\
70 \\
84\end{array}$ & $\begin{array}{l}4 \\
4 \\
4 \\
4\end{array}$ \\
\hline \multirow[b]{3}{*}{ Suner- $\beta$ transus HIP } & & 84 & 3 \\
\hline & \multirow[t]{2}{*}{ Non-supported } & $\begin{array}{l}28 \\
70 \\
84\end{array}$ & $\begin{array}{l}4 \\
4 \\
3\end{array}$ \\
\hline & & 70 & 4 \\
\hline
\end{tabular}

\section{Experimental setup and analysis procedures}

All tests were performed on fatigue precracked and side-grooved Charpy-type specimens. The specimens were machined with integral knife edges that allowed installing a clip-gage for monitoring crack mouth opening displacement (CMOD). The technical drawings are provided in Fig. 1 (specimen before side-grooving) and Fig. 2 (specimen after sidegrooving).

Specimen precracking was performed by cyclic fatigue in accordance with Section 7.4 of ASTM E1820-18a [9] up to a nominal crack-size-to-width ratio $a / W=0.45$. After precracking, specimens were side-grooved with an overall thickness reduction of $2 \mathrm{~mm}$ or $20 \%$ ( $1 \mathrm{~mm}$, or $10 \%$, per side).

Tests were conducted in three-point-bending $\left(\operatorname{span}^{4} S=4 W=40 \mathrm{~mm}\right)$ on a servohydraulic universal machine equipped with a calibrated load cell having $5 \mathrm{kN}$ capacity. As mentioned above, CMOD was measured by means of a clip-gage with a maximum range of 5 $\mathrm{mm}$.

All tests were performed at room temperature, $22{ }^{\circ} \mathrm{C} \pm 2{ }^{\circ} \mathrm{C}$, in air. Tests were conducted in actuator displacement ("stroke") control, at a rate of $0.1 \mathrm{~mm} / \mathrm{min}$ (quasi-static testing).

\footnotetext{
${ }^{4}$ The span $S$ is the distance between the lower rollers in the three-point-bending fixture used for the tests.
} 

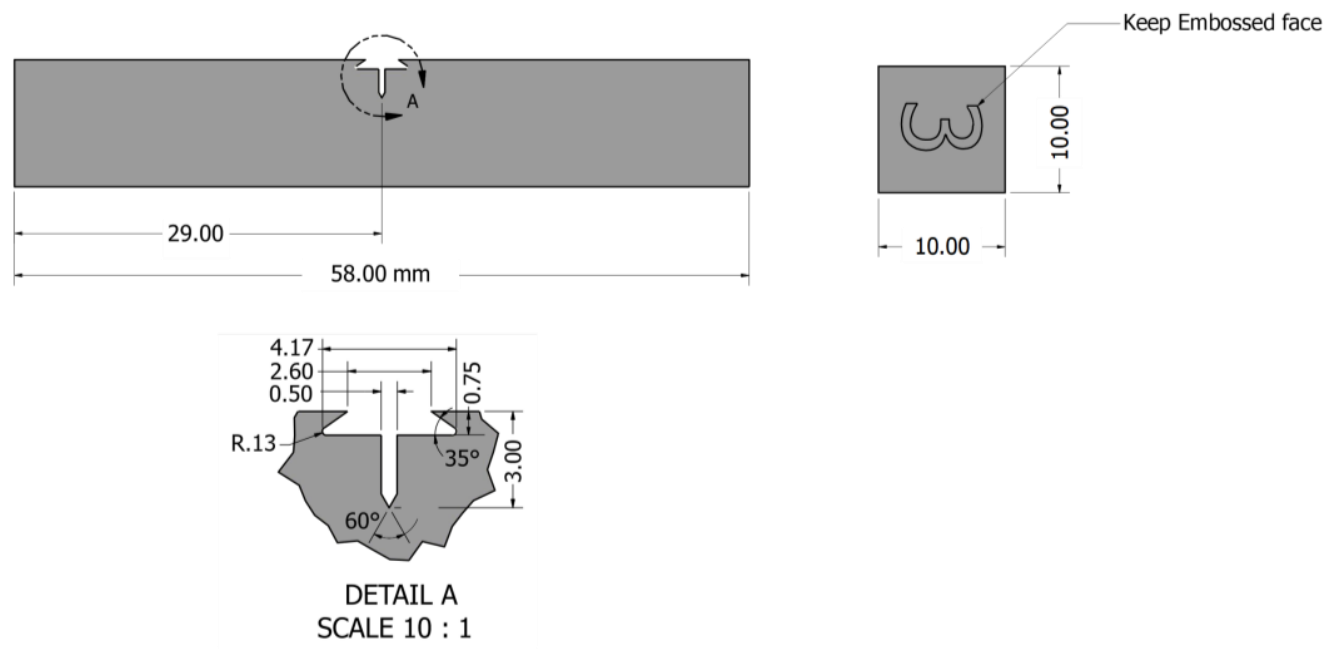

Fig. 1 - Drawing of the Charpy-type specimen before side-grooving.

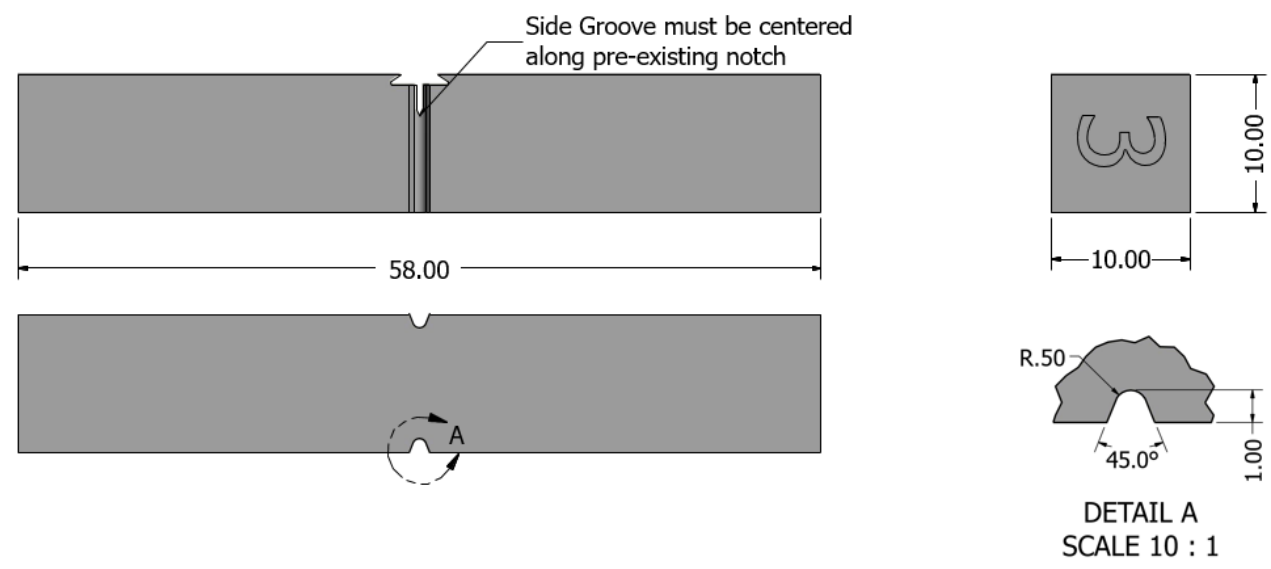

Fig. 2 - Drawing of the Charpy-type specimen after side-grooving.

The single-specimen methodology used to obtain fracture toughness parameters (planestrain fracture toughness, $J_{Q}$, and crack resistance, $J$ - $R$, curves) was the elastic compliance (EC) method, whereby the specimen is periodically unloaded and reloaded during the test to estimate the current crack size based on the specimen elastic compliance ${ }^{5}$ (slope of the linear fit of the unloading/reloading force-CMOD cycle). For every unloading/reloading cycle, the values of $J$-integral and crack extension $\Delta a$ are calculated, so that a complete $J$ - $R$ curve and critical toughness $J_{Q} / J_{I c}$ can be established in accordance with Annexes A8 and A9 of E1820-18a ${ }^{\varepsilon 1}$, respectively. In order to quantify crack resistance, another parameter (currently not included in E1820, but covered in the past by ASTM E813 ${ }^{6}$ ) was calculated and reported: the tearing modulus $T_{M}$, a non-dimensional quantity introduced by Paris in $1977[10,11]$ as:

$$
T_{M}=\frac{E}{\sigma_{0}^{2}} \cdot \frac{d J}{d a} \quad \text {, }
$$

\footnotetext{
${ }^{5}$ (Elastic) compliance is defined in ASTM E1820-18 $\mathrm{a}^{\varepsilon 1}$ as the ratio of displacement increment to force increment. ${ }^{6}$ ASTM E813 (Test Method for $J_{I C}$, A Measure of Fracture Toughness) was a precursor to E1820 and was withdrawn in 1997. Its last version was E813-89
} 
where $E$ is the Young's modulus, $\sigma_{0}$ is the flow stress (average of yield and tensile stresses), and $d J / d a$ is the slope ${ }^{7}$ of the power law fit to the $J-\Delta a$ data points inside the region of qualified data according to E1820. In this study, we reported values of tearing modulus at initiation $\left(J_{Q}\right)$, $T_{M, J Q}$, and the average value between initiation and $J_{\text {limit }}$ (limiting $J$-capacity of the specimen), $T_{M, \text { mean }}$.

In addition to the EC procedure, another single-specimen method was used for analysis: the Normalization Data Reduction (NDR) technique, which is standardized in Annex A15 of ASTM E1820-18 $\mathrm{a}^{\varepsilon 1}$. This approach is used to obtain a $J-R$ curve directly from a forcedisplacement record, together with initial and final crack size measurements taken from the specimen fracture surface [12-15]. The NDR analyses were conducted by means of a freeware tool recently made available by Oak Ridge National Laboratory (ORNL) [16], and the results were eventually compared with those of the EC analyses. Such comparison will be examined in the "Discussion" section.

The tests were conducted according to Section 8 (Procedure) of ASTM E1820-18a ${ }^{\varepsilon 1}$ and the analyses were performed following Section 9 (Analysis of Results). Values of $J$-integral and crack size were calculated by means of the formulas provided in Annex A1 for bend, $\mathrm{SE}(\mathrm{B})$, specimens ${ }^{8}$. For the estimation of crack size from elastic compliance, the recommendations of Appendix X3 were followed:

- only the unload part was used, and

- the first $5 \%$ and the last $5 \%$ of the unload/reload sequence (where significant nonlinearities can occur) were discarded.

Moreover, in order to improve the accuracy of EC crack growth predictions, predicted crack sizes $\left(a_{i, p r e d}\right)$ were adjusted based on the measured initial $\left(a_{0}\right)$ and final $\left(a_{p}\right)$ crack sizes, using the following relationship:

$$
a_{i, a d j}=a_{0 q}+\frac{a_{p}-a_{0 q}}{a_{p, p r e d}-a_{0 q}}\left(a_{i, p r e d}-a_{0 q}\right)
$$

where $a_{i, a d j}$ is the adjusted crack size and $a_{0 q}$ is the initial crack size estimated from compliance in accordance with Annex A9. Eq. (2) is the recommended adjustment for crack size predictions obtained from another single-specimen technique (Direct Current Electric Potential Difference), which is described by Annex A18 of ASTM E1820-18 $\mathrm{a}^{\varepsilon 1}$.

For the analyses, we used tensile properties (yield and tensile stresses) measured at room temperature at NIST on as-built and HIPed specimens in a recent study [17] for various scan lengths. The values of yield stress and tensile stress for the investigated conditions were obtained by linearly fitting the tensile properties measured in [17] as a function of scan length. The value of Young's modulus to be used for all conditions $(E=128.8 \mathrm{GPa})$ was estimated in [6] by forcing the average elastic compliance of sharp-notched specimens to correspond to the known initial value of the machined notch $(V$-notch + EDM slit $=4.5 \mathrm{~mm})$. Table 2 summarizes the tensile properties used in the analysis of the fracture toughness tests.

\footnotetext{
${ }^{7}$ Note that ASTM E813 prescribed a linear fit of the valid $J$ - $\Delta a$ data points, which yielded a unique value of $d J / d a$ and hence of $T_{M}$. However, E1820 prescribes a power law fit, and therefore the tearing modulus assumes different values along the $J-R$ curve.

${ }^{8}$ The precracked Charpy-type specimen is just an example of bend, $\mathrm{SE}(\mathrm{B})$, specimen with $\mathrm{B} \times \mathrm{B}$ cross section $(10 \mathrm{~mm} \times 10 \mathrm{~mm})$. The formulas given in ASTM E1820-18 $\mathrm{a}^{\varepsilon 1}$, Annex A1, for SE(B) specimens are therefore fully applicable.
} 
Table 2 - AM Ti64 room temperature tensile properties used in the analysis of the fracture toughness tests.

\begin{tabular}{|c|c|c|c|c|}
\hline $\begin{array}{l}\text { Material } \\
\text { condition }\end{array}$ & $\begin{array}{l}\text { Non-supported } \\
\text { vs. supported }\end{array}$ & $\begin{array}{l}\text { Scan length } \\
(\mathrm{mm})\end{array}$ & $\begin{array}{l}\text { Yield stress } \\
\text { (MPa) }\end{array}$ & $\begin{array}{l}\text { Tensile stress } \\
\text { (MPa) }\end{array}$ \\
\hline \multirow{8}{*}{ As-built } & \multirow{4}{*}{ Non-supported } & 28 & 826 & 967 \\
\hline & & 56 & 834 & 972 \\
\hline & & 70 & 838 & 975 \\
\hline & & 84 & 841 & 977 \\
\hline & \multirow{5}{*}{ Supported } & 28 & 860 & 960 \\
\hline & & 56 & 876 & 974 \\
\hline & & 70 & 884 & 981 \\
\hline & & 84 & 892 & 988 \\
\hline \multirow{4}{*}{ Classic HIP } & & 84 & 841 & 952 \\
\hline & \multirow{4}{*}{ Non-supported } & 28 & 804 & 919 \\
\hline & & 70 & 836 & 946 \\
\hline & & 84 & 846 & 955 \\
\hline Super- $\beta$ transus HIP & & 70 & $885^{9}$ & $985^{8}$ \\
\hline
\end{tabular}

\section{Test Results - As Built Condition}

\subsection{Non-Supported Specimens}

Sixteen fatigue precracked and side-grooved Charpy-type specimens were tested at room temperature for the as-built, non-supported condition, 4 for each of the following scan lengths: $28 \mathrm{~mm}, 56 \mathrm{~mm}, 70 \mathrm{~mm}$, and $84 \mathrm{~mm}$.

The results obtained from the EC and NDR techniques are provided in Table 3, with average values and standard deviations $(\sigma)$. None of the measured $J_{Q}$ values could be validated as plane-strain fracture toughness $J_{I c}$ in accordance with ASTM E1820-18 $\mathrm{a}^{\varepsilon 1}$ (the reasons for invalidity are indicated in the Table).

$J-\Delta a$ data points and $J-R$ curves are compared in Fig. 3 (scan length $=28 \mathrm{~mm}$ ), Fig. 4 (56 mm), Fig. 5 (70 mm), and Fig. 6 (84 mm).

For several of the tests performed, significant "crack jumps" (large crack advances between two consecutive unloading/reloading cycles) were observed, corresponding to unstable ductile tearing events. The occurrence of these "jumps" was more frequent for shorter scan lengths (Fig. 3 and Fig. 4), causing very low values of tearing modulus for those tests (between $0.1 \mathrm{MPa}$ and $5 \mathrm{MPa}$ ).

Table 3 - Results obtained on as-built (A), non-supported (N) specimens.

\begin{tabular}{|c|c|c|c|c|c|c|c|c|c|}
\hline \multicolumn{2}{|c|}{ Methodology } & \multicolumn{4}{|c|}{ Elastic Compliance } & \multicolumn{4}{|c|}{ Normalization Data Reduction } \\
\hline $\begin{array}{l}\text { Specimen } \\
\text { id }\end{array}$ & $\begin{array}{c}\text { Scan } \\
\text { length }(\mathbf{m m})\end{array}$ & $\begin{array}{c}J_{Q} \\
\left(\mathbf{k J} / \mathbf{m}^{2}\right)\end{array}$ & $\begin{array}{c}\text { Invalidity } \\
\text { causes }\end{array}$ & $\begin{array}{c}T_{M, J Q} \\
(\mathbf{M P a})\end{array}$ & $\begin{array}{l}T_{M, \text { mean }} \\
(\mathrm{MPa})\end{array}$ & $\begin{array}{c}J Q \\
\left(\mathbf{k J} / \mathbf{m}^{2}\right)\end{array}$ & $\begin{array}{c}\text { Invalidity } \\
\text { causes }\end{array}$ & $\begin{array}{c}T_{M, J Q} \\
(\mathrm{MPa})\end{array}$ & $\begin{array}{l}T_{M, \text { mean }} \\
(\mathrm{MPa})\end{array}$ \\
\hline AN-8-1 & \multirow{4}{*}{28} & 89.59 & $\mathrm{c}, \mathrm{f}, \mathrm{g}$ & 3.81 & 2.25 & 67.84 & $\mathrm{e}$ & 8.64 & 5.25 \\
\hline AN-8-2 & & 88.10 & $\mathrm{c}, \mathrm{d}, \mathrm{f}, \mathrm{g}$ & 5.47 & 3.25 & 72.83 & e & 11.17 & 6.91 \\
\hline AN-8-3 & & 102.80 & $\mathrm{c}, \mathrm{d}, \mathrm{f}, \mathrm{g}$ & 1.73 & 1.01 & 71.60 & $\mathrm{e}$ & 11.93 & 7.42 \\
\hline AN-8-4 & & 92.45 & $\mathrm{c}, \mathrm{f}$ & 3.52 & 2.08 & 69.94 & $\mathrm{e}$ & 10.33 & 6.36 \\
\hline \multicolumn{2}{|c|}{ Average } & 93.23 & - & 3.48 & 2.06 & 70.55 & - & 10.52 & 6.49 \\
\hline \multicolumn{2}{|c|}{ Standard deviation } & 6.630 & - & 1.458 & 0.872 & 2.159 & - & 1.413 & 0.932 \\
\hline
\end{tabular}

\footnotetext{
${ }^{9}$ Values measured for scan length $=78 \mathrm{~mm}$ (only value of scan length investigated).
} 


\begin{tabular}{|c|c|c|c|c|c|c|c|c|c|}
\hline \multicolumn{2}{|c|}{ Methodology } & \multicolumn{4}{|c|}{ Elastic Compliance } & \multicolumn{4}{|c|}{ Normalization Data Reduction } \\
\hline $\begin{array}{l}\text { Specimen } \\
\text { id }\end{array}$ & $\begin{array}{c}\text { Scan } \\
\text { length }(\mathbf{m m})\end{array}$ & $\begin{array}{c}J Q \\
\left(\mathbf{k J} / \mathbf{m}^{2}\right)\end{array}$ & $\begin{array}{l}\text { Invalidity } \\
\text { causes }\end{array}$ & $\begin{array}{c}T_{M, J Q} \\
\text { (MPa) }\end{array}$ & $\begin{array}{l}T_{M, \text { mean }} \\
(\mathrm{MPa})\end{array}$ & $\begin{array}{c}J Q \\
\left(\mathbf{k J} / \mathbf{m}^{2}\right)\end{array}$ & $\begin{array}{l}\text { Invalidity } \\
\text { causes }\end{array}$ & $\begin{array}{c}T_{M, J Q} \\
(\mathrm{MPa})\end{array}$ & $\begin{array}{l}T_{M, \text { mean }} \\
(\mathrm{MPa})\end{array}$ \\
\hline AN-6-1 & \multirow{4}{*}{56} & 95.93 & $\mathrm{c}, \mathrm{f}$ & 2.07 & 1.21 & 70.11 & $\mathrm{e}$ & 10.75 & 6.65 \\
\hline AN-6-2 & & 90.37 & $\mathrm{c}, \mathrm{d}, \mathrm{f}, \mathrm{g}$ & 0.57 & 0.33 & 70.49 & e & 8.23 & 5.00 \\
\hline AN-6-3 & & 88.32 & $c, f$ & 4.21 & 2.49 & 73.26 & $\mathrm{e}$ & 7.96 & 4.82 \\
\hline $\mathrm{AN}-6-4$ & & 96.24 & $c, f$ & 0.10 & 0.06 & 70.77 & e & 9.29 & 5.68 \\
\hline \multicolumn{2}{|c|}{ Average } & 92.71 & - & 1.74 & 1.02 & 71.16 & - & 9.06 & 5.54 \\
\hline \multicolumn{2}{|c|}{ Standard deviation } & 3.981 & - & 1.850 & 1.096 & 1.430 & - & 1.266 & 0.828 \\
\hline AN-5-1 & \multirow{4}{*}{70} & 142.32 & $\mathrm{c}, \mathrm{d}$ & 6.60 & 3.97 & 102.33 & $\mathrm{e}$ & 18.77 & 11.99 \\
\hline AN-5-2 & & 134.41 & c & 6.86 & 4.12 & 99.91 & $\mathrm{e}$ & 15.78 & 9.92 \\
\hline AN-5-3 & & 130.78 & $\mathrm{c}$ & 8.65 & 5.23 & 101.31 & $\mathrm{e}$ & 16.81 & 10.62 \\
\hline AN-5-4 & & 126.95 & $\mathrm{c}$ & 9.66 & 5.87 & 92.09 & $\mathrm{e}$ & 17.28 & 11.01 \\
\hline \multicolumn{2}{|c|}{ Average } & 133.61 & - & 7.94 & 4.80 & 98.91 & - & 17.16 & 10.89 \\
\hline \multicolumn{2}{|c|}{ Standard deviation } & 6.554 & - & 1.463 & 0.908 & 4.654 & - & 1.245 & 0.867 \\
\hline AN-4-1 & \multirow{4}{*}{84} & 101.99 & $\mathrm{c}, \mathrm{d}$ & 4.11 & 2.43 & 94.93 & $\mathrm{e}$ & 10.01 & 6.10 \\
\hline AN-4-2 & & 135.18 & $\mathrm{c}, \mathrm{d}$ & 13.47 & 8.31 & 104.49 & $\mathrm{e}$ & 22.76 & 14.90 \\
\hline AN-4-3 & & 130.02 & c & 17.31 & 10.86 & 98.70 & $\mathrm{e}$ & 24.37 & 16.23 \\
\hline AN-4-4 & & 117.36 & $\mathrm{c}$ & 2.93 & 1.73 & 85.13 & e & 16.97 & 10.86 \\
\hline \multicolumn{2}{|c|}{ Average } & 121.14 & - & 9.45 & 5.83 & 95.81 & - & 18.53 & 12.02 \\
\hline \multicolumn{2}{|c|}{ Standard deviation } & 14.797 & - & 7.046 & 4.464 & 8.134 & - & 6.509 & 4.560 \\
\hline
\end{tabular}

LEGEND - Invalidity causes: $\mathrm{c}$ - Correlation coefficient of the fit used to calculate $a_{0 q}<0.96$.

$\mathrm{d}$ - One or more individual values of initial crack size, estimated from unloading/reloading sequences in the elastic range of the test, differ from the mean by more than $\pm 0.002 \mathrm{~W}$.

e - Final crack extension larger than $15 \%$ of the initial uncracked ligament.

$\mathrm{f}-$ Number of data points inside region of qualified data $<5$.

$\mathrm{g}$ - Distribution of data points inside the region of qualified data invalid (see ASTM E1820 section A9.6.4).

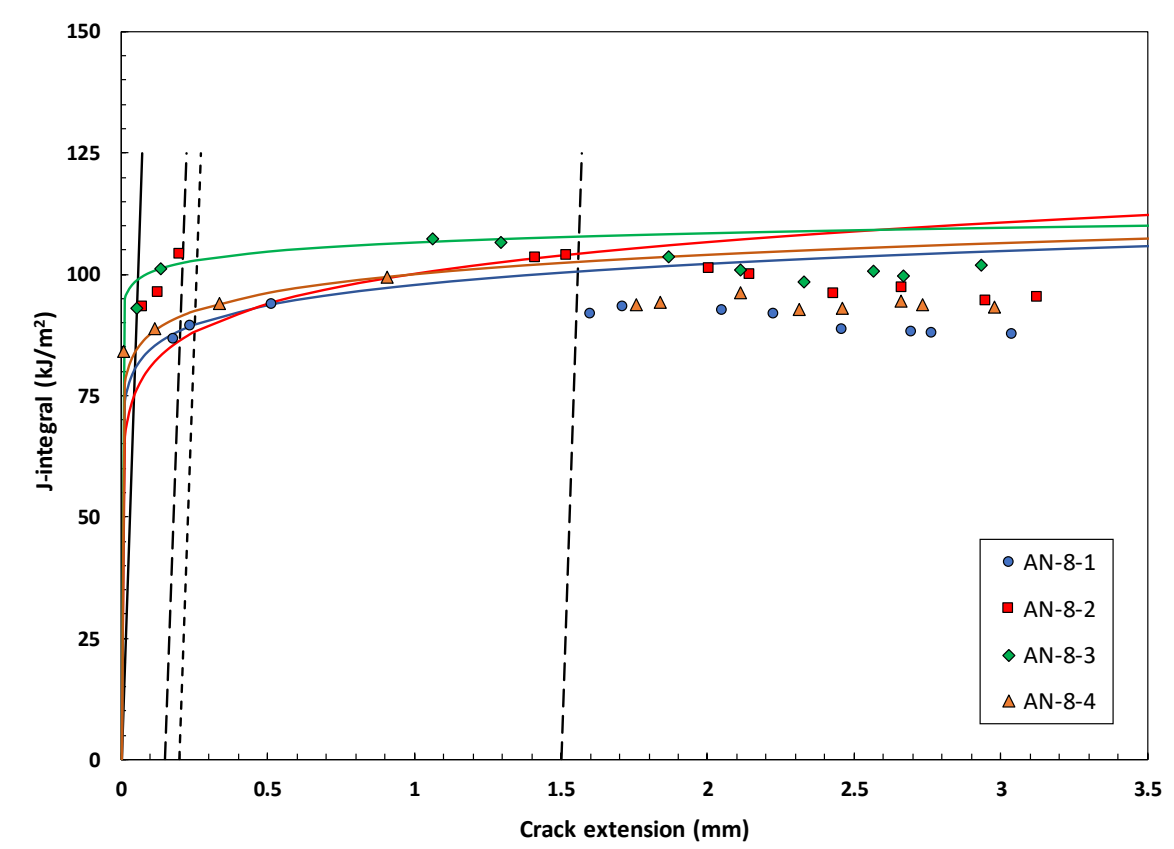

Fig. 3 - Data points and $J-R$ curves for as-built, non-supported specimens (scan length $=28$ $\mathrm{mm}) . J-R$ curves were obtained by fitting data points lying between dashed lines. 


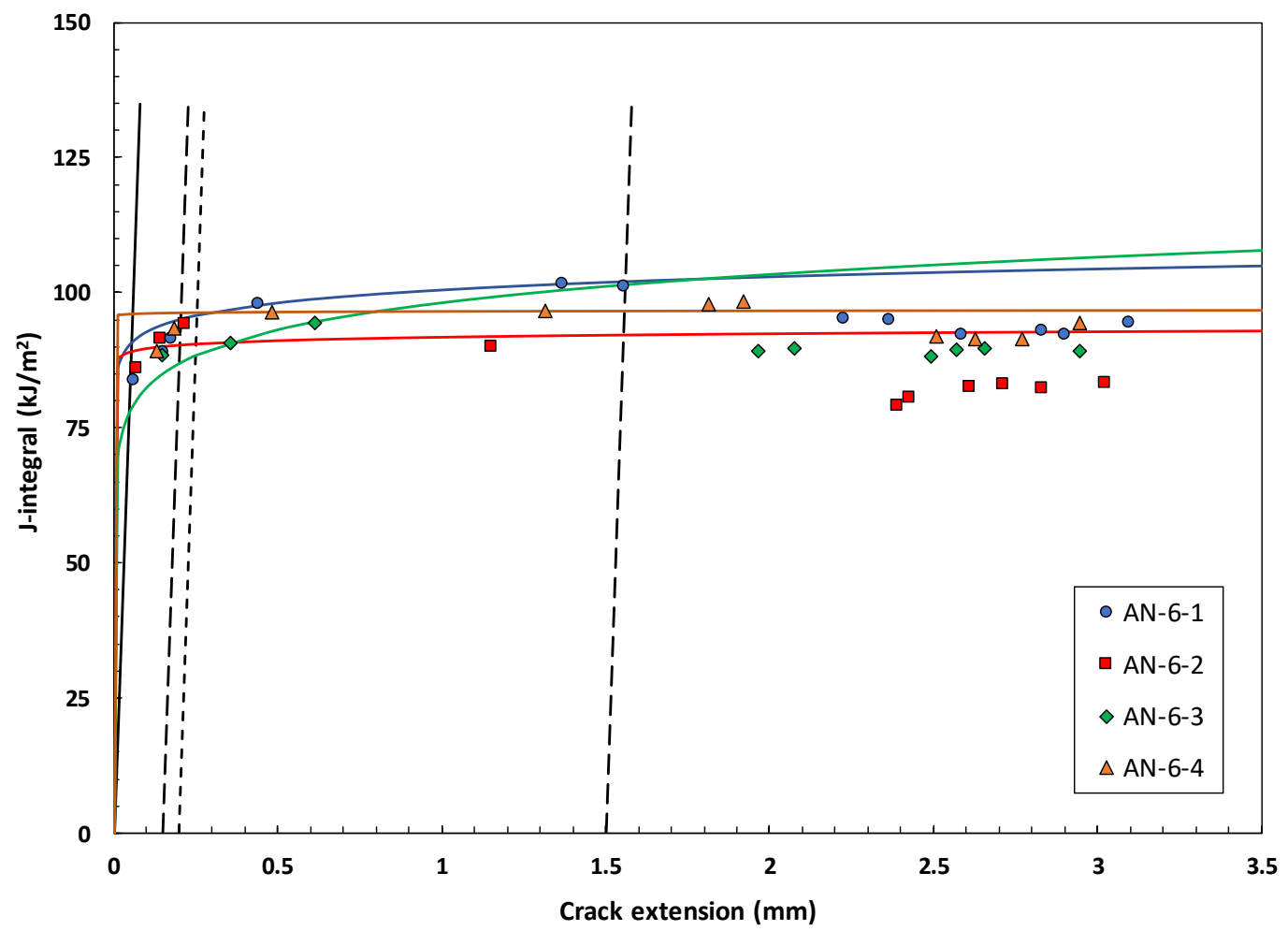

Fig. 4 - Data points and $J-R$ curves for as-built, non-supported specimens (scan length $=56$ $\mathrm{mm}) . J-R$ curves were obtained by fitting data points lying between the dashed lines.

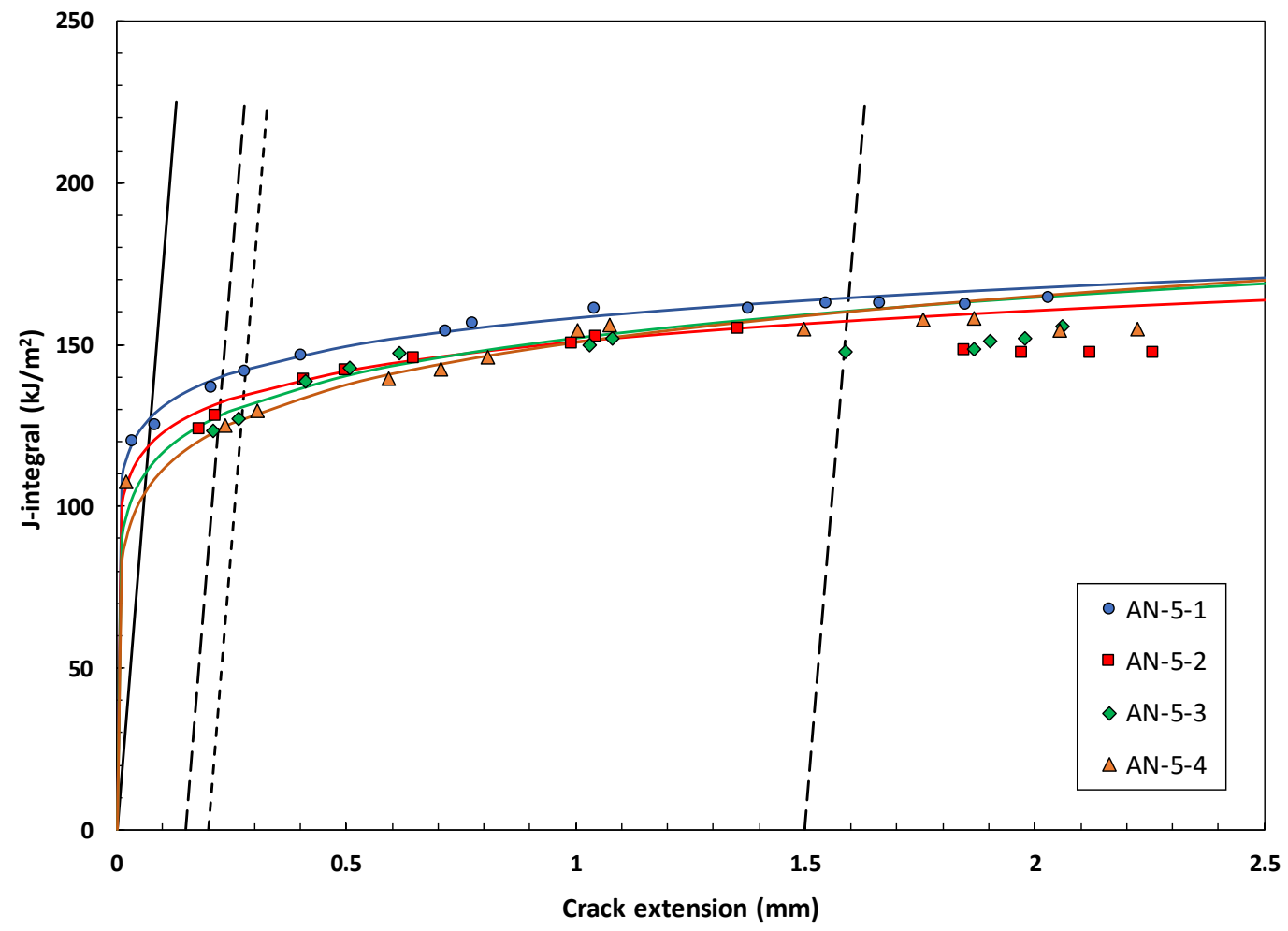

Fig. 5 - Data points and $J-R$ curves for as-built, non-supported specimens (scan length $=70$ $\mathrm{mm}) . J-R$ curves were obtained by fitting data points lying between the dashed lines. 


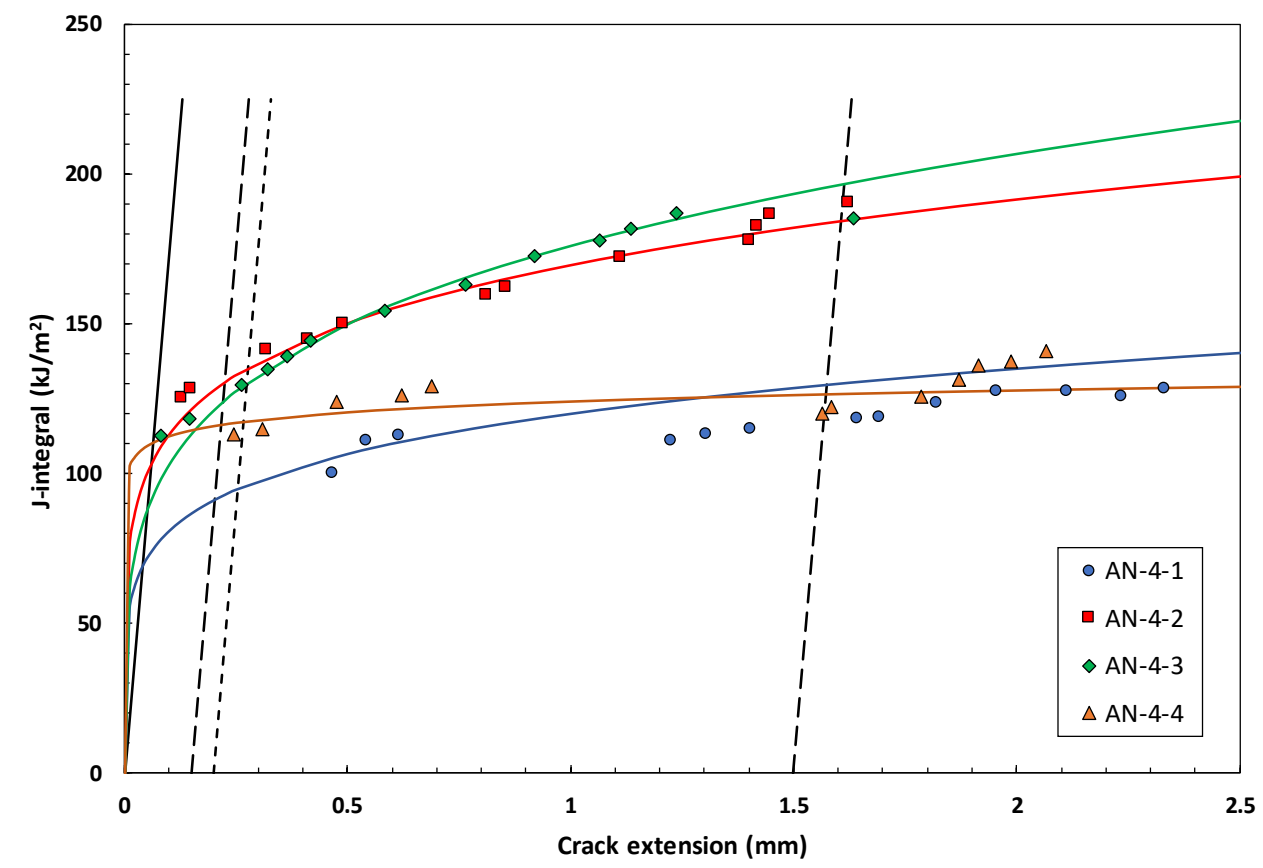

Fig. 6 - Data points and $J-R$ curves for as-built, non-supported specimens (scan length $=84$ $\mathrm{mm}) . J-R$ curves were obtained by fitting data points lying between the dashed lines.

The $J-R$ curves obtained for the different scan lengths are compared in Fig. 7 (individual curves) and Fig. 8 (mean curves with errors corresponding to one standard deviation, $1 \sigma)$. We observe that fracture toughness is higher for the longest scan lengths (70 $\mathrm{mm}$ and $84 \mathrm{~mm}$ ), both in terms of $J_{Q}$ and tearing modulus (slope of the $J-R$ curve). The longest scan length $(84 \mathrm{~mm})$ exhibits the largest scatter, while the shortest $(28 \mathrm{~mm})$ shows the smallest.

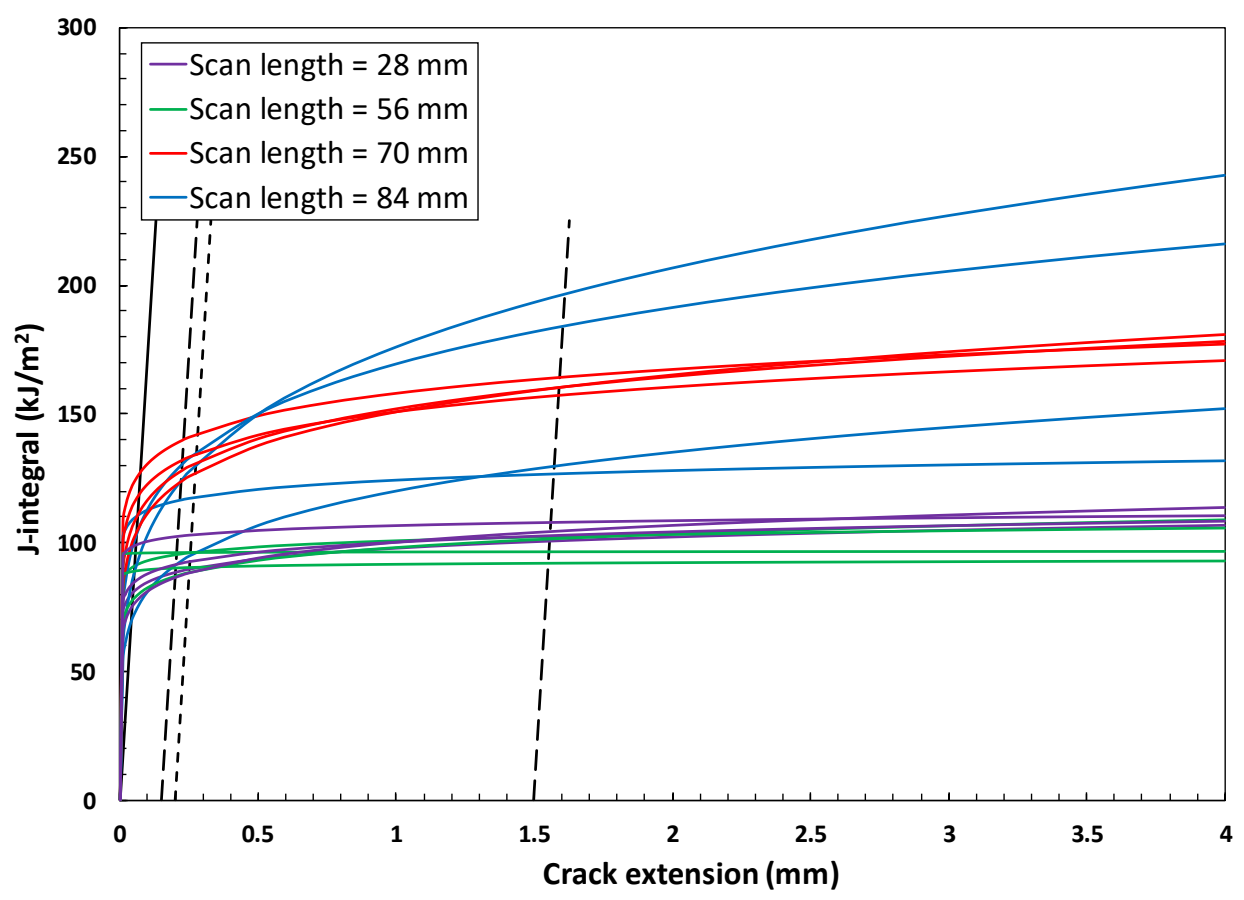

Fig. 7 - Individual $J-R$ curves for as-built, non-supported specimens. 


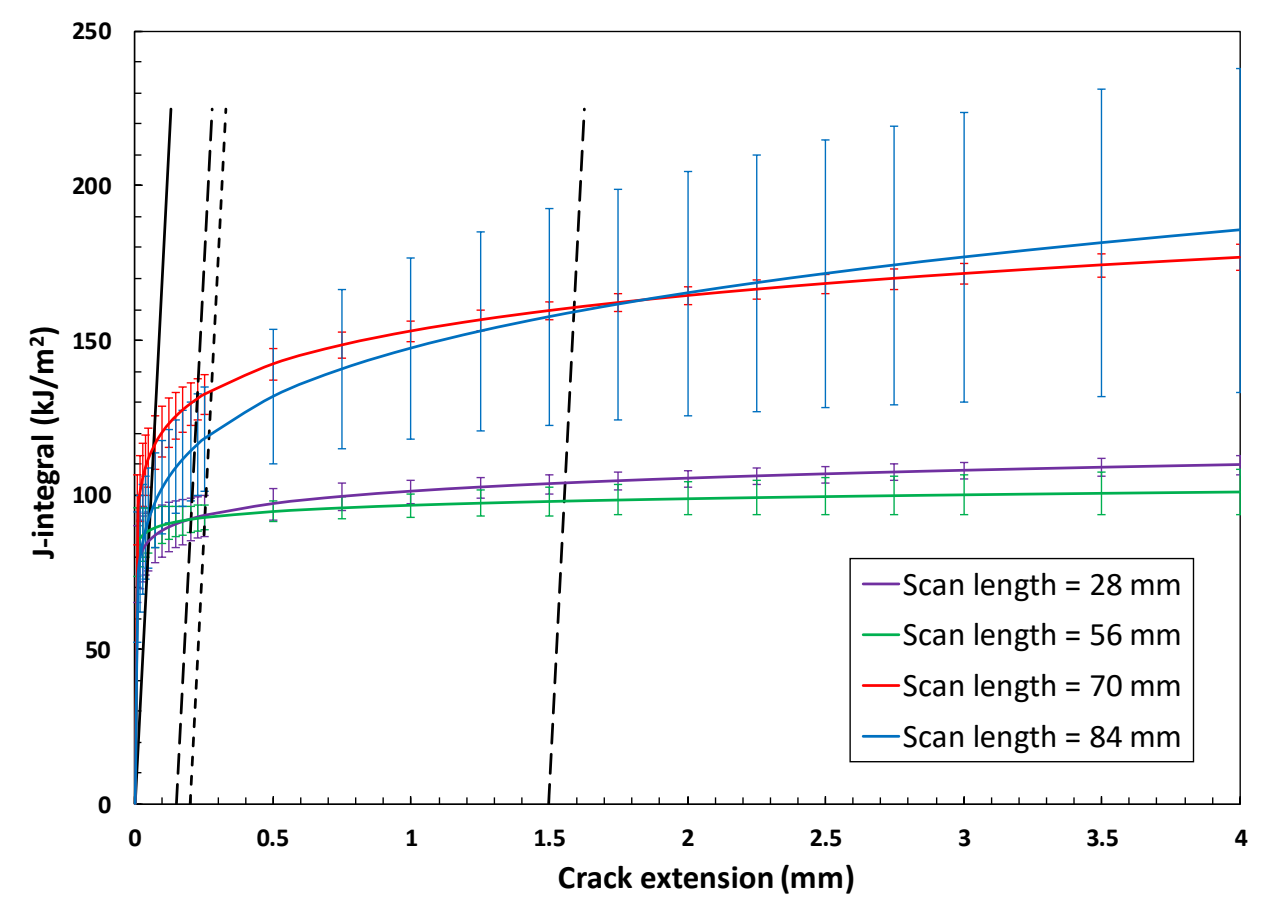

Fig. 8 - Mean $J-R$ curves with $\pm 1 \sigma$ error bars for as-built, non-supported specimens.

Mean values of $J_{Q}$ and $T_{M, \text { mean }}$, with $\pm 1 \sigma$ error bars, are plotted in Fig. 9 as a function of scan length.

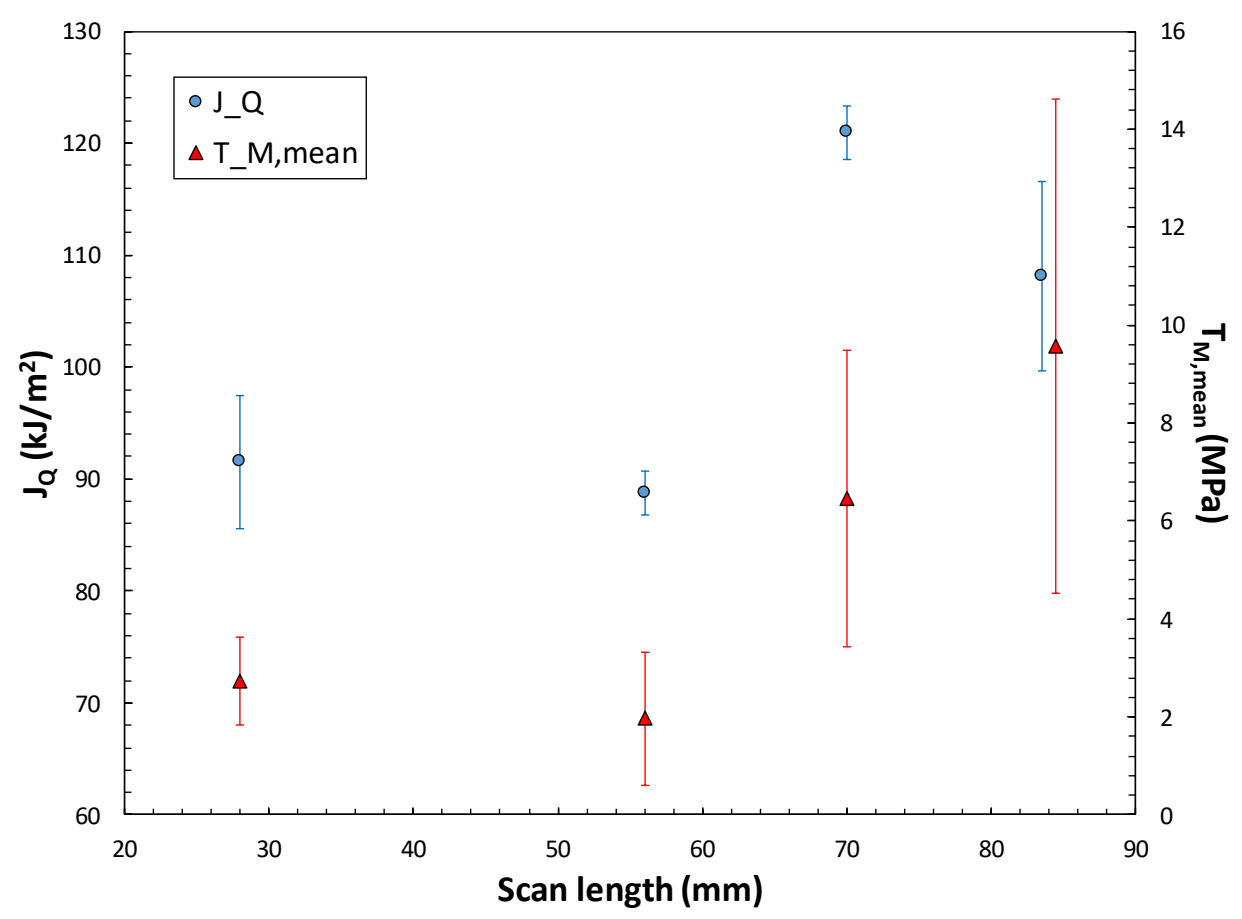

Fig. 9 - Mean values of $J_{Q}$ and $T_{M \text {,mean }}$ as a function of scan length for as-built, non-supported specimens. NOTE: points corresponding to scan length $=84 \mathrm{~mm}$ are slightly staggered for visual clarity. 
Test details for each of the tests performed on as-built, non-supported specimens are provided in Annex 1.

\subsection{Supported Specimens}

Sixteen fatigue precracked and side-grooved Charpy-type specimens were tested at room temperature for the as-built, supported condition, 4 for each of the following scan lengths: $28 \mathrm{~mm}, 56 \mathrm{~mm}, 70 \mathrm{~mm}$, and $84 \mathrm{~mm}$.

The results obtained from the EC and NDR techniques are provided in Table 4, with average values and standard deviations. None of the measured $J_{Q}$ values could be validated as plane-strain fracture toughness $J_{I c}$ in accordance with ASTM E1820-18 $\mathrm{a}^{11}$ (the reasons for invalidity are detailed in the Table).

Table 4 - Results obtained on as-built (A), supported (S) specimens.

\begin{tabular}{|c|c|c|c|c|c|c|c|c|c|}
\hline $\begin{array}{l}\text { Specimen } \\
\text { id }\end{array}$ & $\begin{array}{c}\text { Scan } \\
\text { length }(\mathbf{m m})\end{array}$ & $\begin{array}{c}J_{Q} \\
\left(\mathbf{k J} / \mathbf{m}^{2}\right)\end{array}$ & $\begin{array}{c}\text { Invalidity } \\
\text { causes }\end{array}$ & $\begin{array}{c}T_{M, J Q} \\
(\mathrm{MPa})\end{array}$ & $\begin{array}{l}T_{M, m e a n} \\
\text { (MPa) }\end{array}$ & $\begin{array}{c}J_{Q} \\
\left(\mathbf{k J} / \mathbf{m}^{2}\right)\end{array}$ & $\begin{array}{c}\text { Invalidity } \\
\text { causes }\end{array}$ & $\begin{array}{c}T_{M, J Q} \\
(\mathrm{MPa})\end{array}$ & $\begin{array}{l}T_{M, m e a n} \\
\text { (MPa) }\end{array}$ \\
\hline AS-8-1 & \multirow{4}{*}{28} & 92.11 & $\mathrm{c}, \mathrm{d}$ & 6.74 & 4.04 & 77.88 & $\mathrm{e}$ & 5.81 & 3.47 \\
\hline AS-8-2 & & 97.52 & $\mathrm{c}$ & 8.04 & 4.85 & 74.14 & $\mathrm{e}$ & 9.74 & 5.97 \\
\hline AS-8-3 & & 93.63 & $\mathrm{a}, \mathrm{c}$ & 7.92 & 4.77 & 77.44 & $\mathrm{e}$ & 7.99 & 4.84 \\
\hline AS-8-4 & & 86.14 & $\mathrm{c}, \mathrm{d}$ & 12.13 & 7.51 & 78.01 & $\mathrm{e}$ & 7.74 & 4.68 \\
\hline \multicolumn{2}{|c|}{ Average } & 92.35 & - & 8.71 & 5.29 & 76.87 & - & 7.82 & 4.74 \\
\hline \multicolumn{2}{|c|}{ Standard deviation } & 4.724 & - & 2.359 & 1.523 & 1.836 & - & 1.612 & 1.025 \\
\hline AS-6-1 & \multirow{4}{*}{56} & 80.44 & $\mathrm{c}, \mathrm{d}$ & 5.86 & 3.50 & 65.95 & $\mathrm{e}$ & 6.00 & 3.60 \\
\hline AS-6-2 & & 92.07 & $\mathrm{a}, \mathrm{c}, \mathrm{d}$ & 6.38 & 3.82 & 76.68 & $\mathrm{e}$ & 7.57 & 4.57 \\
\hline AS-6-3 & & 102.30 & $\mathrm{c}, \mathrm{d}, \mathrm{f}$ & 2.32 & 1.37 & 65.10 & $\mathrm{e}$ & 7.10 & 4.29 \\
\hline AS-6-4 & & 86.21 & $\mathrm{c}, \mathrm{f}, \mathrm{g}$ & 4.60 & 2.73 & 71.06 & $\mathrm{e}$ & 5.48 & 3.27 \\
\hline \multicolumn{2}{|c|}{ Average } & 90.25 & - & 4.79 & 2.85 & 69.70 & - & 6.54 & 3.93 \\
\hline \multicolumn{2}{|c|}{ Standard deviation } & 9.329 & - & 1.806 & 1.092 & 5.349 & - & 0.962 & 0.602 \\
\hline AS-5-1 & \multirow{4}{*}{70} & 124.02 & $\mathrm{c}$ & 9.07 & 5.50 & 97.53 & $\mathrm{e}$ & 14.51 & 9.10 \\
\hline AS-5-2 & & 136.63 & $\mathrm{c}, \mathrm{d}$ & 13.65 & 8.44 & 90.92 & $\mathrm{e}$ & 20.40 & 13.40 \\
\hline AS-5-3 & & 128.79 & c & 13.84 & 8.57 & 90.61 & e & 18.29 & 11.82 \\
\hline AS-5-4 & & 122.00 & $\mathrm{c}, \mathrm{d}$ & 12.76 & 7.87 & 84.29 & $\mathrm{e}$ & 17.89 & 11.61 \\
\hline \multicolumn{2}{|c|}{ Average } & 127.86 & - & 12.33 & 7.60 & 90.84 & - & 17.77 & 11.48 \\
\hline \multicolumn{2}{|c|}{ Standard deviation } & 6.505 & - & 2.224 & 1.430 & 5.405 & - & $\mathbf{2 . 4 3 7}$ & 1.779 \\
\hline AS-4-1 & \multirow{4}{*}{84} & 124.65 & c & 15.77 & 9.87 & 74.82 & e & 17.09 & 10.55 \\
\hline AS-4-2 & & 127.38 & $\mathrm{c}$ & 9.93 & 6.05 & 89.69 & $\mathrm{e}$ & 17.49 & 11.27 \\
\hline AS-4-3 & & 112.93 & $\mathrm{c}, \mathrm{f}$ & 5.61 & 3.35 & 45.09 & $\mathrm{e}$ & 12.81 & 8.56 \\
\hline AS-4-4 & & 129.60 & $c, f$ & 8.18 & 4.95 & 72.25 & $\mathrm{e}$ & 15.04 & 9.68 \\
\hline \multicolumn{2}{|c|}{ Average } & 123.64 & - & 9.87 & 6.05 & 70.46 & - & 15.61 & 10.01 \\
\hline Standard & deviation & 7.422 & - & 4.313 & 2.775 & 18.582 & - & 2.151 & 1.169 \\
\hline
\end{tabular}

LEGEND - Invalidity causes: a - Predicted initial crack size $\left(a_{0 q}\right)$ differs from the measured value $\left(a_{0}\right)$ by more than $\pm 0.5 \mathrm{~mm}$.

$\mathrm{c}$ - Correlation coefficient of the fit used to calculate $a_{0 q}<0.96$.

$\mathrm{d}$ - One or more individual values of initial crack size, estimated from unloading/reloading sequences in the elastic range of the test, differ from the mean by more than $\pm 0.002 \mathrm{~W}$.

e - Final crack extension larger than $15 \%$ of the initial uncracked ligament.

$\mathrm{f}-$ Number of data points inside region of qualified data $<5$.

$\mathrm{g}$ - Distribution of data points inside the region of qualified data invalid (see ASTM E1820 section A9.6.4). 
$J-\Delta a$ data points and $J-R$ curves are compared in Fig. 10 (scan length $=28 \mathrm{~mm}$ ), Fig. 11 (56 mm), Fig. 12 (70 mm), and Fig. 13 (84 mm).

The $J-R$ curves obtained for the different scan lengths are compared in Fig. 14 (individual curves) and Fig. 15 (mean curves with $\pm 1 \sigma$ error bars). The general trends for supported specimens as a function of scan length confirm those observed for non-supported specimens:

- Fracture toughness (initiation and crack resistance) tends to decrease with scan length. However, closer examination of Fig. 15 reveals an "inversion" for the two longer and the two shorter scan lengths: $70 \mathrm{~mm}$ is tougher than $84 \mathrm{~mm}$ and $28 \mathrm{~mm}$ is tougher than $56 \mathrm{~mm}$. Nonetheless, the differences cannot be considered statistically significant, since in both cases the $\pm 1 \sigma$ bars overlap.

- The same qualitative trend is observed for the variability, visually indicated by the magnitude of the $\pm 1 \sigma$ bars in Fig. 15: shorter scan lengths (28 $\mathrm{mm}$ and $56 \mathrm{~mm}$ ) have less scatter between the individual $J-R$ curves than the longer scan lengths ( $70 \mathrm{~mm}$ and $84 \mathrm{~mm})$.

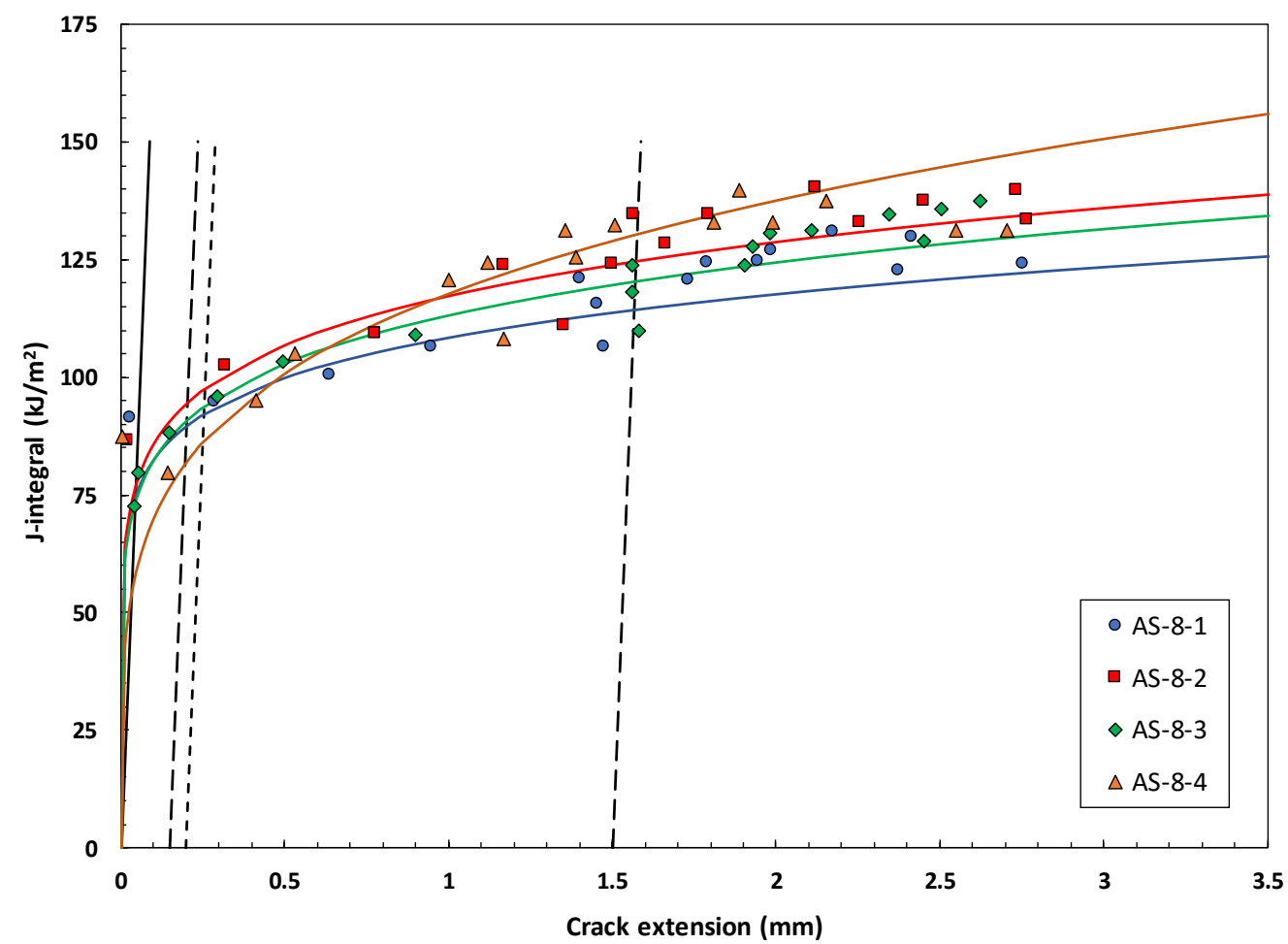

Fig. 10 - Data points and $J-R$ curves for as-built, supported specimens (scan length = $28 \mathrm{~mm}$ ). $J-R$ curves were obtained by fitting data points lying between dashed lines. 


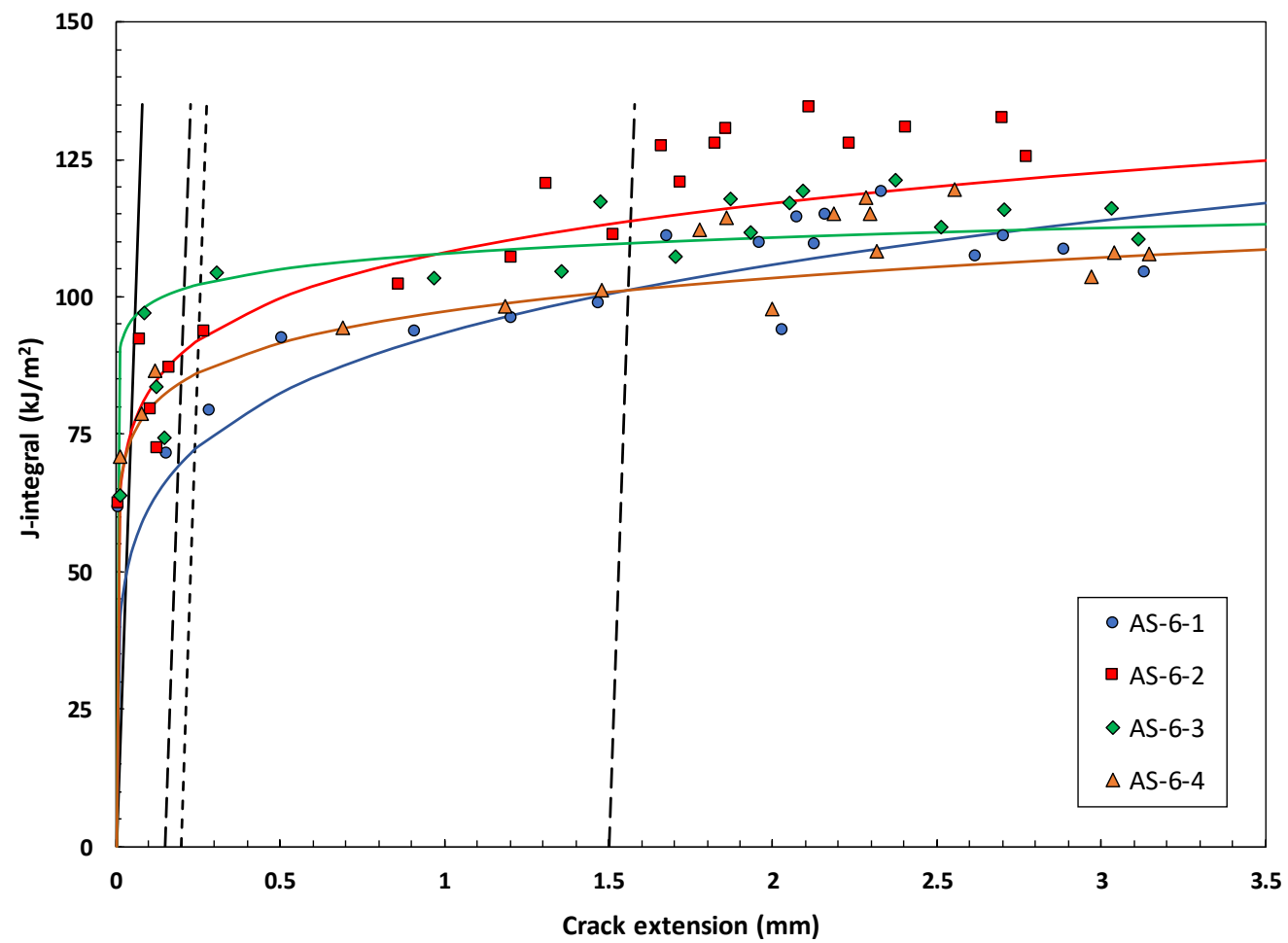

Fig. 11 - Data points and $J-R$ curves for as-built, supported specimens (scan length = $56 \mathrm{~mm}) . J-R$ curves were obtained by fitting data points lying between the dashed lines.

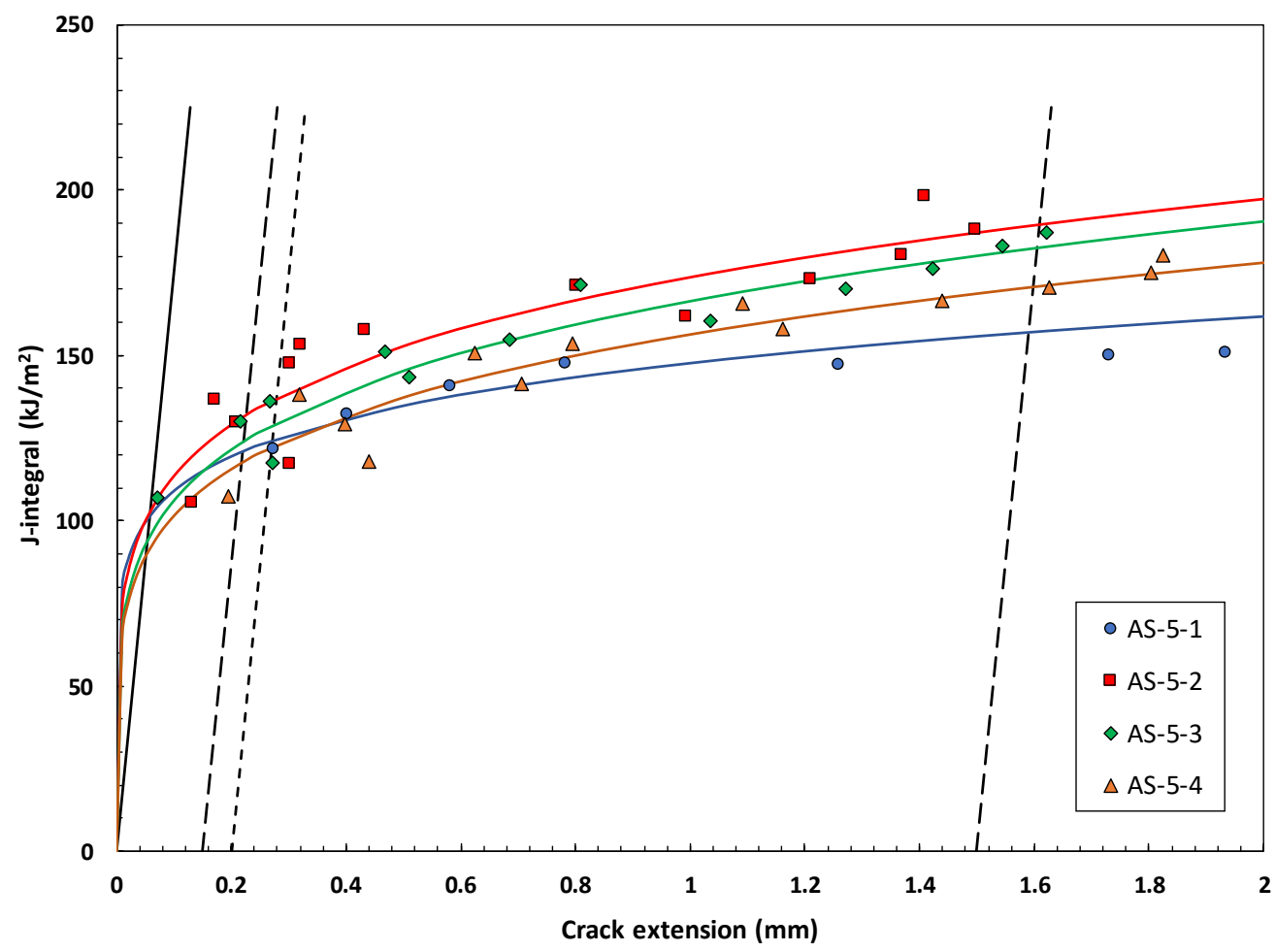

Fig. 12 - Data points and $J-R$ curves for as-built, supported specimens (scan length = $70 \mathrm{~mm}$ ). $J-R$ curves were obtained by fitting data points lying between the dashed lines. 


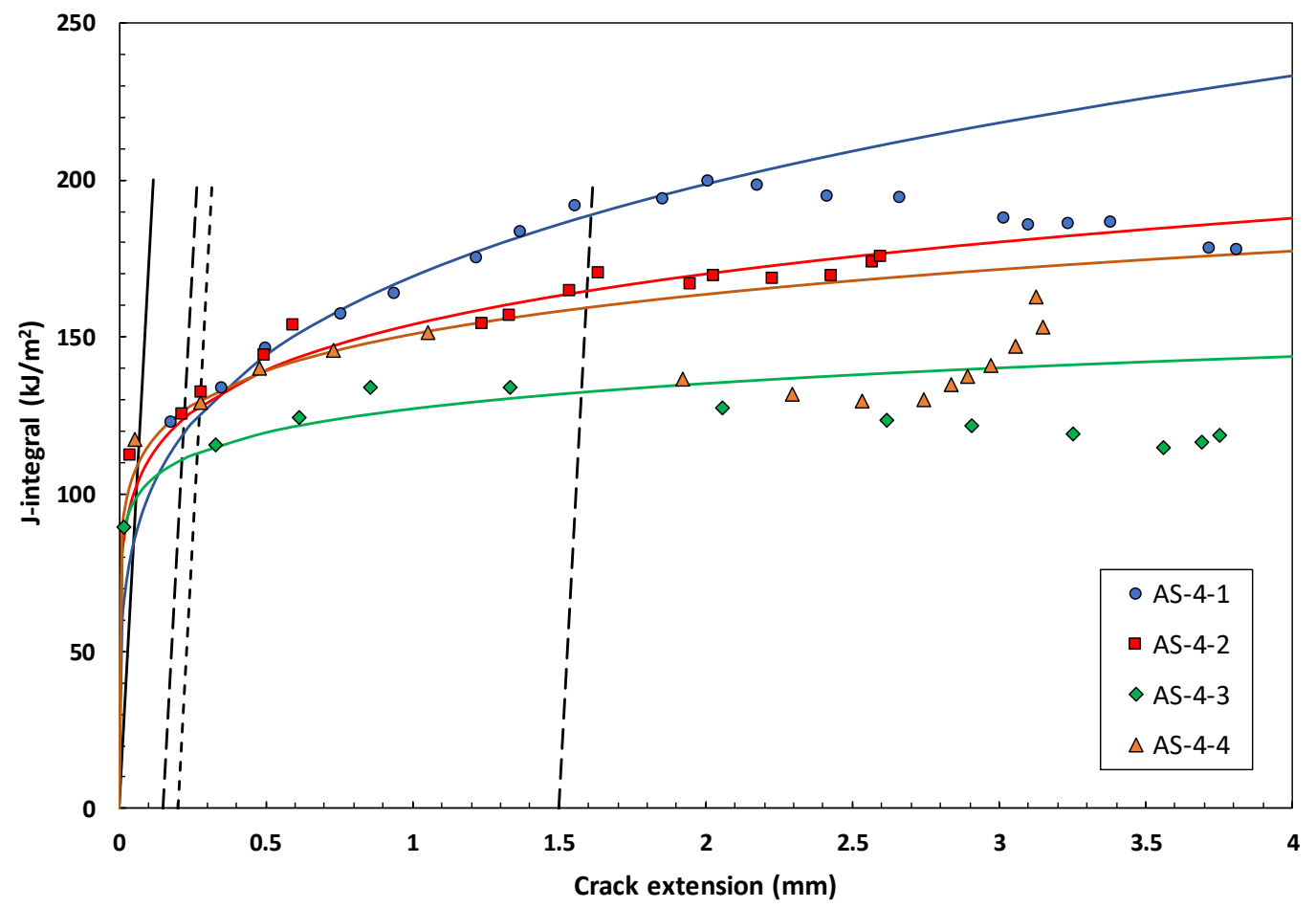

Fig. 13 - Data points and $J-R$ curves for as-built, supported specimens (scan length = $84 \mathrm{~mm}$ ). $J$ - $R$ curves were obtained by fitting data points lying between the dashed lines.

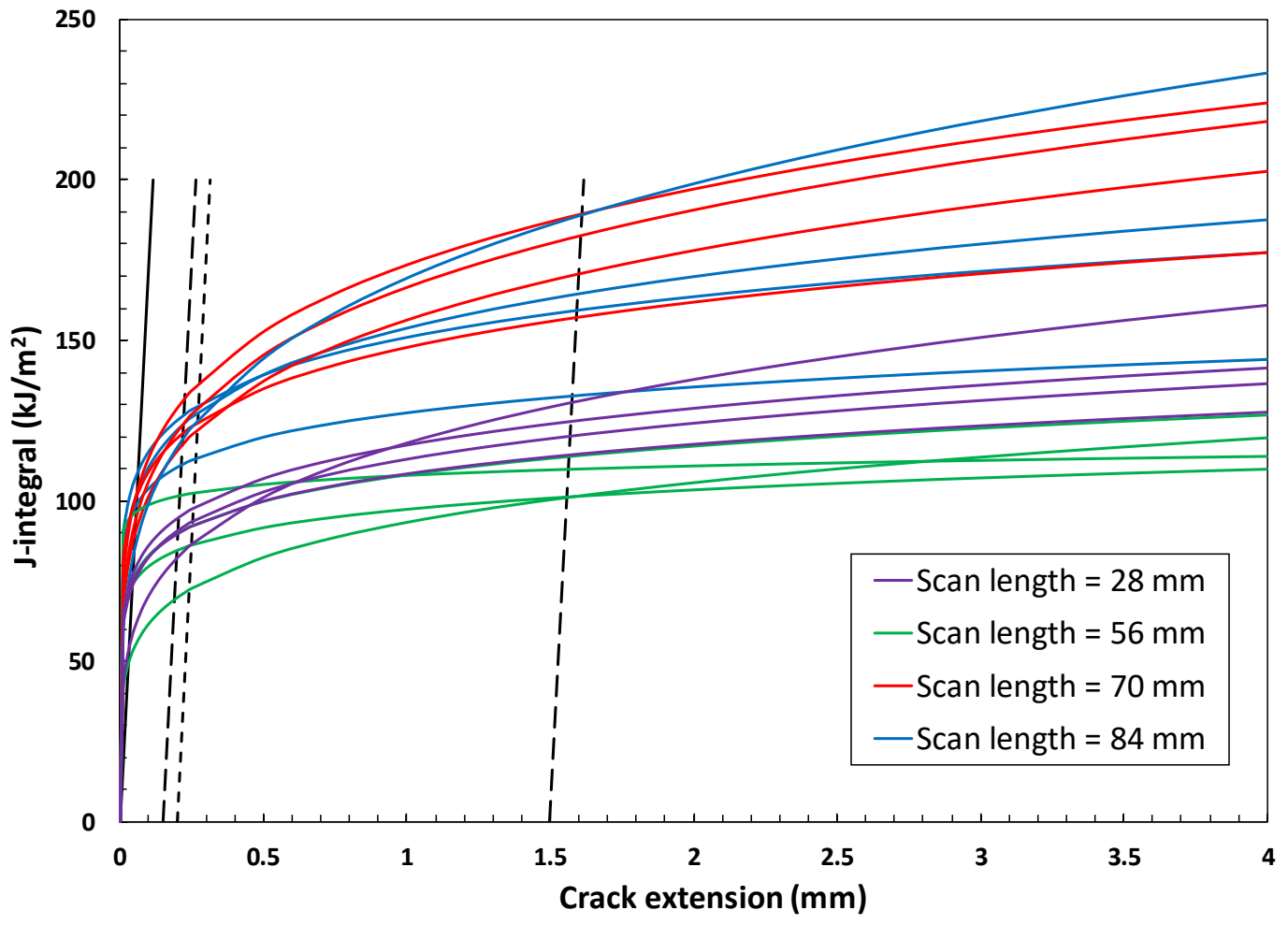

Fig. 14 - Individual $J-R$ curves for as-built, supported specimens. 


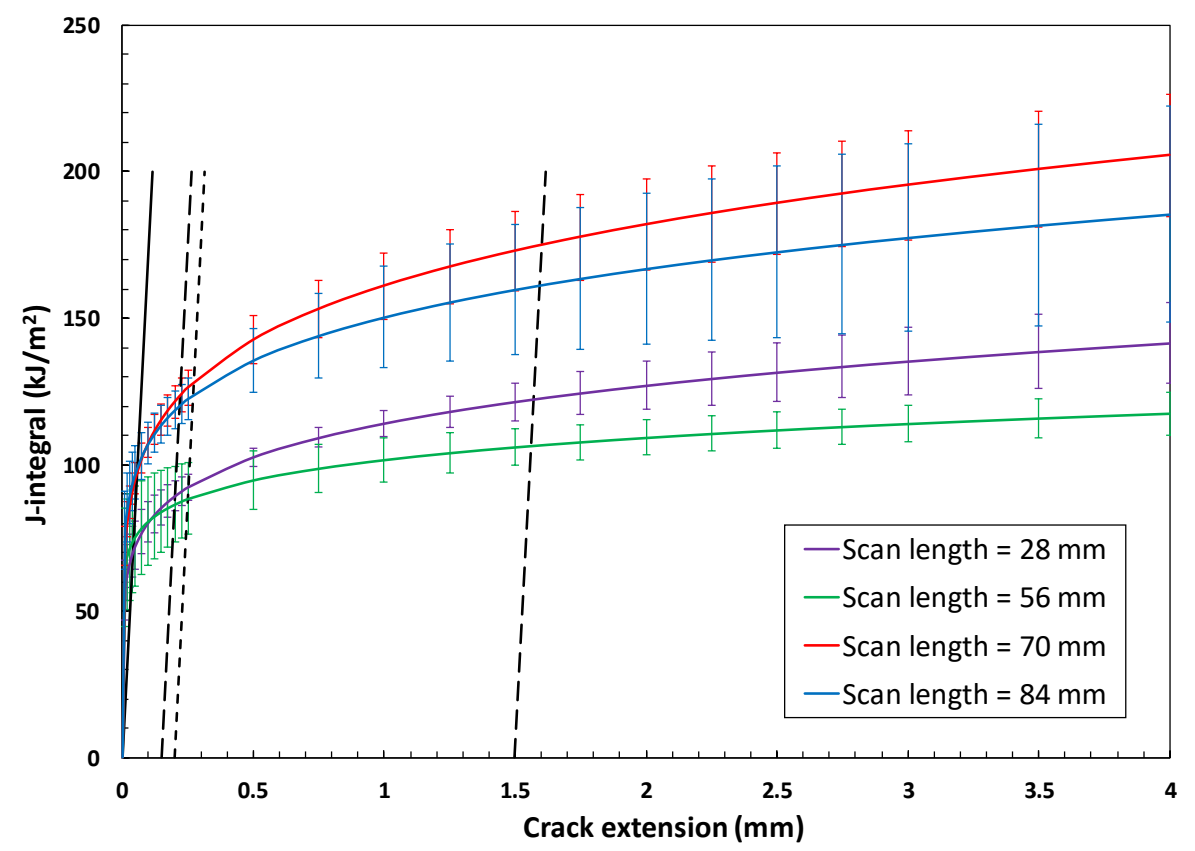

Fig. 15 - Mean $J-R$ curves with errors $( \pm 1 \sigma)$ for as-built, supported specimens.

As in the case of non-supported specimens (Figs. 3-6), crack jumps are observed for most of the tests performed, negatively affecting the overall crack resistance (tearing moduli) of the specimens.

Mean values of $J_{Q}$ and $T_{M \text {,mean }}$, with $\pm 1 \sigma$ error bars, are plotted in Fig. 16 as a function of scan length.

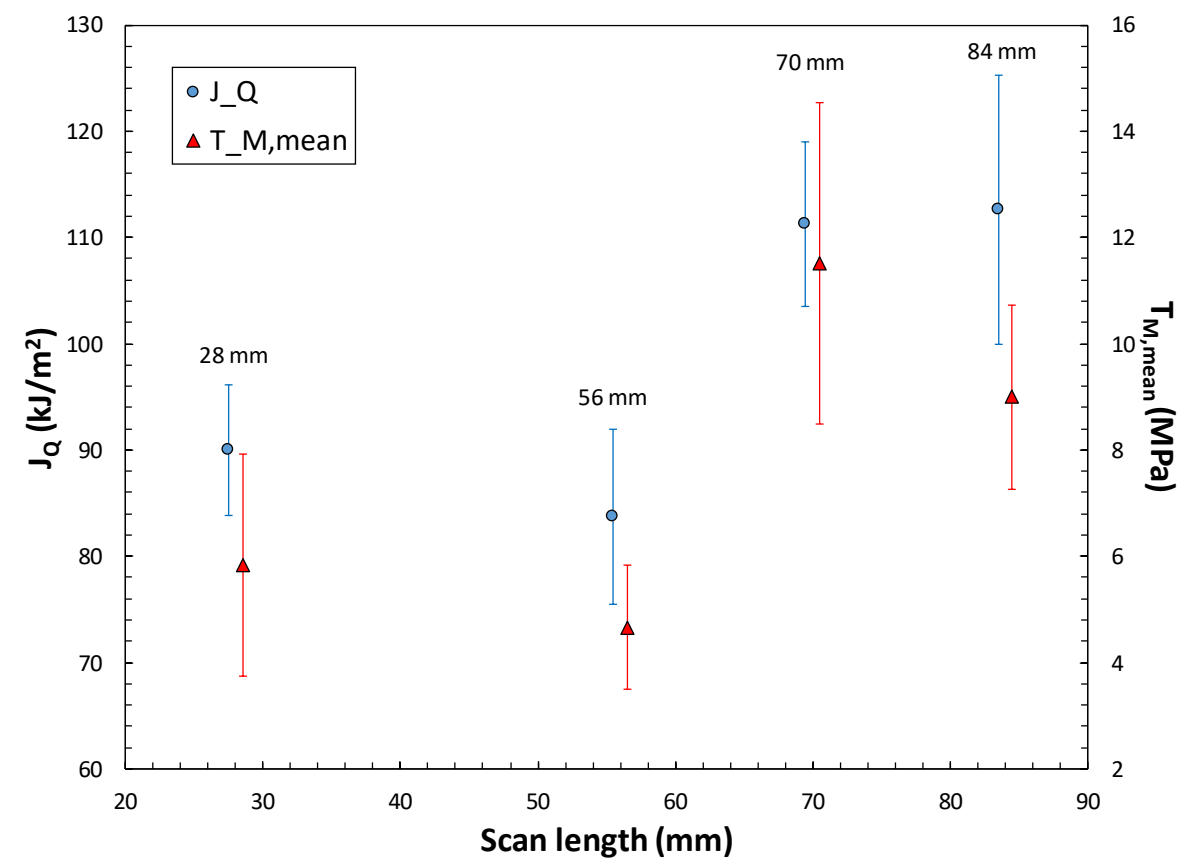

Fig. 16 - Mean values of $J_{Q}$ and $T_{M \text {,mean }}$ as a function of scan length for as-built, supported specimens. NOTE: scan lengths are slightly staggered for visual clarity. 
Test details for each of the 16 tests performed on as-built, supported specimens are provided in Annex 2.

\section{Test Results - Classic HIP Condition}

\subsection{Non-Supported Specimens}

Eleven fatigue precracked and side-grooved Charpy-type specimens were tested at room temperature for the classic HIP, non-supported condition. Three scan lengths were chosen: $28 \mathrm{~mm}$ ( 3 tests), $70 \mathrm{~mm}$ ( 5 tests), and $84 \mathrm{~mm}$ (3 tests).

The results obtained from the EC and NDR techniques are provided in Table 5, with average values and standard deviations. None of the measured $J_{Q}$ values could be validated as plane-strain fracture toughness $J_{I c}$ in accordance with ASTM E1820-18a ${ }^{\varepsilon 1}$ (the reasons for invalidity are detailed in the Table).

Three of the tests could not be analyzed by means of the NDR technique, since the analysis did not converge.

Table 5 - Results obtained on classically HIPed (C), non-supported (N) specimens.

\begin{tabular}{|c|c|c|c|c|c|c|c|c|c|}
\hline $\begin{array}{l}\text { Specimen } \\
\text { id }\end{array}$ & $\begin{array}{c}\text { Scan } \\
\text { length }(\mathbf{m m})\end{array}$ & $\begin{array}{c}J Q \\
\left(\mathbf{k J} / \mathbf{m}^{2}\right)\end{array}$ & $\begin{array}{c}\text { Invalidity } \\
\text { causes }\end{array}$ & $\begin{array}{c}T_{M, J Q} \\
(\mathrm{MPa})\end{array}$ & $\begin{array}{l}T_{M, \text { mean }} \\
(\mathrm{MPa})\end{array}$ & $\begin{array}{c}J_{Q} \\
\left(\mathbf{k J} / \mathbf{m}^{2}\right)\end{array}$ & $\begin{array}{c}\text { Invalidity } \\
\text { causes }\end{array}$ & $\begin{array}{c}T_{M, J Q} \\
(\mathrm{MPa})\end{array}$ & $\begin{array}{l}T_{M, \text { mean }} \\
\text { (MPa) }\end{array}$ \\
\hline $\mathrm{CN}-8-1$ & \multirow{3}{*}{28} & 129.04 & $\mathrm{c}$ & 10.84 & 6.60 & 95.80 & $\mathrm{e}$ & 19.30 & 12.31 \\
\hline $\mathrm{CN}-8-2$ & & 161.98 & $\mathrm{c}, \mathrm{f}$ & 6.79 & 4.10 & 110.81 & $\mathrm{e}$ & 23.64 & 15.30 \\
\hline $\mathrm{CN}-8-3$ & & 163.82 & $\mathrm{c}, \mathrm{d}$ & 10.95 & 6.69 & 107.66 & $\mathrm{e}$ & 26.11 & 17.17 \\
\hline \multicolumn{2}{|c|}{ Average } & 151.61 & - & 9.53 & 5.80 & 104.76 & - & 23.01 & 14.93 \\
\hline \multicolumn{2}{|c|}{ Standard deviation } & 19.571 & - & 2.370 & 1.471 & 7.913 & - & 3.446 & 2.452 \\
\hline CN-5-1 & \multirow{5}{*}{70} & 181.13 & $\mathrm{cc}$ & 14.82 & 9.18 & N/A & N/A & N/A & N/A \\
\hline $\mathrm{CN}-5-2$ & & 184.05 & $\mathrm{c}$ & 13.27 & 8.18 & N/A & N/A & N/A & N/A \\
\hline $\mathrm{CN}-5-3$ & & 169.96 & $\mathrm{c}, \mathrm{d}$ & 6.83 & 4.13 & 129.97 & $\mathrm{e}$ & 22.78 & 14.63 \\
\hline $\mathrm{CN}-5-4$ & & 196.84 & $\mathrm{c}$ & 15.77 & 9.81 & 169.65 & $\mathrm{e}$ & 23.93 & 15.30 \\
\hline $\mathrm{CN}-5-5$ & & 181.24 & $\mathrm{c}$ & 14.74 & 9.13 & 122.26 & $\mathrm{e}$ & 29.19 & 19.48 \\
\hline \multicolumn{2}{|c|}{ Average } & 182.65 & - & 13.09 & 8.09 & 140.62 & - & 25.30 & 16.47 \\
\hline \multicolumn{2}{|c|}{ Standard deviation } & 9.602 & - & 3.759 & 2.288 & 25.427 & - & 3.417 & 2.629 \\
\hline CN-4-1 & \multirow{3}{*}{84} & 176.29 & $\mathrm{~b}, \mathrm{~d}$ & 9.73 & 5.93 & 125.57 & $\mathrm{e}$ & 23.61 & 15.28 \\
\hline $\mathrm{CN}-4-2$ & & 161.37 & $\mathrm{c}$ & 14.30 & 8.84 & 106.64 & $\mathrm{e}$ & 32.07 & 22.29 \\
\hline CN-4-3 & & 135.34 & $\mathrm{c}, \mathrm{d}$ & 8.80 & 5.33 & N/A & N/A & N/A & N/A \\
\hline \multicolumn{2}{|c|}{ Average } & 157.67 & - & 10.94 & 6.70 & 116.51 & - & 27.84 & 18.78 \\
\hline \multicolumn{2}{|c|}{ Standard deviation } & 20.725 & - & 2.944 & 1.878 & 13.230 & - & 5.985 & 4.956 \\
\hline
\end{tabular}

LEGEND - Invalidity causes: $\mathrm{b}$ - Number of data points available to calculate $a_{0 q}<8$.

$\mathrm{c}-$ Correlation coefficient of the fit used to calculate $a_{0 q}<0.96$.

$\mathrm{d}$ - One or more individual values of initial crack size, estimated from

unloading/reloading sequences in the elastic range of the test, differ from the mean by more than $\pm 0.002 \mathrm{~W}$.

e - Final crack extension larger than $15 \%$ of the initial uncracked ligament.

$\mathrm{f}-$ Number of data points inside region of qualified data $<5$.

$\mathrm{N} / \mathrm{A}=$ not available.

$J-\Delta a$ data points and $J-R$ curves are compared in Fig. 17 (scan length $=28 \mathrm{~mm}$ ), Fig. 18 (70 mm), and Fig. $19(84 \mathrm{~mm})$. 
The $J-R$ curves obtained for the different scan lengths are compared in Fig. 20 (individual curves) and Fig. 21 (mean curves with $\pm 1 \sigma$ error bars). The $70 \mathrm{~mm}$ scan length provides the highest values of $J_{Q}$ and tearing moduli, while the least tough condition corresponds to the smallest scan length $(28 \mathrm{~mm})$. There is, however, ample overlapping of the respective $\pm 1 \sigma$ error bars.

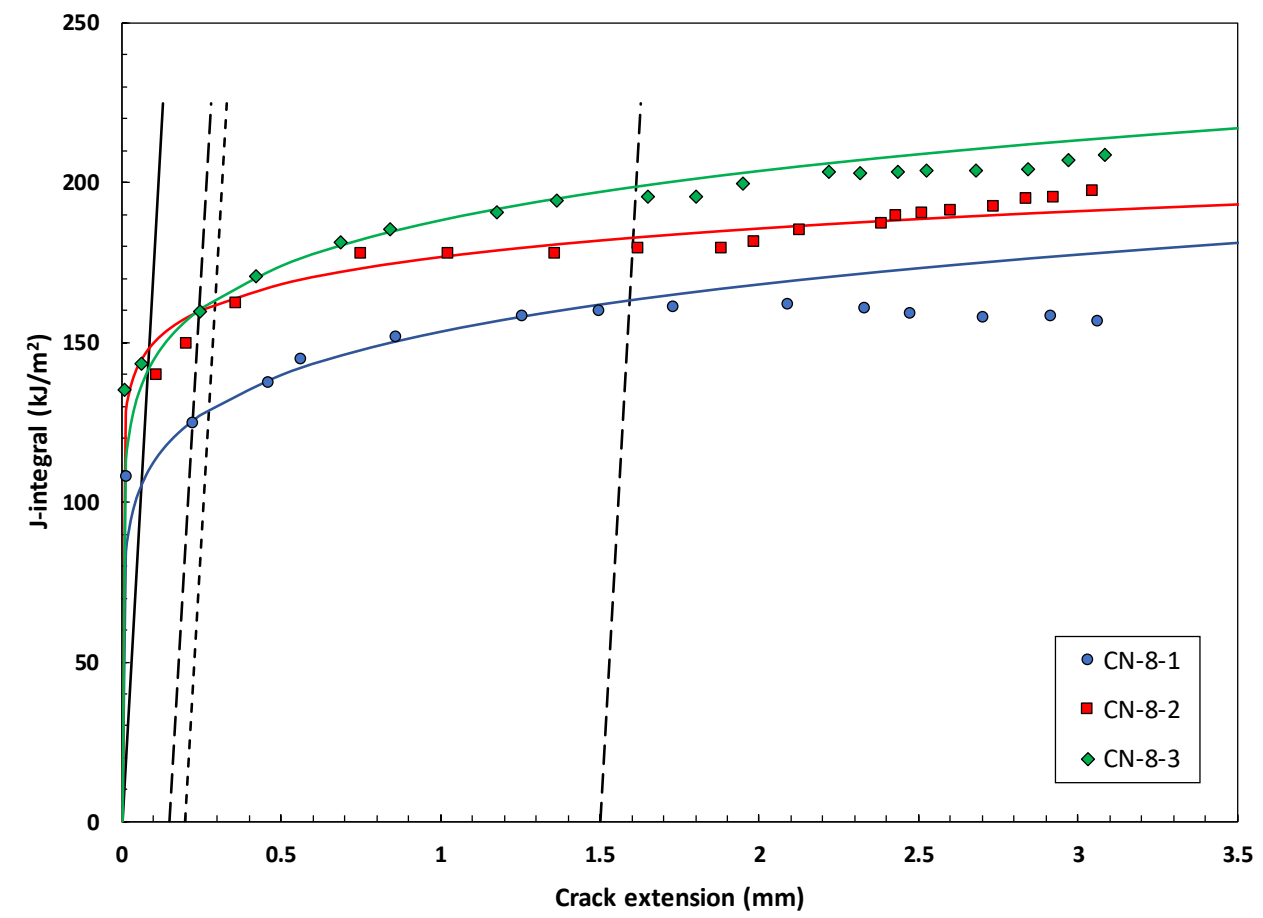

Fig. 17 - Data points and $J-R$ curves for classically HIPed, non-supported specimens (scan length $=28 \mathrm{~mm}$ ). $J-R$ curves were obtained by fitting points lying between dashed lines.

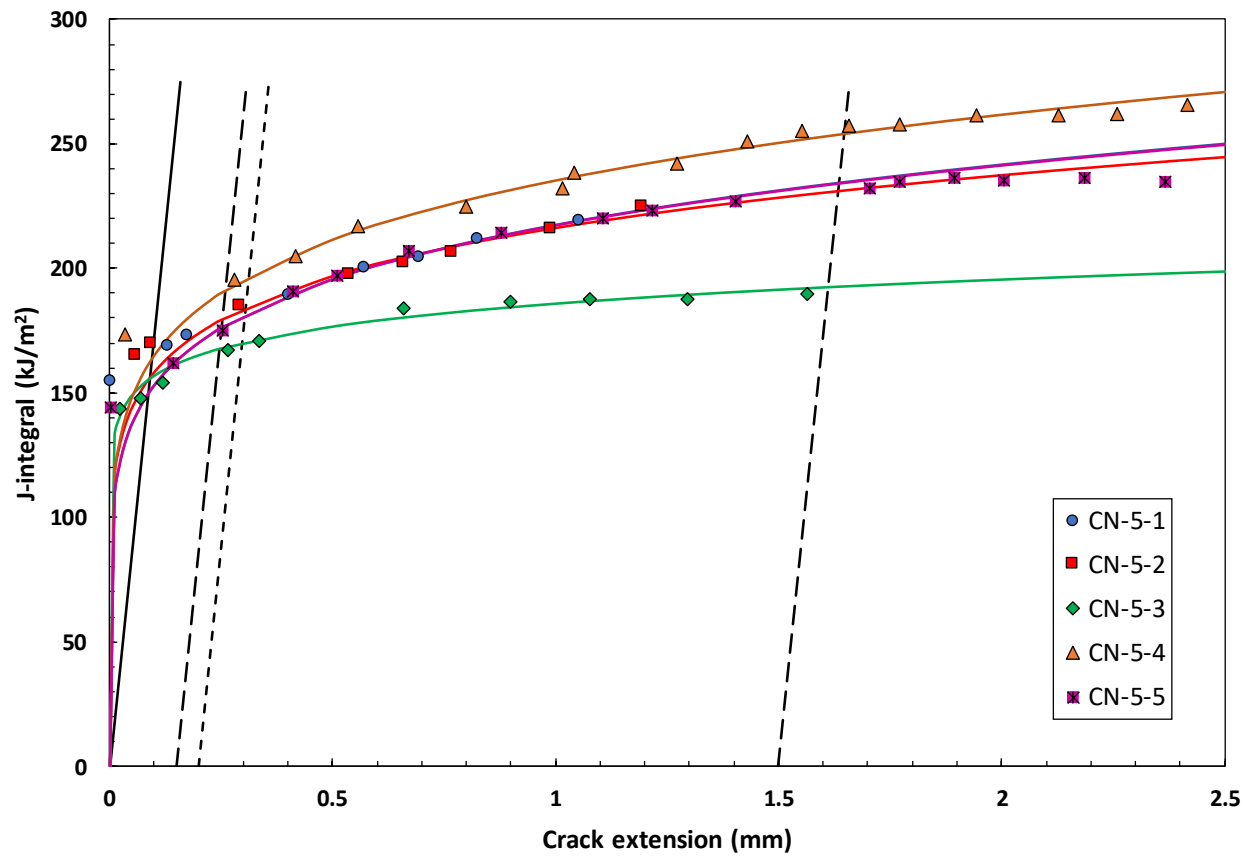

Fig. 18 - Data points and $J-R$ curves for classically HIPed, non-supported specimens (scan length $=70 \mathrm{~mm}$ ). $J-R$ curves were obtained by fitting points lying between the dashed lines. 


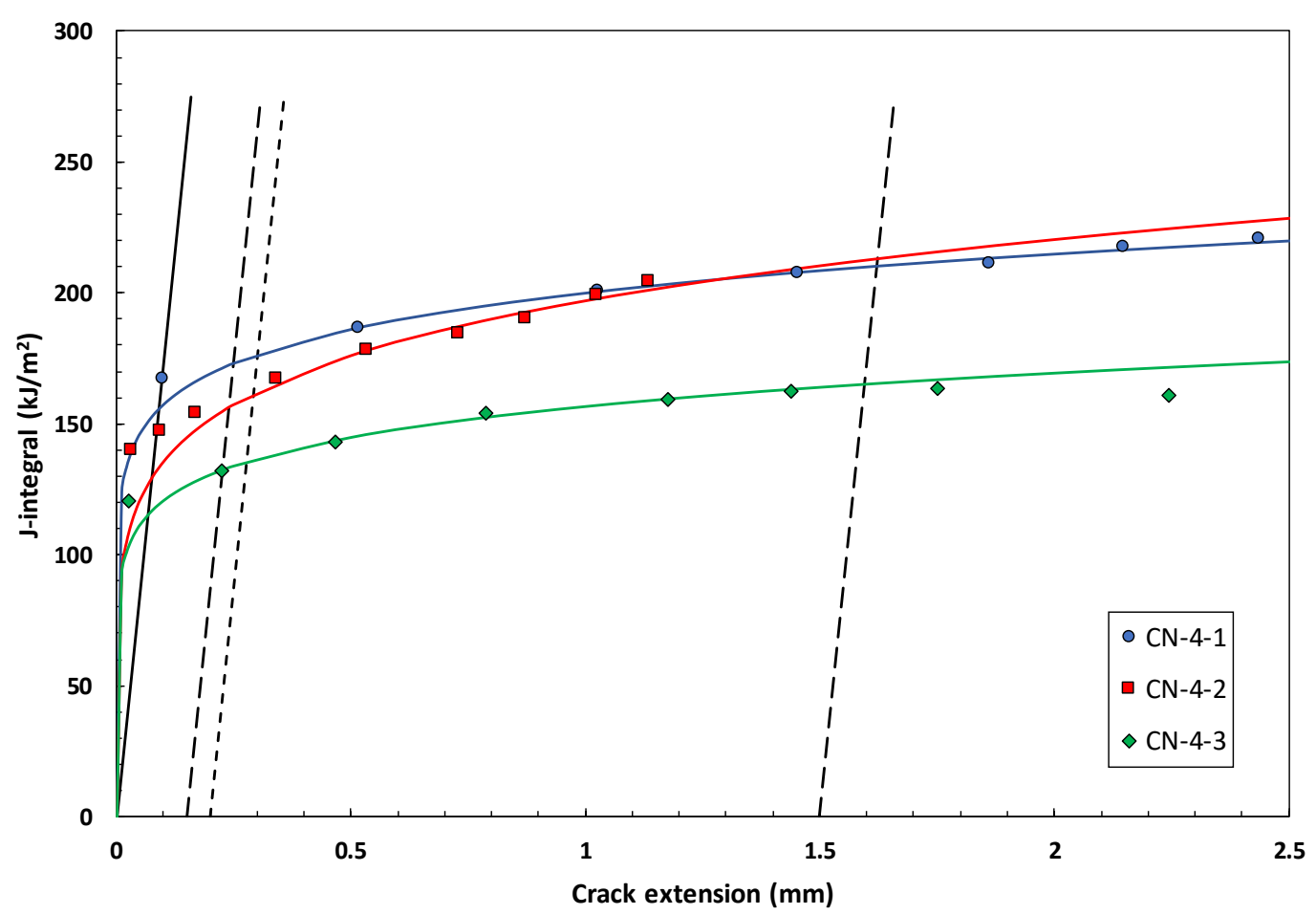

Fig. 19 - Data points and $J-R$ curves for classically HIPed, non-supported specimens (scan length $=84 \mathrm{~mm}$ ). $J-R$ curves were obtained by fitting points lying between the dashed lines.

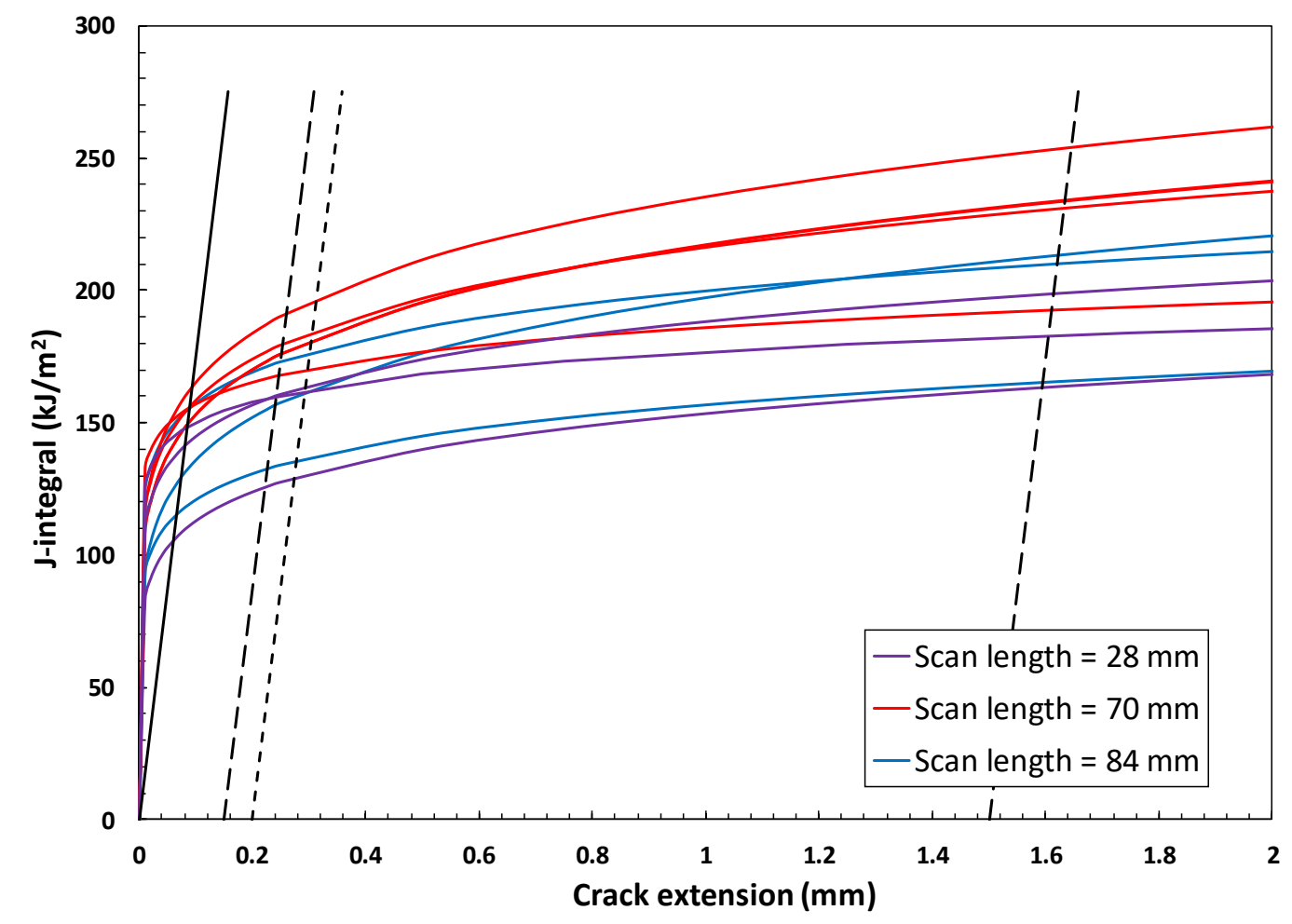

Fig. 20 - Individual $J-R$ curves for classically HIPed, non-supported specimens. 


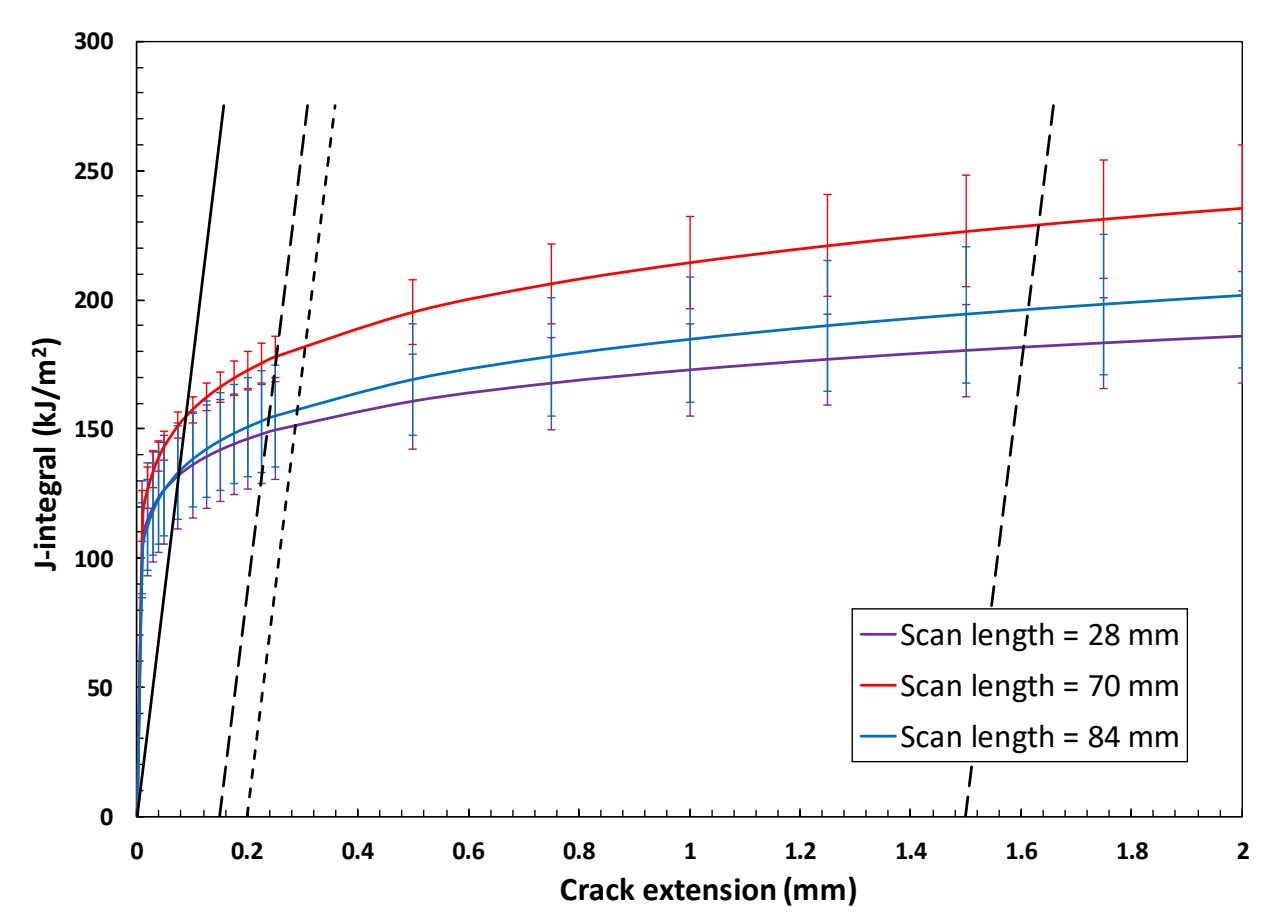

Fig. 21 - Mean $J-R$ curves with $\pm 1 \sigma$ errors for classically HIPed, non-supported specimens.

Mean values of $J_{Q}$ and $T_{M, \text { mean }}$, with $\pm 1 \sigma$ error bars, are plotted in Fig. 22 as a function of scan length.

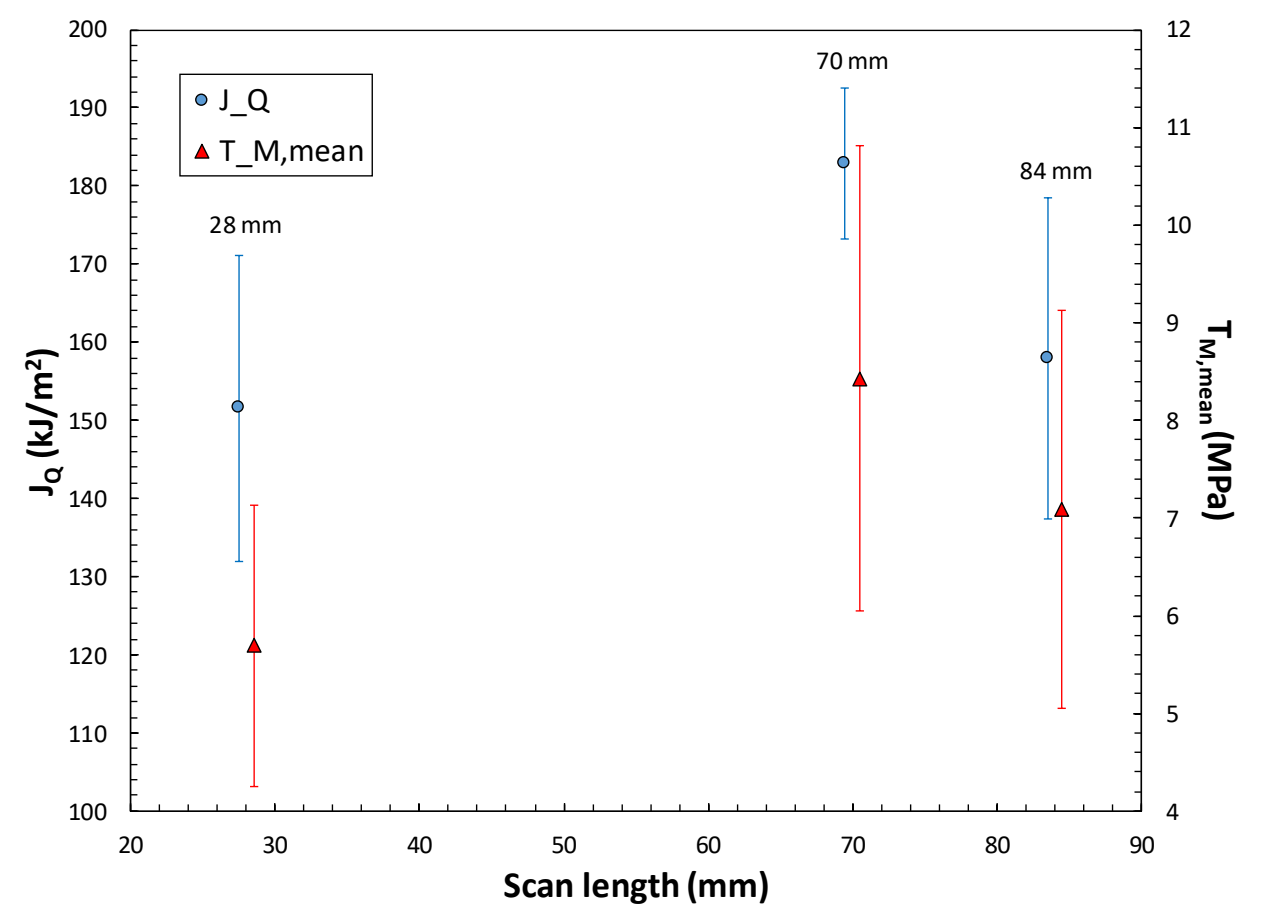

Fig. 22 - Mean values of $J_{Q}$ and $T_{M \text {,mean }}$ as a function of scan length for classically HIPed and supported specimens. NOTE: scan lengths are slightly staggered for visual clarity. 
Although a tendency for both $J_{Q}$ and $T_{M \text {,mean }}$ to increase with scan length is visible in Fig. 22, in both cases a t-statistic regression test shows no statistical evidence of a slope different than zero (i.e., no evidence of a relationship between toughness and scan length) at a significance level of $5 \%$.

Test details for each of the 11 tests performed on classically HIPed, non-supported specimens are provided in Annex 3.

\subsection{Supported Specimens}

Three fatigue precracked and side-grooved Charpy-type specimens were tested at room temperature for the classic HIP, supported condition. Only one scan length was considered: 84 $\mathrm{mm}$.

The results obtained from the EC and NDR techniques are provided in Table 6, with average values and standard deviations. None of the measured $J_{Q}$ values could be validated as plane-strain fracture toughness $J_{I c}$ in accordance with ASTM E1820-18a ${ }^{\varepsilon 1}$ (the reasons for invalidity are detailed in the Table).

$J-\Delta a$ data points and $J-R$ curves are compared in Fig. 23.

Test details for each of the 3 tests performed on classically HIPed, supported specimens are provided in Annex 4.

Table 6 - Results obtained on classically HIPed (C), supported (S) specimens.

\begin{tabular}{|c|c|c|c|c|c|c|c|c|c|}
\hline \multicolumn{2}{|c|}{ Methodology } & \multicolumn{4}{|c|}{ Elastic Compliance } & \multicolumn{4}{|c|}{ Normalization Data Reduction } \\
\hline $\begin{array}{l}\text { Specimen } \\
\text { id }\end{array}$ & $\begin{array}{c}\text { Scan } \\
\text { length }(\mathrm{mm})\end{array}$ & $\begin{array}{c}J Q \\
\left(\mathbf{k J} / \mathbf{m}^{2}\right)\end{array}$ & $\begin{array}{c}\text { Invalidity } \\
\text { causes }\end{array}$ & $\begin{array}{c}T_{M, J Q} \\
(\mathrm{MPa})\end{array}$ & $\begin{array}{l}T_{M, \text { mean }} \\
\text { (MPa) }\end{array}$ & $\begin{array}{c}J_{Q} \\
\left(\mathbf{k J} / \mathbf{m}^{2}\right)\end{array}$ & $\begin{array}{c}\text { Invalidity } \\
\text { causes }\end{array}$ & $\begin{array}{c}T_{M, J Q} \\
(\mathrm{MPa})\end{array}$ & $\begin{array}{l}T_{M, \text { mean }} \\
\text { (MPa) }\end{array}$ \\
\hline CS-4-1 & \multirow{3}{*}{84} & 190.29 & $\mathrm{c}$ & 18.35 & 11.50 & 121.36 & $\mathrm{e}$ & 30.45 & 20.53 \\
\hline CS-4-2 & & 156.38 & $\mathrm{c}$ & 16.63 & 10.36 & 170.07 & $\mathrm{e}$ & 19.29 & 12.13 \\
\hline CS-4-3 & & 185.65 & $\mathrm{c}, \mathrm{d}$ & 16.74 & 10.44 & 200.67 & $\mathrm{e}$ & 27.08 & 17.46 \\
\hline \multicolumn{2}{|c|}{ Average } & 177.44 & - & 17.24 & 10.77 & 164.03 & - & 25.61 & 16.71 \\
\hline \multicolumn{2}{|c|}{ Standard deviation } & 18.385 & - & 0.963 & 0.636 & 39.998 & - & 5.724 & 4.250 \\
\hline
\end{tabular}

LEGEND - Invalidity causes: c c Correlation coefficient of the fit used to calculate $a_{0 q}<0.96$.

$\mathrm{d}$ - One or more individual values of initial crack size, estimated from unloading/reloading sequences in the elastic range of the test, differ from the mean by more than $\pm 0.002 \mathrm{~W}$.

e - Final crack extension larger than $15 \%$ of the initial uncracked ligament. 


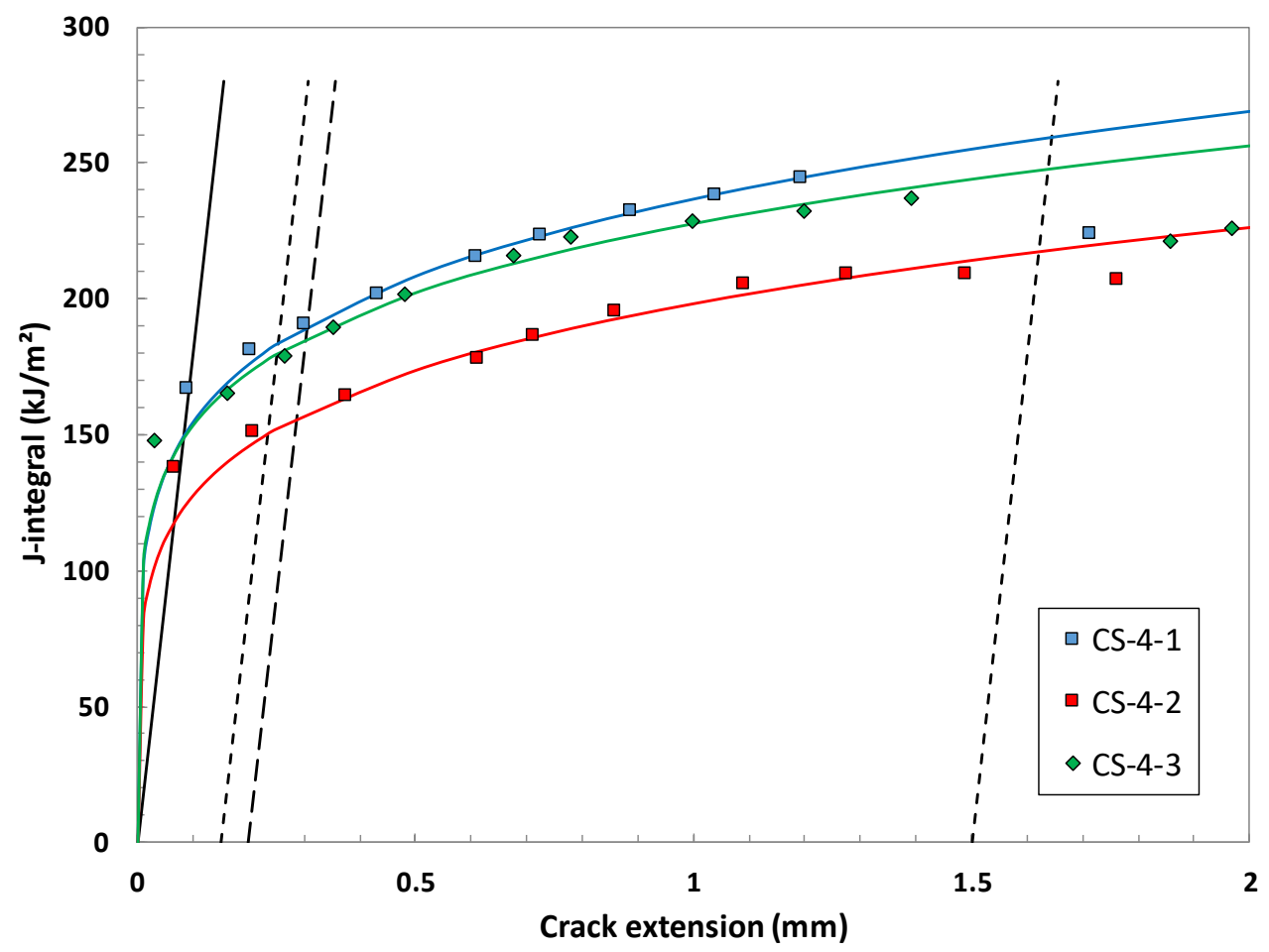

Fig. 23 - Data points and $J-R$ curves for classically HIPed, supported specimens (scan length $=84 \mathrm{~mm}) . J-R$ curves were obtained by fitting points lying between the dashed lines.

\section{Test Results - Super- $\beta$ Transus HIP, Non-Supported Condition}

Four fatigue precracked and side-grooved Charpy-type specimens were tested at room temperature for the super- $\beta$ transus HIP, non-supported condition. Only one scan length $(70 \mathrm{~mm})$ was investigated.

For this material condition, clearly visible crack "jumps" between consecutive unloadings were observed, occurring soon after the onset of plastic deformation in the specimens. For all tests, the number of data points falling inside the region of qualified data (bounded by the exclusion lines with offset $0.15 \mathrm{~mm}$ and $1.5 \mathrm{~mm}$ ) was less than the minimum (5) required by ASTM E1820. Specifically, three tests had just one point between the exclusion line, while the fourth (BN-5-2) had none. It's therefore impossible to derive meaningful values of $J_{Q}$ or tearing modulus.

However, for the three tests that had at least one data point inside the region of qualified data, we obtained rough engineering estimates of EC initiation toughness by ignoring the second exclusion line (offset $=1.5 \mathrm{~mm}$ ) and fitting all data points to the right of this line (i.e., the fit included points with $\Delta a>\Delta a_{\text {limit }}$ ). Such engineering estimates are indicated by $J_{Q(e s t)}^{*}$ in Table 7, where an approximate value of $0 \mathrm{MPa}$ (indicating negligible crack resistance) was attributed to all corresponding values of EC tearing modulus. All NDR results in Table 7, on the other hand, are acceptable in accordance with ASTM E1820 Annex A15, except for violating the crack extension limit (15\% of the initial ligament size). 
Table 7 - Results obtained on super- $\beta$ transus HIPed, non-supported specimens.

\begin{tabular}{|c|c|c|c|c|c|c|c|c|}
\hline \multicolumn{2}{|c|}{ Methodology } & \multicolumn{3}{|c|}{ Elastic Compliance } & \multicolumn{4}{|c|}{ Normalization Data Reduction } \\
\hline $\begin{array}{l}\text { Specimen } \\
\text { id }\end{array}$ & $\begin{array}{c}\text { Scan } \\
\text { length }(\mathrm{mm})\end{array}$ & $\begin{array}{l}\left.J_{Q(e s t)}^{*}\right) \\
\left(\mathbf{k J} / \mathbf{m}^{2}\right)\end{array}$ & $\begin{array}{c}T_{M, J Q(e s t)}^{*} \\
(\mathrm{MPa})\end{array}$ & 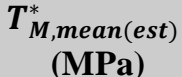 & $\begin{array}{c}J Q \\
\left(\mathbf{k J} / \mathbf{m}^{2}\right)\end{array}$ & $\begin{array}{c}\text { Invalidity } \\
\text { causes }\end{array}$ & $\begin{array}{c}T_{M, J Q} \\
(\mathbf{M P a})\end{array}$ & $\begin{array}{l}T_{M, \text { mean }} \\
(\mathbf{M P a})\end{array}$ \\
\hline BN-5-1 & \multirow{4}{*}{70} & $\sim 64$ & $\sim 0$ & $\sim 0$ & 53.05 & e & 3.18 & 1.88 \\
\hline BN-5-2 & & $\mathrm{N} / \mathrm{A}^{10}$ & N/A & N/A & 53.68 & $\mathrm{e}$ & 5.95 & 3.59 \\
\hline BN-5-3 & & $\sim 70$ & $\sim 0$ & $\sim 0$ & 46.94 & e & 4.41 & 2.63 \\
\hline BN-5-4 & & $\sim 76$ & $\sim 0$ & $\sim 0$ & 51.93 & e & 6.17 & 3.74 \\
\hline \multicolumn{2}{|c|}{ Average } & & & & 51.40 & - & 4.93 & 2.96 \\
\hline Standar & deviation & & & & 3.060 & - & 1.404 & 0.872 \\
\hline
\end{tabular}

LEGEND - Invalidity causes: e - Final crack extension larger than $15 \%$ of the initial uncracked ligament.

The $J-\Delta a$ data points obtained from the EC analyses are shown in Fig. 24.

Test details for each of the 4 tests performed on super- $\beta$ transus HIPed, non-supported specimens are provided in Annex 5.

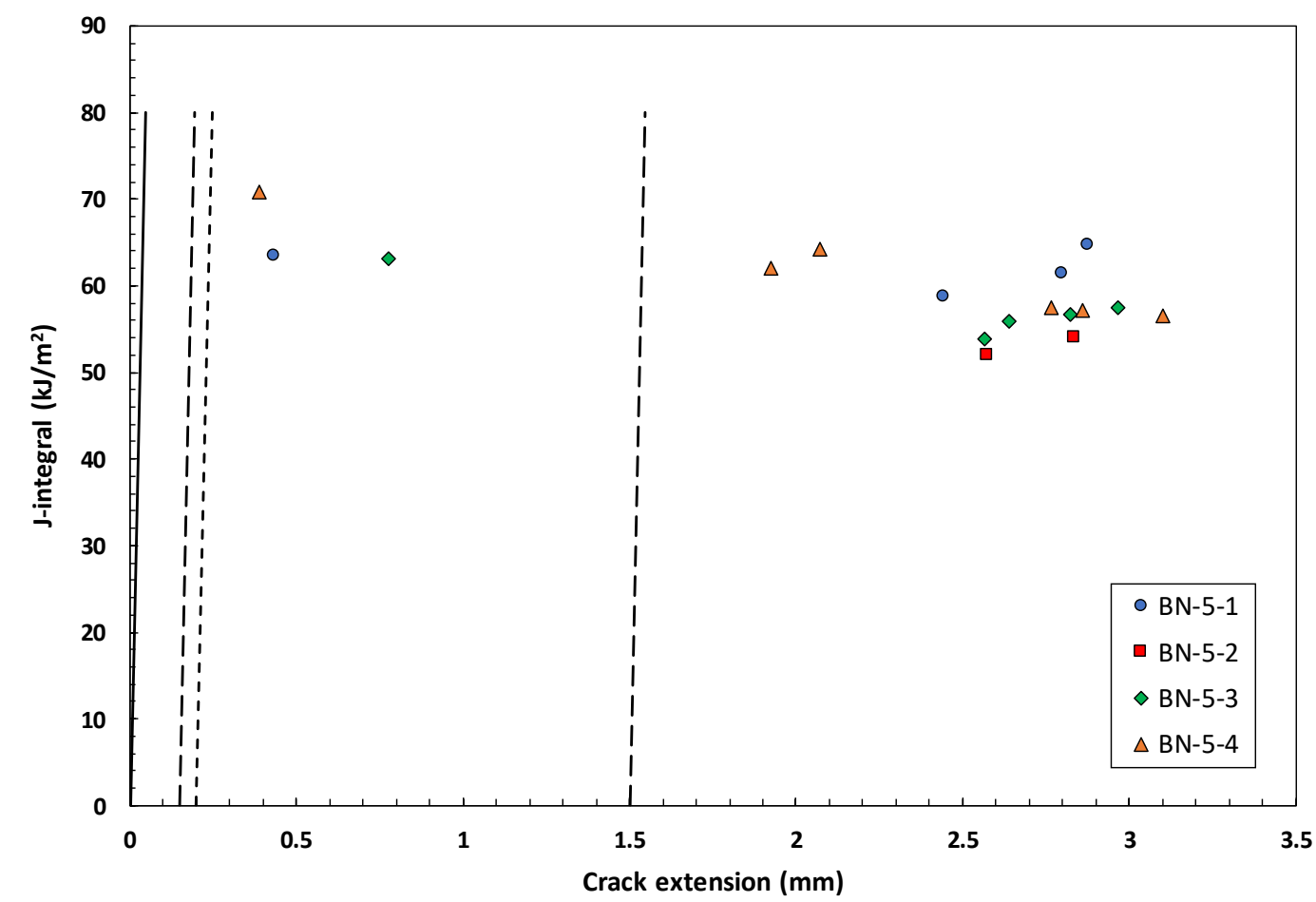

Fig. 24 - Data points obtained from the EC analyses for super- $\beta$ transus HIPed, non-supported specimens (scan length $=70 \mathrm{~mm}$ ).

${ }^{10}$ No data points inside the region of qualified data. 


\section{Discussion}

\subsection{Non-supported vs. supported}

For the as-built and classic HIP conditions, direct comparisons can be made between fracture toughness results obtained from non-supported and supported specimens for the same scan length.

Average values of $J_{Q}, T_{M, J Q}$, and $T_{M \text {,mean }}$ are summarized, with standard deviations, in Table 8, Fig. $25\left(J_{Q}\right)$, Fig. $26\left(T_{M, J Q}\right)$, and Fig. $27\left(T_{M, \text { mean }}\right)$.

Table 8 - Comparison between fracture toughness of non-supported and supported specimens.

\begin{tabular}{|c|c|c|c|c|c|}
\hline $\begin{array}{l}\text { Material } \\
\text { condition }\end{array}$ & $\begin{array}{l}\text { Scan length } \\
\text { (mm) }\end{array}$ & $\begin{array}{l}\text { Non-supported } \\
\text { vs. supported }\end{array}$ & $\begin{array}{c}J_{Q} \\
\left(\mathbf{k J} / \mathbf{m}^{2}\right)\end{array}$ & $\begin{array}{c}T_{M, J Q} \\
(\mathrm{MPa})\end{array}$ & $\begin{array}{l}T_{M, \text { mean }} \\
(\mathrm{MPa})\end{array}$ \\
\hline \multirow{7}{*}{ As-built } & 28 & Non-supported & $93.23 \pm 6.630$ & $3.48 \pm 1.458$ & $2.06 \pm 0.872$ \\
\hline & \multirow[b]{2}{*}{56} & Non-supporte & $92.71 \pm 3.981$ & $\begin{array}{l}0.11 \pm 2.359 \\
1.74 \pm 1.850\end{array}$ & $\begin{array}{l}5.29 \pm 1.525 \\
1.02 \pm 1.096\end{array}$ \\
\hline & & Supported & $90.25 \pm 9.329$ & $4.79 \pm 1.806$ & $2.85 \pm 1.092$ \\
\hline & \multirow{2}{*}{70} & Non-supported & $133.61 \pm 6.554$ & $7.94 \pm 1.463$ & $4.80 \pm 0.908$ \\
\hline & & Supported & $127.86 \pm 6.505$ & $12.33 \pm 2.224$ & $7.60 \pm 1.430$ \\
\hline & \multirow{4}{*}{84} & Non-supported & $121.14 \pm 14.797$ & $9.45 \pm 7.046$ & $5.83 \pm 4.464$ \\
\hline & & Supported & $123.64 \pm 7.422$ & $9.87 \pm 4.313$ & $6.05 \pm 2.775$ \\
\hline \multirow{2}{*}{ Classic HIP } & & Non-supported & $157.67 \pm 20.725$ & $10.94 \pm 2.944$ & $6.70 \pm 1.878$ \\
\hline & & Supported & $177.44 \pm 18.385$ & $17.24 \pm 0.963$ & $10.77 \pm 0.636$ \\
\hline
\end{tabular}

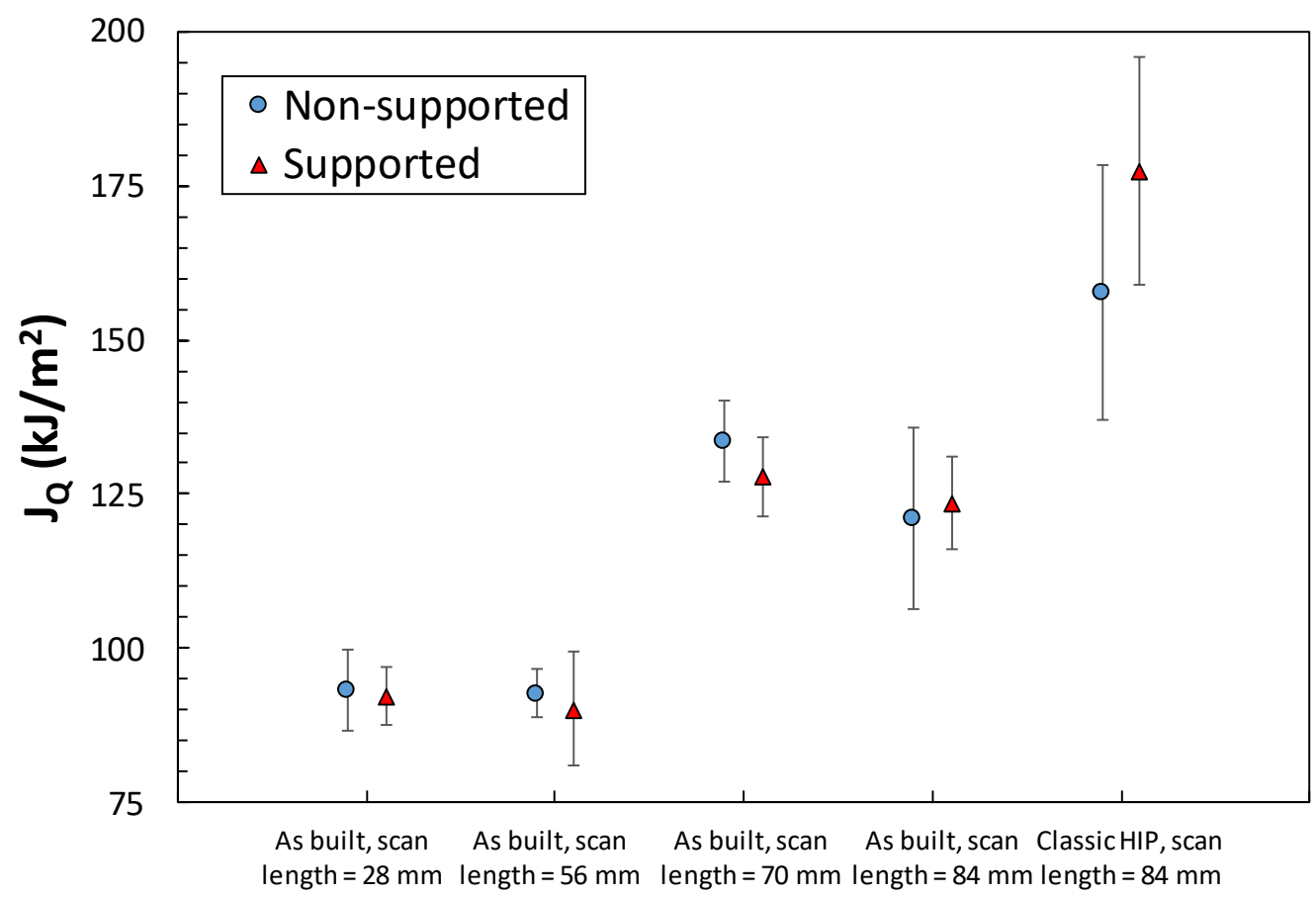

Fig. 25 - Critical toughness values for non-supported and supported specimens, with $\pm 1 \sigma$ error bars. 


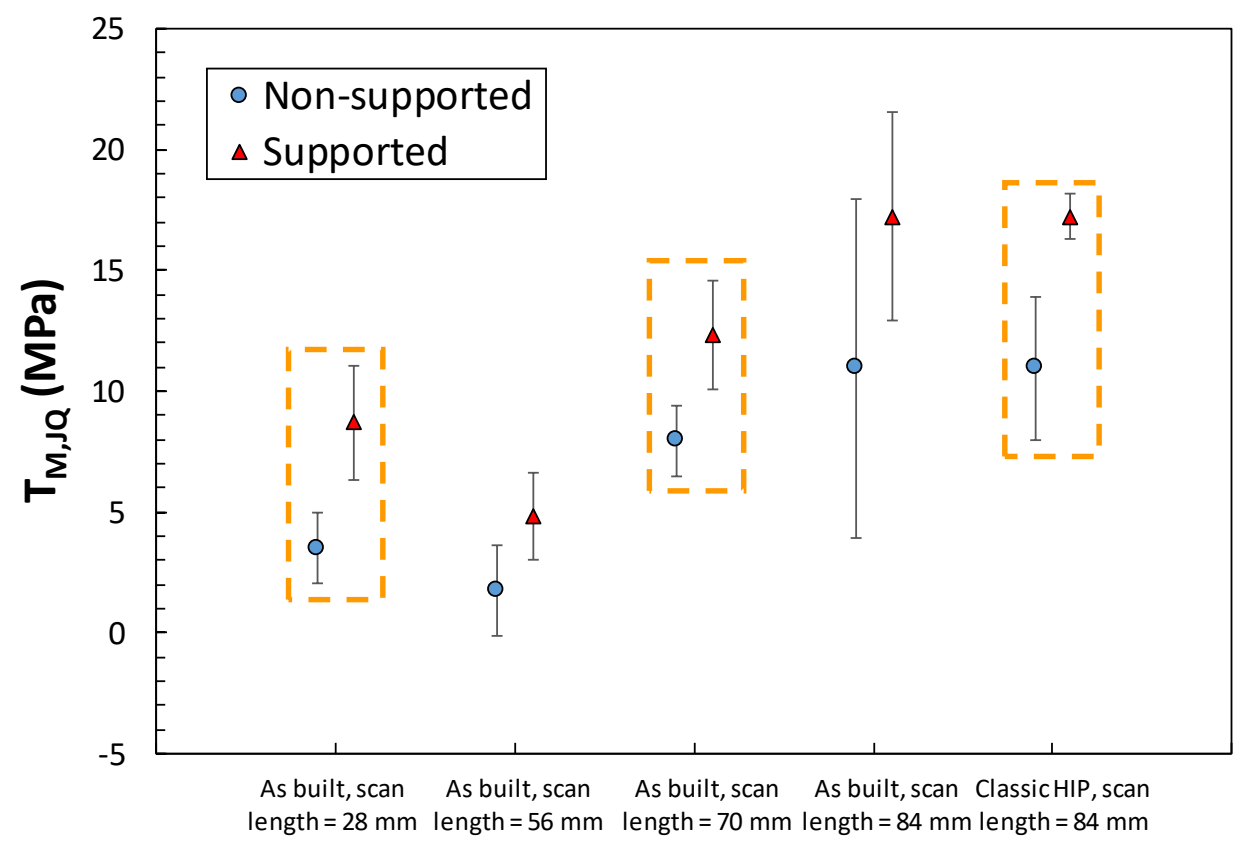

Fig. 26 - Tearing moduli at initiation for non-supported and supported specimens, with $\pm 1 \sigma$ error bars. Orange boxes indicate cases where the bars to not overlap.

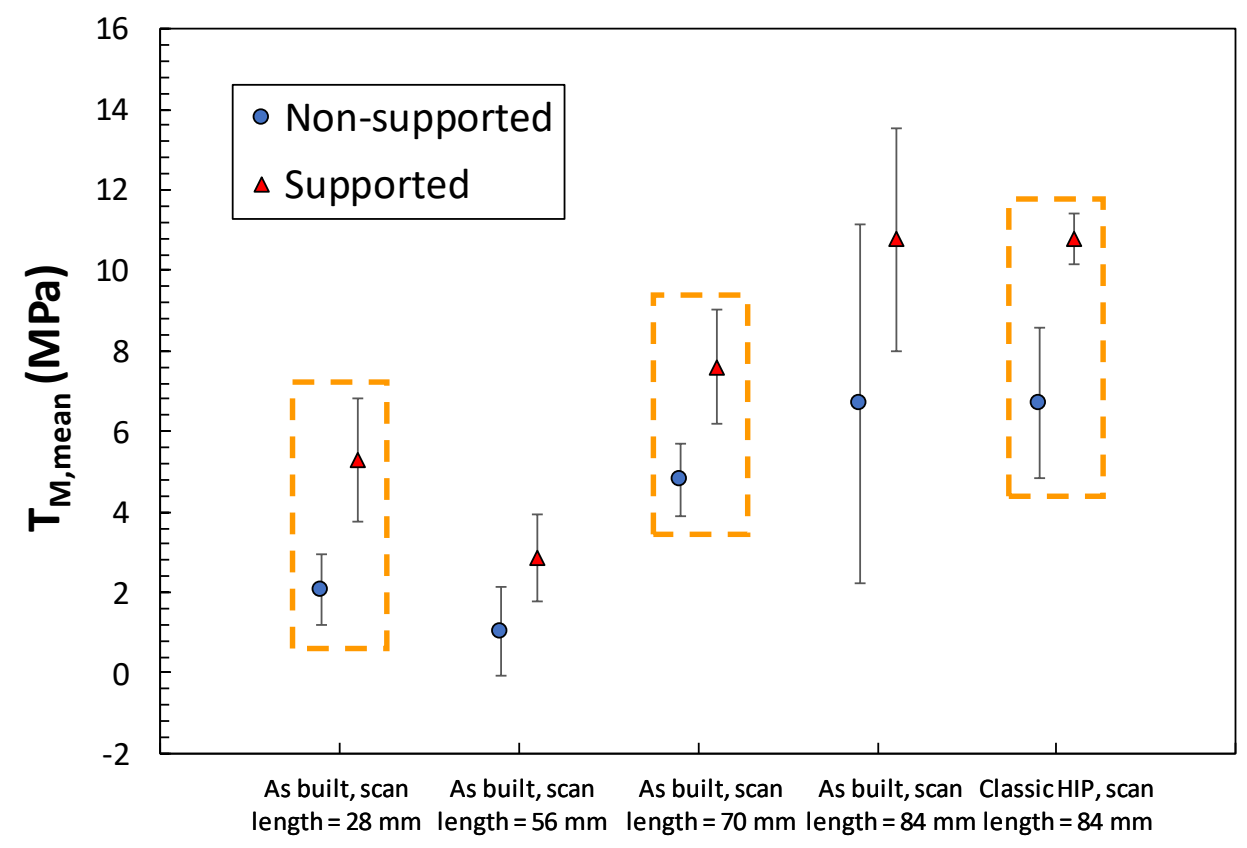

Fig. 27 - Mean values of tearing modulus for non-supported and supported specimens, with $\pm 1 \sigma$ error bars. Orange boxes indicate cases where the bars to not overlap.

Unpaired t-tests were conducted to assess the statistical significance of the differences observed between non-supported and supported mean values of $J_{Q}, T_{M, J Q}$, and $T_{M \text {,mean }}$ for the different conditions. The results are summarized in Table 9 in terms of $p$ value. 
The influence of the type of support is negligible for initiation toughness values (Fig. 25), while differences in tearing moduli were found to be significant for three of the examined conditions (outlined by dashed boxes in the figures), where the $\pm 1 \sigma$ bars do not overlap (Figs. 26 and 27). In general, supported specimens tend to provide higher crack resistance.

Table 9 - Results of unpaired t-tests on the differences between non-supported and supported mean values (significance level $=0.05$ ). $p$-values $<0.05$ (green) indicate that differences are not statistically significant; $p$-values $>0.05$ (red) indicate that differences are statistically significant.

\begin{tabular}{|c|c|c|c|c|}
\hline \multirow{2}{*}{$\begin{array}{l}\text { Material } \\
\text { condition }\end{array}$} & \multirow{2}{*}{$\begin{array}{l}\text { Scan length } \\
(\mathbf{m m})\end{array}$} & \multicolumn{3}{|c|}{$p$-value } \\
\hline & & $J_{Q}$ & $T_{M, J Q}$ & $T_{M, \text { mean }}$ \\
\hline \multirow{4}{*}{ As-built } & 28 & 0.84 & 0.01 & 0.01 \\
\hline & 56 & 0.64 & 0.06 & 0.06 \\
\hline & 70 & 0.26 & 0.02 & 0.02 \\
\hline & \multirow{2}{*}{84} & 0.77 & 0.92 & 0.94 \\
\hline Classic HIP & & 0.28 & 0.02 & 0.02 \\
\hline
\end{tabular}

\subsection{Influence of scan length}

The effect of scan length on fracture toughness test results has already been addressed in the Results section for the different material conditions. In this section, we summarize the influence of scan length on specific fracture parameters (measured with the EC technique) for the conditions investigated: $J_{Q}$ in Fig. 28, $T_{M, J Q}$ in Fig. 29, and $T_{M \text {,mean }}$ in Fig. 30.

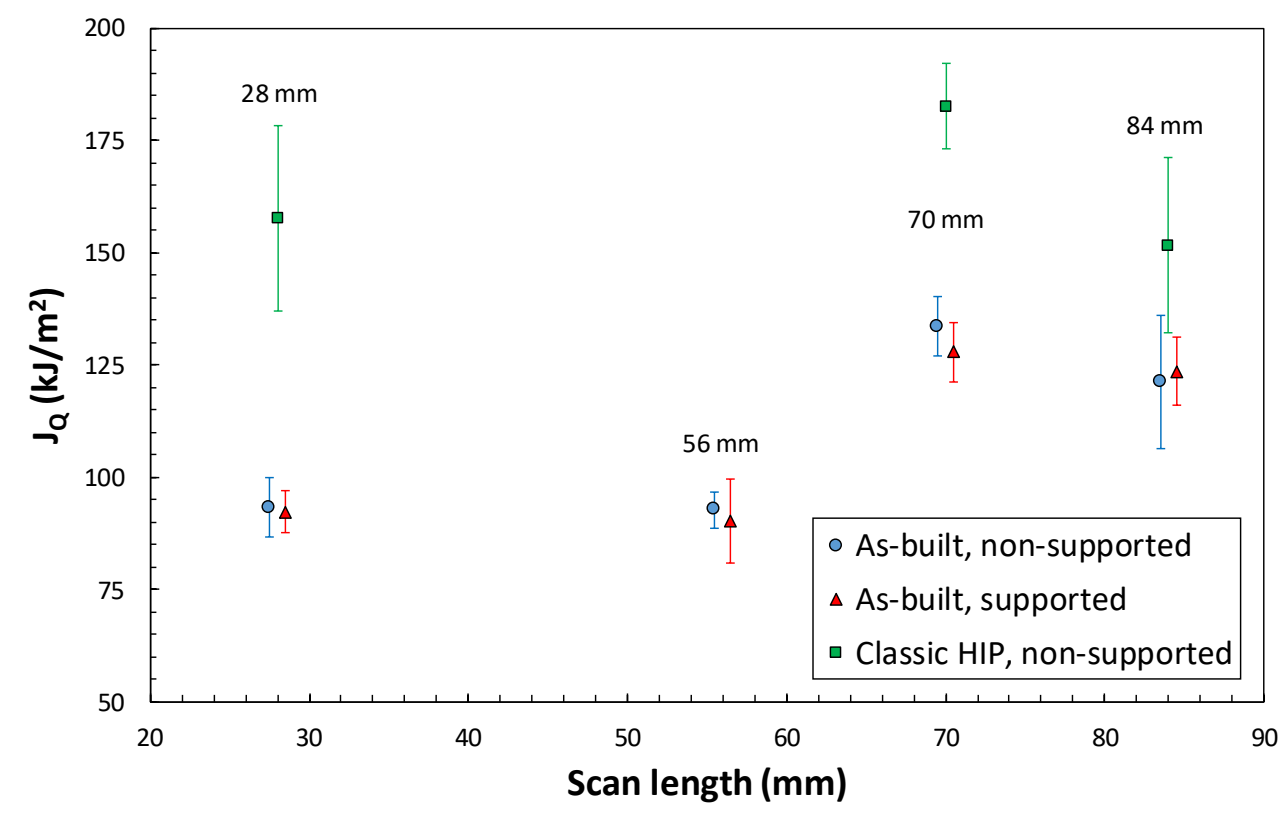

Fig. 28 - Mean values of $J_{Q}$ as a function of scan length. NOTE: scan lengths for as-built specimens are slightly staggered for clarity. 


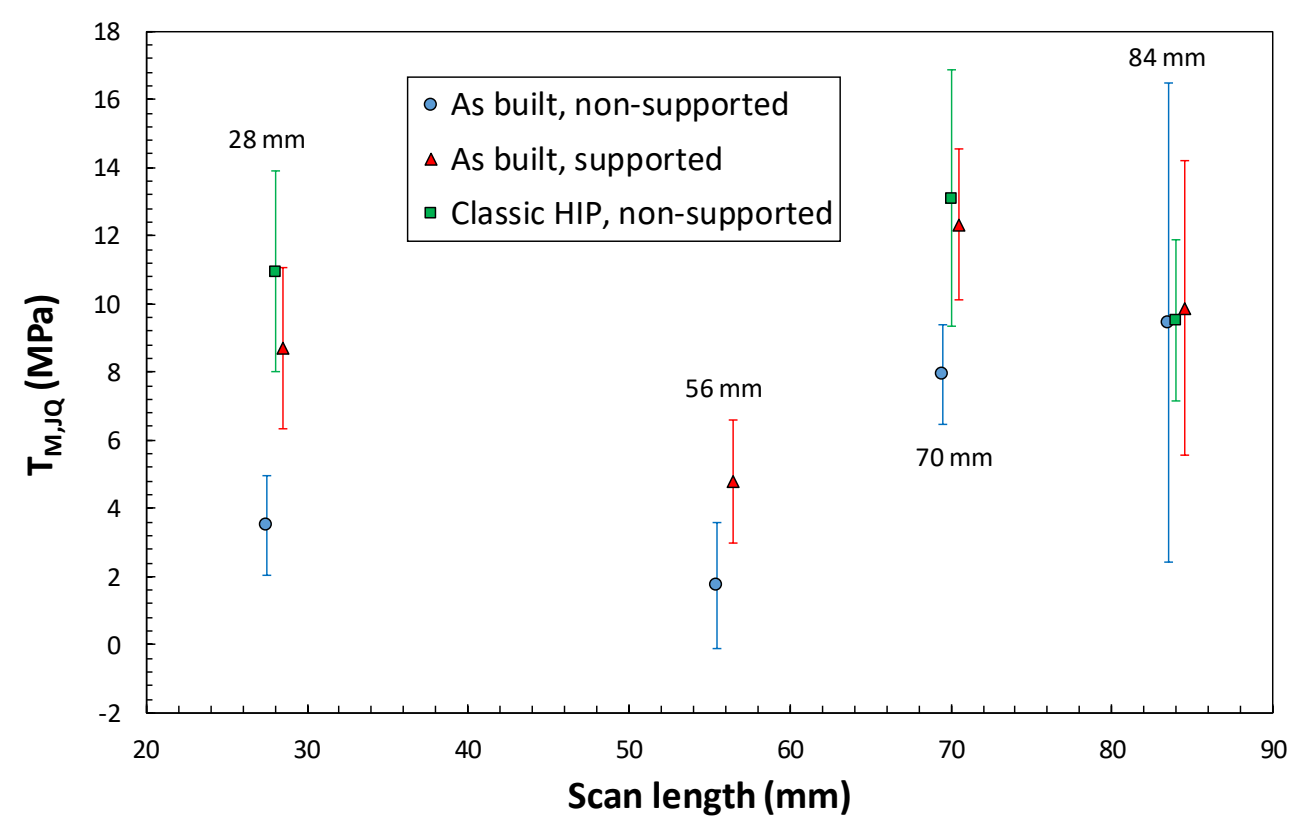

Fig. 29 - Mean values of $T_{M, J Q}$ as a function of scan length. NOTE: scan lengths are slightly staggered for clarity.

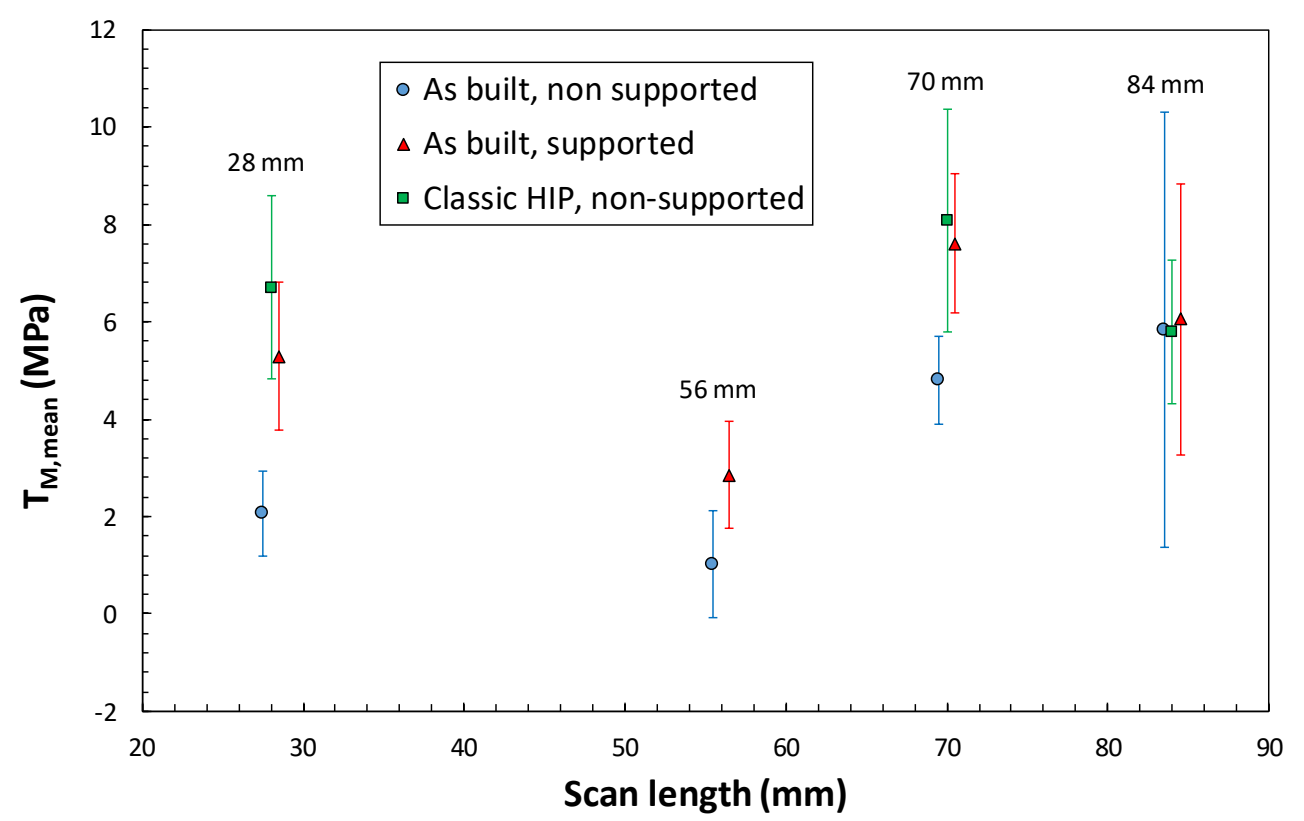

Fig. 30 - Mean values of $T_{M \text {,mean }}$ as a function of scan length. NOTE: scan lengths are slightly staggered for clarity.

We performed analyses of residuals (ANOVA) on the correlations between scan length and toughness parameters, which revealed no statistically significant correlation for any of the investigated conditions $(P>0.05)$. Fig. 28 also provides confirmation that the type of support has a negligible influence on initiation toughness for the as-built material. 


\subsection{As-built vs. HIP (classic and super- $\beta$ transus)}

Based on the test matrix of this investigation (Table 1), there is only one specimen condition (non-supported, scan length $=70 \mathrm{~mm}$ ) that allows comparing as-built, classic HIP and super- $\beta$ transus HIP in terms of initiation toughness $J_{Q}$. (Fig. 31). As stated in Section 6, $J_{Q}$ values for the super- $\beta$ transus HIP are just engineering estimates, since a regular E1820 analysis could not be performed due to the occurrence of significant "crack jumps".

Comparisons between as-built and classic HIP can be made for non-supported specimens with three scan lengths: $28 \mathrm{~mm}, 70 \mathrm{~mm}$, and $84 \mathrm{~mm}$ (Figs. 32-34).

The classic HIP treatment $\left(2 \mathrm{~h}, 900{ }^{\circ} \mathrm{C}, 100 \mathrm{MPa}\right)$ increases initiation toughness with respect to the as-built condition, whereas its effect on crack resistance is less clear, and seems to depend on scan length. The super- $\beta$ transus HIP treatment $\left(2 \mathrm{~h}, 1050^{\circ} \mathrm{C}, 100 \mathrm{MPa}\right.$ followed by additional $\mathrm{HIP}-2 \mathrm{~h}, 800^{\circ} \mathrm{C}, 30 \mathrm{MPa}$ ) appears to have a deleterious effect on the material's fracture toughness, primarily due to the occurrence of episodes of tearing instability.

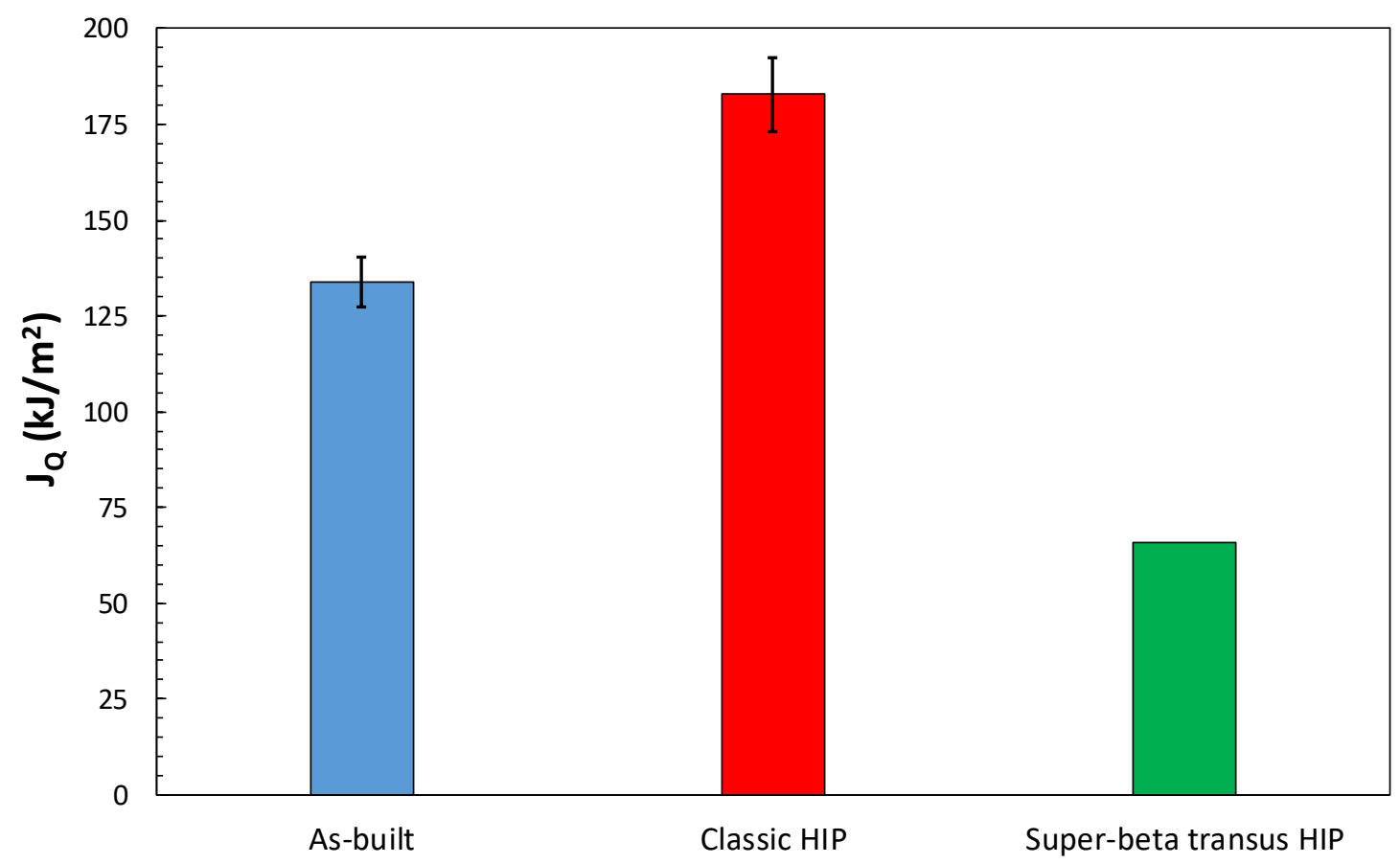

Fig. 31 - Mean values of $J_{Q}$ with $\pm 1 \sigma$ error bars for non-supported specimens with scan length $=70 \mathrm{~mm}$. NOTE: the value for super- $\beta$ transus HIP is a rough engineering estimate. 


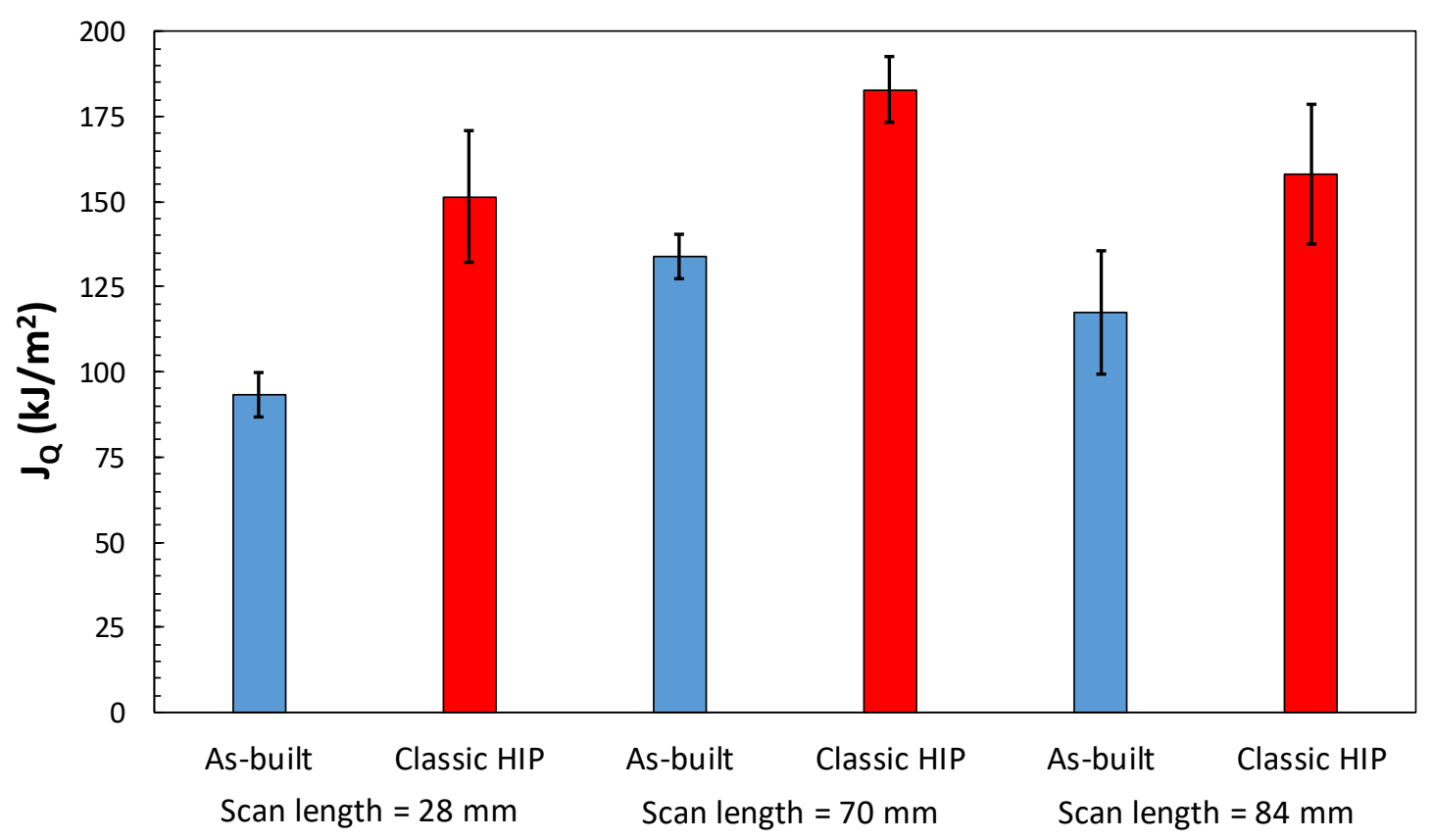

Fig. 32 - Mean values of $J_{Q}$ with $\pm 1 \sigma$ error bars for non-supported specimens with $28 \mathrm{~mm}$, $70 \mathrm{~mm}$, and $84 \mathrm{~mm}$ scan lengths.

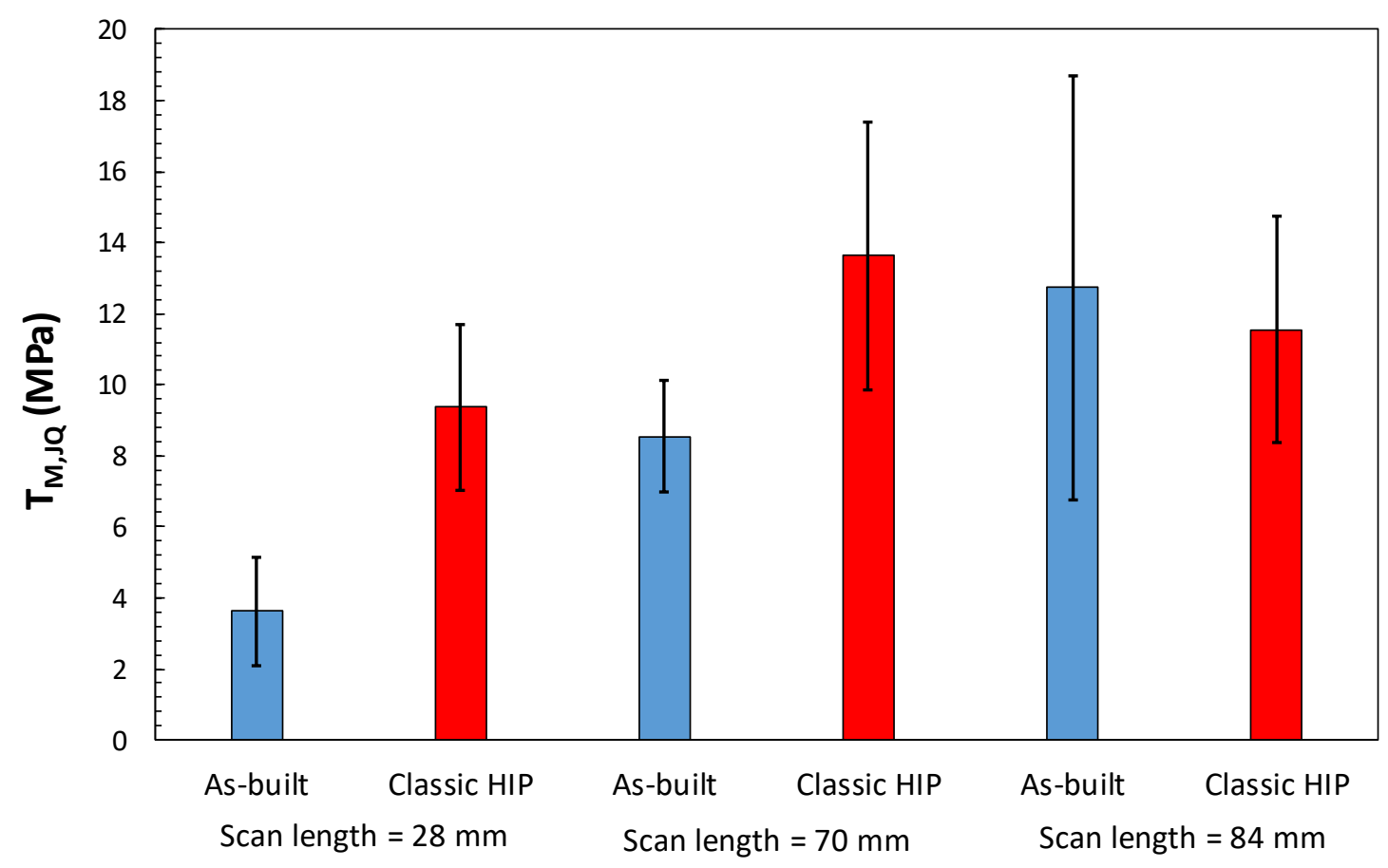

Fig. 33 - Mean values of $T_{M, J Q}$ with $\pm 1 \sigma$ error bars for non-supported specimens with 28 $\mathrm{mm}, 70 \mathrm{~mm}$, and $84 \mathrm{~mm}$ scan lengths. 


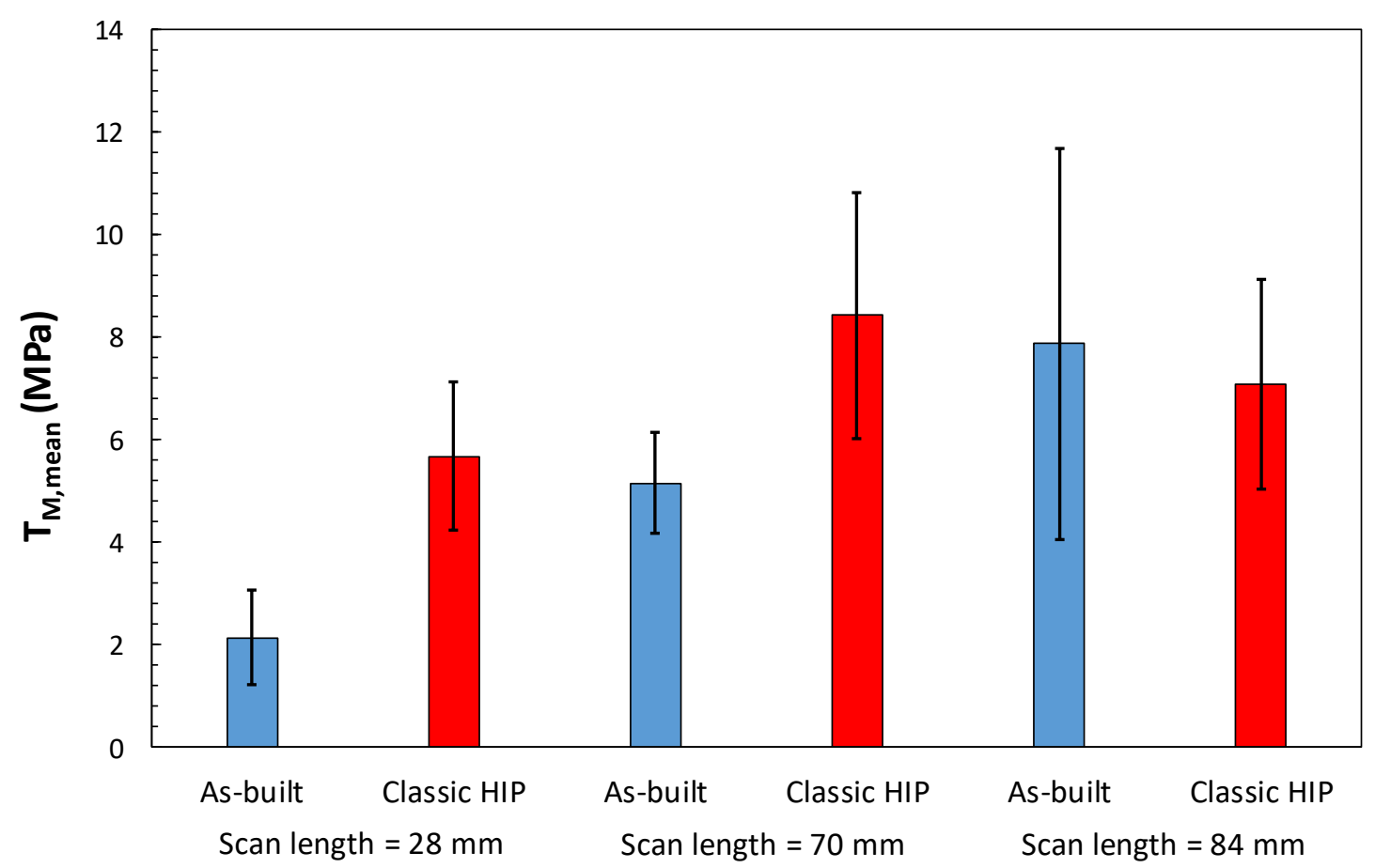

Fig. 34 - Mean values of $T_{M \text {,mean }}$ with $\pm 1 \sigma$ error bars for non-supported specimens with 28 $\mathrm{mm}, 70 \mathrm{~mm}$, and $84 \mathrm{~mm}$ scan lengths.

\subsection{Crack jumps and lack-of-fusion (LoF) pores}

In an elastic compliance test, which is commonly performed in actuator displacement ("stroke") control, unloading/reloading cycles are equally spaced at regular displacement intervals. In most cases, this corresponds to approximately equally spaced crack size (or crack extension) values. However, for materials subject to the occurrence of significant "crack jumps", this doesn't hold true anymore.

An example of such behavior is given in Fig. 35, where force and predicted crack size data are plotted as a function of CMOD for specimen BN-5-1 (super- $\beta$ transus HIP, non-supported, scan length $=70 \mathrm{~mm}$ ). The two largest increments of crack size are marked in the figure, corresponding to drops of the applied force after reaching its maximum values.

These force drops and crack size increments correspond to episodes of unstable ductile crack growth, which are commonly denominated "tearing instabilities" [10,18-21].

The most common cause of tearing instabilities in fracture toughness specimens is the presence of large microstructural features (defects) encountered by the crack while propagating through the ligament. Another possible cause is the presence of residual stresses in the material.

In the preliminary fracture toughness investigation of AM Ti64 documented in [6], we observed the presence of large lack-of-fusion $(\mathrm{LoF})$ pores on the fracture surface of some of the specimens tested, caused by improper or incomplete fusion among layers and hatches during the AM process [22-24]. LoF is detrimental for the mechanical properties of the AM part, and is often the cause for rejection [5]. LoF pores, when exposed to the surface, cannot be healed by HIPing, since the Ar gas enters the part via those pores. 


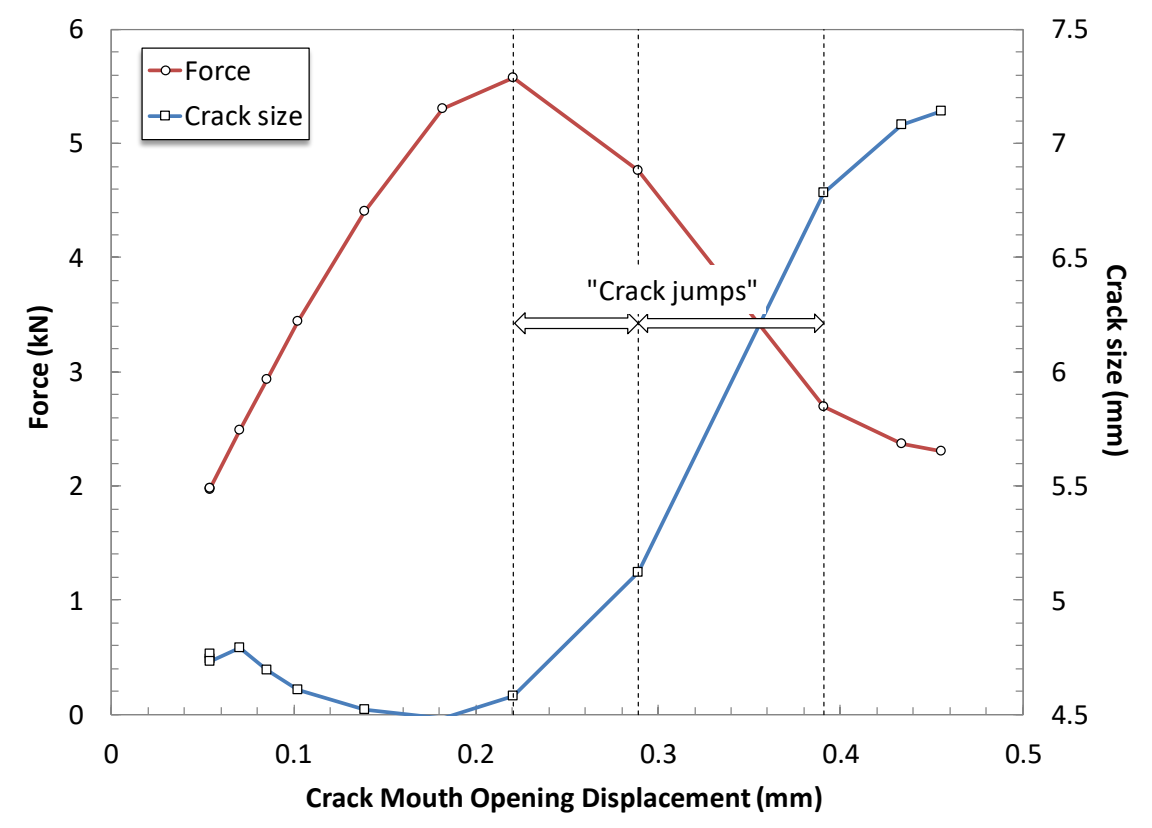

Fig. 35 - Force and crack size vs. CMOD for specimen BN-5-1. NOTE: unloading/reloading cycles have been removed from the force/CMOD plot for clarity.

In [6], we associated LoF to the large scan length used $(84 \mathrm{~mm})$, and stated that the presence of such defects can be avoided by using shorter scan lengths [5]. Such statements were confirmed by the present investigation, insofar as $79 \%$ (11 out of 14) of the specimens corresponding to the longest scan length $(84 \mathrm{~mm})$ exhibited various amounts of LoF porosity. In some cases (Fig. 36a), LoF pores are spread all over the fracture surface; in other cases, (Fig. 36b), only a few pores are observed, and they are not located on the path of crack propagation.

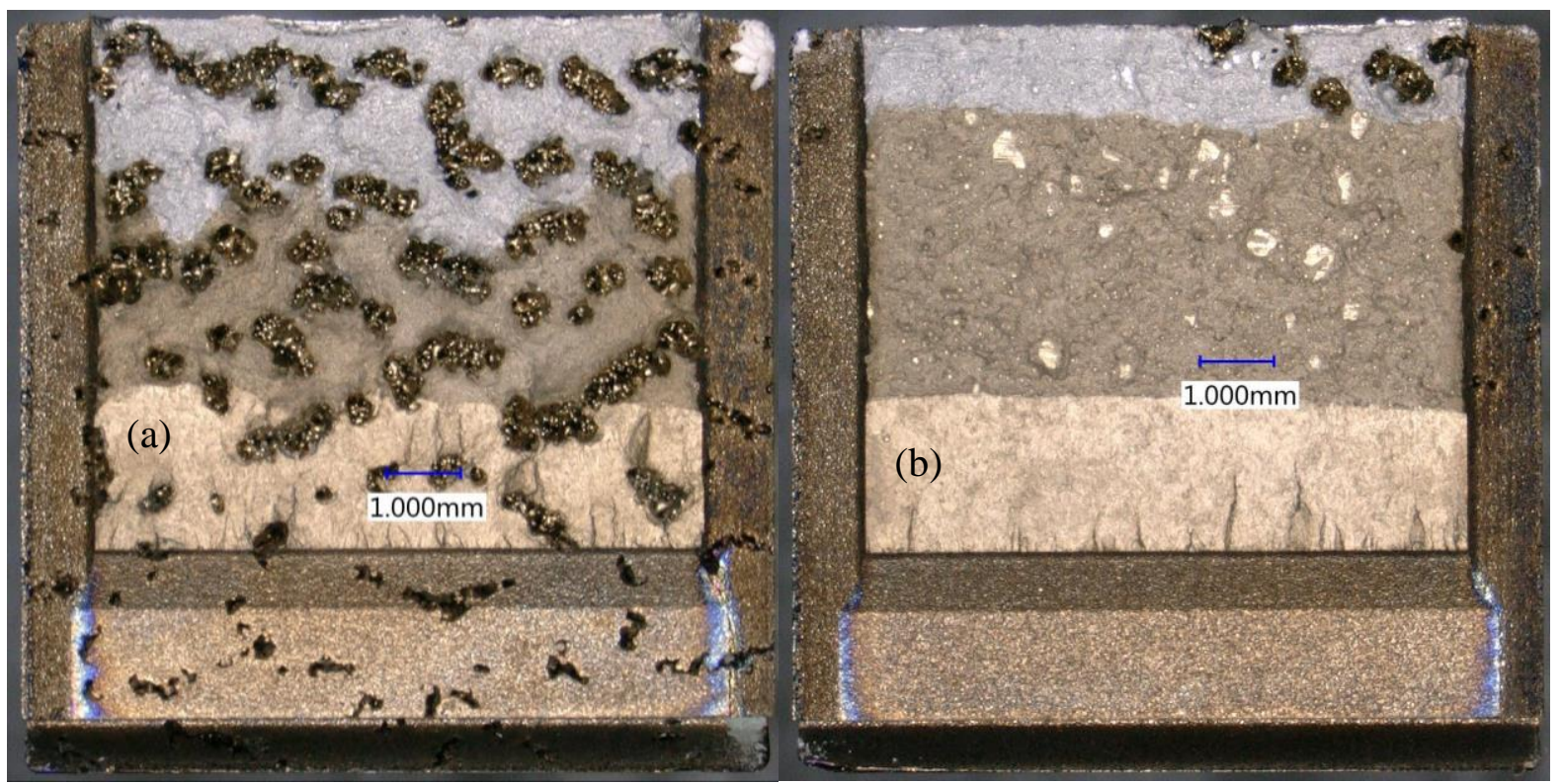

Fig. 36 - Fracture surfaces of specimens AS-4-2 (high density of LoF pores) and AS-4-3 (low density of LoF pores). Material condition: as-built, supported, scan length $=84 \mathrm{~mm}$. 
The number/density of LoF pores does not appear to have a direct relationship with fracture toughness properties: namely, in reference with the two examples of Fig. 36, the specimen with the highest LoF density (AS-4-2, Fig. 36a) does not correspond to the lowest $J-R$ curve in Fig. 13, and the specimen with the lowest LoF density (AS-4-3, Fig. 36b) does not correspond to the highest $J-R$ curve, but actually to the lowest.

The real cause(s) of crack jumps and the true driving factor(s) that influence fracture toughness in AM Ti64 will require further investigations of the different material conditions.

\subsection{Validity of the measured fracture toughness parameters}

ASTM E1820-18 $\mathrm{a}^{\varepsilon 1}$ provides many requirements that need to be fulfilled for the test results to be considered valid, i.e., corresponding to the elastic-plastic fracture toughness of the tested material (not just the tested specimen). In other words, fulfilling all the requirements guarantees that the measured $J_{Q}$ and $J-R$ curve are size-independent material properties.

The requirements can be classified in the following categories:

- Estimate of initial crack size (section 8.6.3.1): at the very beginning of the test, the standard requires performing at least three unloading/reloading cycles over a force range of 0.5 to 1.0 times the final maximum precracking force. The corresponding estimates of initial crack size, $a_{0 q}$, must not differ from the mean by more than $\pm 0.002 W$ (for the specimens tested, specimen width is $W=10 \mathrm{~mm}$, and therefore the tolerance becomes $\pm 0.02 \mathrm{~mm}$ ).

- Comparison between predicted and measured crack extension (section 9.1.5.2): the difference between the total crack extension predicted by the EC method at the last unloading, $\Delta a_{\text {pred }}$, and the optical measurement on the fracture surface, $\Delta a_{\text {pred }}$, must not differ by more than $\pm 0.03 b_{0}$ (for the specimens tested, initial ligament size $b_{0} \approx 5 \mathrm{~mm}$, and the tolerance becomes $\pm 0.15 \mathrm{~mm}$ ). Note: as mentioned in section 3, all predicted crack sizes were adjusted by means of Eq. (2), hence this requirement does not apply.

- $\quad$ Adjustment of the predicted initial crack size, $a_{0 q}$ (section A9.3.3): the revised value of $a_{0 q}$ to be used for analysis is obtained by fitting all data points before maximum force by means of the following equation:

$$
a=a_{0 q}+\frac{J}{2 \sigma_{Y}}+B J^{2}+C J^{3},
$$

where the coefficients, including $a_{0 q}$, are found using a least squares fit procedure. The following requirements have to be met:

a. the number of fitted points must be at least 8 ;

b. three of the fitted data points must lie between $0.4 J_{Q}$ and $J_{Q}$;

c. the correlation coefficient of the fit must be at least 0.96 ;

d. $a_{0 q}$ must match the measured initial crack size, $a_{0}$, within $\pm 0.5 \mathrm{~mm}$.

- Establishment of the $J-R$ curve and calculation of $J_{Q}$ (sections A9.6.4, A9.6.6.6, and A9.9.1): the $J-R$ curve is obtained by fitting data points inside a qualified data region by means of the following power law relationship:

$$
J=C_{1} \Delta a^{C_{2}},
$$

where the coefficients are found using a least squares fit procedure. The following requirements must be met: 
a. the distribution of data points inside the region of qualified data must follow the prescriptions of section A9.6.4;

b. the number of data points to be fitted inside the region of qualified data must be at least 5 (section A9.6.6.6);

c. the exponent $C_{2}$ in Eq. (4) must be less than 1.0 (section A9.9.1).

- Qualification of $J_{Q}$ as $J_{I c}$ (section A9.10): the calculated value of $J_{Q}$ is qualified as $J_{I c}$ if both specimen thickness, B, and initial ligament size, $b_{0}$, are bigger than $10 \frac{J_{Q}}{\sigma_{Y}}$.

None of the 50 tests performed in this investigation fulfilled all the requirements listed above. Excluding the 4 specimens with super- $\beta$ transus HIP, which could not be analyzed in accordance with E1820, the specific statistics were:

- 17 specimens (46\%) failed the requirement on the initial estimate of $a_{0}(1)$.

- 1 specimen (2\%) failed the requirement on the minimum number of points in the $a_{0 q}$ fit (3a).

- 45 specimens $\left(98 \%\right.$ ) failed the requirement on the correlation coefficient of the $a_{0 q}$ fit (3c).

- 2 specimens (4\%) failed the requirement on the difference between $a_{0}$ and $a_{0 q}(3 \mathrm{~d})$.

- 5 specimens $(11 \%)$ failed the requirement on the distribution of qualified data points (4a).

- 5 specimens $(11 \%)$ failed the requirement on the minimum number of qualified data points (4b).

- The following requirements were fulfilled by all specimens tested: minimum number of data points between $0.4 J_{Q}$ and $J_{Q}(3 \mathrm{~b})$; power law exponent, $C_{2}$, lower than $1.0(4 \mathrm{c})$; requirements to qualify $J_{Q}$ as $J_{I c}$ based on the specimen dimensions ( $W$ and $b_{0}$ ) (5).

From the list provided above, it can be noted that the two most violated requirements (46\% and $98 \%$ respectively) both concern the estimation/prediction of the initial crack size. However, only $4 \%$ of the specimens failed to acceptably predict the measured $a_{0}$, and therefore the starting point of the analyses can be considered substantially reliable for the majority of the tests.

Conversely, other requirements that can be deemed more substantial in determining the soundness of the $J-R$ curves obtained, and therefore of the corresponding critical values, such as number and distribution of the qualified data points, power law exponent, size independence of $J_{Q}$, were satisfied by all, or nearly all, specimens tested.

Therefore, based on the authors' experience and the reasoning expressed above, the EC results obtained in the present study provide a reliable characterization of the fracture toughness of AM Ti64 in the investigated conditions (with the exception of super- $\beta$ transus HIP).

As far as the NDR analyses are concerned, Annex A15 of ASTM E1820-18 $\mathrm{a}^{\varepsilon^{1}}$ limits crack extension to no more than the lesser of $4 \mathrm{~mm}$ and $15 \%$ of $b_{0}$ (in this study, this limit corresponds to $\Delta a_{p, \max } \approx 0.75 \mathrm{~mm}$ ). For the 50 specimens tested, total crack extension ranged from $1.05 \mathrm{~mm}\left(21.1 \%\right.$ of $\left.b_{0}\right)$ and $3.97 \mathrm{~mm}\left(79.3 \%\right.$ of $\left.b_{0}\right)$, and therefore none of the tests could be in principle analyzed in accordance with the standard.

Historically, when Annex A15 was added to E1820 in the 2001 version, this requirement was set equal to the crack extension capacity for the determination of the $J-R$ 
curve, $\Delta a_{\max }$. Later, $\Delta a_{\max }$ was increased from $0.15 \cdot b_{0}$ to $0.25 \cdot b_{0}$, based on additional research performed, but the requirement for NDR remained unchanged. It is however reasonable to assume that this requirement could be increased to $25 \%$ of $b_{0}$ without loss of accuracy [25]. In this case, only 3 tests (specimens $\mathrm{CN}-4-2, \mathrm{CN}-5-1$, and CN-5-2) could be considered valid.

Since the ORNL software allowed to run the NDR analyses irrespective of the total crack extension, we decided to analyze of all tests performed, also because the real crack extension limit is still under discussion within the responsible ASTM sub-committee (E08.07.06).

\subsection{Elastic Compliance vs. Normalization Data Reduction}

It being understood that EC is the reference technique in this study and NDR was added as a secondary analysis approach (and its results might be questionable due to excessive crack extension), we compared the fracture toughness parameters $\left(J_{Q}, T_{M, J Q}\right.$, and $\left.T_{M \text {,mean }}\right)$ obtained from the two methodologies in Fig. 37, Fig. 38, and Fig. 39 respectively. The comparison was effectively possible on 43 tests, since for 3 specimens the NDR analysis did not converge (CN-4-3, CN-5-1, and CN-5-2) and for the 4 tests on super- $\beta$ transus HIPed specimens (Table 7) the EC analysis only provided engineering estimates of the fracture parameters.

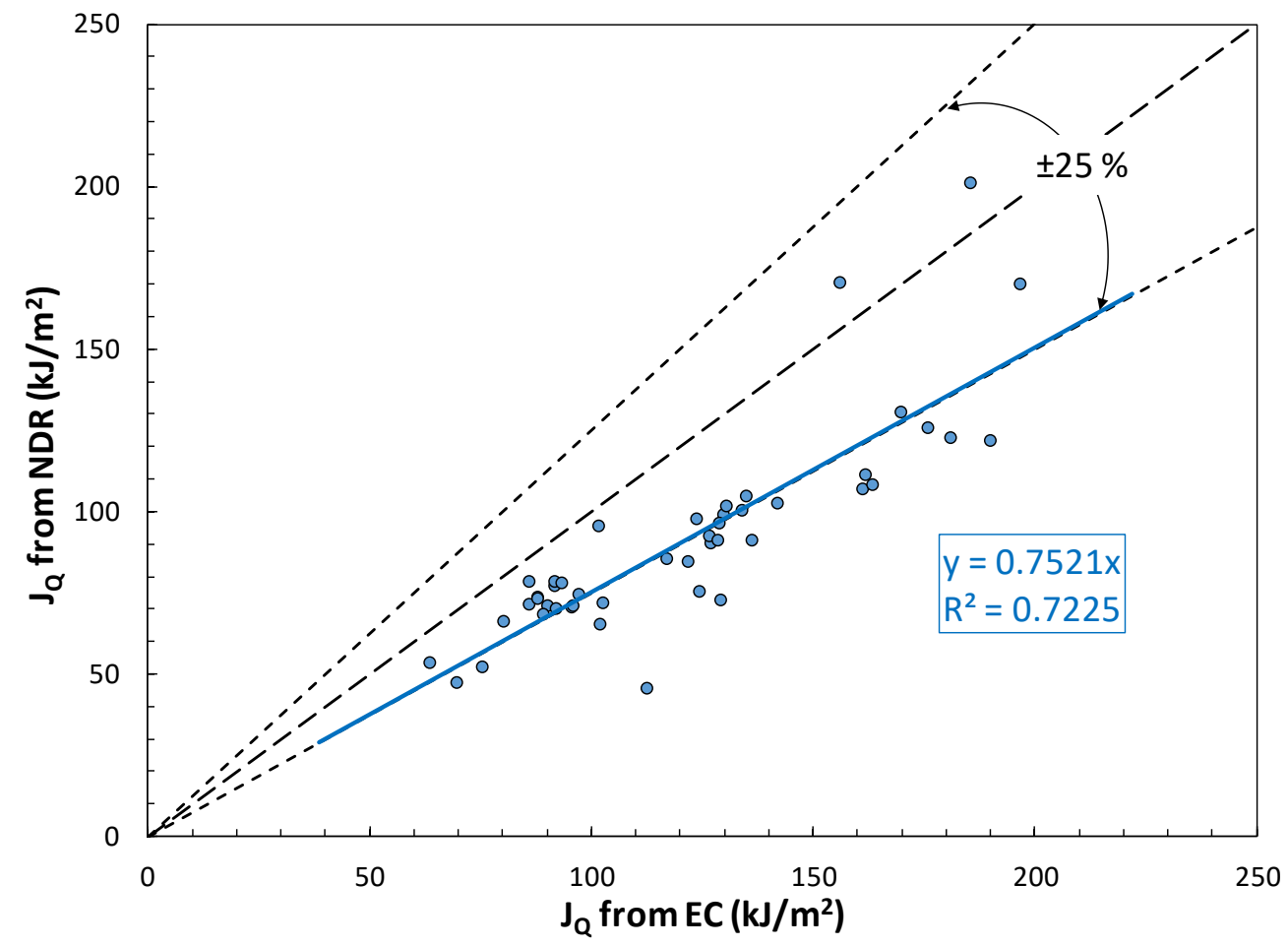

Fig. 37 - Comparison between values of critical fracture toughness, $J_{Q}$, obtained from EC and NDR analyses. 


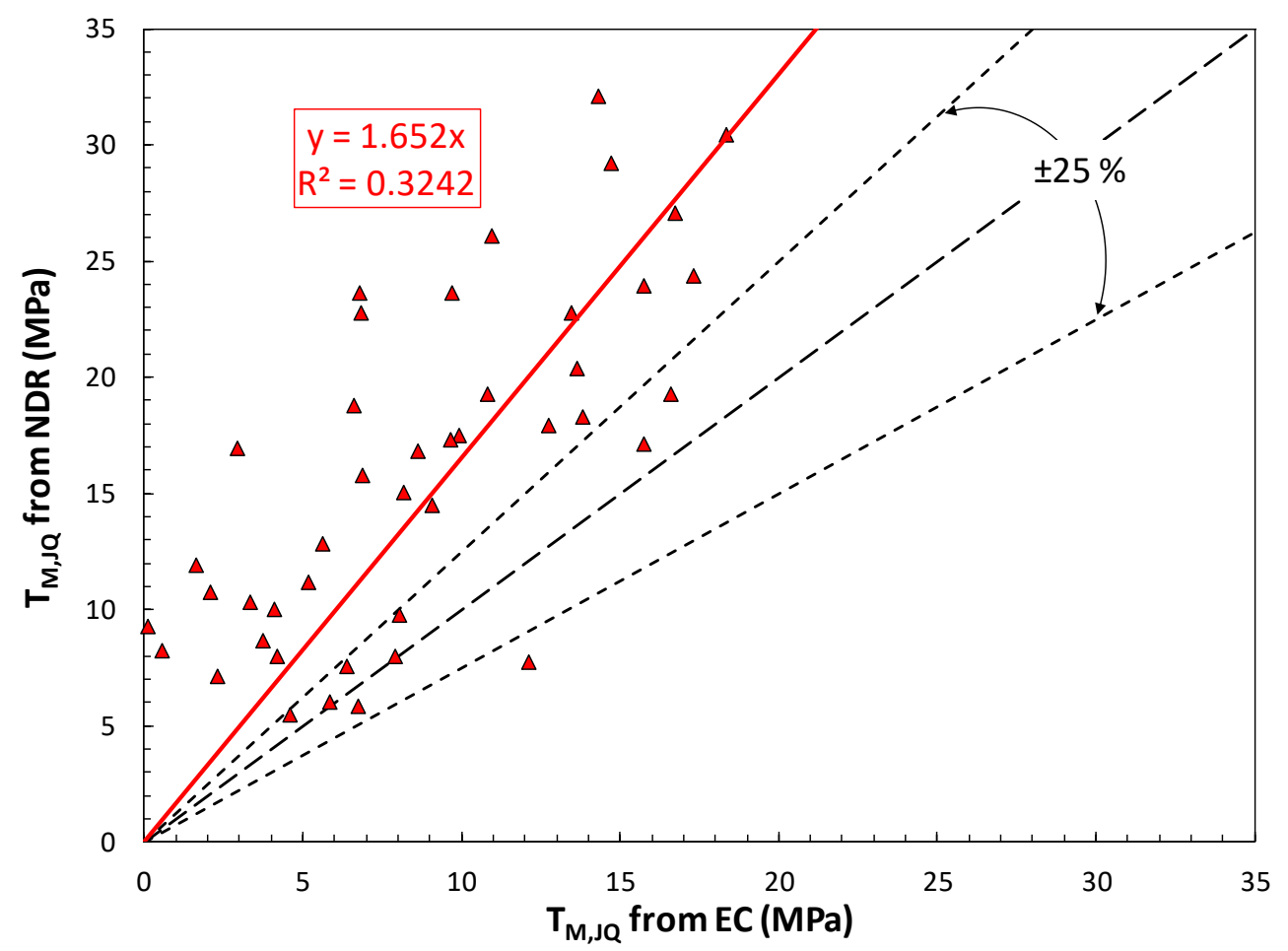

Fig. 38 - Comparison between values of tearing modulus at initiation, $T_{M, J Q}$, obtained from EC and NDR analyses.

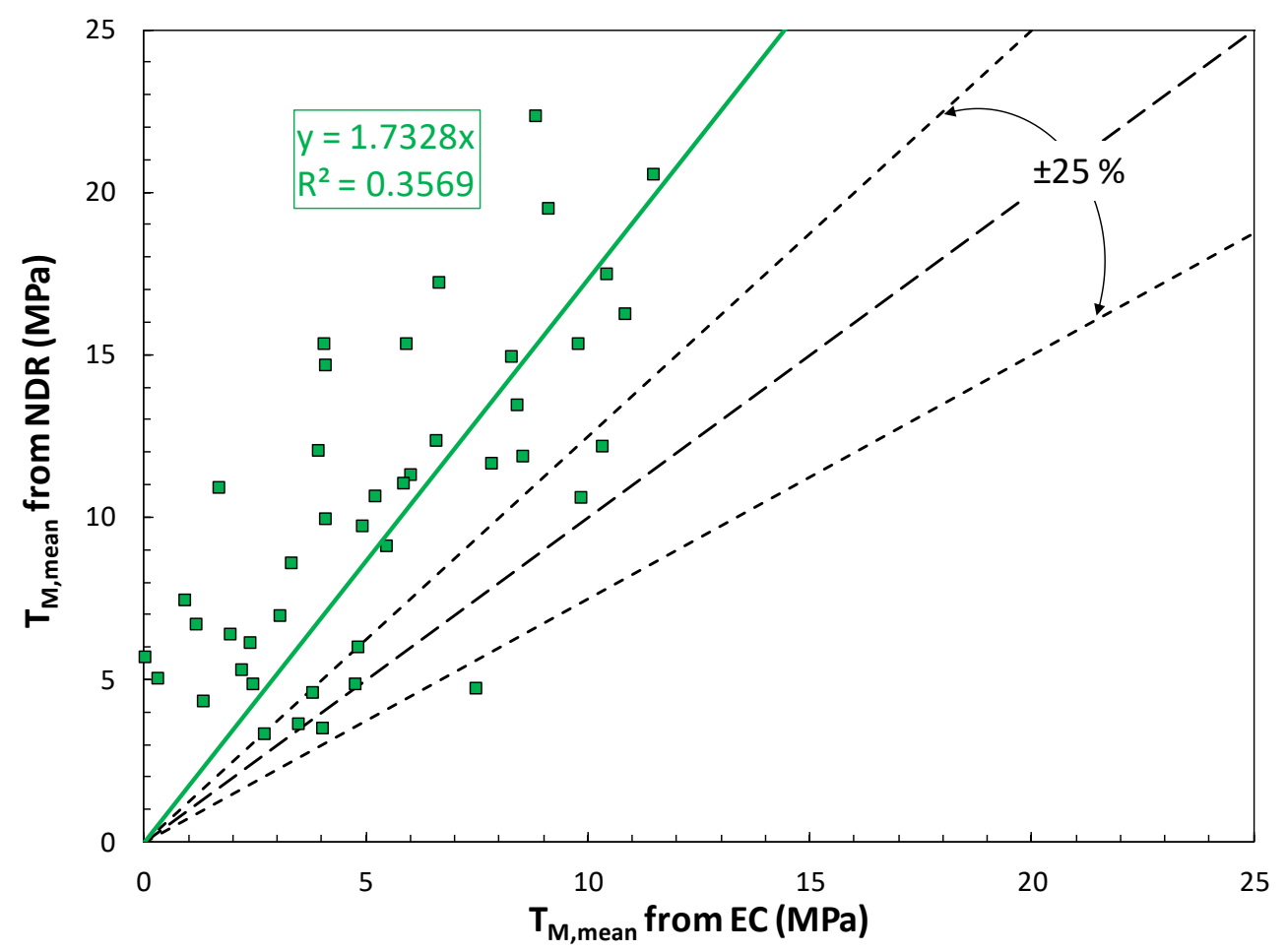

Fig. 39 - Comparison between values of mean tearing modulus, $T_{M, \text { mean }}$, obtained from EC and NDR analyses. 
Despite significant scatter, general trends are quite clear in Figs. 37-39:

- $J_{Q}$ values from NDR were lower than from EC for all tests (except two), with an average ratio $J_{Q(N D R)} / J_{Q(E C)}=0.75 \pm 0.12$.

- $T_{M, J Q}$ values from NDR were higher than from EC for all tests (except three), with an average ratio $T_{M, J Q(N D R)} / T_{M, J Q(E C)}=4.55 \pm 13.91$.

- $T_{M, \text { mean }}$ values from NDR were also higher than from EC for all tests (except three), with an average ratio $T_{M, J Q(N D R)} / T_{M, J Q(E C)}=4.78 \pm 14.62$.

In summary, NDR analyses appear to provide generally lower initiation toughness and higher crack resistance (steeper $J$ - $R$ curves).

Such differences are not consistent with information available from some early NDR references [13-15], which showed good to excellent agreement between EC and NDR $J-R$ curves. In 2013, a large database of $348 J-R$ curve tests on $\mathrm{C}(\mathrm{T})$ and $\mathrm{SE}(\mathrm{B})$ specimens, performed at $\mathrm{SCK} \cdot \mathrm{CEN}$ (the Belgian Nuclear Center) and analyzed by means of three different single-specimen techniques (EC, NDR, and EPD - electric potential difference), was presented at an ASTM Special Technical Meeting on Use of Potential Drop in Elastic-Plastic Fracture Toughness Testing [26]. Based on the presentation and only considering tests on SE(B) specimens, $J_{Q} / J_{I c}$ values from NDR were on the average $5 \%$ higher than from EC, while tearing modulus at initiation $\left(T_{M, J Q}\right)$ from NDR was on the average $31 \%$ lower than from EC. For both parameters, however, scatter bands were huge (ratio NDR/EC: $0.59-7.14$ for $J_{Q}$, $0.34-3.46$ for $\left.T_{M, J Q}\right)$. 


\subsection{Comparison with literature fracture toughness values}

\subsubsection{Non-AM Ti64}

Room temperature fracture toughness values for non-AM Ti64 were collected from the literature [27-36] and compared to the results obtained in this investigation in Table 10.

Table 10 - Literature fracture toughness values for non-AM Ti64, and results obtained on AM Ti64 in this investigation.

\begin{tabular}{|c|c|c|c|}
\hline Reference & Material form/condition & Reported toughness & Remarks \\
\hline $\begin{array}{l}\text { Tobler, } 1976 \\
\text { [27] }\end{array}$ & $\begin{array}{l}1 \mathrm{~m} \text { diameter hemisphere, } 51 \\
\mathrm{~mm} \text { wall thickness; forging }\end{array}$ & $K_{Q}=77.5 \mathrm{MPa} \sqrt{ } \mathrm{m}-94.0 \mathrm{MPa} \sqrt{\mathrm{m}}$ & $\begin{array}{l}\mathrm{C}(\mathrm{T}) \text { specimens } 10 \mathrm{~mm}-25.4 \\
\text { mm thick, various } \\
\text { orientations }\end{array}$ \\
\hline $\begin{array}{l}\text { Munz et al., } \\
1976[28]\end{array}$ & $\begin{array}{l}\text { Forged and annealed plate, } \\
\text { thickness }=44 \mathrm{~mm} \\
\text { Rolled and annealed plate, } \\
\text { thickness }=82 \mathrm{~mm}\end{array}$ & $\begin{array}{l}K_{Q}=58.0 \mathrm{MPa} \sqrt{\mathrm{m}}-92.7 \mathrm{MPa} \sqrt{\mathrm{m}} \\
K_{Q}=43.5 \mathrm{MPa} \sqrt{\mathrm{m}}-83.5 \mathrm{MPa} \sqrt{\mathrm{m}}\end{array}$ & $\begin{array}{c}\mathrm{SE}(\mathrm{B}) \text { specimens, } W / B=1-6 \\
\mathrm{SE}(\mathrm{B}) \text { specimens, } W / B= \\
1-20\end{array}$ \\
\hline $\begin{array}{l}\text { Kishi et al., } \\
1980 \text { [29] }\end{array}$ & Rolled plate, 1 in. thick & $K_{I c}=40.0 \mathrm{MPa} \sqrt{\mathrm{m}}-71.9 \mathrm{MPa} \sqrt{\mathrm{m}}$ & $\begin{array}{l}\mathrm{C}(\mathrm{T}) \text { specimens, } \\
B=7 \mathrm{~mm} \text { or } 20 \mathrm{~mm}\end{array}$ \\
\hline $\begin{array}{l}\text { Rhodes et al., } \\
1982[30]\end{array}$ & $\alpha / \beta$ processed, quenched & $K_{Q}=53 \mathrm{MPa} \sqrt{\mathrm{m}}-75 \mathrm{MPa} \sqrt{\mathrm{m}}$ & $\begin{array}{l}\text { Precracked Charpy } \\
\text { specimens }\end{array}$ \\
\hline $\begin{array}{l}\text { Niinomi et al., } \\
1988 \text { [31] }\end{array}$ & $\begin{array}{l}\text { Rolled plate } 12 \mathrm{~mm} \text { thick, } \\
\text { various HT }\end{array}$ & $\begin{array}{c}K_{Q}=68.8 \mathrm{MPa} \sqrt{\mathrm{m}}-90.6 \mathrm{MPa} \sqrt{\mathrm{m}} \\
J_{I c(P D)}=19.6 \mathrm{~kJ} / \mathrm{m}^{2}-55.3 \mathrm{~kJ} / \mathrm{m}^{2} \\
T_{M, J Q}=2.5 \mathrm{MPa}-19 \mathrm{MPa}\end{array}$ & $\begin{array}{l}\mathrm{C}(\mathrm{T}) \text { specimens, } \\
\text { thick }\end{array}$ \\
\hline $\begin{array}{c}\text { Donachie, } 2000 \\
{[32]}\end{array}$ & $\begin{array}{c}\text { As-cast } \\
\text { Cast }+ \text { HIP } \\
\text { Wrought } \beta \text {-annealed }\end{array}$ & $\begin{aligned} K_{I c} & =107 \mathrm{MPa} \sqrt{\mathrm{m}} \\
K_{I c} & =109 \mathrm{MPa} \sqrt{\mathrm{m}} \\
K_{I c} & =91 \mathrm{MPa} \sqrt{\mathrm{m}}\end{aligned}$ & \\
\hline $\begin{array}{l}\text { Peters et al., } \\
2001 \text { [33] }\end{array}$ & Forging & $K_{I c}=66 \mathrm{MPa} \sqrt{\mathrm{m}}$ & \\
\hline $\begin{array}{l}\text { Marmy, } 2004 \\
{[34]}\end{array}$ & Rod, diameter $=150 \mathrm{~mm}$ & $\begin{array}{c}J_{Q}=60 \mathrm{~kJ} / \mathrm{m}^{2} \\
K_{Q}=88 \mathrm{MPa} \sqrt{\mathrm{m}}^{2}\end{array}$ & $\begin{array}{l}\text { Miniature (KLST) } \\
\text { precracked Charpy } \\
\text { specimens }\end{array}$ \\
\hline $\begin{array}{l}\text { Salem et al., } \\
2008 \text { [35] }\end{array}$ & $\begin{array}{l}\alpha / \beta \text { forged plate, } 3.5 \text { in. thick } \\
\text { (1970) }\end{array}$ & $K_{Q}=78 \mathrm{MPa} \sqrt{\mathrm{m}}-101 \mathrm{MPa} \sqrt{\mathrm{m}}$ & Mill annealed \\
\hline $\begin{array}{l}\text { Feng et al., } \\
2013[36]\end{array}$ & $\begin{array}{c}\text { As-cast cylinder } \\
\text { Cast and HIPed cylinder }\end{array}$ & $\begin{array}{l}K_{Q}=83 \mathrm{MPa} \sqrt{\mathrm{m}}-86 \mathrm{MPa} \sqrt{\mathrm{m}} \\
K_{Q}=93 \mathrm{MPa} \sqrt{\mathrm{m}}-97 \mathrm{MPa} \sqrt{\mathrm{m}}\end{array}$ & $\begin{array}{l}\mathrm{C}(\mathrm{T}) \text { specimens, } 15 \mathrm{~mm} \\
\text { thick }\end{array}$ \\
\hline This study & $\begin{array}{c}\text { As-built AM Ti64 } \\
\text { Classically HIPed AM Ti64 }\end{array}$ & $\begin{array}{c}K_{J Q}{ }^{I I}=108 \mathrm{MPa} \sqrt{\mathrm{m}}-131 \mathrm{MPa} \sqrt{\mathrm{m}} \\
K_{J Q}=140 \mathrm{MPa} \sqrt{\mathrm{m}}-154 \mathrm{MPa} \sqrt{\mathrm{m}}\end{array}$ & $\begin{array}{l}\text { Scan lengths }=28 \mathrm{~mm} \text { to } \\
84 \mathrm{~mm}\end{array}$ \\
\hline
\end{tabular}

The results obtained in this study are higher than the values reported in the literature, particularly in the HIPed condition.

\footnotetext{
${ }^{11}$ The value of stress intensity factor $K_{J Q}$ corresponding to a $J_{Q}$ value is given by $K_{J Q}=\sqrt{J_{Q} \cdot E}$, where $E$ is the Young's modulus at the test temperature.
} 


\subsubsection{AM Ti64}

Some literature references were identified, presenting fracture toughness results on AM Ti64 specimens manufactured according to procedures similar to the ones used in this investigation.

Fracture toughness results were reported by Lewandowski and Seifi in a review of mechanical properties of various additively manufactured metallic materials [37]. The values presented in Table 10 were obtained for electron beam melting (EBM) manufactured Ti64, mostly in as built condition, in different orientations, and for different machine types.

Table 11 - Literature fracture toughness values for AM Ti64 reported in [37] and results obtained in this investigation.

\begin{tabular}{|c|c|c|c|}
\hline $\begin{array}{l}\text { Machine } \\
\text { type }\end{array}$ & Condition & Reported toughness & Remarks \\
\hline Arcam A1 & As built & $K_{Q}=102 \mathrm{MPa} \sqrt{ } \mathrm{m}-110 \mathrm{MPa} \sqrt{\mathrm{m}}$ & \multirow{2}{*}{$\begin{array}{c}\mathrm{C}(\mathrm{T}) \\
\text { specimens }\end{array}$} \\
\hline Arcam & $\begin{array}{l}\text { As built } \\
\text { HIPed }\end{array}$ & $\begin{array}{l}K_{Q}=78 \mathrm{MPa} \sqrt{ } \mathrm{m}-97 \mathrm{MPa} \sqrt{\mathrm{m}} \\
K_{Q}=83 \mathrm{MPa} \sqrt{\mathrm{m}}-99 \mathrm{MPa} \sqrt{\mathrm{m}}\end{array}$ & \\
\hline Arcam A2 & As built & $K_{Q}=65 \mathrm{MPa} \sqrt{\mathrm{m}}-100 \mathrm{MPa} \sqrt{\mathrm{m}}$ & \multirow{2}{*}{$\begin{array}{c}\mathrm{SE}(\mathrm{B}) \\
\text { specimens }\end{array}$} \\
\hline $\begin{array}{l}\text { Arcam A1 } \\
\text { (this study) }\end{array}$ & $\begin{array}{c}\text { As built } \\
\text { HIPed }\left(900{ }^{\circ} \mathrm{C}, 100 \mathrm{MPa}, 2 \mathrm{~h}, \mathrm{Ar}\right)\end{array}$ & $\begin{array}{l}\mathrm{K}_{\mathrm{JQ}}=108 \mathrm{MPa} \sqrt{\mathrm{m}}-131 \mathrm{MPa} \sqrt{\mathrm{m}} \\
\mathrm{K}_{\mathrm{JQ}}=140 \mathrm{MPa} \sqrt{\mathrm{m}}-154 \mathrm{MPa} \sqrt{\mathrm{m}}\end{array}$ & \\
\hline
\end{tabular}

We observe that the values of initiation fracture toughness measured in this study are higher than those reported in [37].

Seifi et al. [38] documented orientation-dependent fracture and fatigue properties of as-deposited (as-built) and HIPed Ti64 produced by different generations of Arcam machines (A2 and A2X). Fracture tests were conducted on bend specimens with $B=10 \mathrm{~mm}$ and $W=20$ $\mathrm{mm}$. The fracture property ranges shown in Table 11 were reported.

Table 12 - Literature fracture toughness values for AM Ti64 reported in [38] and results obtained in this investigation.

\begin{tabular}{|c|c|c|}
\hline $\begin{array}{l}\text { Machine } \\
\text { type }\end{array}$ & Condition & Reported toughness \\
\hline Arcam A2 & $\begin{array}{c}\text { As built } \\
\text { HIPed }\left(950{ }^{\circ} \mathrm{C}, 100 \mathrm{MPa}, 3 \mathrm{~h}, \mathrm{Ar}\right)\end{array}$ & $\begin{array}{c}K_{Q}=43 \mathrm{MPa} \sqrt{\mathrm{m}}-95 \mathrm{MPa} \sqrt{\mathrm{m}}-T_{M, \text { mean }} \approx 0 \mathrm{MPa} \\
J_{I c}=29 \mathrm{~kJ} / \mathrm{m}^{2}-42 \mathrm{~kJ} / \mathrm{m}^{2}-T_{M, \text { mean }}=3 \mathrm{MPa}-8 \mathrm{MPa}\end{array}$ \\
\hline Arcam A2X & $\begin{array}{c}\text { As built } \\
\text { HIPed }\left(950^{\circ} \mathrm{C}, 100 \mathrm{MPa}, 3 \mathrm{~h}, \mathrm{Ar}\right)\end{array}$ & $\begin{array}{c}K_{Q}=47 \mathrm{MPa} \sqrt{\mathrm{m}}-105 \mathrm{MPa} \sqrt{\mathrm{m}}-T_{\text {M, mean }}=3 \mathrm{MPa}-19 \mathrm{MPa} \\
J_{I C}=45 \mathrm{~kJ} / \mathrm{m}^{2}-66 \mathrm{~kJ} / \mathrm{m}^{2}-T_{M, \text { mean }} \approx 8 \mathrm{MPa}-15 \mathrm{MPa}\end{array}$ \\
\hline $\begin{array}{l}\text { Arcam A1 } \\
\text { (this study) }\end{array}$ & $\begin{array}{c}\text { As built } \\
\text { HIPed }\left(900{ }^{\circ} \mathrm{C}, 100 \mathrm{MPa}, 2 \mathrm{~h}, \mathrm{Ar}\right)\end{array}$ & $\begin{array}{c}\mathrm{K}_{\mathrm{JQ}}=108 \mathrm{MPa} \sqrt{\mathrm{m}}-131 \mathrm{MPa} \sqrt{\mathrm{m}}-J_{Q}=90 \mathrm{~kJ} / \mathrm{m}^{2}-134 \mathrm{~kJ} / \mathrm{m}^{2} \\
T_{M, \text { mean }}=1 \mathrm{MPa}-9 \mathrm{MPa} \\
\mathrm{K}_{\mathrm{JQ}}=140 \mathrm{MPa} \sqrt{\mathrm{m}}-154 \mathrm{MPa} \sqrt{\mathrm{m}}-J_{Q}=152 \mathrm{~kJ} / \mathrm{m}^{2}-183 \mathrm{~kJ} / \mathrm{m}^{2} \\
T_{M, \text { mean }}=6 \mathrm{MPa}-12 \mathrm{MPa}\end{array}$ \\
\hline
\end{tabular}

Again, the results of our tests are higher than the results reported in [38]. 


\section{Conclusions}

An in-depth characterization of the room temperature fracture toughness of additively manufactured Ti-6Al-4V was performed at NIST, by testing 50 fatigue precracked and side-grooved Charpy-type specimens in as built and hot isostatically pressed (classic and super- $\beta$ transus) conditions. Additional parameters investigated included non-supported and supported specimens, and scan length (between $28 \mathrm{~mm}$ and $84 \mathrm{~mm}$ ).

Fracture toughness tests were conducted with the Elastic Compliance (EC) methodology. Force-crack mouth opening displacement curves were also analyzed in accordance with the Normalization Data Reduction (NDR) technique, although total crack extension was too long for the analyses to be compliant with ASTM E1820-18 ${ }^{\varepsilon 1}$.

From the results obtained, the following conclusions can be drawn.

- No statistical differences were observed between non-supported and supported specimens in terms of initiation fracture toughness. Tearing moduli, on the other hand, were found to be higher for supported specimens in all the conditions examined.

- Fracture toughness (initiation values and crack resistance) tends to improve with increasing scan length. The highest values of $J_{Q}$ were obtained, for both as built and classically HIPed specimens, with a scan length of $70 \mathrm{~mm}$. The lowest correspond to $56 \mathrm{~mm}$.

- Two HIP treatments were investigated: classic HIP $\left(900{ }^{\circ} \mathrm{C}, 100 \mathrm{MPa}\right.$ for $2 \mathrm{~h}$ ) and super- $\beta$ transus HIP (1050 ${ }^{\circ} \mathrm{C}, 100 \mathrm{MPa}$ for $2 \mathrm{~h}+$ additional HIP). Classically HIPed specimens exhibited significantly better toughness than as built specimens. Specimens subject to the super- $\beta$ transus HIP, on the other hand, exhibited large "crack jumps" (unstable ductile tearing events), which caused low initiation values and poor resistance to crack propagation.

- The occurrence of "crack jumps", or tearing instabilities, was observed on several material conditions investigated and needs to be clarified through microstructural investigations. These events were unrelated to the presence of lack-of-fusion $(\mathrm{LoF})$ pores on the fracture surface, which was observed on most of the specimens corresponding to the longest scan length $(84 \mathrm{~mm})$. Although LoF has been reported to be detrimental to the mechanical properties of AM parts and cannot be sealed by HIP, we did not find a direct relationship with the fracture toughness values measured in this study.

- In this investigation, the Elastic Compliance (EC) single-specimen methodology was used as the primary method to measure the fracture toughness properties of AM Ti64. None of the tests performed were strictly valid according to ASTM E1820-18 $\mathrm{a}^{\varepsilon 1}$, if all the requirements stated in the standard are taken into account. However, most of the requirements that were not fulfilled concerned the estimation of the initial crack size, which was nonetheless acceptably predicted for the vast majority of the tests performed. Therefore, in the authors' judgment, the results obtained in this study can be considered reliable measurements of the fracture toughness of AM Ti64 in the different conditions examined.

- An additional methodology (Normalization Data Reduction - NDR) was used to analyze the force-crack mouth opening displacement records of the tests performed. For all specimens, final crack extension exceeded the limit prescribed by ASTM E1820-18 $\mathrm{a}^{\varepsilon 1}$, and 
therefore the calculated parameters can be considered questionable. Nevertheless, when compared to the outcomes of the EC methodology, the NDR approach generally provided lower values of critical toughness and steeper $J-R$ curves (i.e., higher crack resistance).

- In terms of critical fracture toughness at crack initiation, the results we obtained in this investigation are generally higher than values found in the literature for both non-AM and AM Ti64, under comparable manufacturing conditions.

\section{Acknowledgements}

Sincere thanks to Ross Rentz, who provided invaluable assistance in the preparation and execution of the tests. This research was performed while Jake Benzing held a National Research Council Postdoctoral Research Associateship at the National Institute of Standards and Technology.

\section{References}

[1] M. Gorelik, Additive manufacturing in the context of structural integrity, Int. J. Fatigue. 94 (2017), pp. 168-177.

[2] N. Hrabe, N. Barbosa, S.R. Daniewicz, and N. Shamsaei, Findings from the NIST/ASTM Workshop on Mechanical Behavior of Additive Manufacturing Components, NIST Advanced Manufacturing Series 100-4, 2016.

[3] E. Lucon, Instrumented impact tests on miniaturized Charpy specimens of additively manufactured (AM) Ti-6Al-4V, NIST Technical Note 1936, September 2016.

[4] E. Lucon and N. Hrabe, Instrumented Impact Testing of Miniaturized Charpy Specimens of AM Ti-6Al-4V, Mat. Perf. Char., Vol. 7, No. 1, 2018.

[5] N. Hrabe, T. Gnäupel-Herold, and T. Quinn, Fatigue properties of a titanium alloy (Ti6Al-4V) fabricated via electron beam melting (EBM): Effects of internal defects and residual stress, Int. J. Fatigue. Vol. 94, 2017, pp. 202-210.

[6] E. Lucon, J. Benzing, and N. Hrabe, Effect of Notch Geometry and Lack-of-Fusion on the Elastic-Plastic Fracture Toughness of Additively Manufactured Ti-6Al-4V parts, submitted to Materials Performance and Characterization, 2019.

[7] E. Lucon, Cost-Effective Alternatives to Conventional Charpy Tests for Measuring the Impact Toughness of Very-High-Toughness Steels, J. Press. Vess. Tech., Vol. 140, April 2018, pp. 021401-1 to 021401-7.

[8] ASTM F3001-14, Standard Specification for Additive Manufacturing Titanium-6 Aluminum-4 Vanadium ELI (Extra Low Interstitial) with Powder Bed Fusion, ASTM International, West Conshohocken, PA.

[9] ASTM E1820-18 $\mathrm{a}^{\varepsilon 1}$, Standard Test Method for Measurement of Fracture Toughness, Vol. 03.01, ASTM International, West Conshohocken, PA.

[10] P. C. Paris, H. Tada, A. Zahoor, and H. Ernst, A Treatment of the Subject of Tearing Instability, U.S. Nuclear Regulatory Commission, Washington, DC, Report No. NUREG-0311, 1977.

[11] P.C. Paris, H.A. Ernst, and C.E. Turner, A J-Integral Approach to Development of $\eta$-Factors, in "Fracture Mechanics, Proceedings of the Twelfth National Symposium on 
Fracture Mechanics," ASTM STP 700, American Society for Testing and Materials, Philadelphia, PA, 1980.

[12] J. A. Joyce, Analysis of a High Rate Round Robin Based on Proposed Annexes to ASTM E1820, J. Test. and Eval., JTEVA, Vol 29. No. 4. July 2001, pp. 329-351.

[13] R. Herrera, R. and J. D. Landes, Direct J-R Curve Analysis: A Guide to the Methodology, in "Fracture Mechanics: Twenty-First Symposium," ASTM STP 1074, J.P. Gudas, J.A. Joyce, and E.M. Hackett, Eds., ASTM, Conshohocken, PA, 1990, pp 24-43.

[14] J. D. Landes, Z. Zhou, K. Lee, and R. Herrera, R., Normalization Method for Developing $J$ R Curves with the LMN Function, J. Test. and Eval., JTEVA, Vol 19, No. 4, July 1991, pp. 305-311.

[15] K. Lee, Elastic-Plastic Fracture Toughness Determination Under Some Difficult Conditions, Ph.D Dissertation, The University of Tennessee, Knoxville, August 1995.

[16] A. Esteban Linares, L. Clowers, X. Chen, M. Sokolov, and R. Nanstad, Using Automated J R Curve Analysis Software to Simplify Testing and Save Time, Adv. Mat. \& Proc., Vol. 177, No. 2, Feb/Mar 2019, pp. 27-30 (software available at https://code.ornl.gov/xc8/ANJR.git).

[17] J. Benzing, N. Hrabe, T. Quinn, R. White, and R. Rentz, Manipulation of microstructure and tensile properties of additively manufactured Ti-6Al-4V parts, presented at the $19^{\text {th }}$ International ASTM/ESIS Symposium on Fatigue and Fracture Mechanics ( $42^{\text {nd }}$ National Symposium on Fatigue and Fracture Mechanics), May 15-17, 2019, Denver, CO, USA.

[18] P.C. Paris, H. Tada, A. Zahoor, and H. Ernst, The Theory of Instability of the Tearing Mode of Elastic-Plastic Crack Growth, in "Elastic-Plastic Fracture," ASTM STP 668, J.D. Landes, J.A. Begley, and G.A. Clarke, Eds., American Society for Testing and Materials, Philadelphia, PA, 1979, pp. 5-36.

[19] H. Ernst, P.C. Paris, M. Rossow, and J.W. Hutchinson, Analysis of Load-Displacement Relationship to Determine J-R curve and Tearing Instability Material Properties, in "Fracture Mechanics," ASTM STP 677, C.W. Smith, Ed., American Society for Testing and Materials, Philadelphia, PA, 1979, pp. 581-599.

[20] M.G. Vassilaros, R.A. Hays, J.P. Gudas, and J.A. Joyce, J-Integral Tearing Instability Analysis for 8-inch Diameter ASTM A106 Steel Pipe, DTNSRDC/SME-83-104, David W. Taylor Naval Ship Research and Development Center, Bethesda, Maryland, May 1984.

[21] J.D.G. Sumpter, Size effects in tearing instability: An analysis based on energy dissipation rate, Eng. Frac. Mech. 74 (2007) pp. 2352-2374.

[22] B. Zhang, Y. Li, and Q. Bai, Defect Formation Mechanisms in Selective Laser Melting: A Review, Chinese Journal of Mechanical Engineering, Vol. 30, Issue 3, May 2017, pp. 515-527.

[23] T. Mukherjee and T. DebRoy, Mitigation of lack of fusion defects in powder bed fusion additive manufacturing, Journal of Manufacturing Processes 36 (2018), pp. 442-449.

[24] S. Coeck, M. Bisht, J. Plas, and F. Verbist, Prediction of lack of fusion porosity in selective laser melting based on melt pool monitoring data, Additive Manufacturing 25 (2019), pp. 347-356.

[25] J.A. Joyce (retired from US Naval Academy), Private email communication to E. Lucon, July $15^{\text {th }}, 2019$.

[26] M. Scibetta and E. Lucon, $S C K \bullet C E N$ Activities for the Qualification of the Potential Drop Technique, presented at the ASTM E08.07 Special Technical Meeting on Use of 
Potential Drop in Elastic-Plastic Fracture Toughness Testing, 12 November 2013, Jacksonville, FL.

[27] R.L. Tobler, Low Temperature Fracture Behavior of a Ti-6Al-4V Alloy and its Electron Beam Welds, NBSIR 76-836, Kirtland Air Force Base, Albuquerque, New Mexico, April 1976.

[28] D. Munz, K.H. Galda, and F. Link, Effect of Specimen Size on Fracture Toughness of a Titanium Alloy, in "Mechanics of Crack Growth," ASTM STP 590, American Society for Testing and Materials, Philadelphia, PA, 1976, pp. 219-234.

[29] T. Kishi, H.S. Park, R. Horiuchi, T. Kakimi, M. Nakanose, and T. Tanabe, Fracture Toughness of Ti-6Al-4V Alloys Determined by ASTM Standard and AE Method, in "Titanium '80," Proceedings of the Fourth International Conference on Titanium, Kyoto, Japan, May 19-22, 1980, H. Kimura and O. Izumi, Eds.

[30] C.G. Rhodes, M.R. Mitchell, and J.C. Chesnutt, Fracture \& Fatigue Characteristics in Titanium Alloys, Final Report for the period July 1, 1979 through September 30, 1981, Rockwell International Science Center, June 1982.

[31] M. Niinomi and T. Kobayashi, Toughness and Microstructural Factors of Ti-6Al-4V Alloy, Mat. Sci. and Eng. 100 (1988), pp. 45-55.

[32] M.J. Donachie, Jr., Titanium - A Technical Guide, Second Edition, ASM International, Materials Park, Ohio, 2000.

[33] J.O. Peters and G. Lütjering, Comparison of the Fatigue and Fracture of $\alpha+\beta$ and $\beta$ Titanium Alloys, Metallurgical and Materials Transactions A, Vol. 32A, Nov 2011, pp. 2805-2818.

[34] P. Marmy, Fracture toughness and tensile properties of the titanium alloys Ti6Al4V and Ti5Al2.5S before and after proton and neutron irradiations at $150^{\circ} \mathrm{C}$, EFDA Task TW1TVV/Titan and TW3-TVM-TICRFA: Titanium Alloys Irradiation Testing, May 2004.

[35] J.A. Salem, B. Lerch, J.C. Thesken, J. Sutter, and R. Russell, Strength, Fatigue, and Fracture Toughness of Ti-6Al-4V Liner from a Composite Over-Wrapped Pressure Vessel, NASA/TM-2008-215147, March 2008.

[36] X. Feng, A., Wang, Y. Ma, X. Wu, J. Lei, Y. Cui, and R. Yang, Influence of Microstructure on Fatigue Crack Propagation and Fracture, $13^{\text {th }}$ International Conference on Fracture, June 16-21, 2013, Beijing, China.

[37] J.J. Lewandowski and M. Seifi, Metal Additive Manufacturing: A Review of Mechanical Properties, Annu. Rev. Mater. Res. 46, 2016, pp. 151-186.

[38] M. Seifi, A. Salem, D. Satko, J. Shaffer, J.J. Lewandowski, Defect distribution and microstructure heterogeneity effects on fracture resistance and fatigue behavior of EBM Ti-6Al-4V, International Journal of Fatigue 94, 2017, pp. 263-287. 
ANNEX 1

As-built, non-supported 

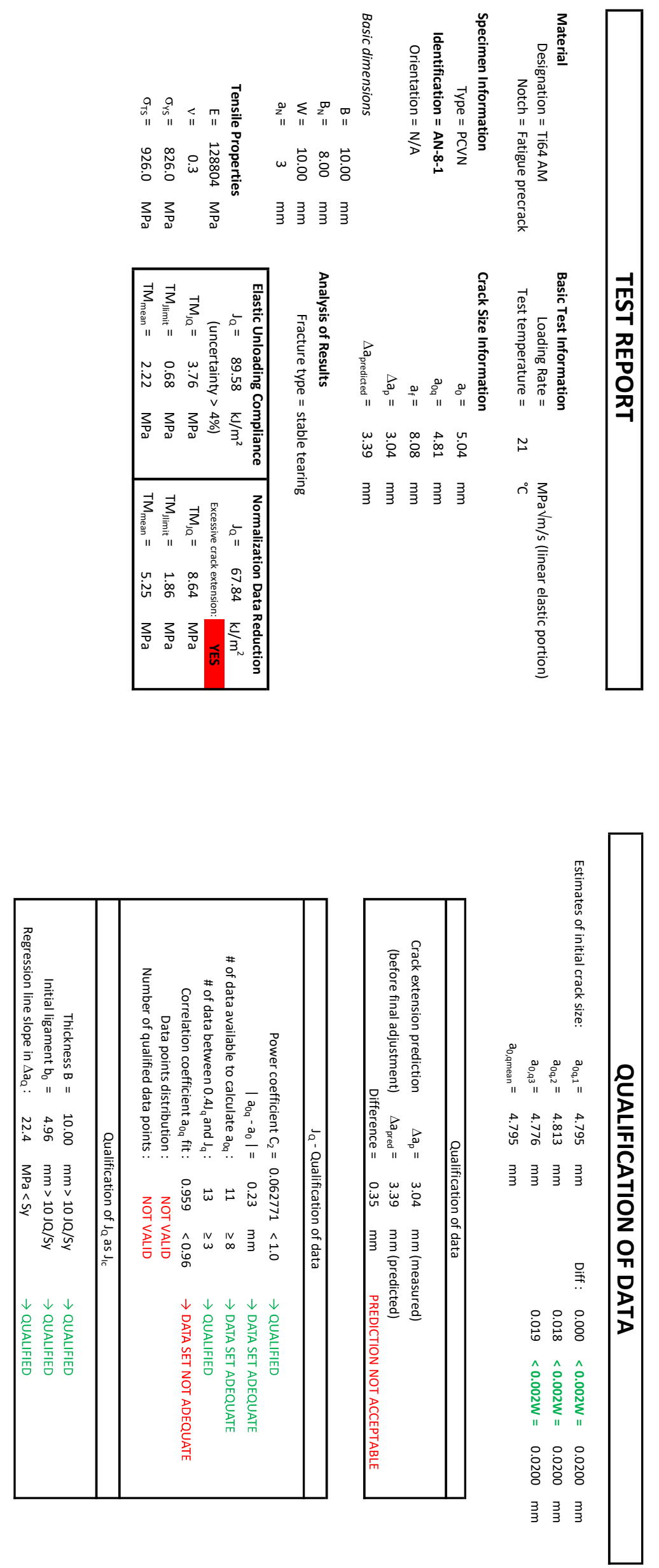

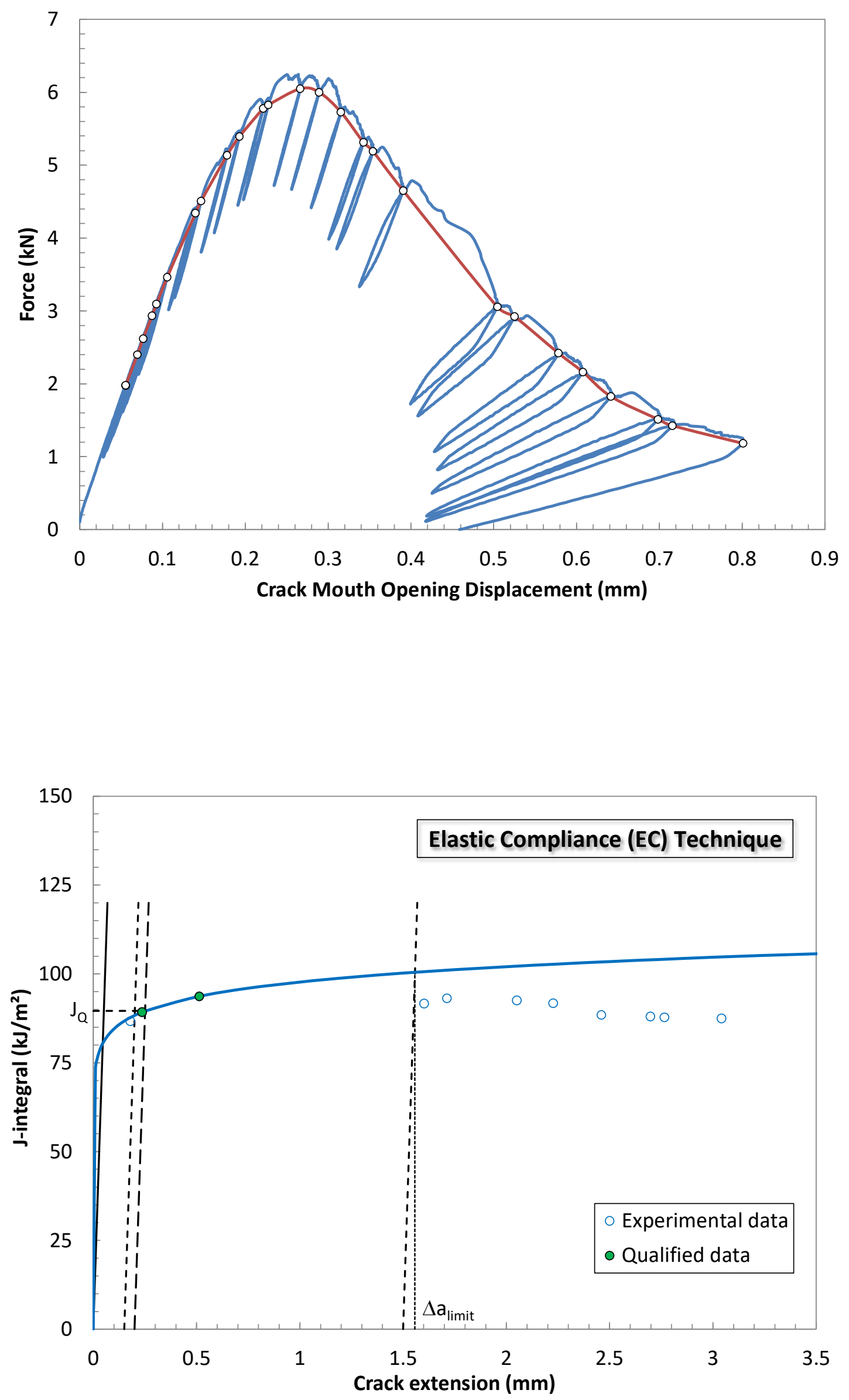

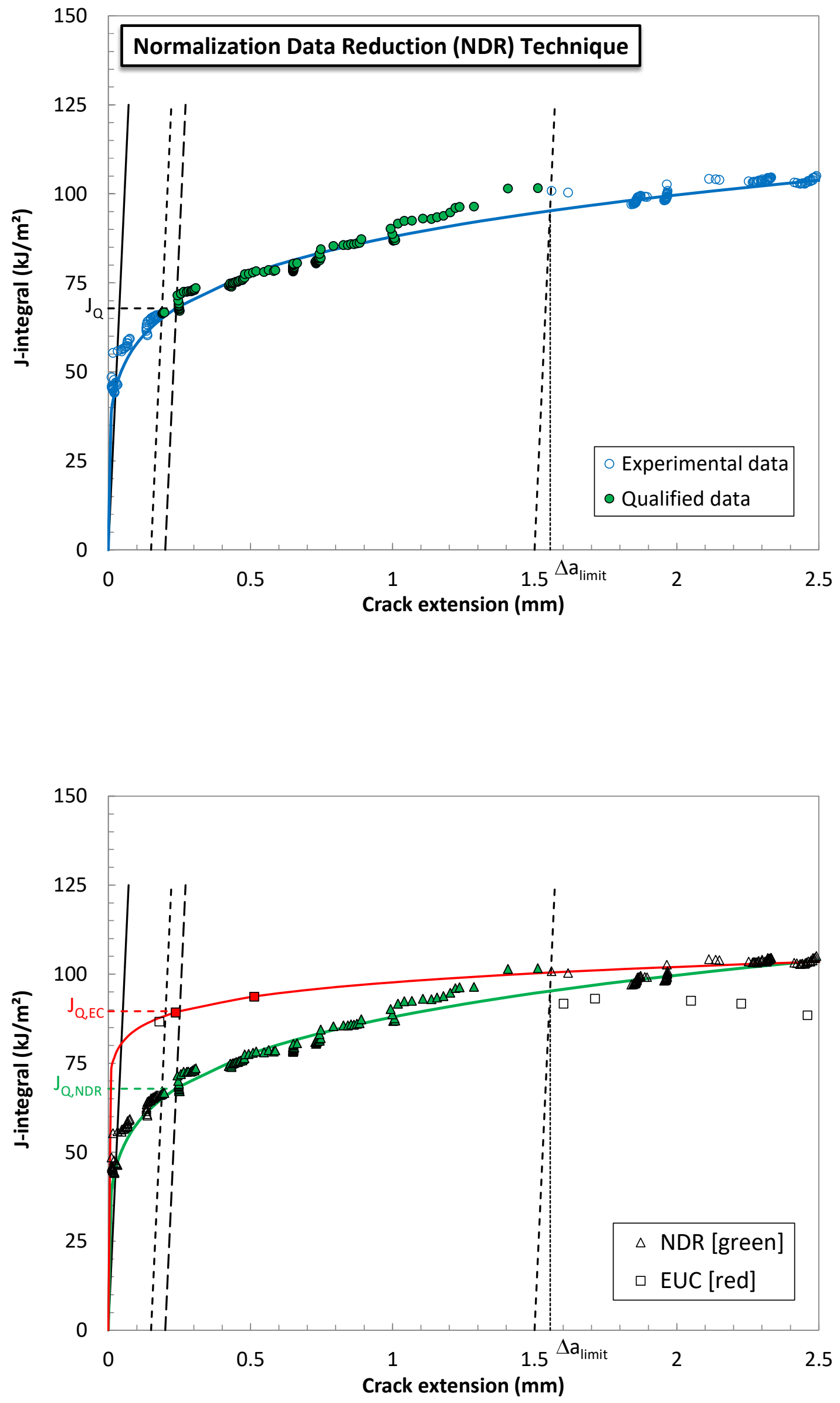

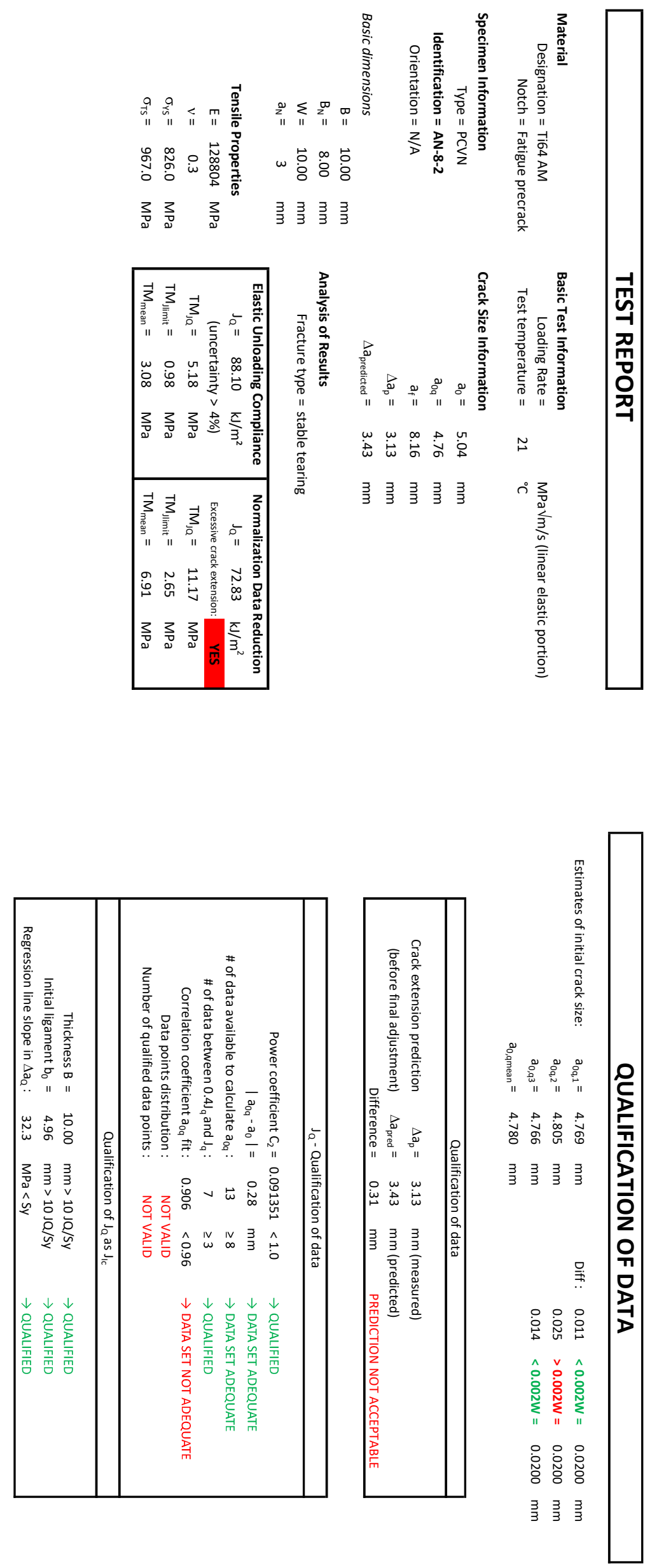

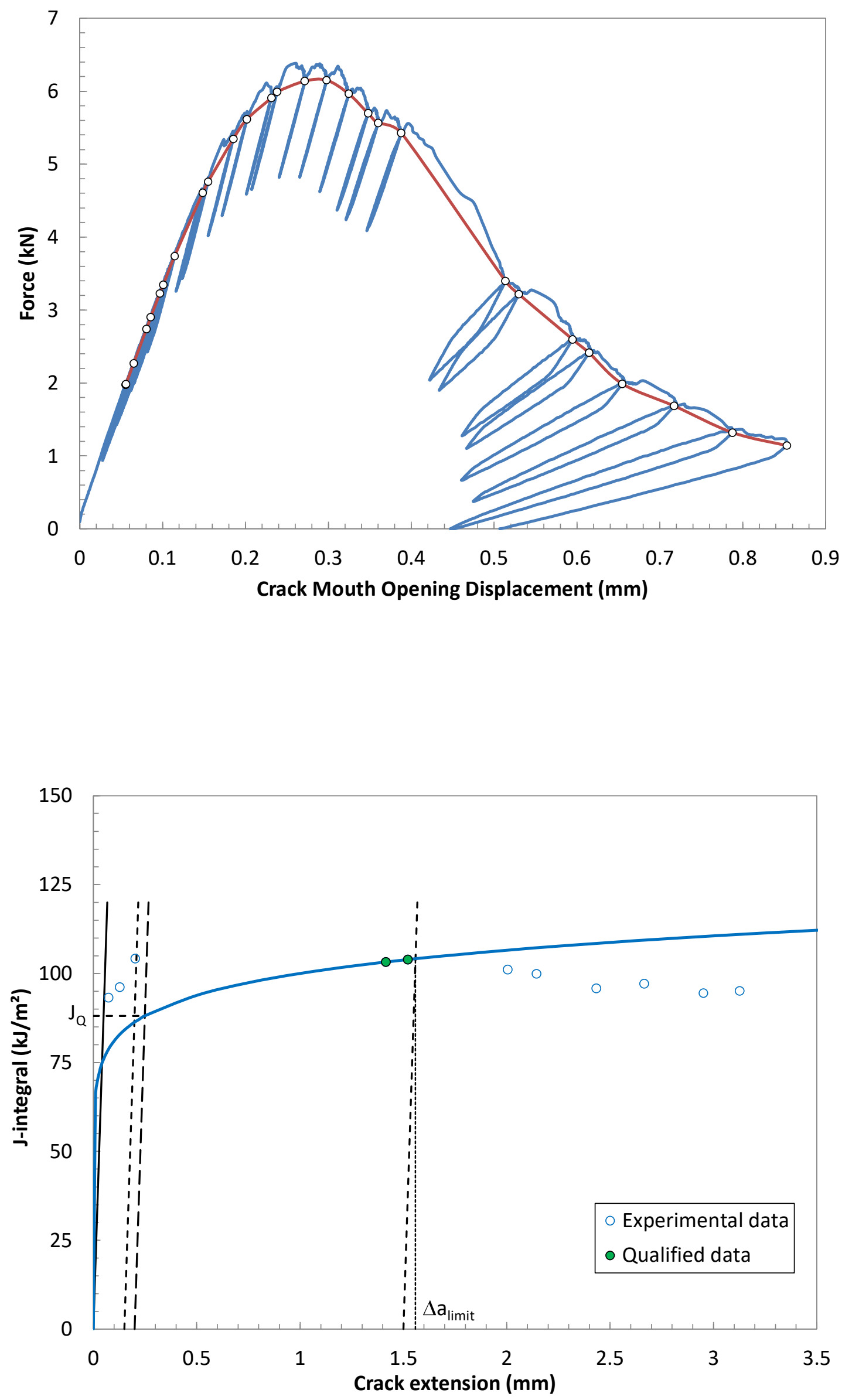

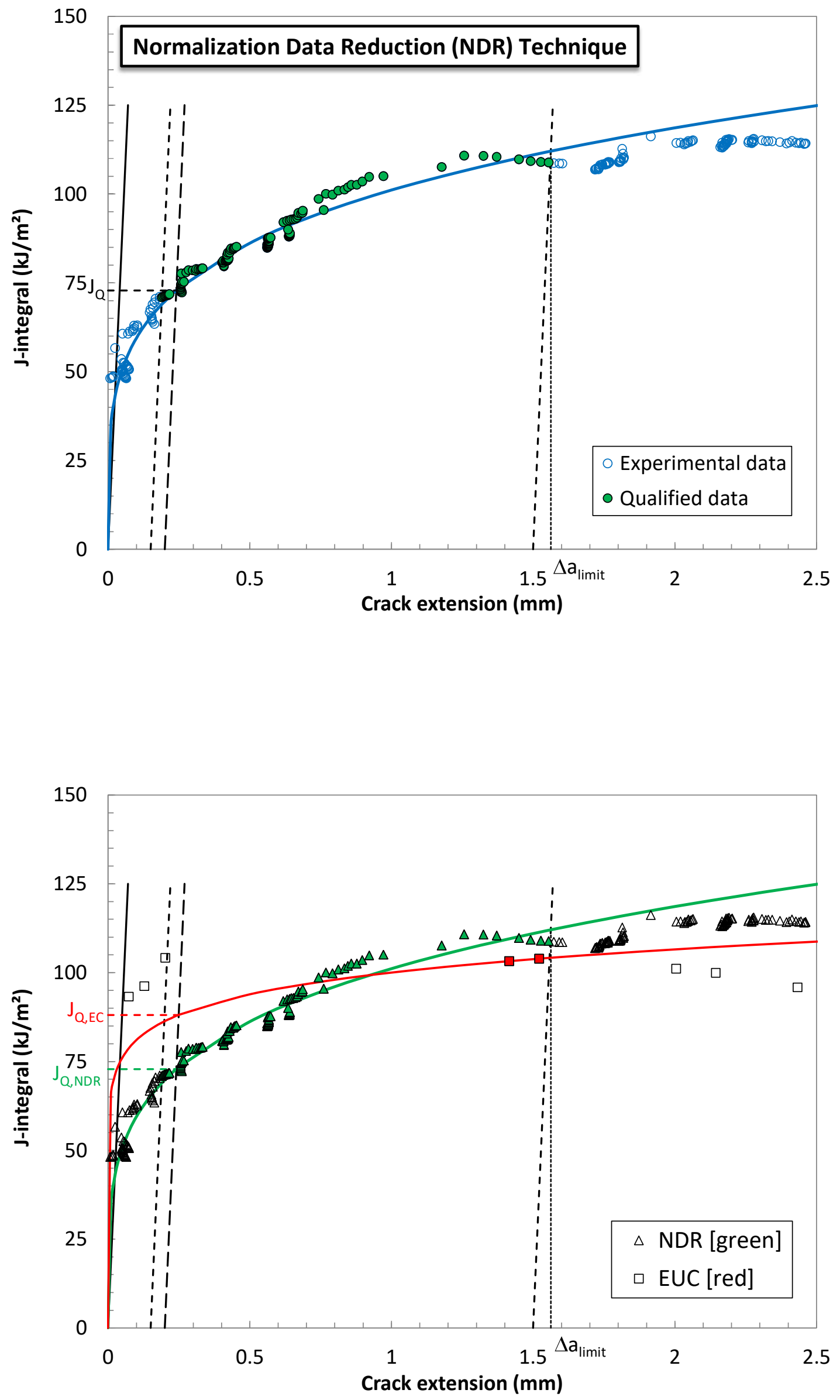

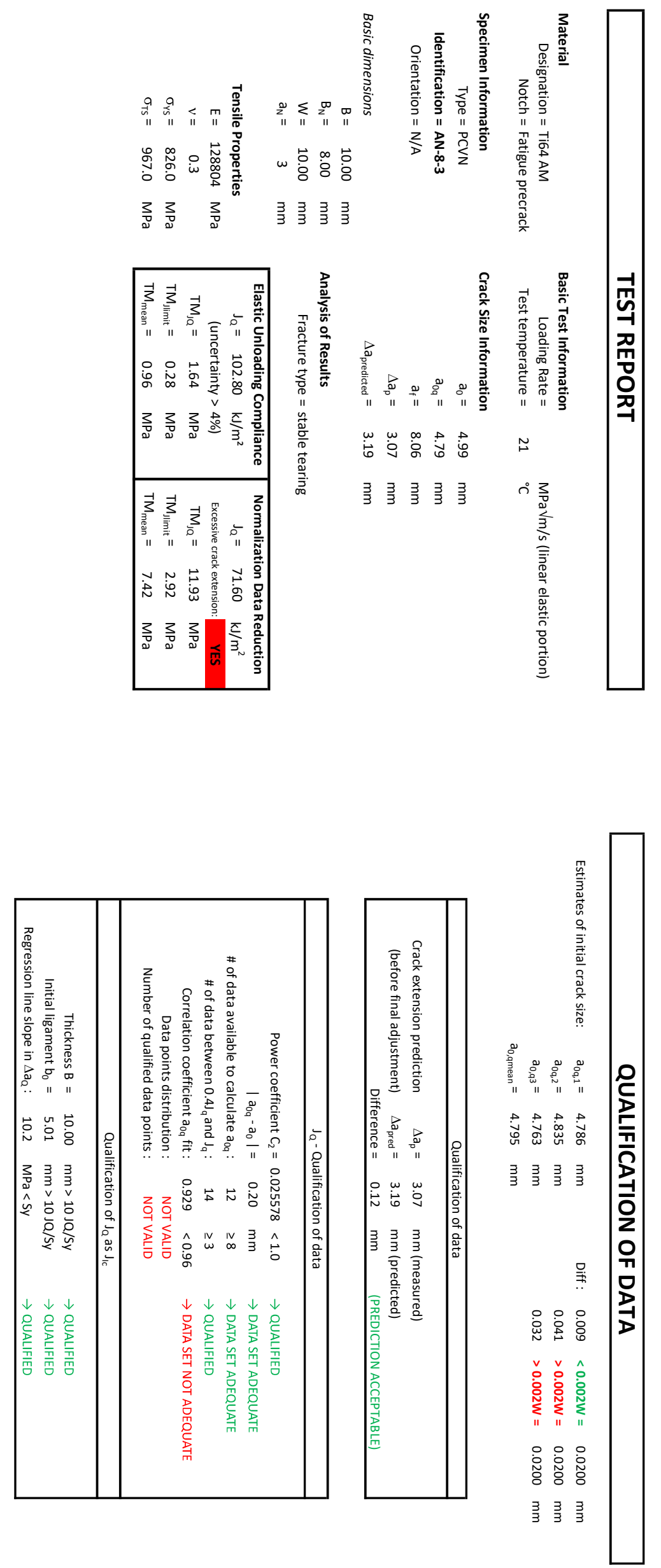

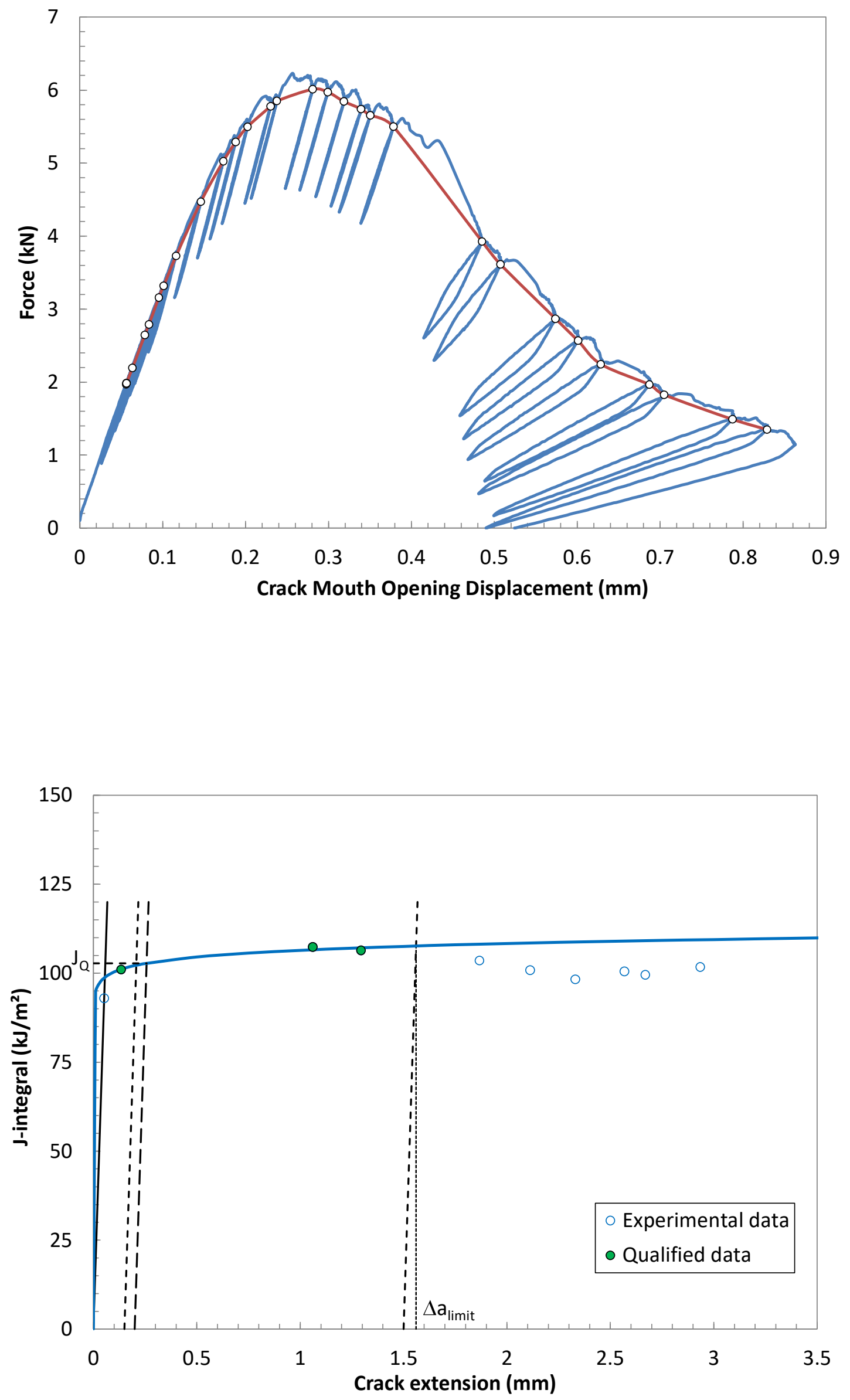

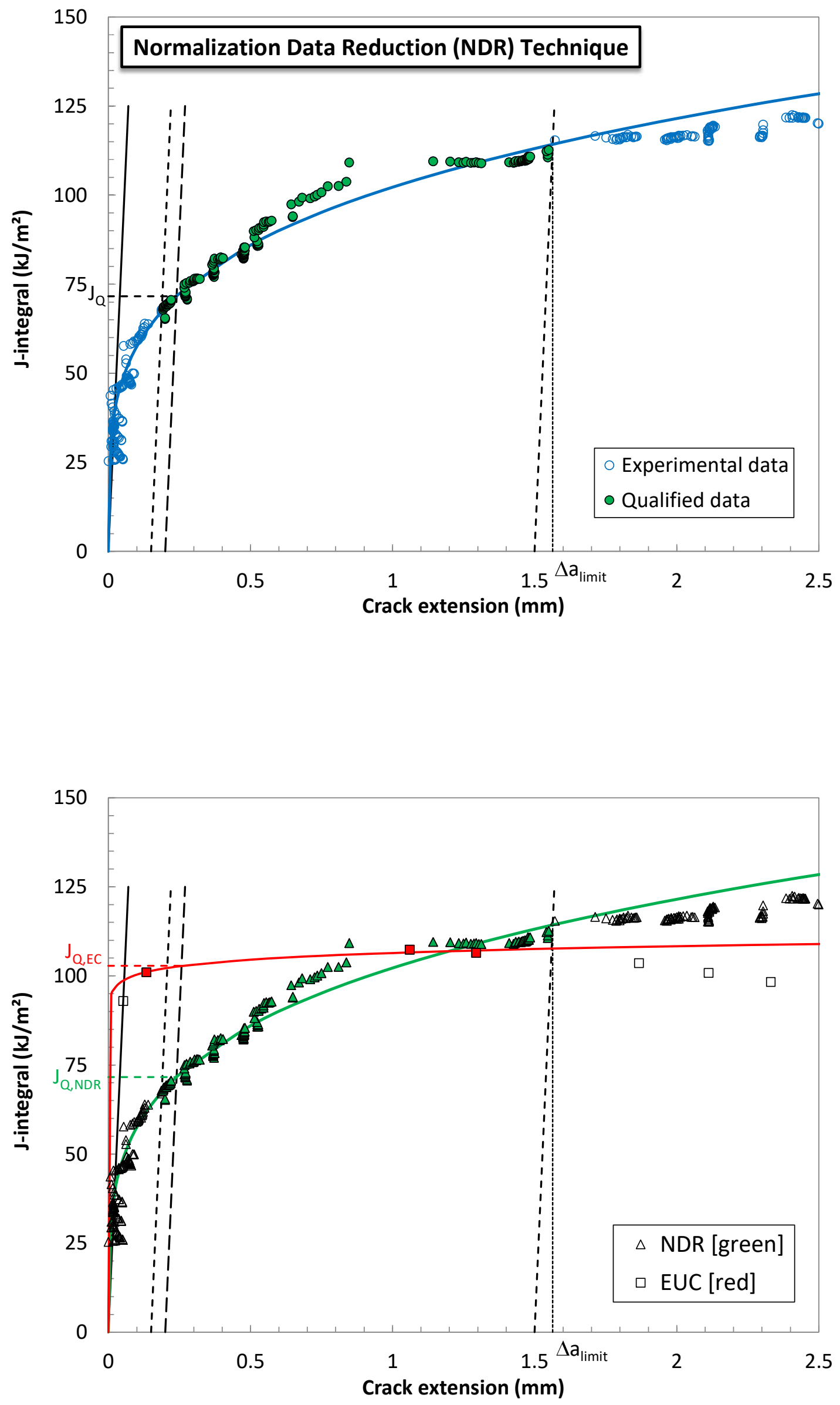

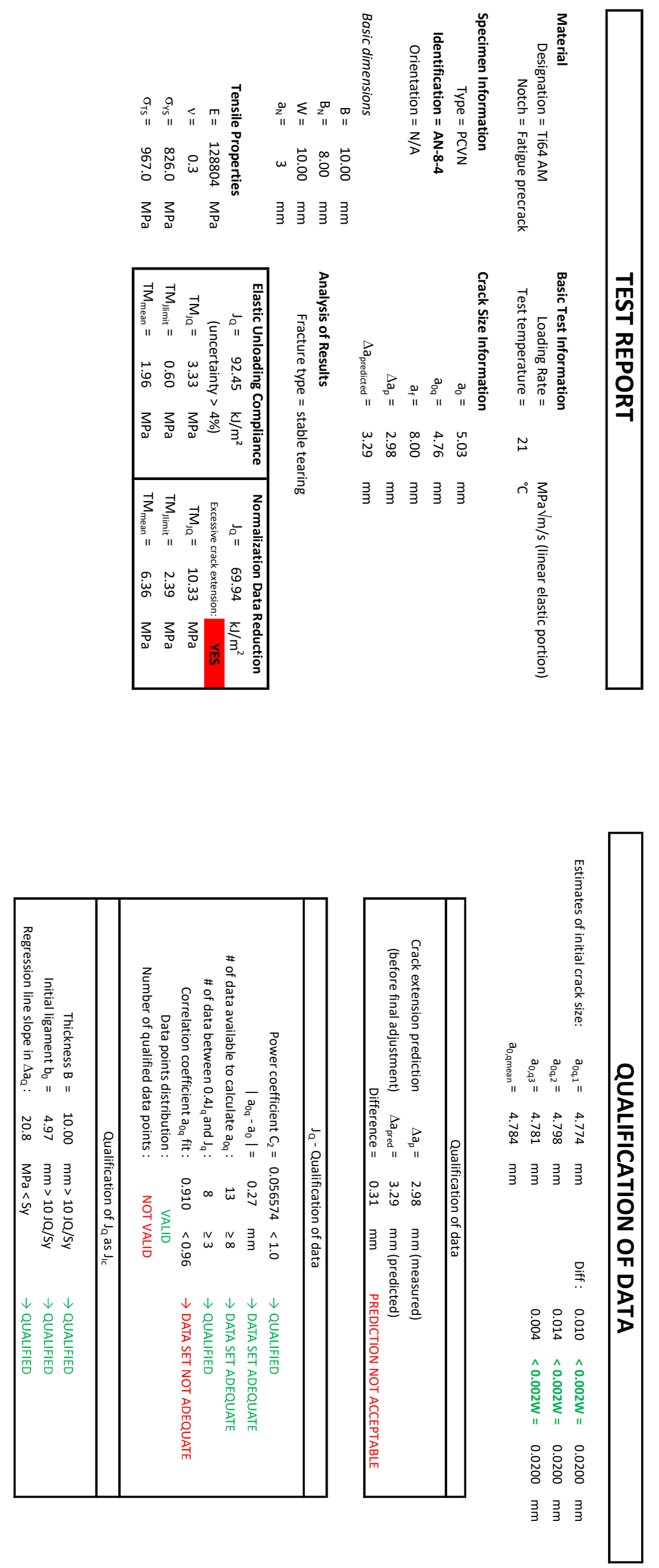

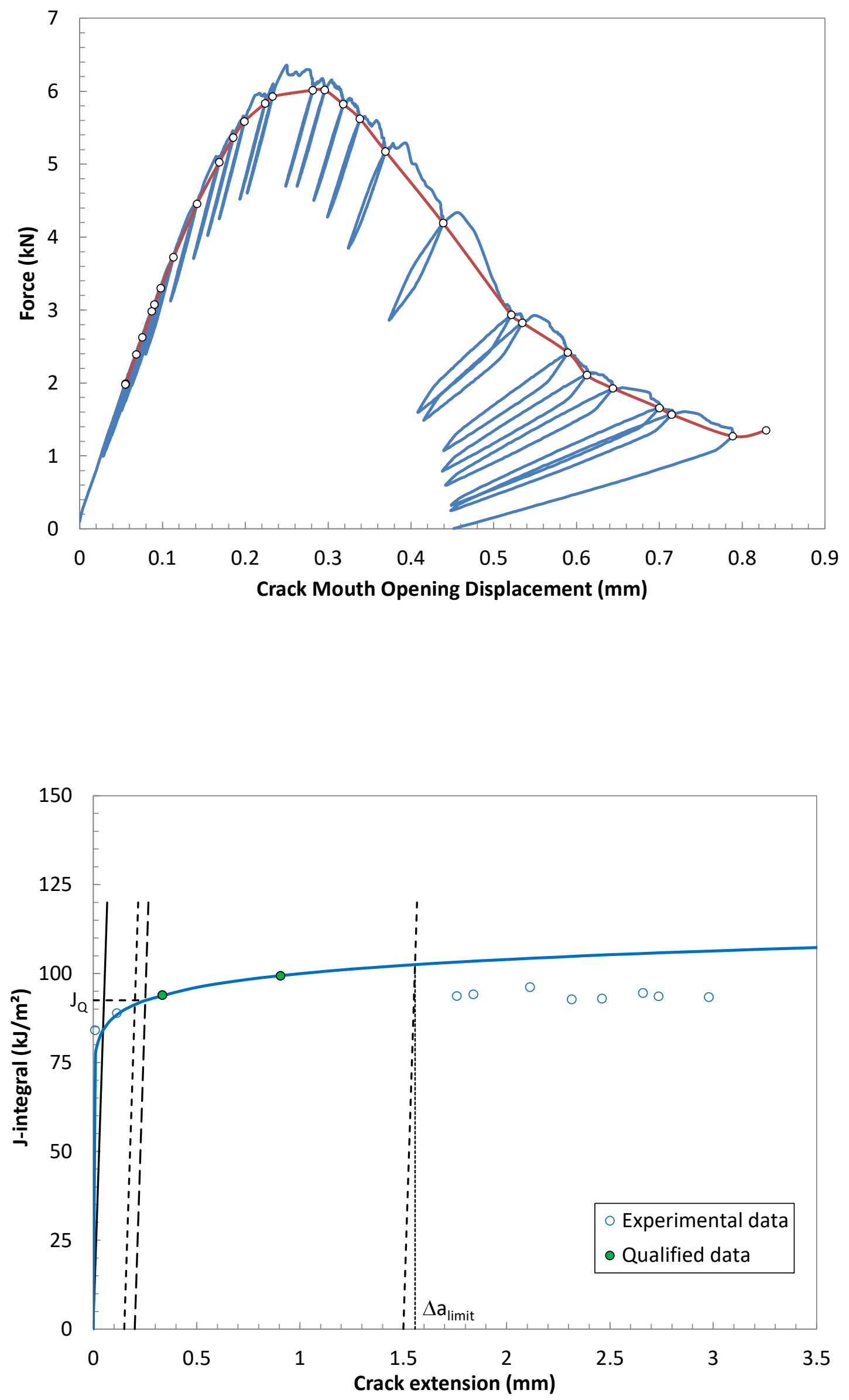

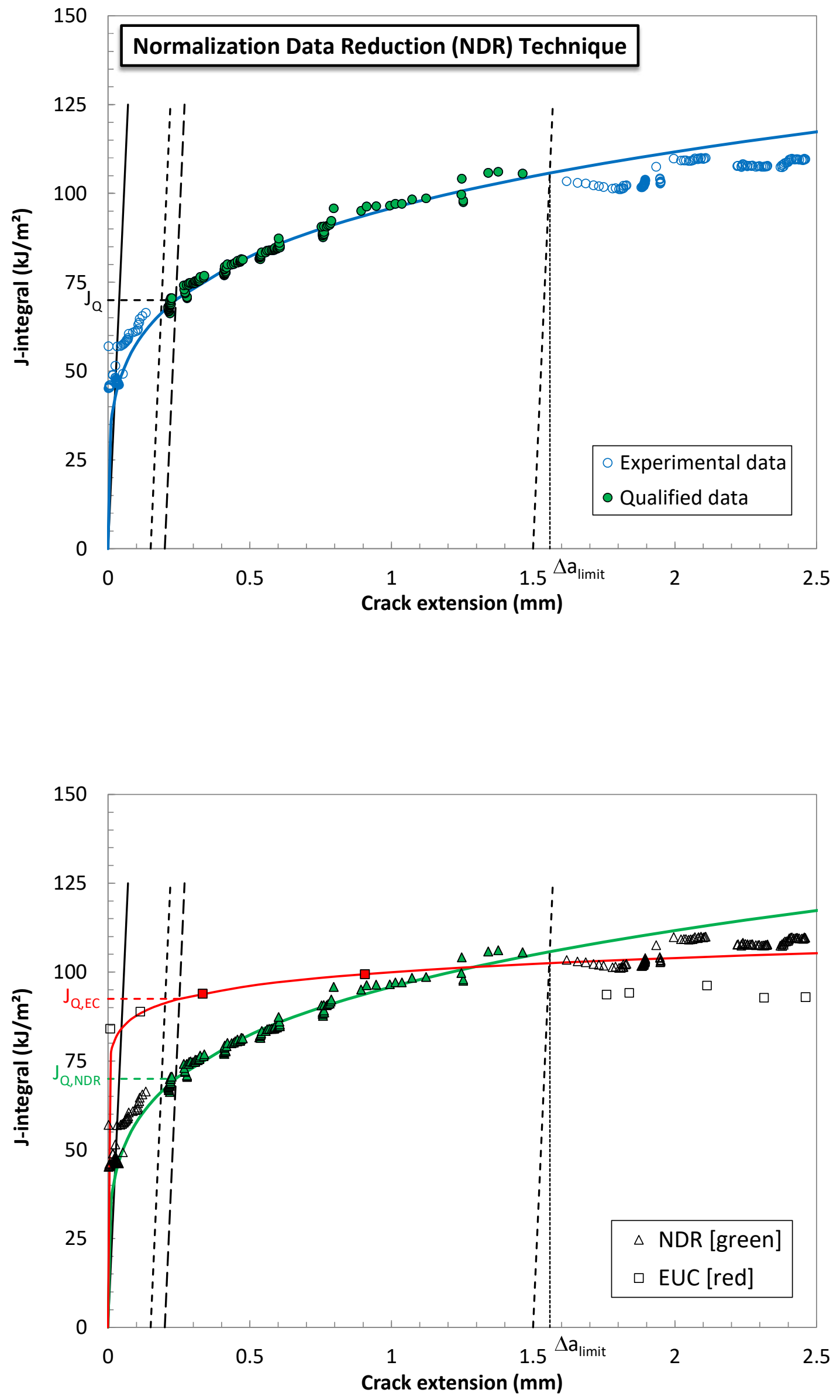

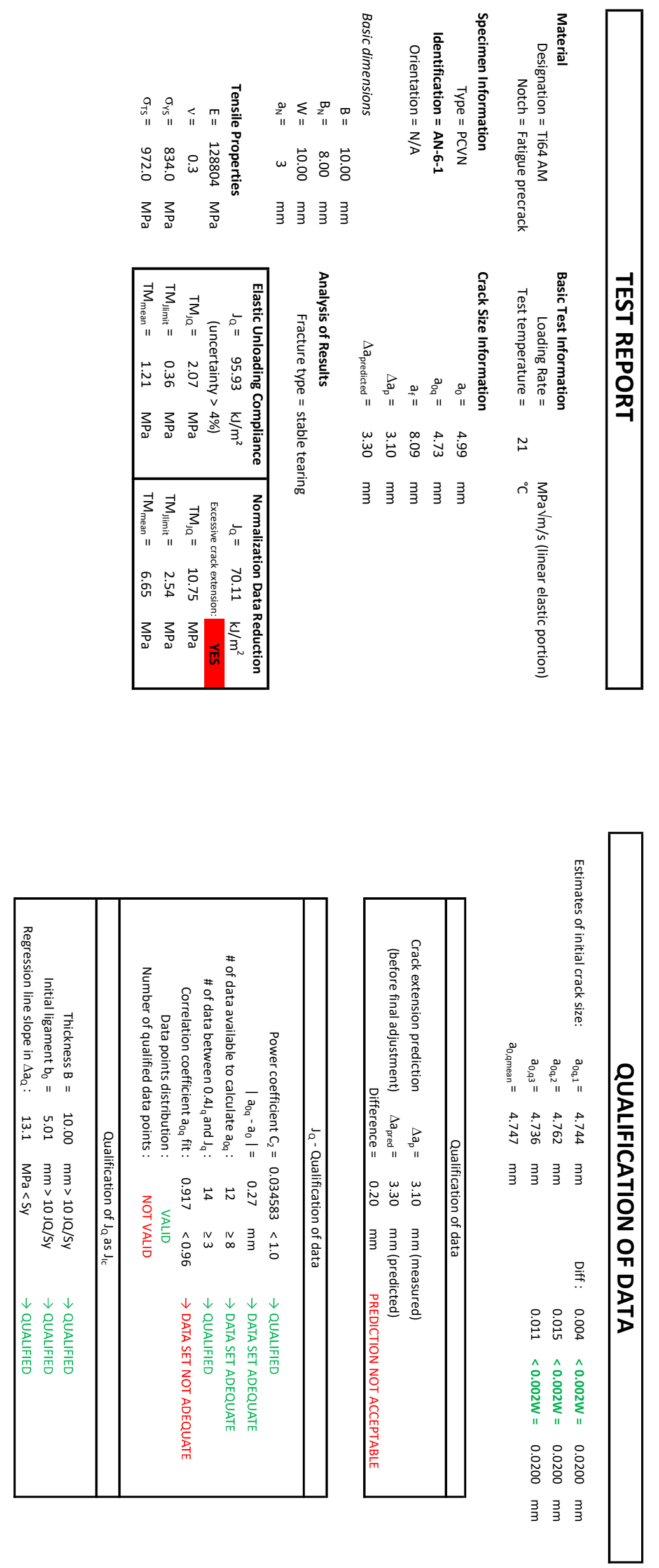

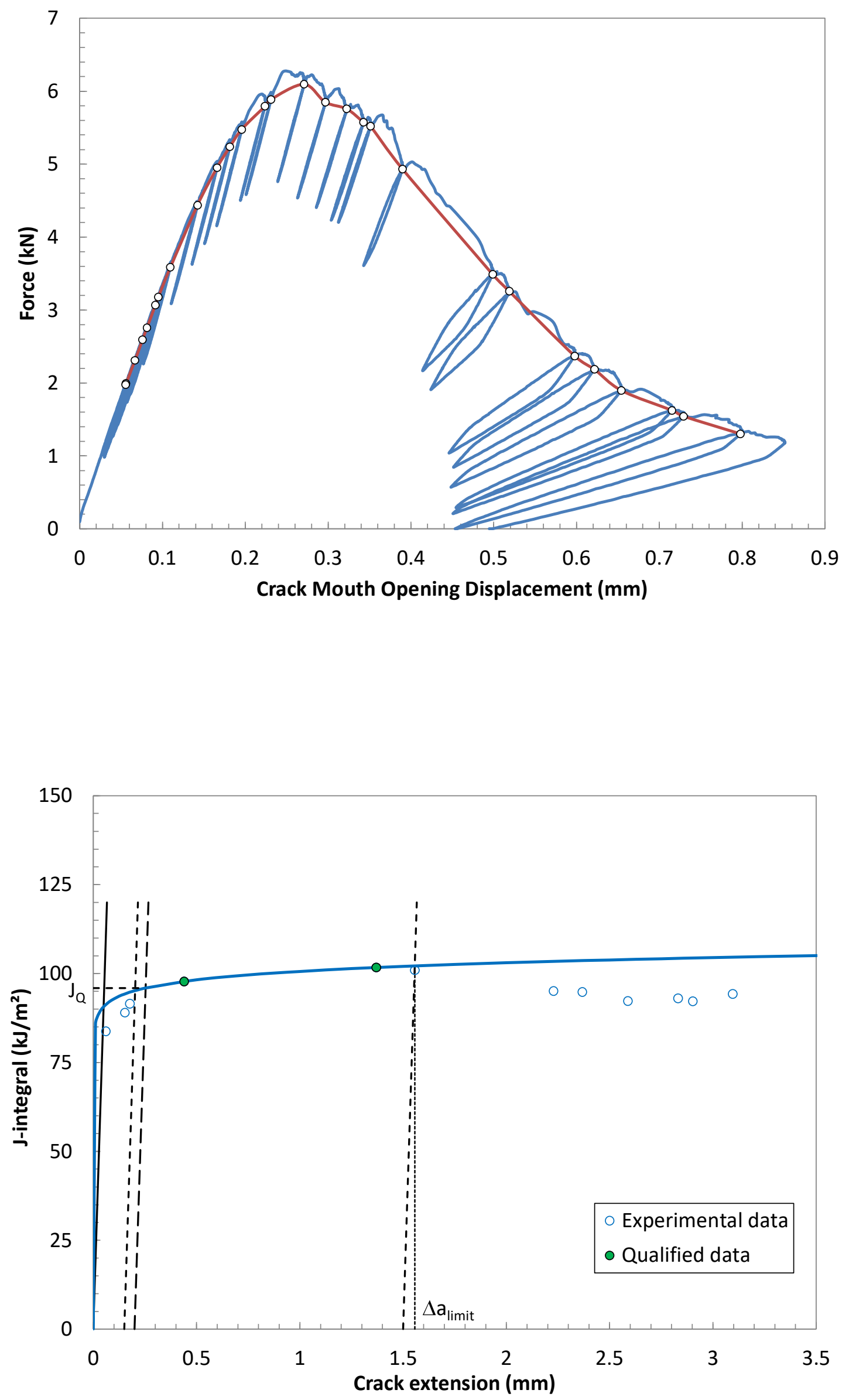

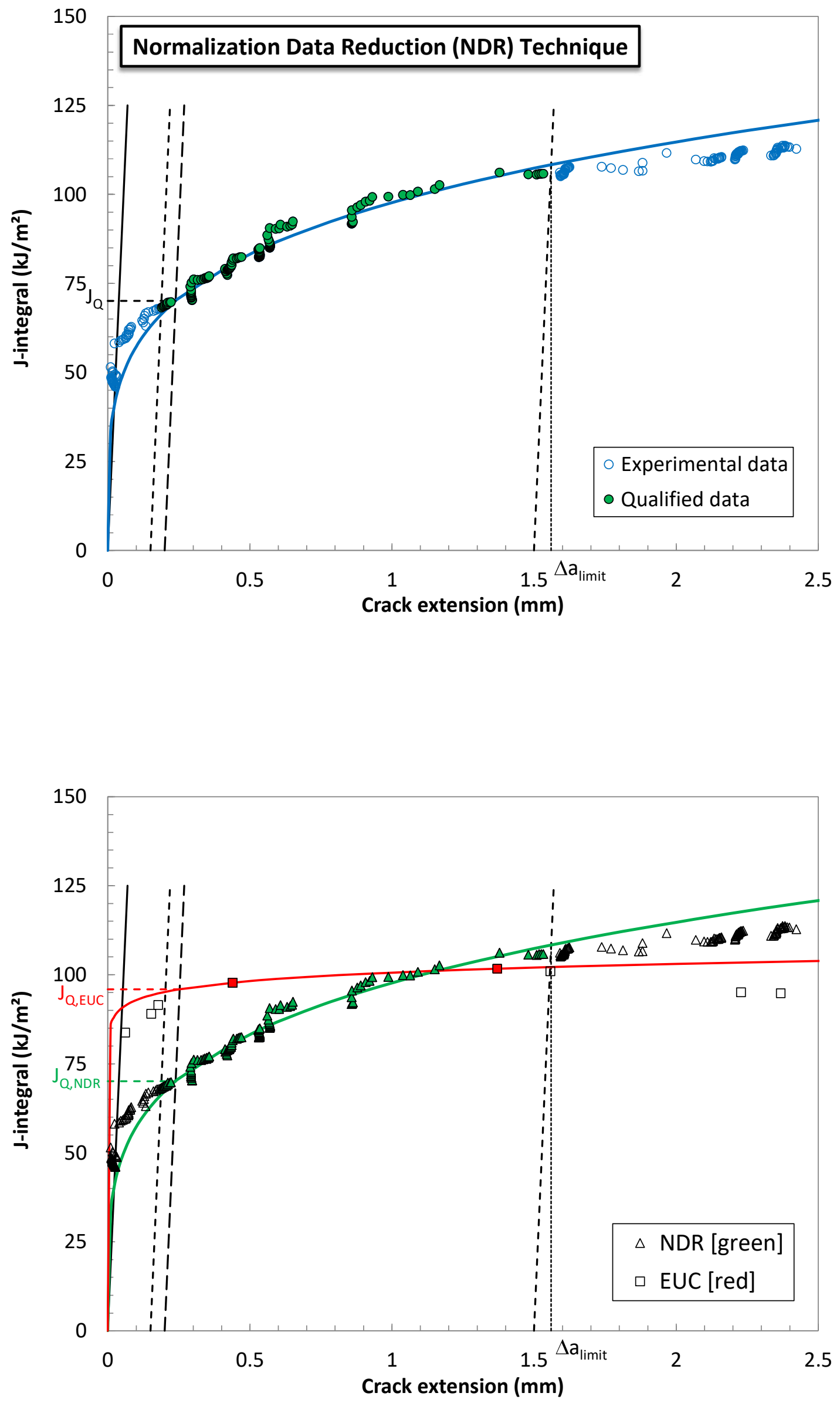

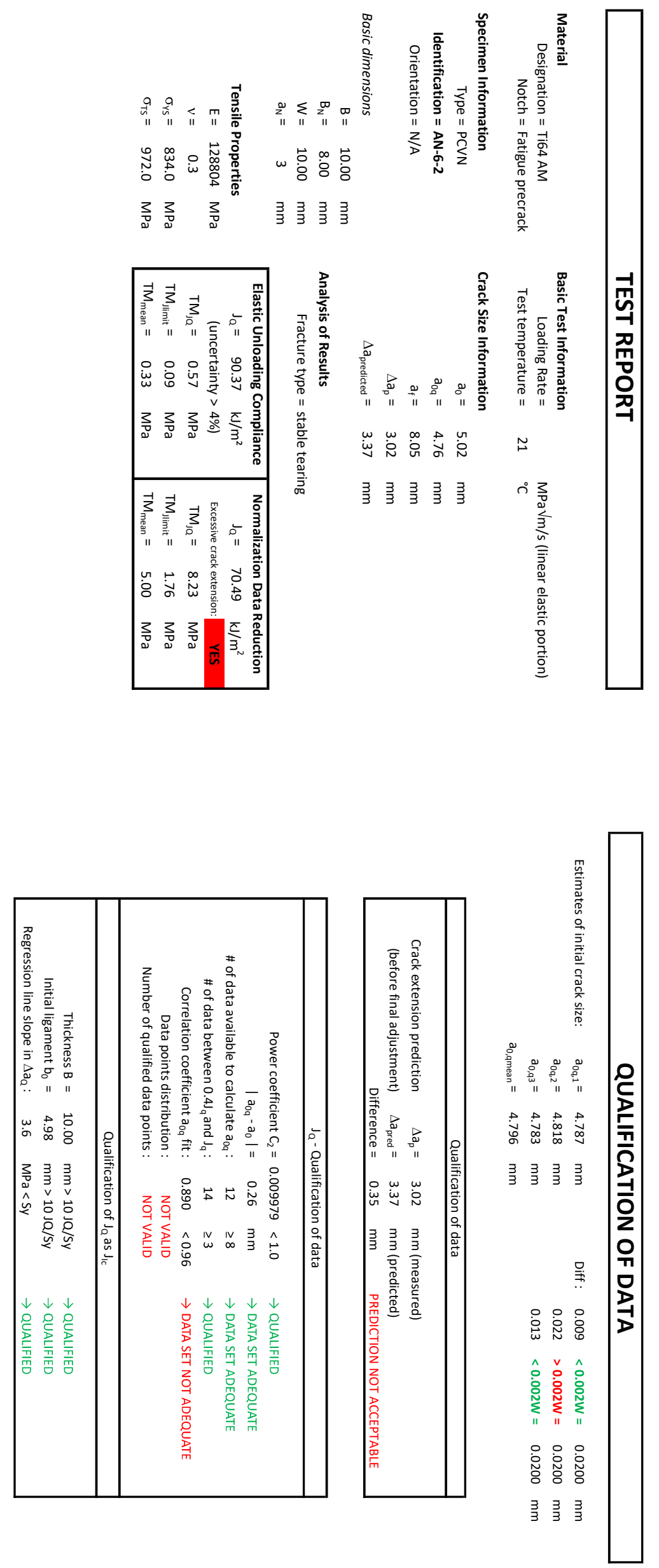

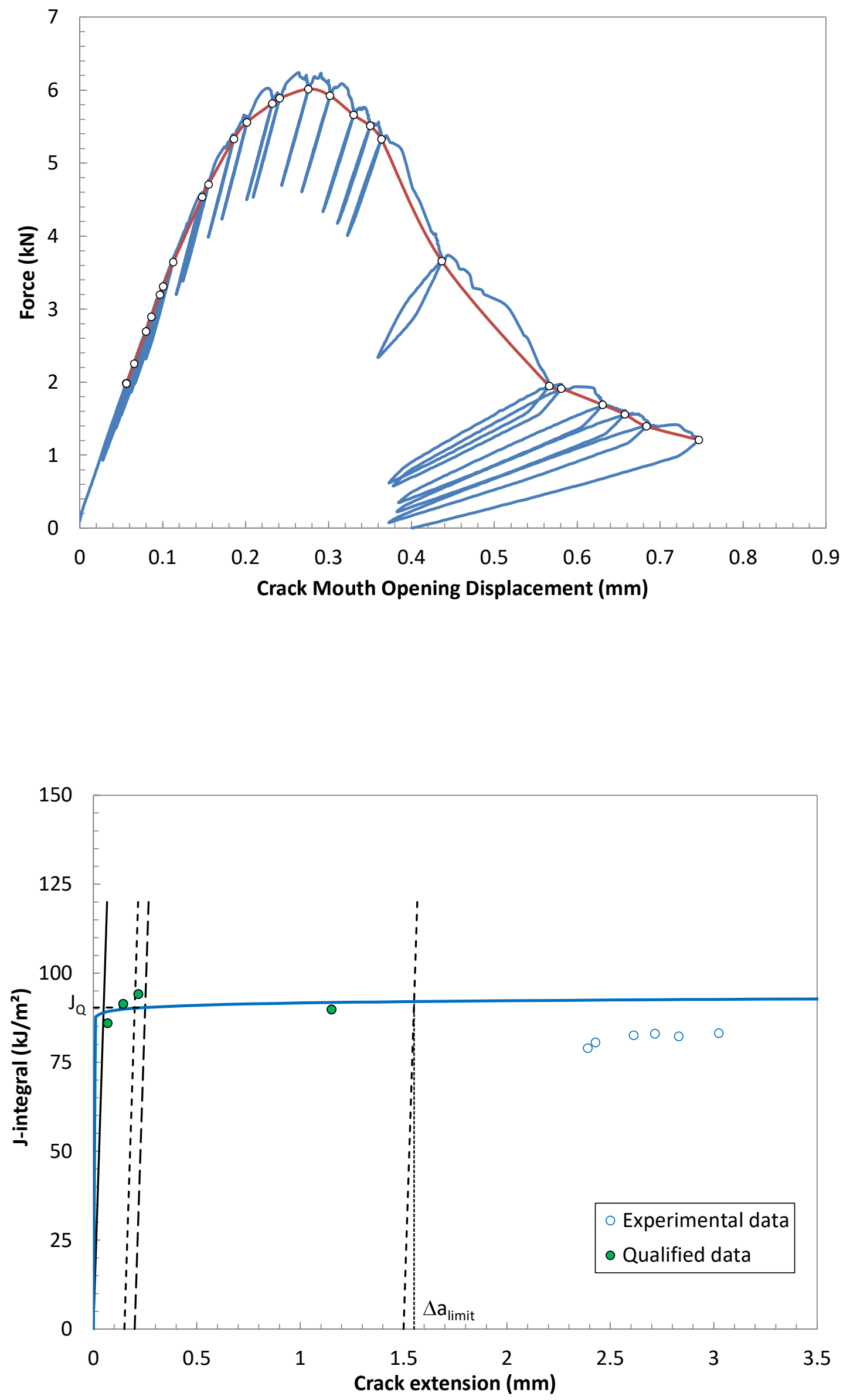

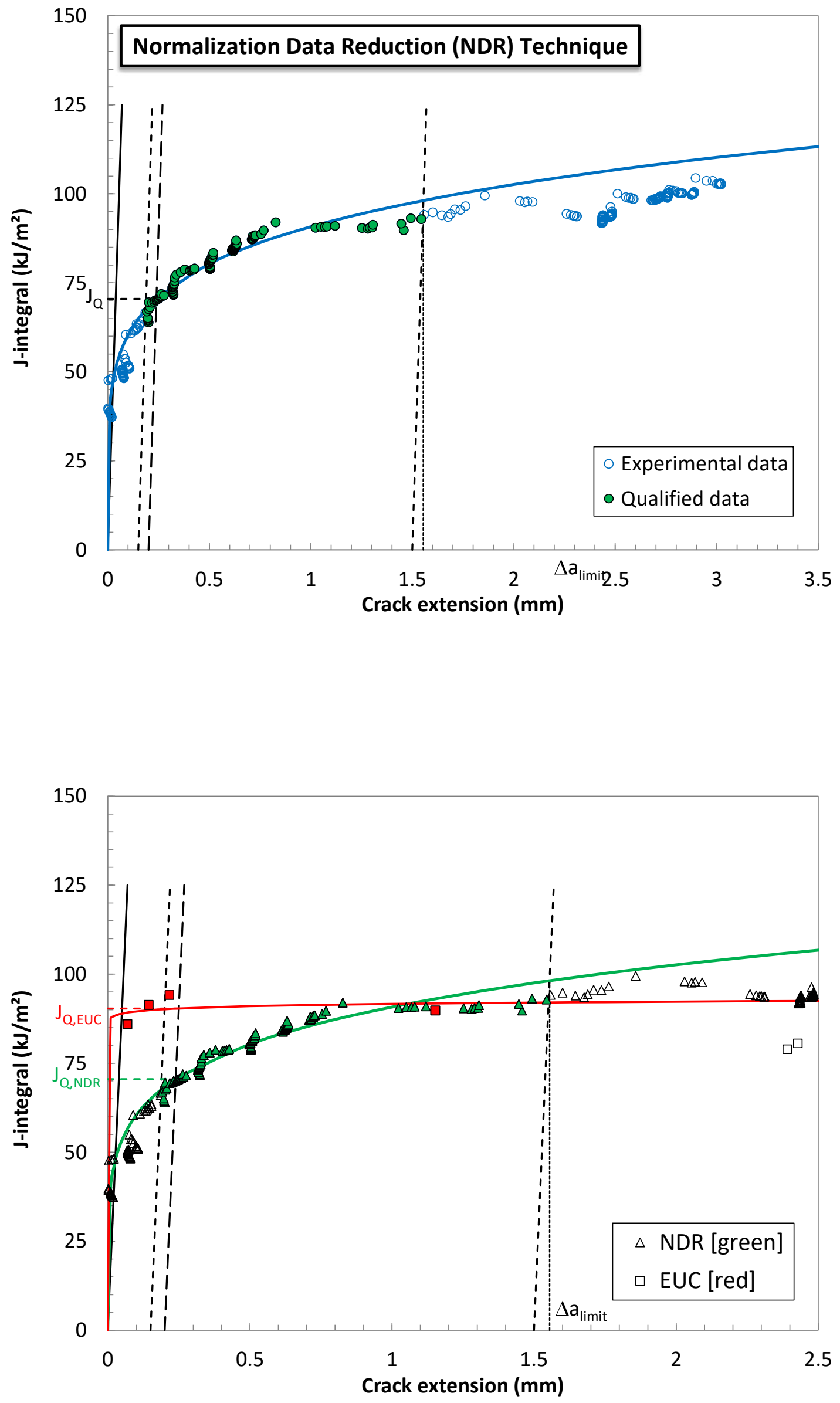

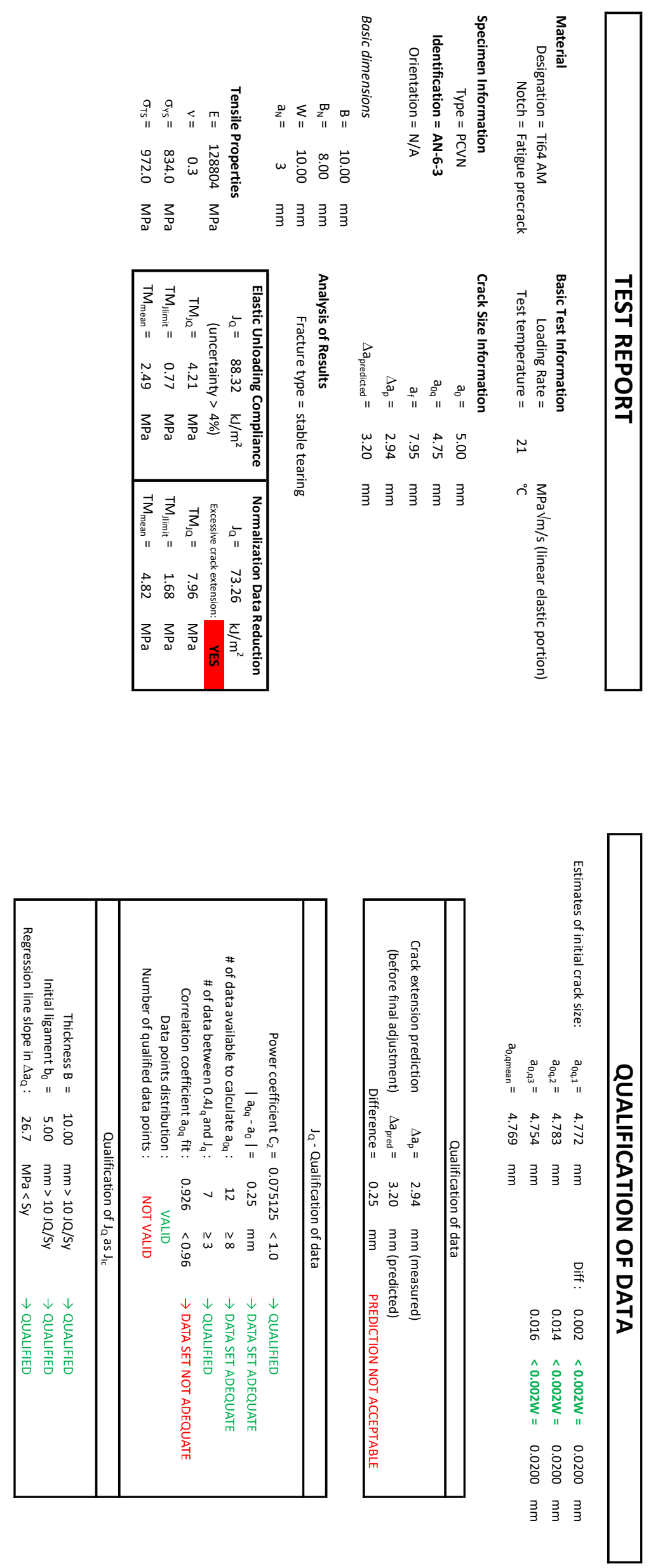

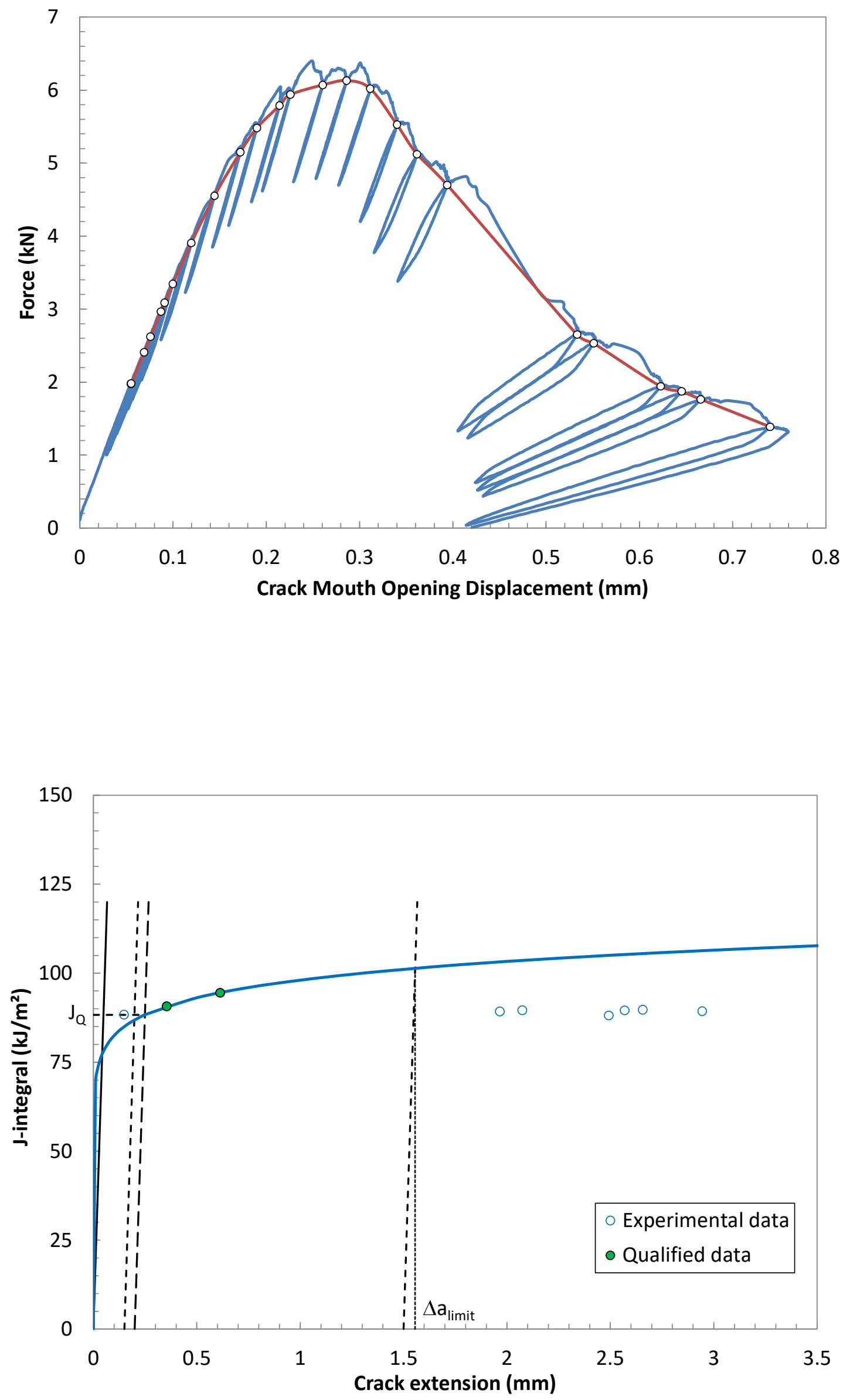

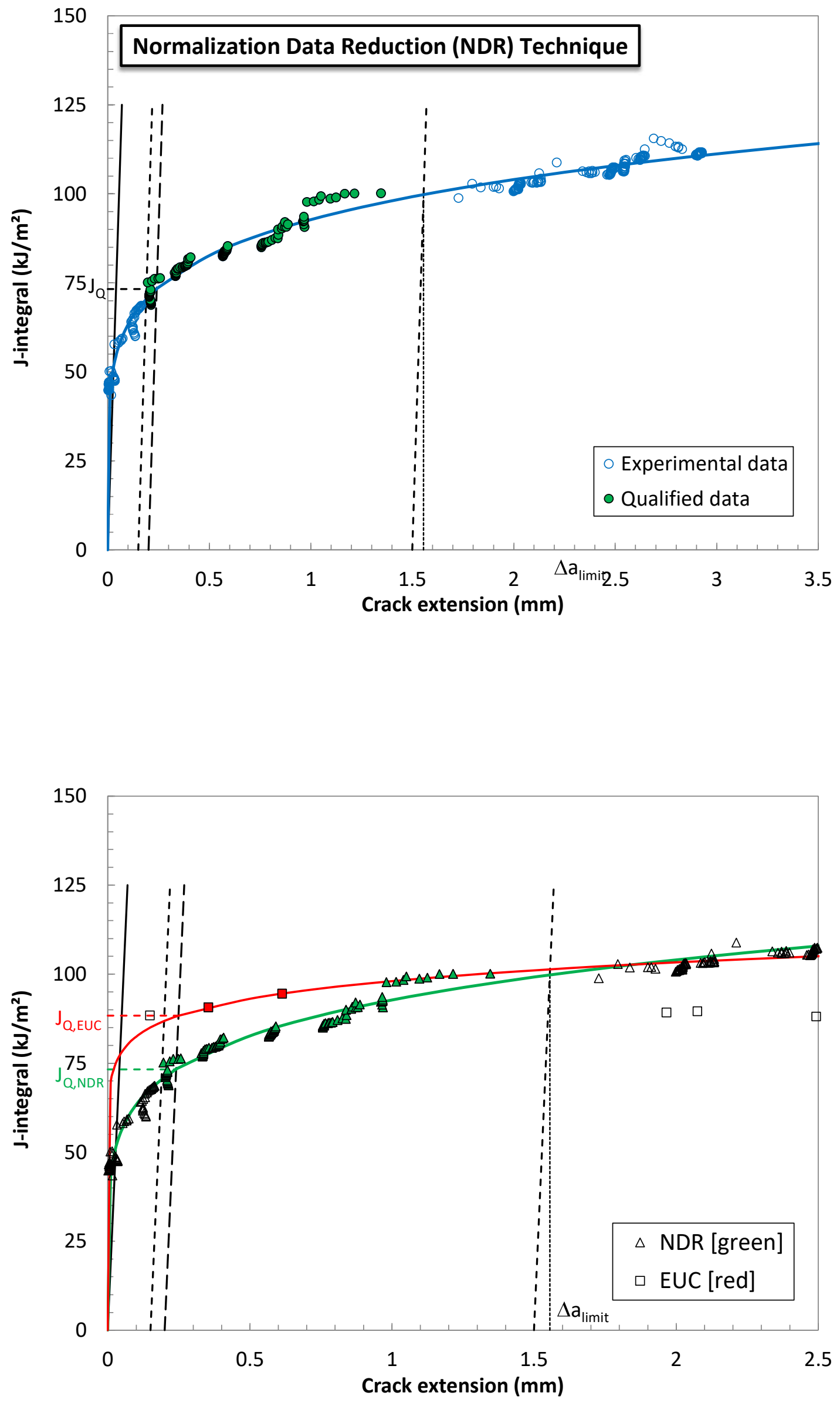

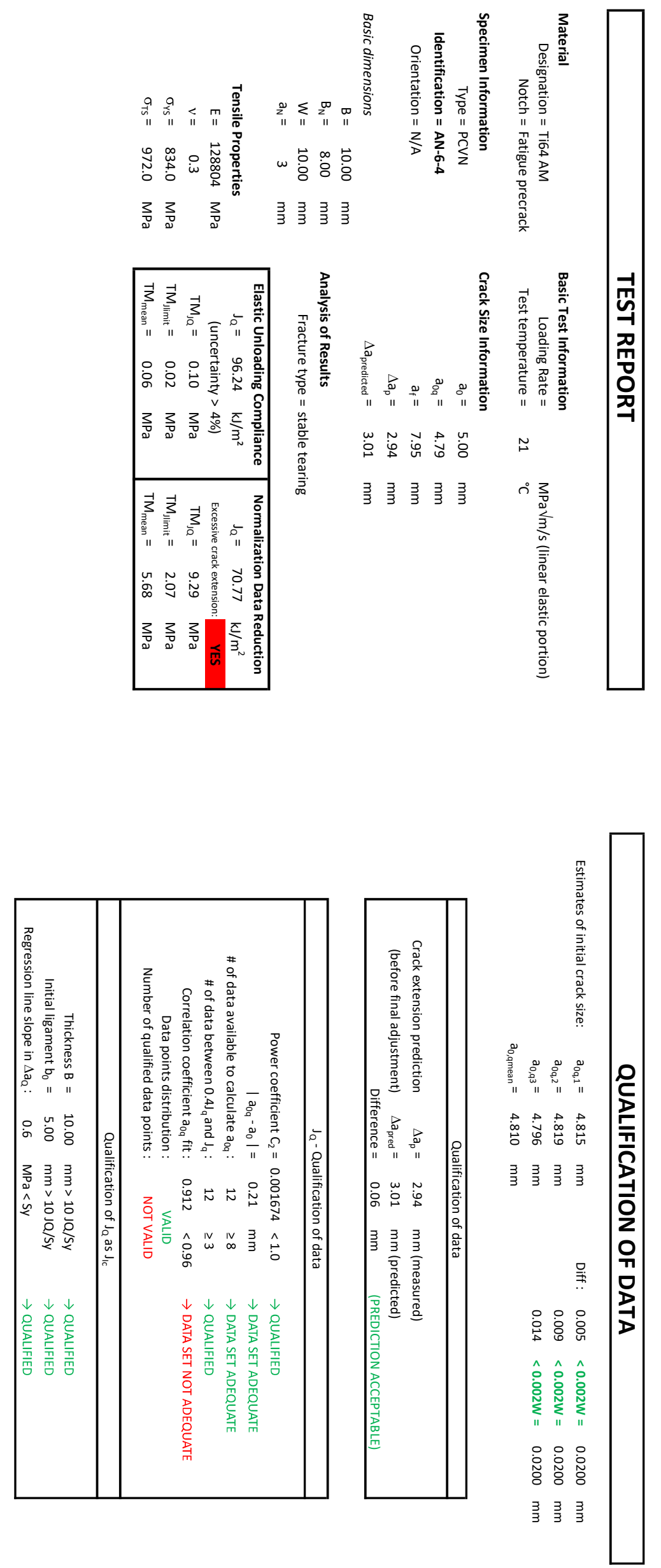

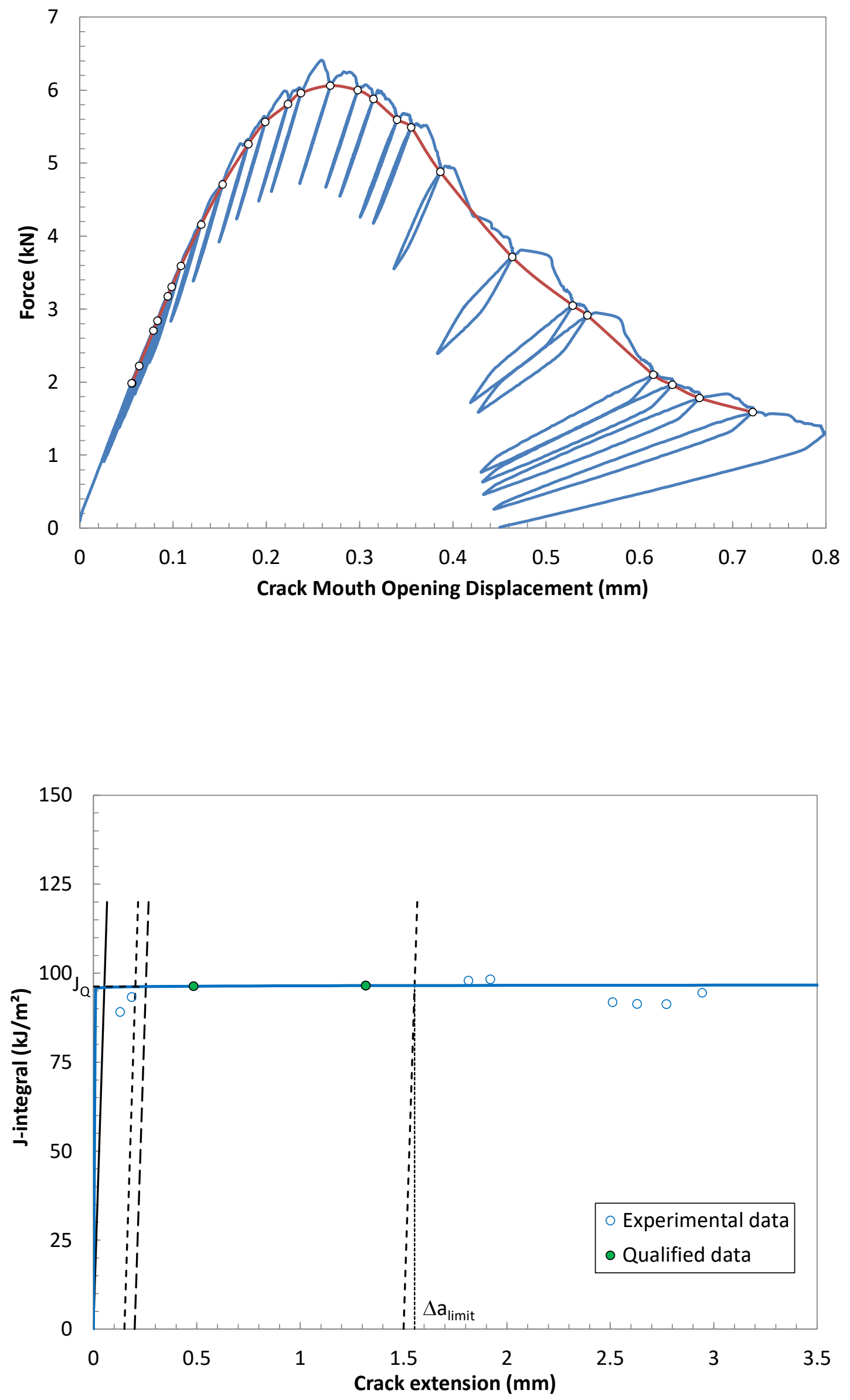

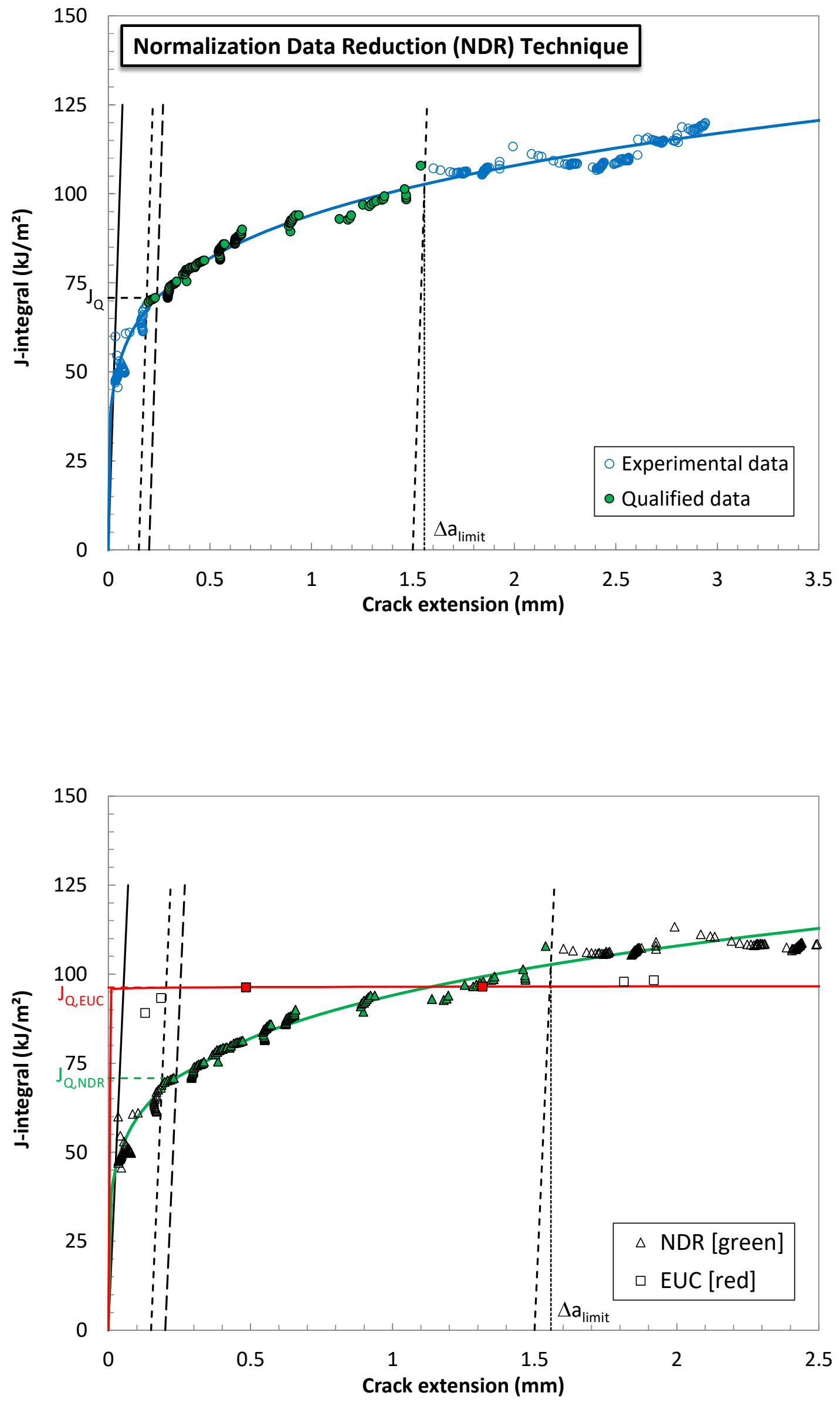

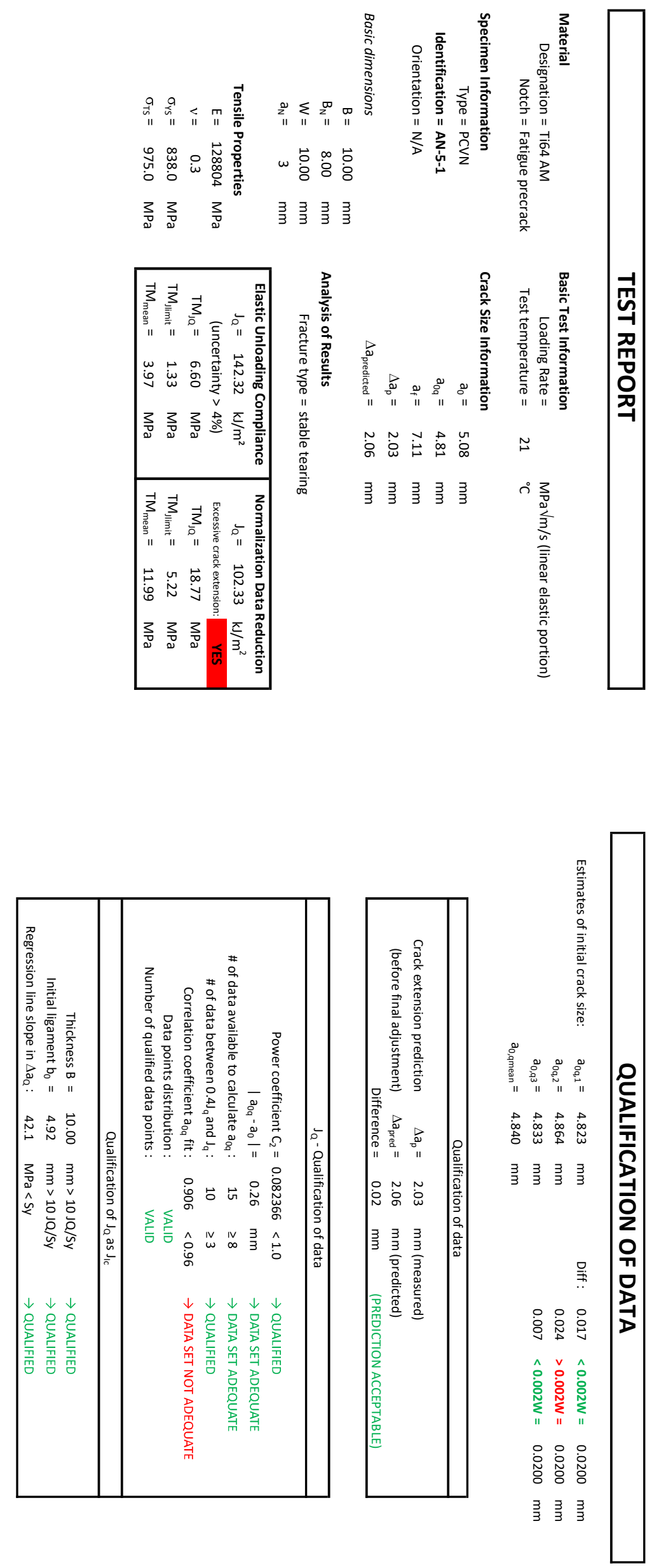

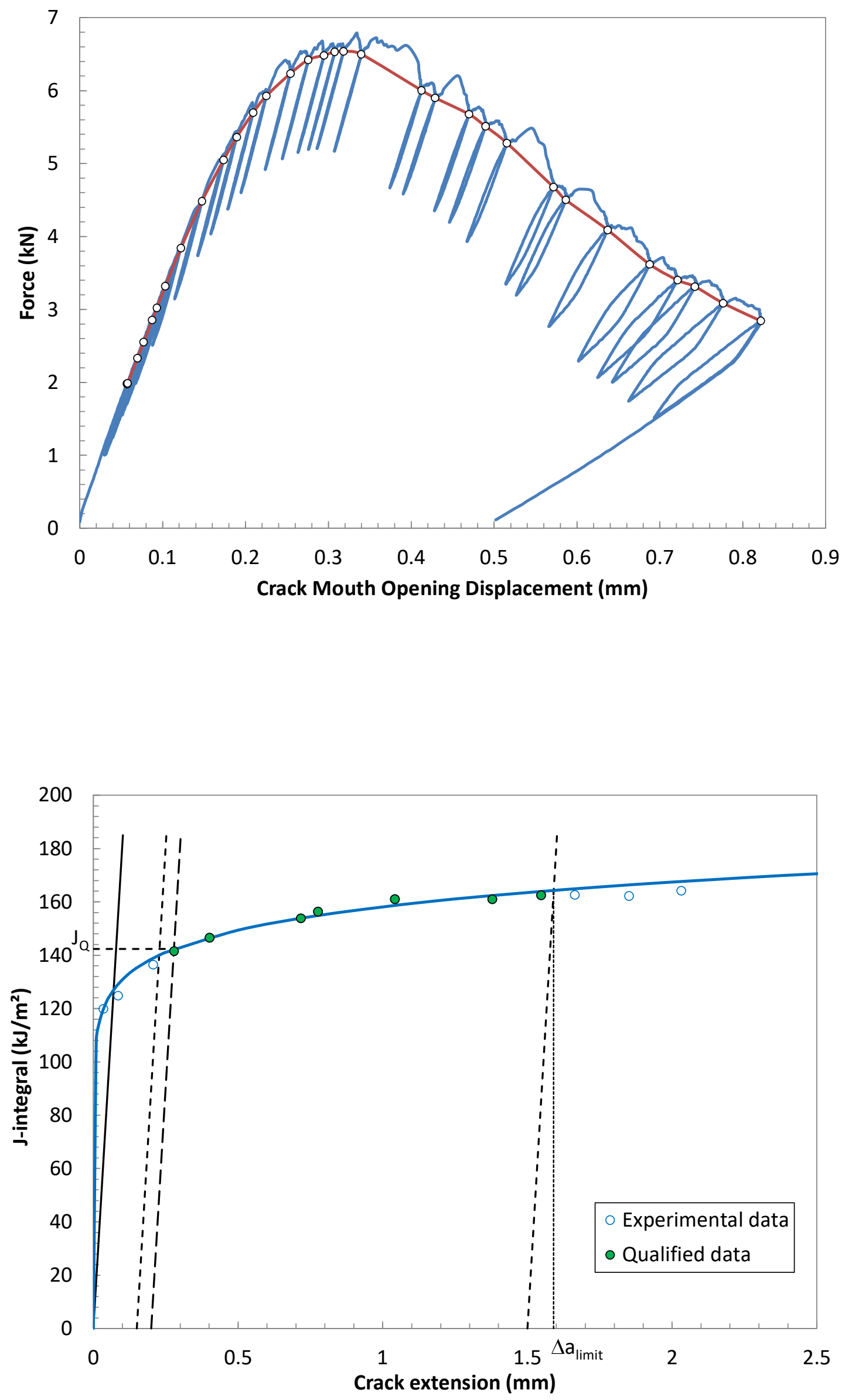

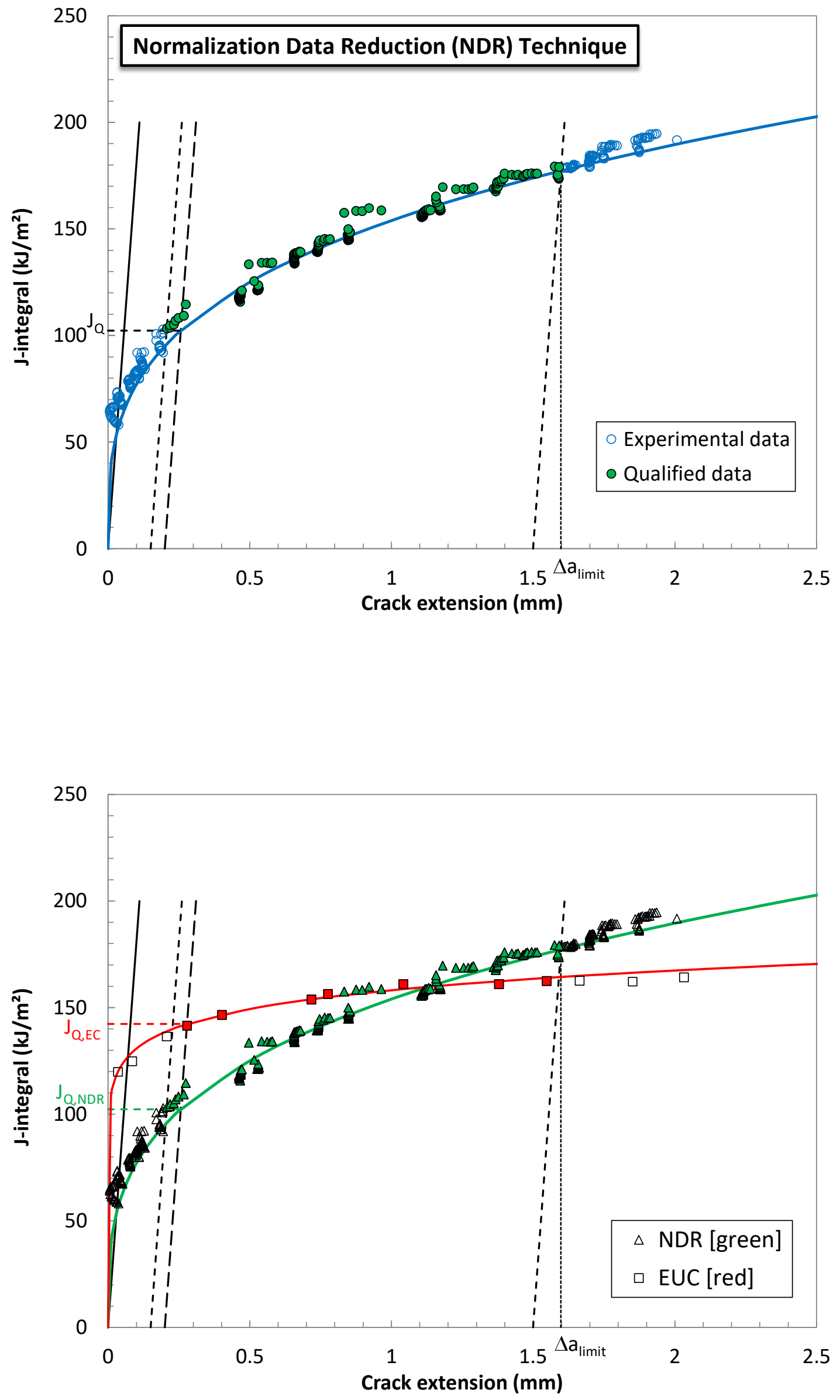

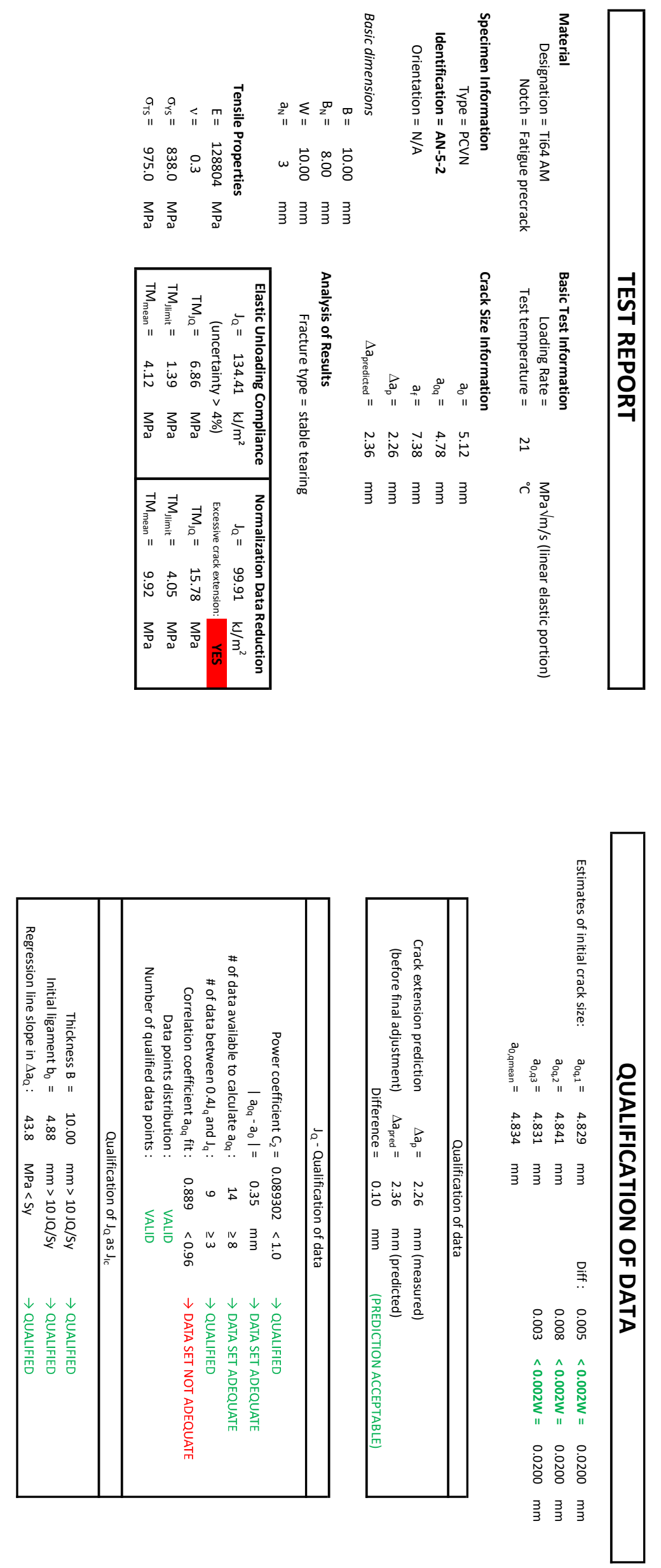

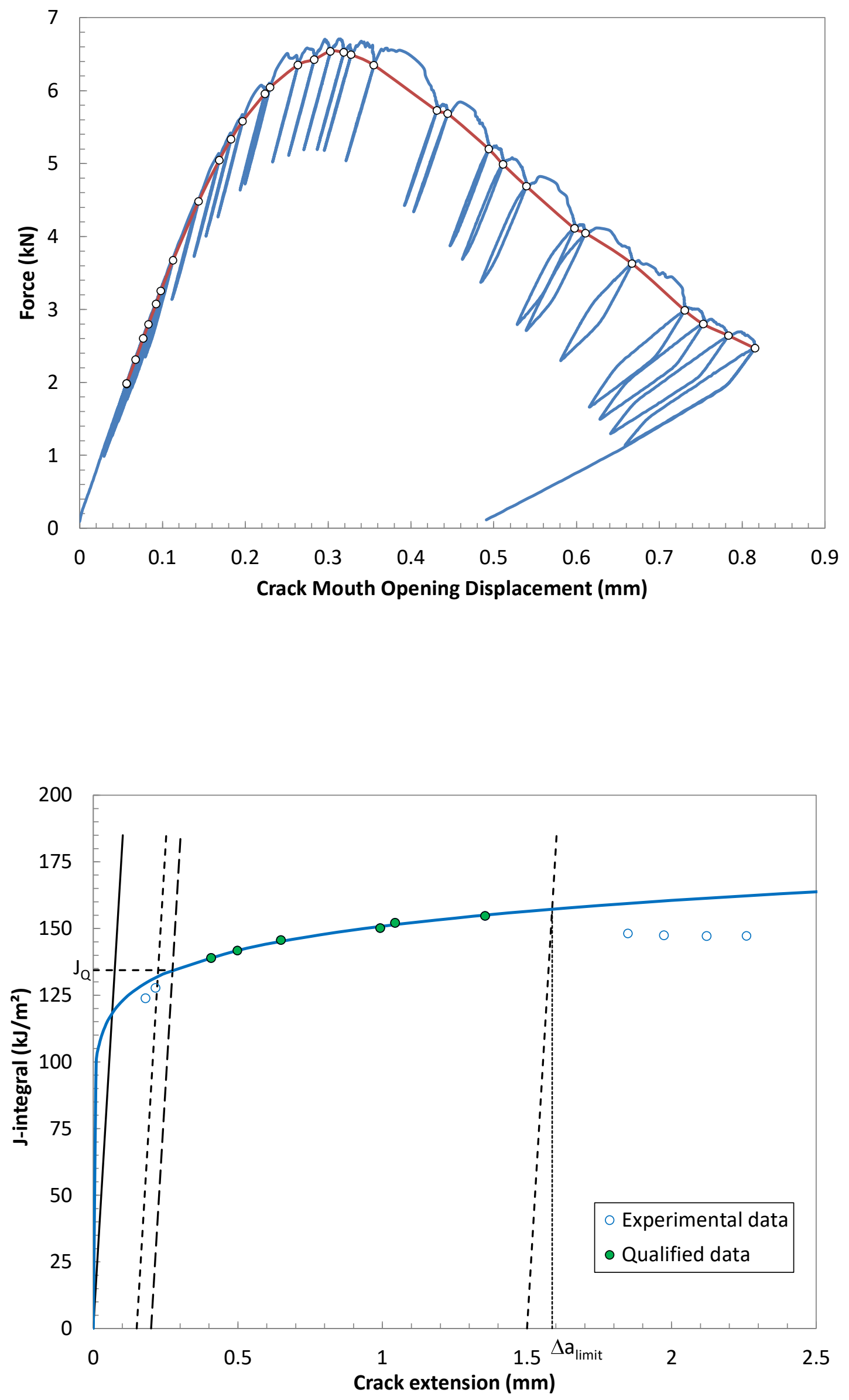

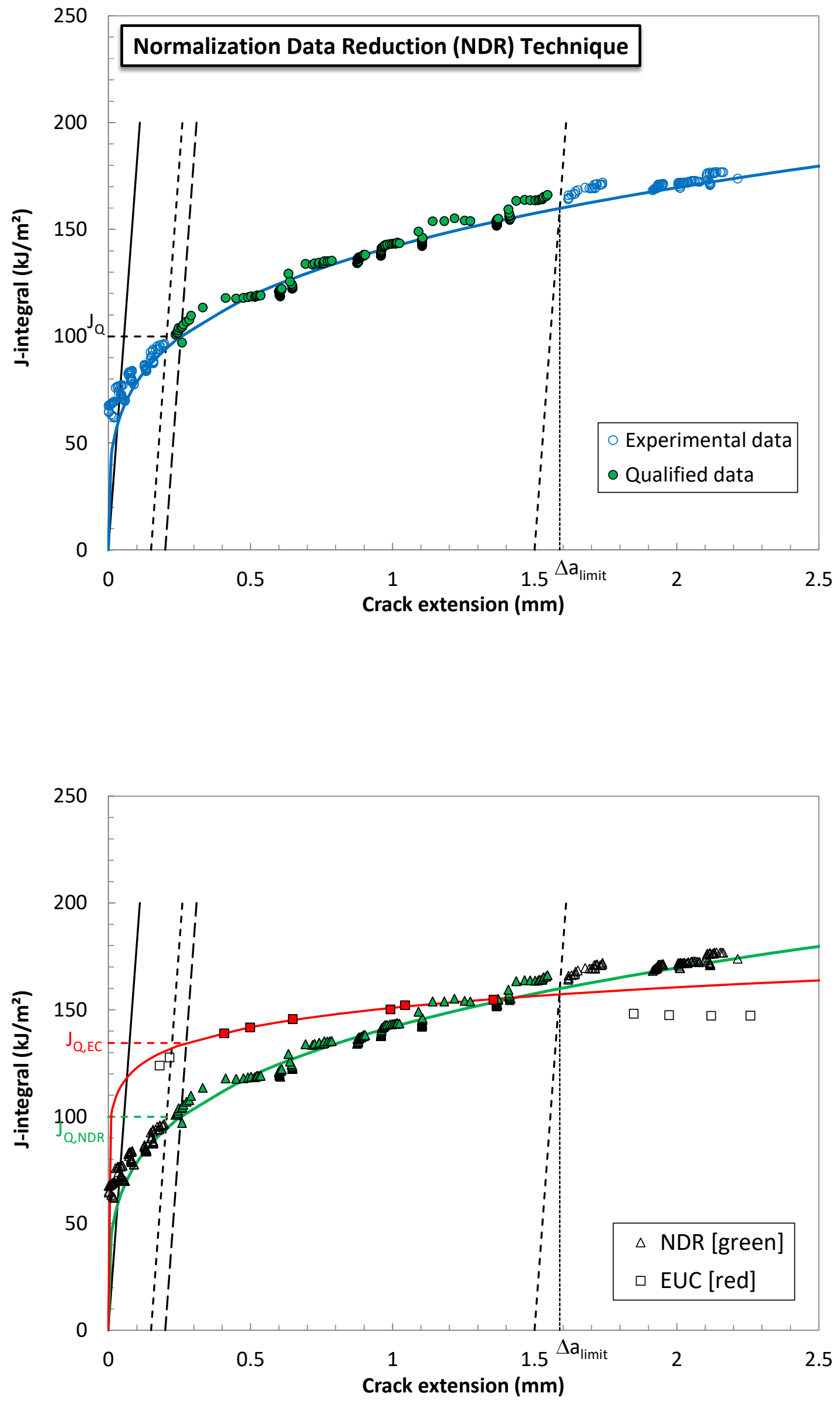

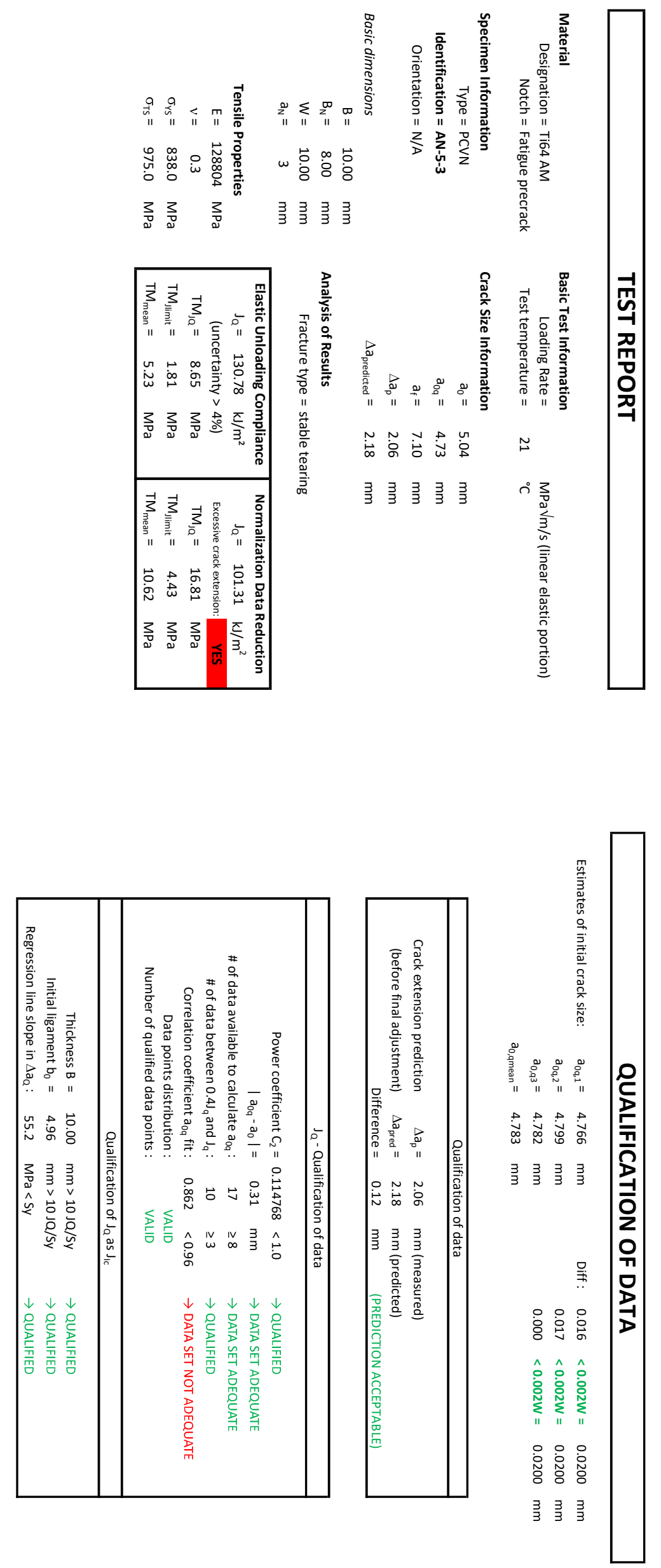

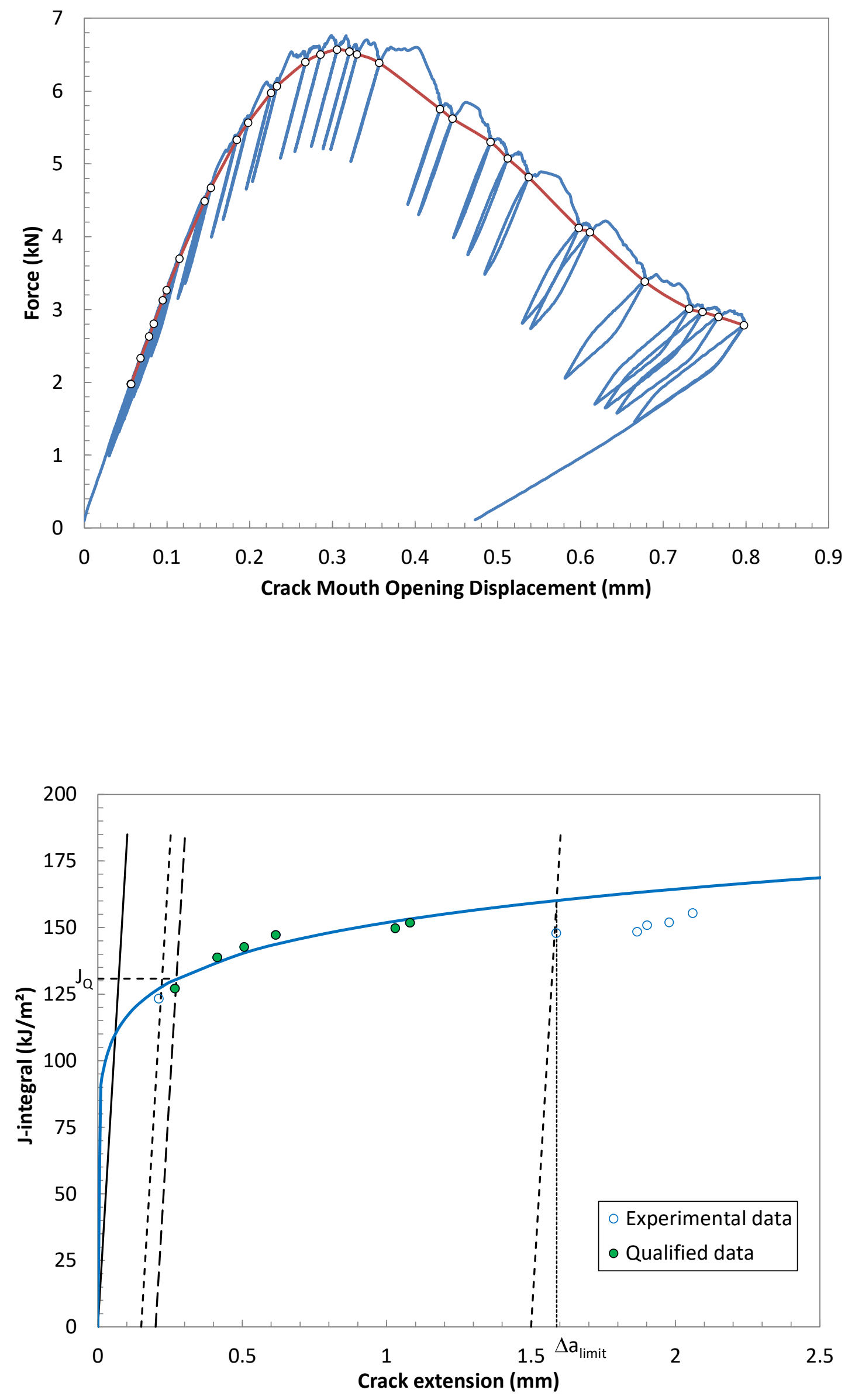

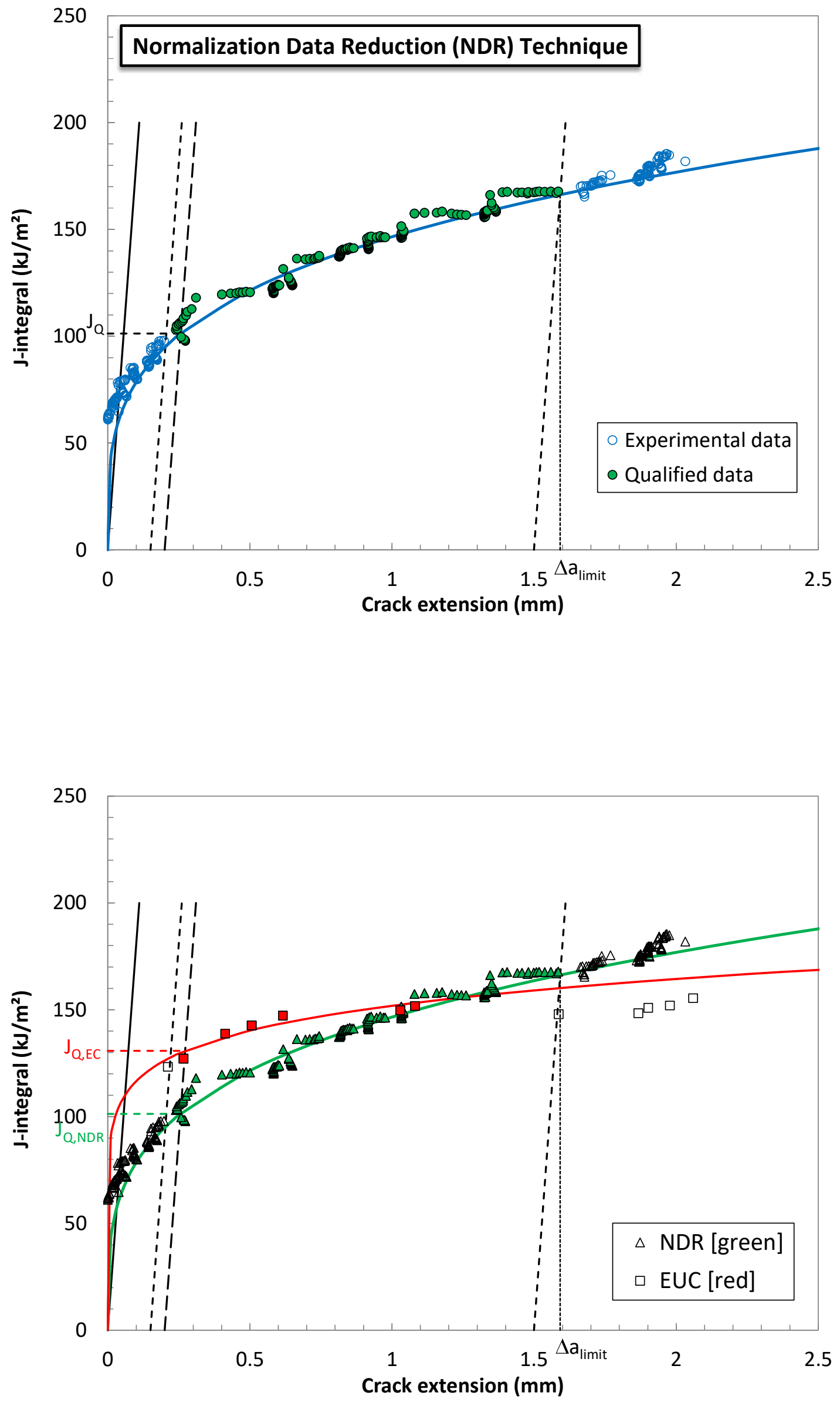

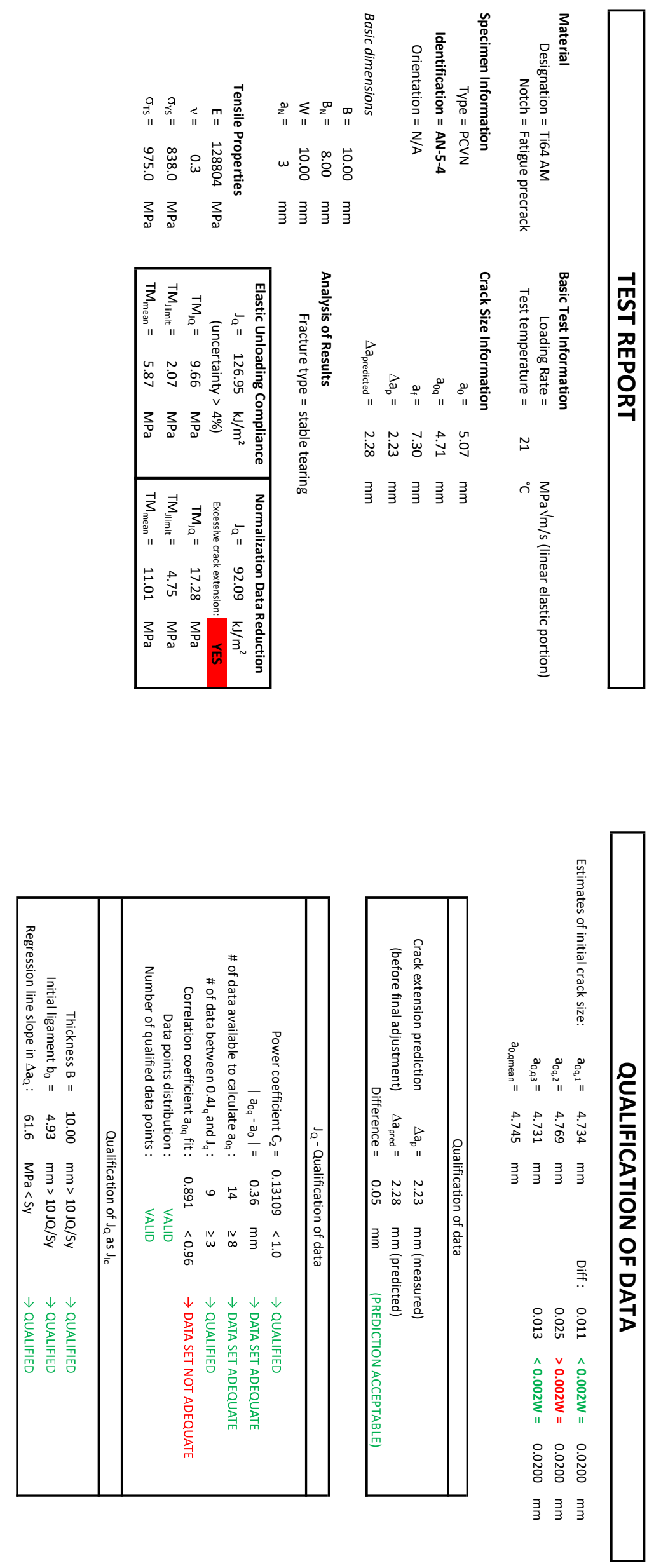

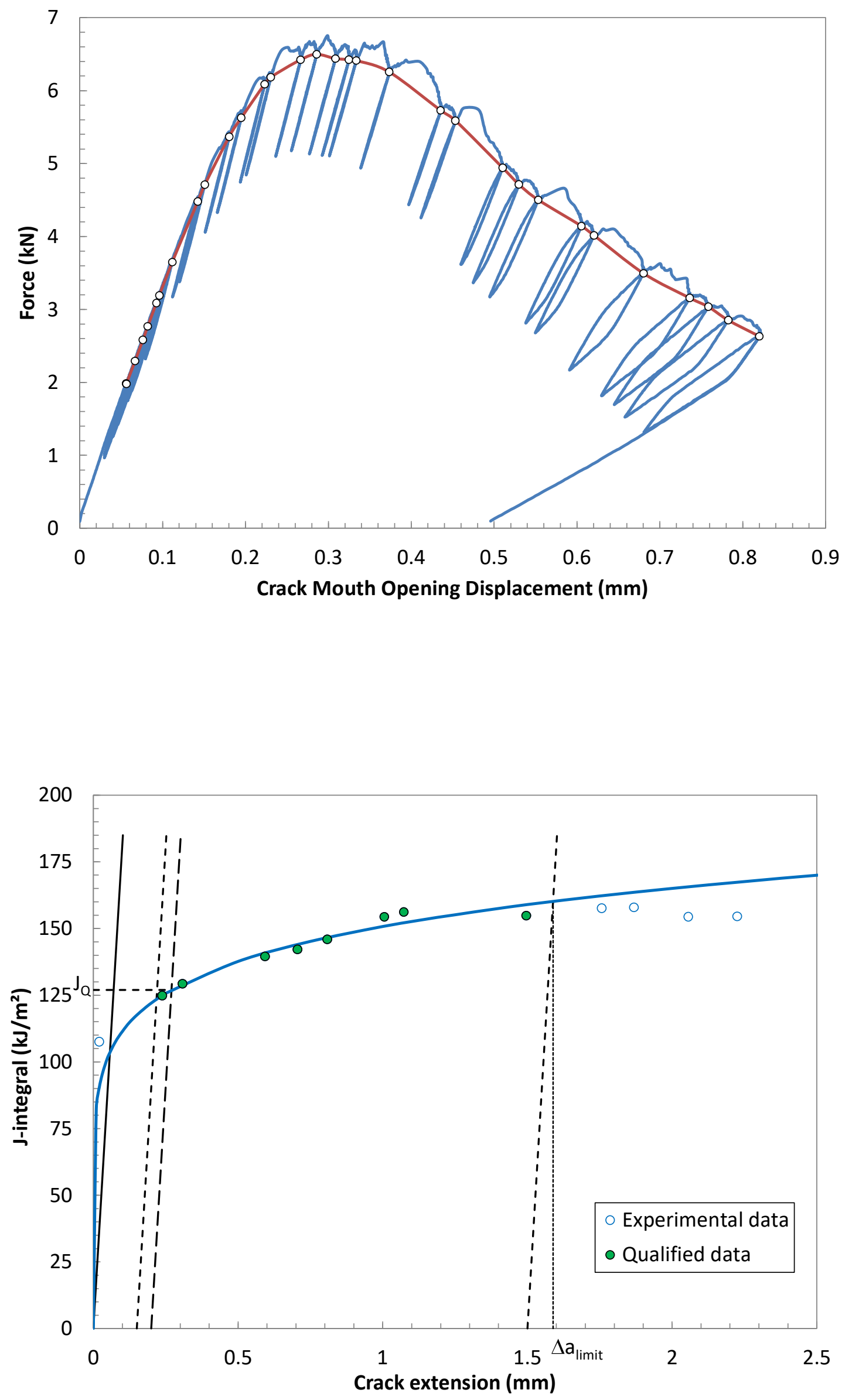

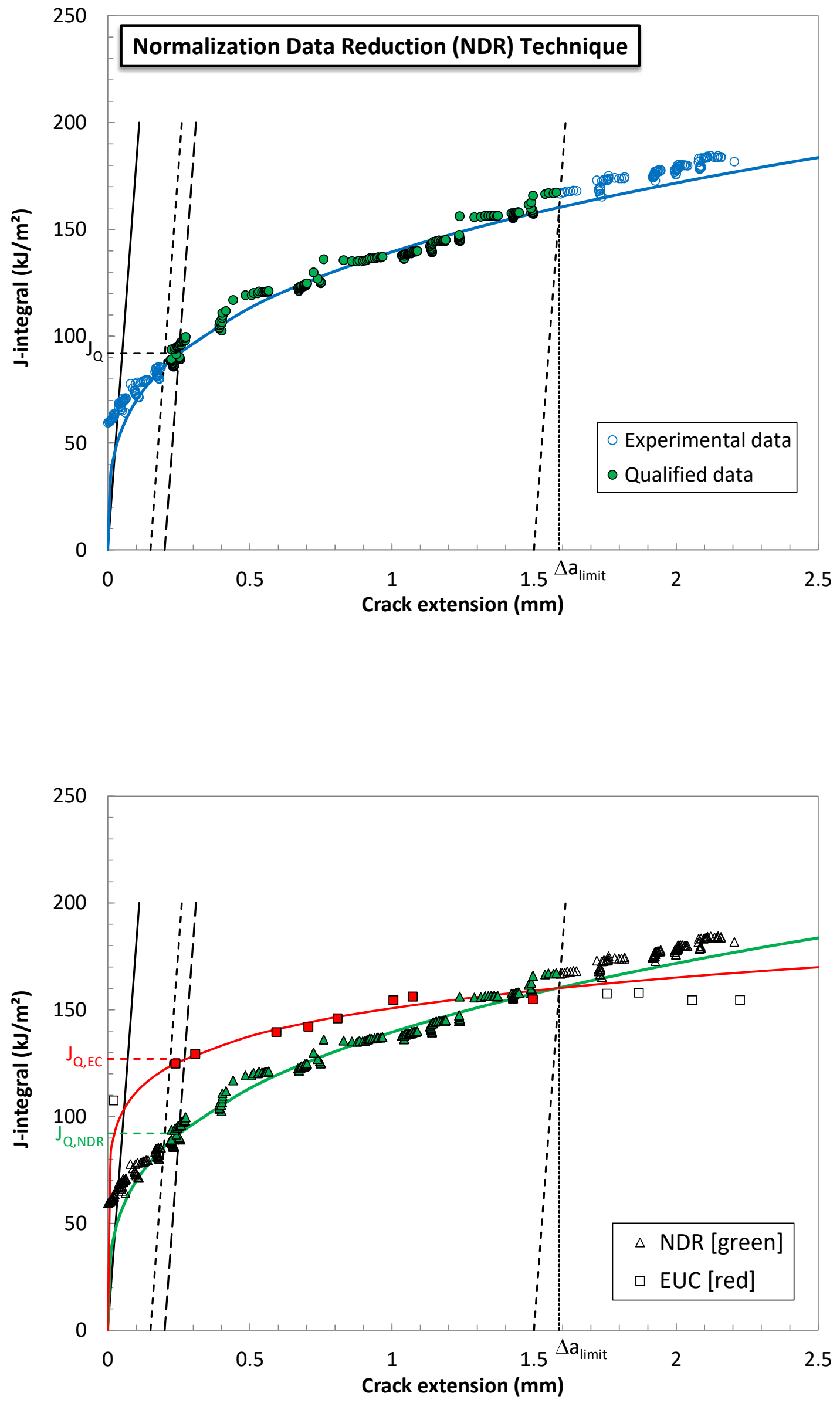

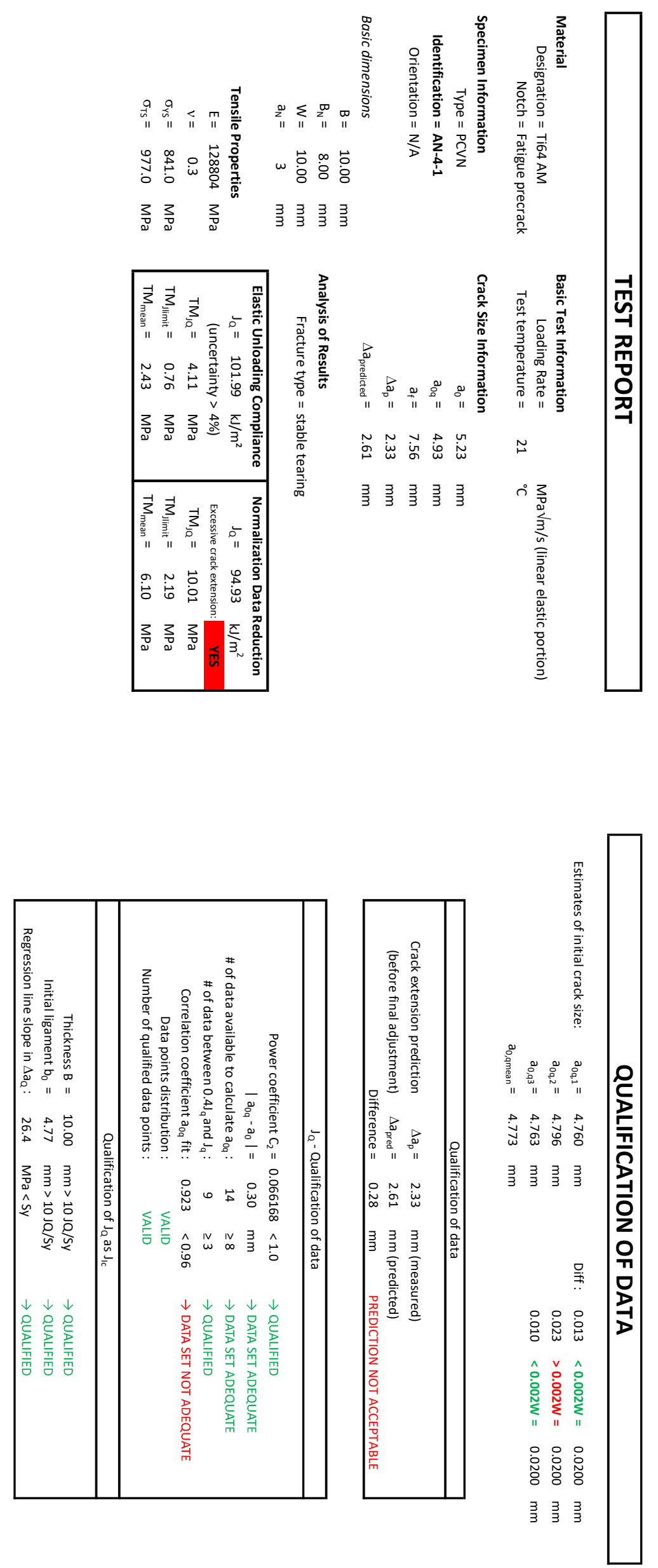

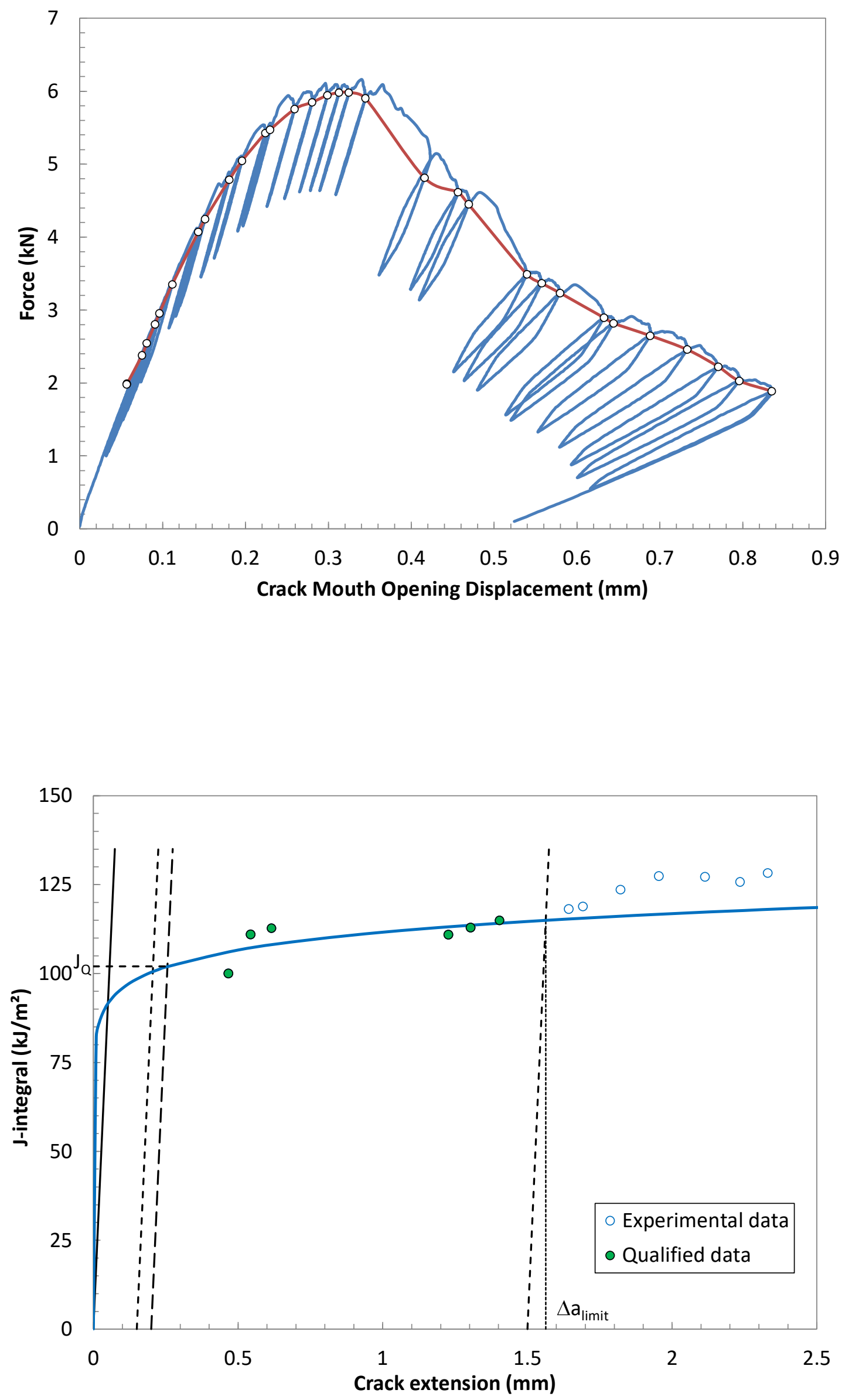

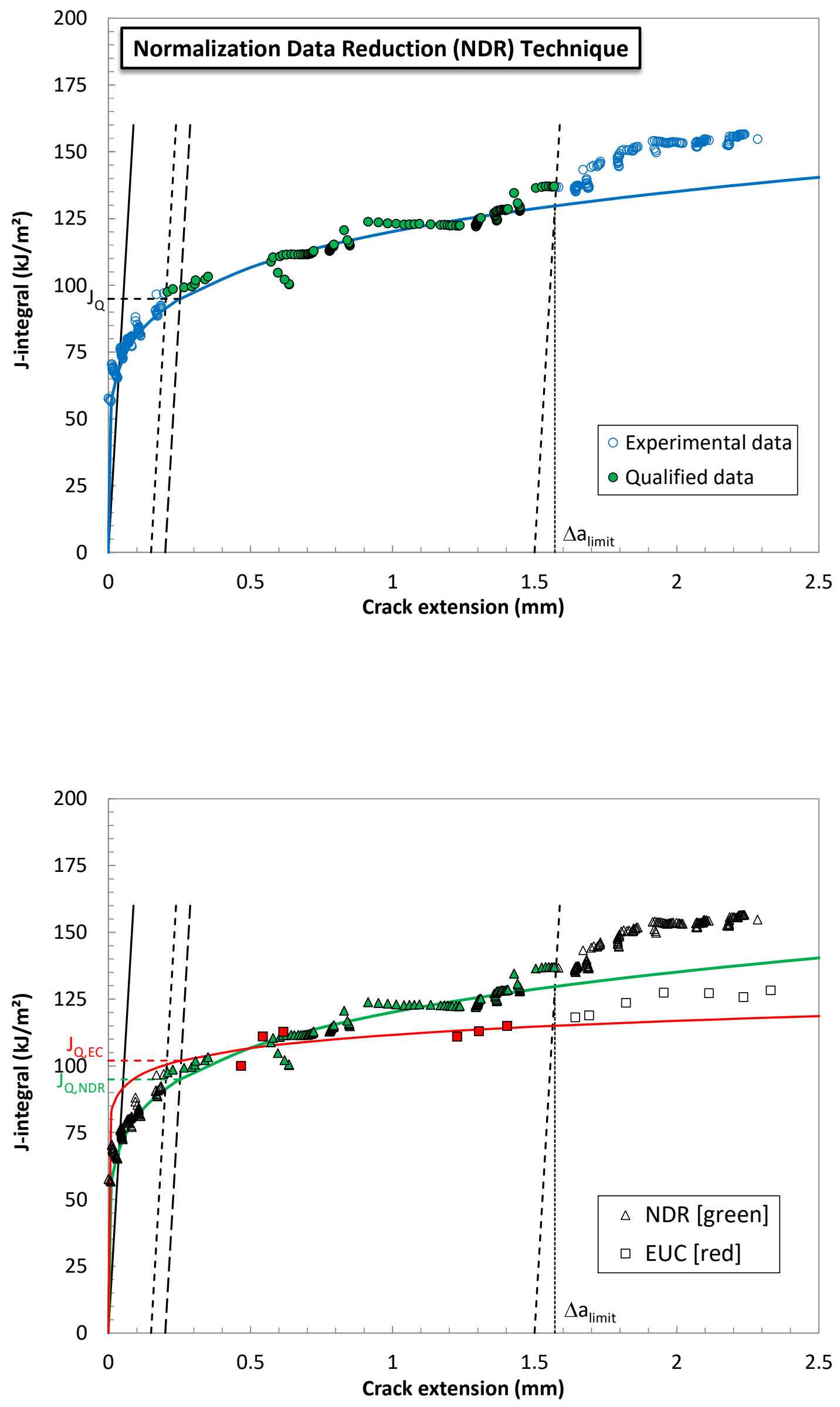

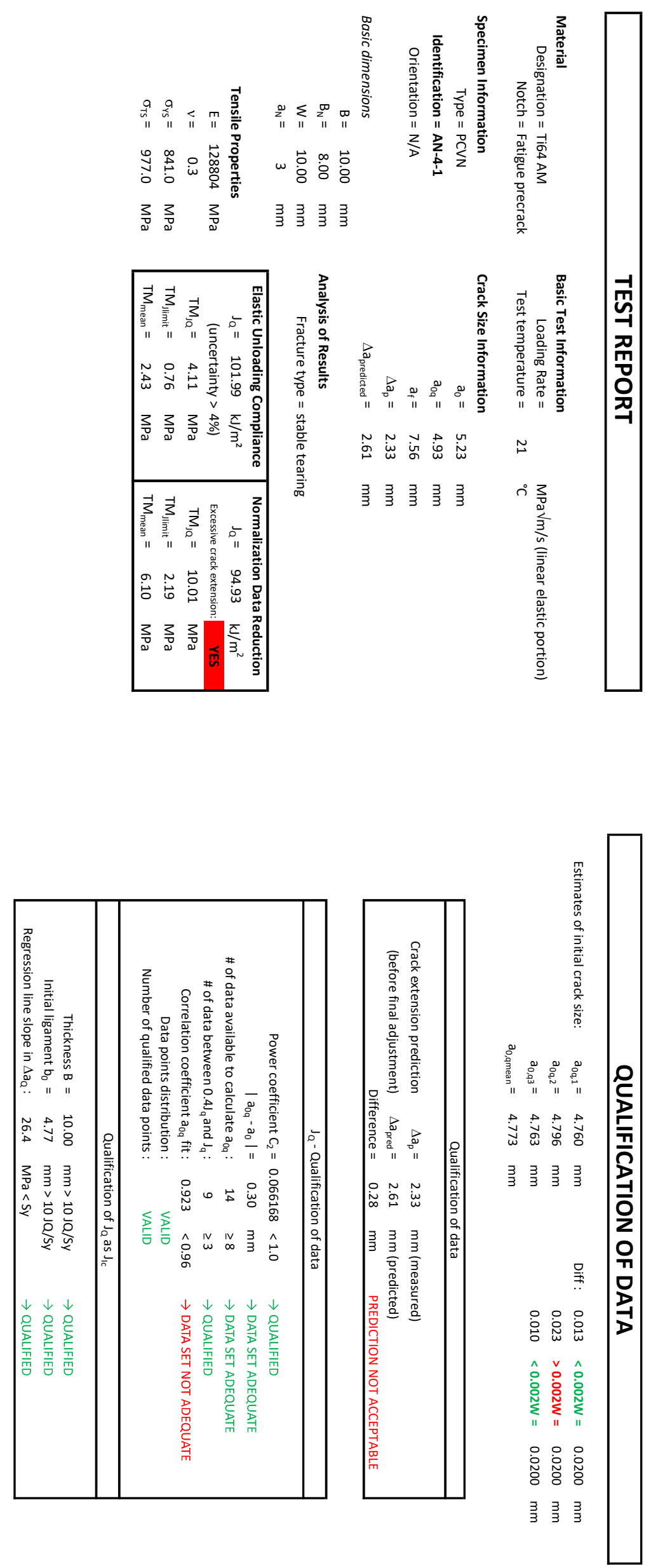

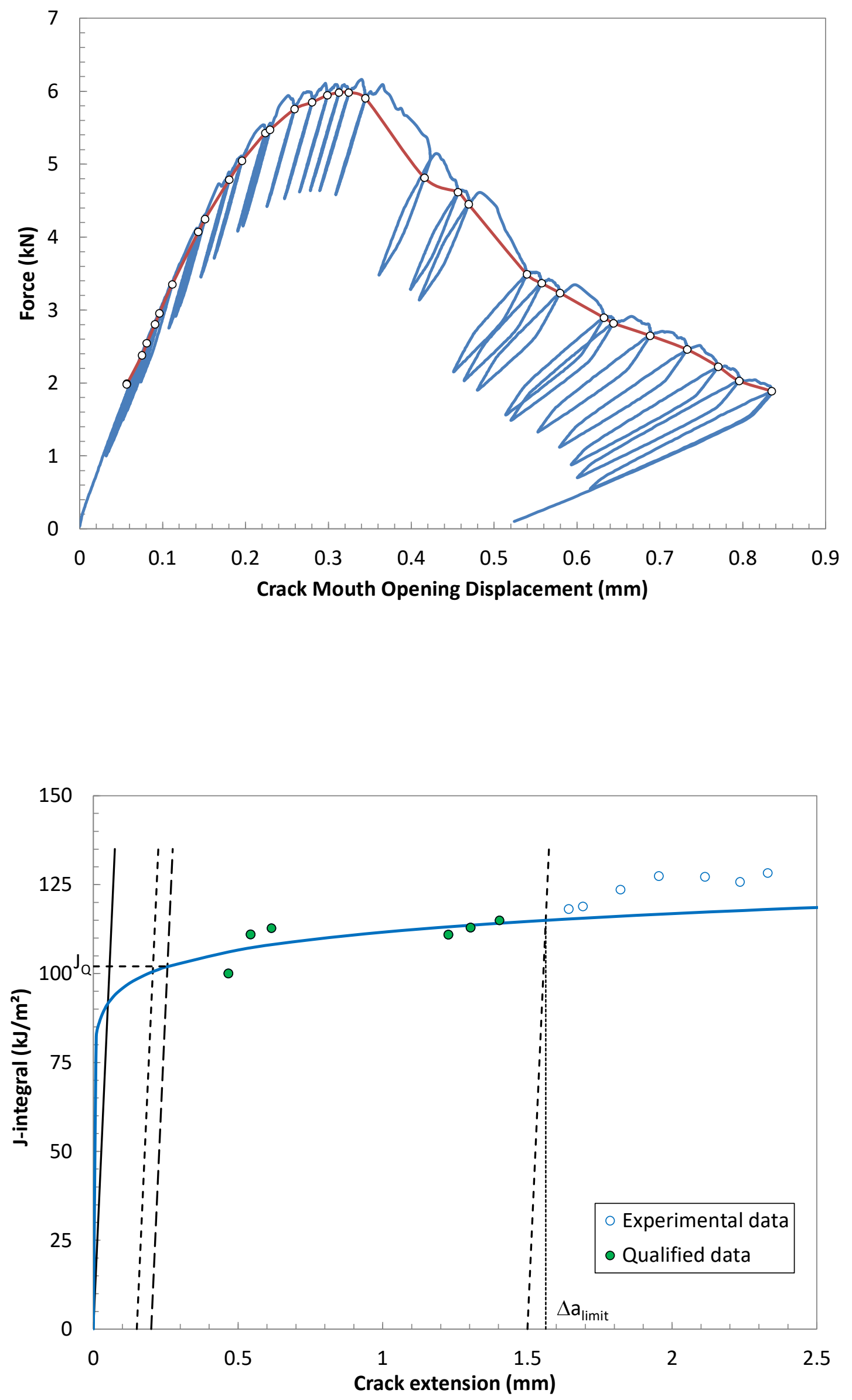

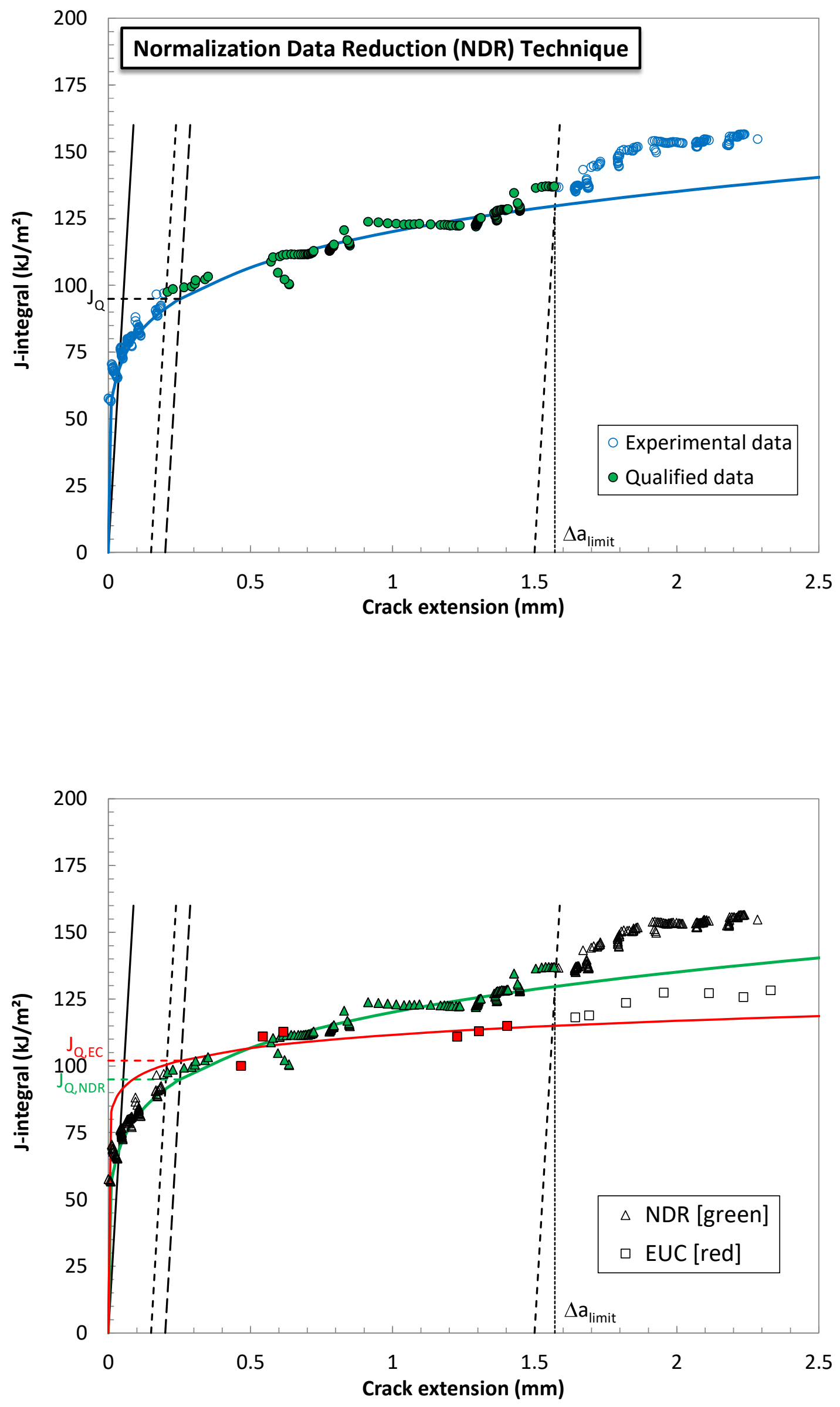

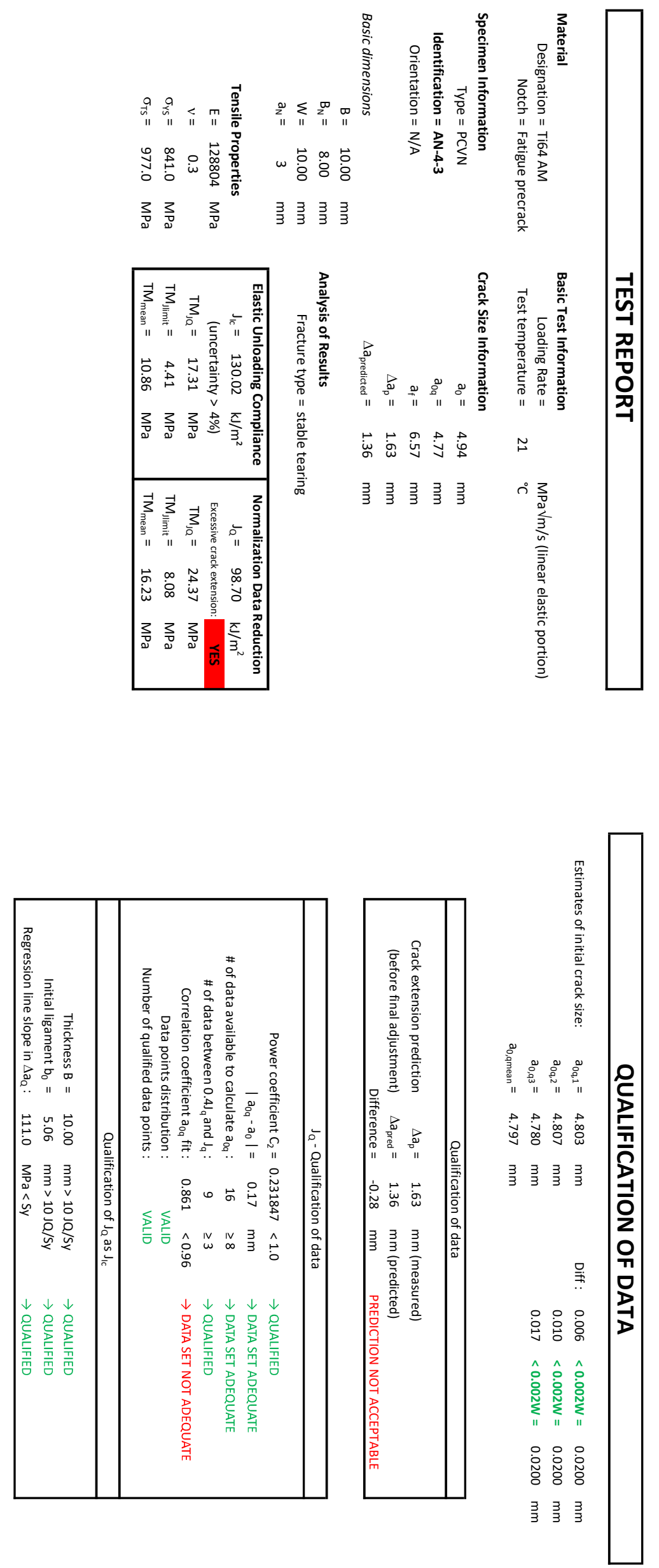

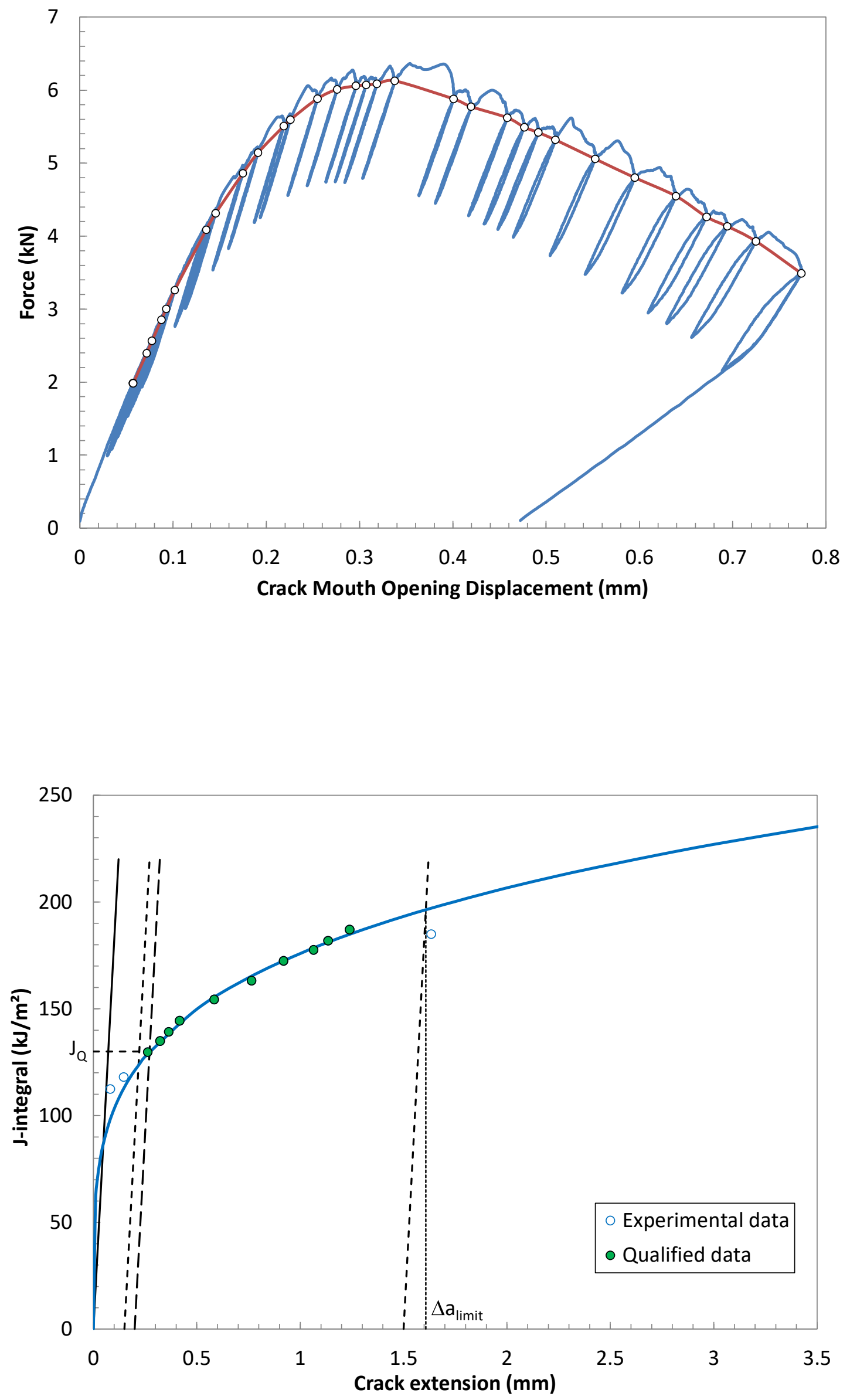

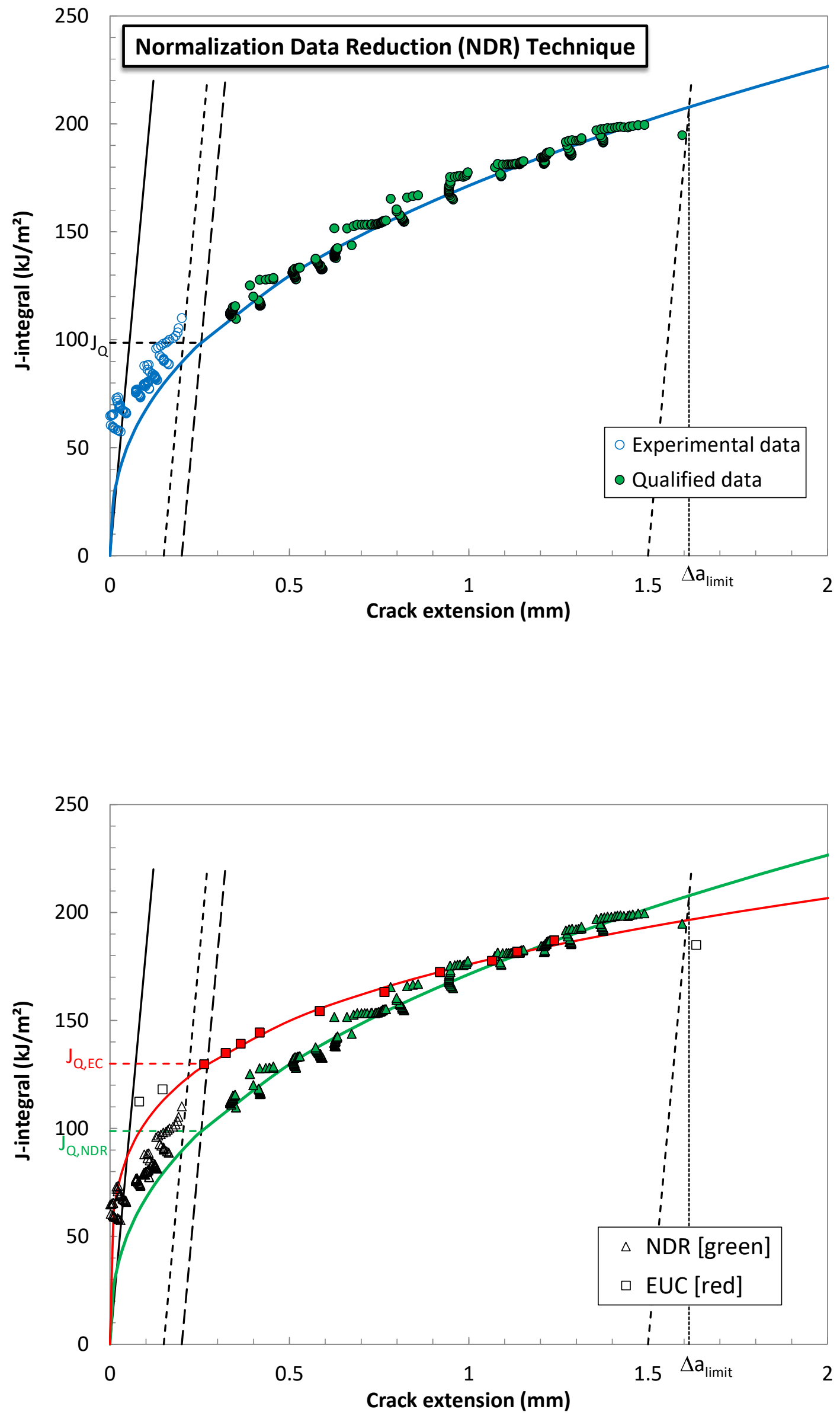

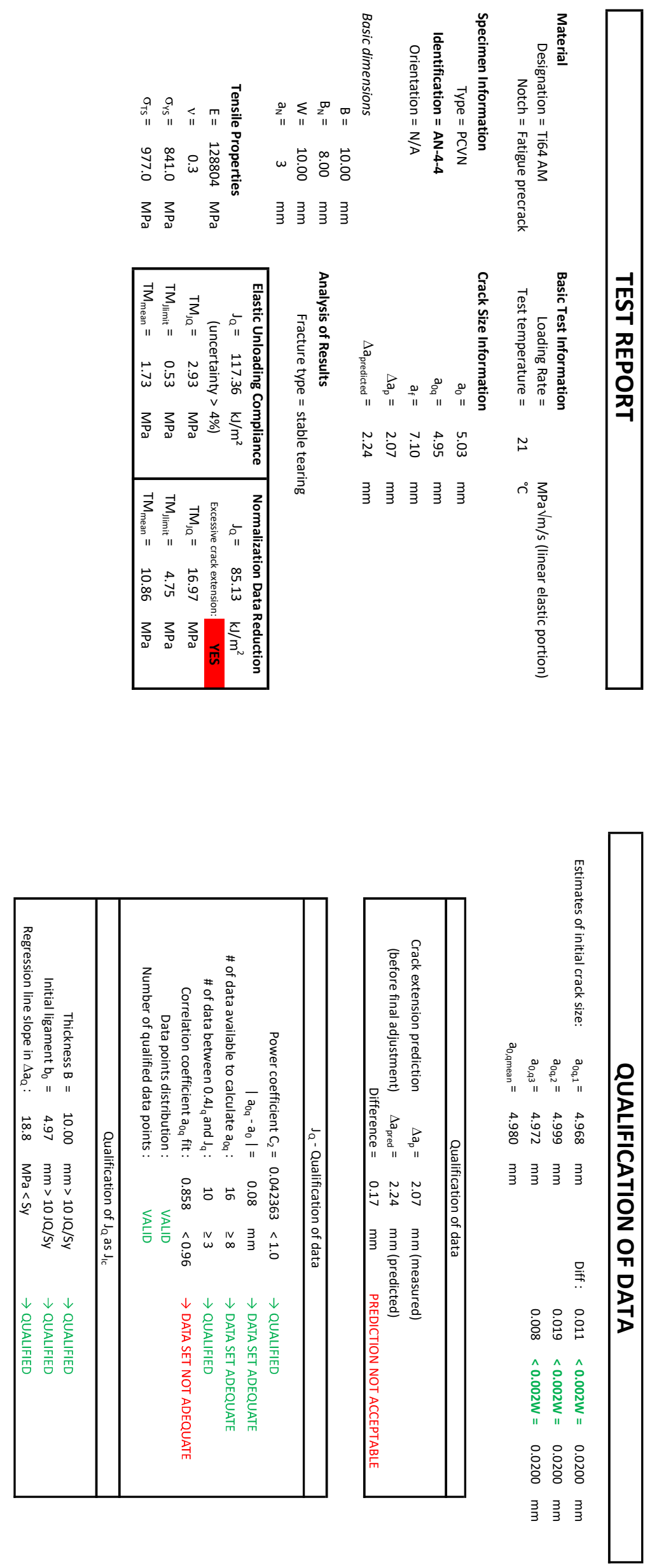

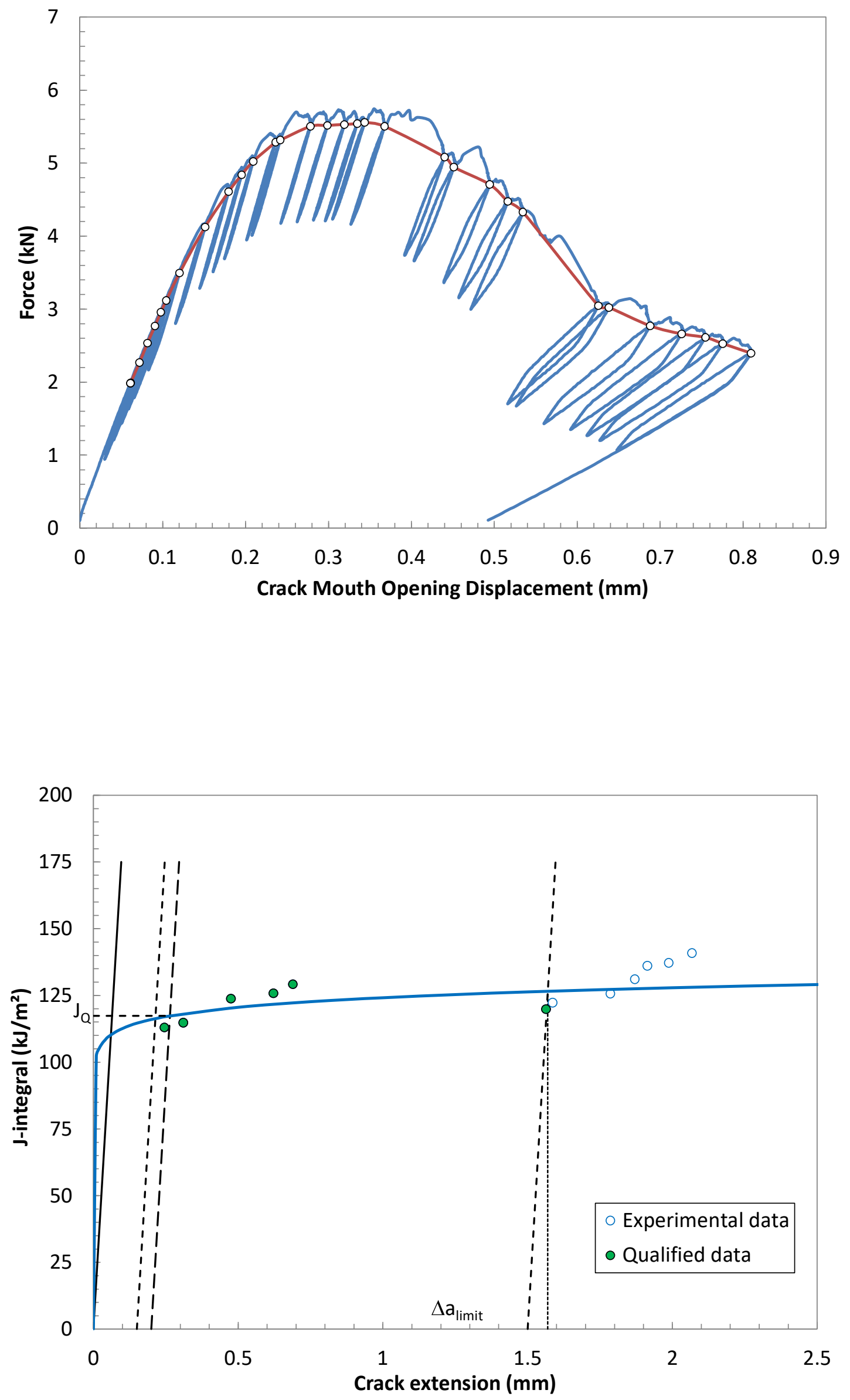

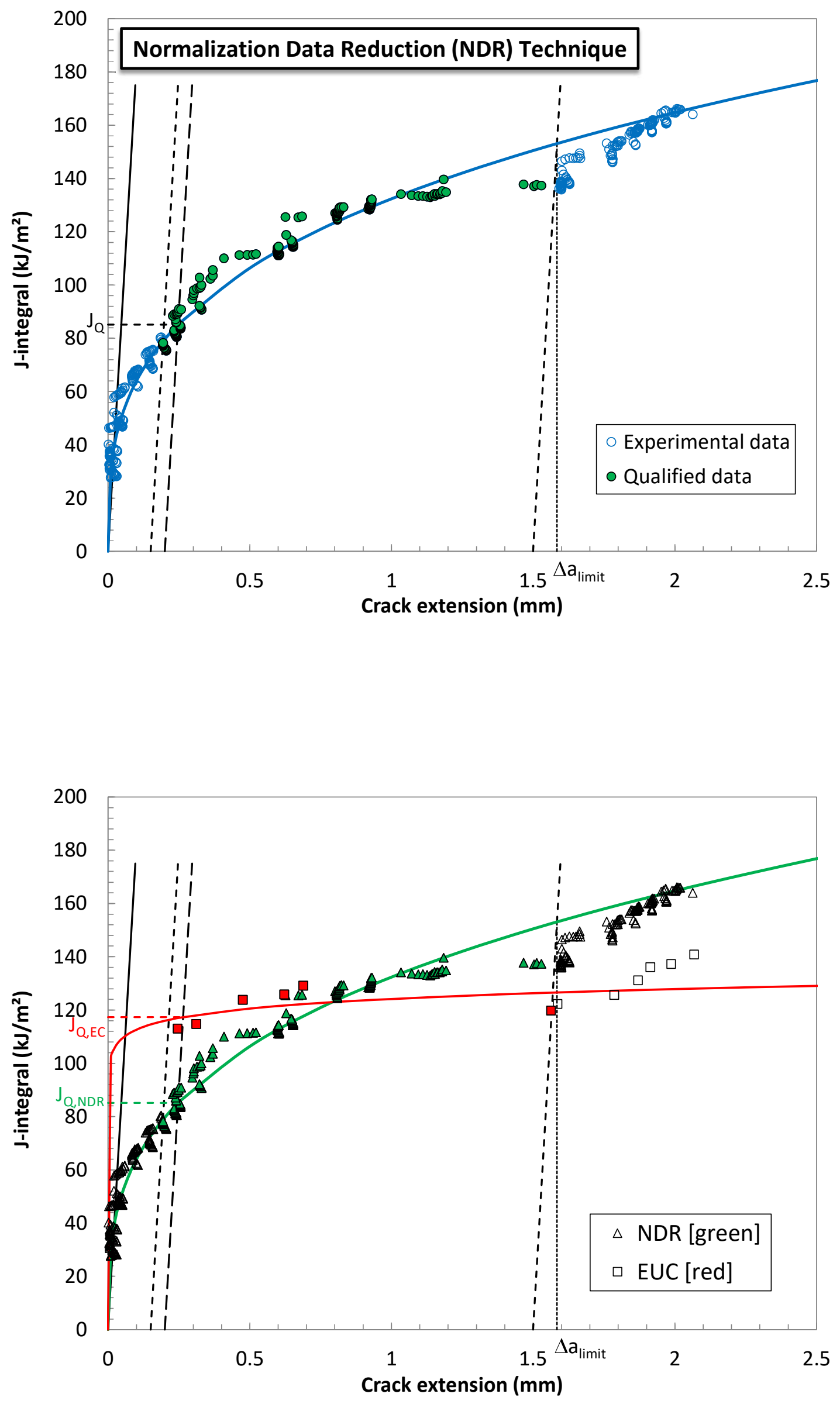

ANNEX 2

\section{As-built, supported}



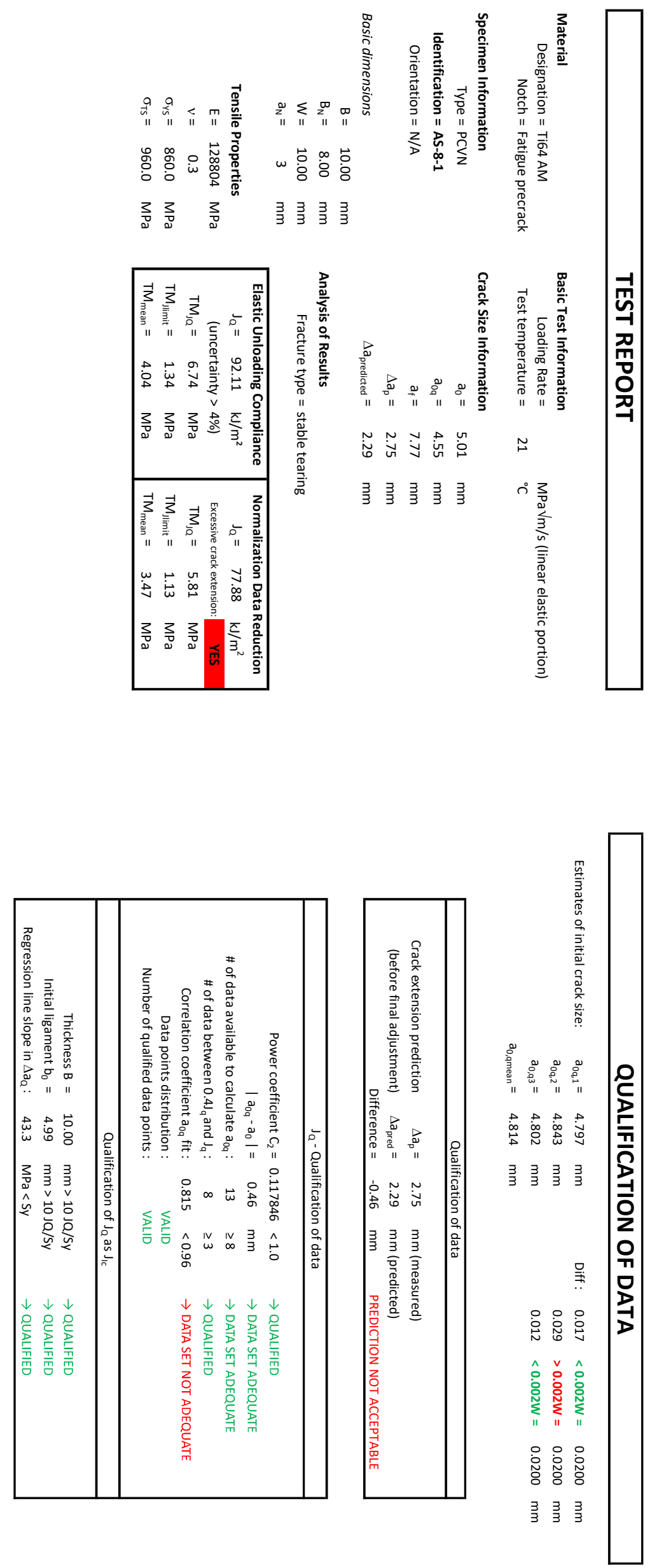

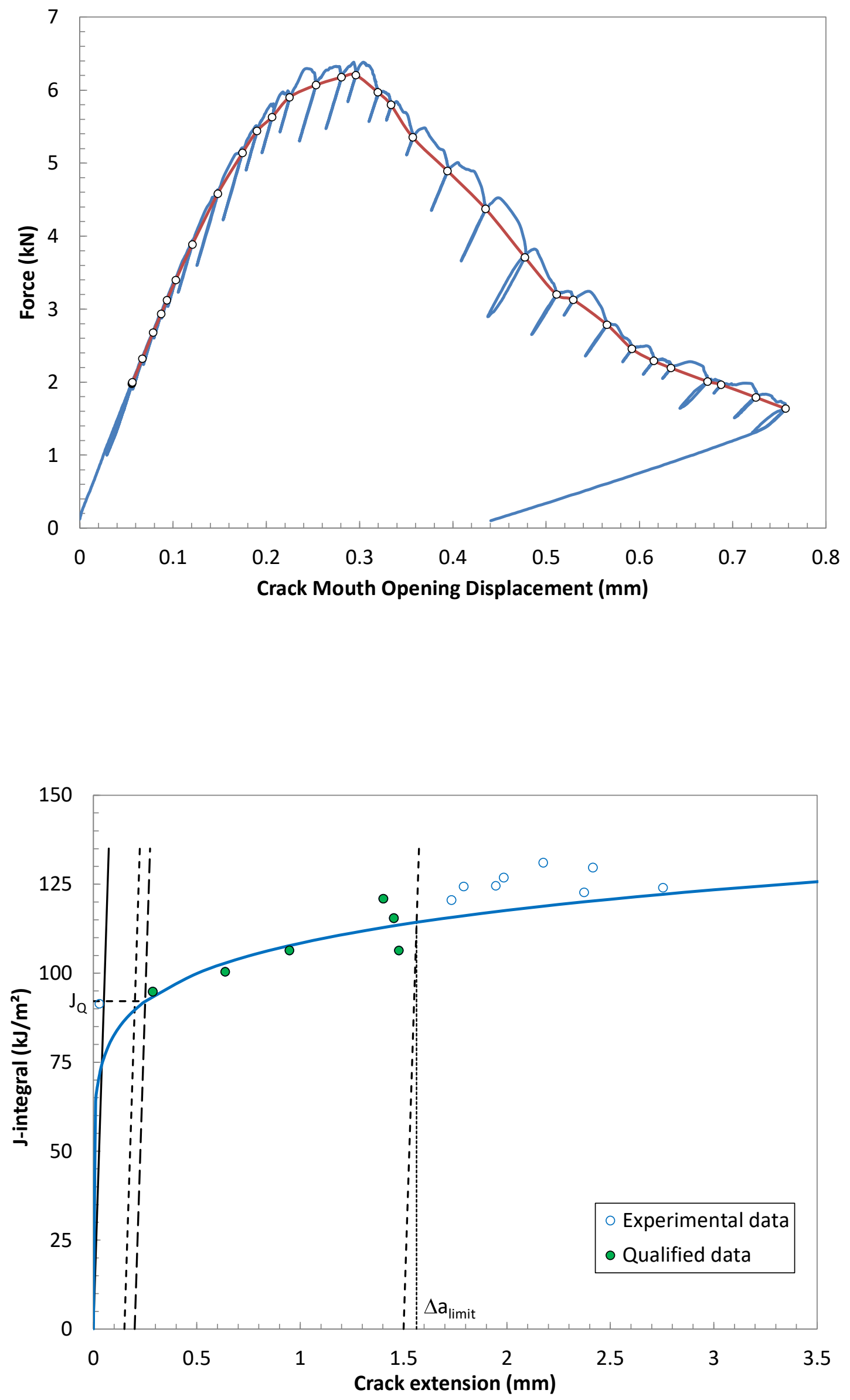

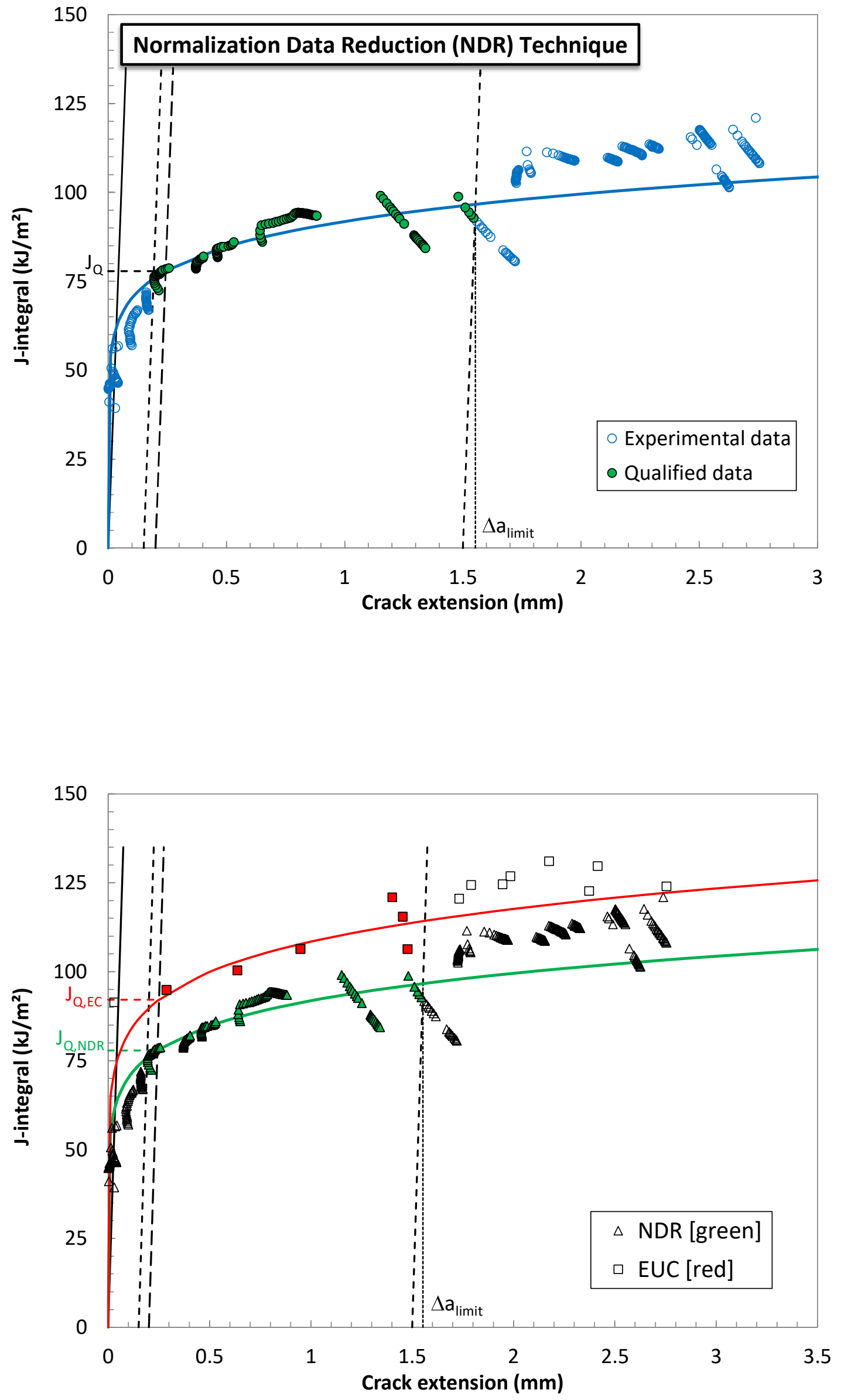

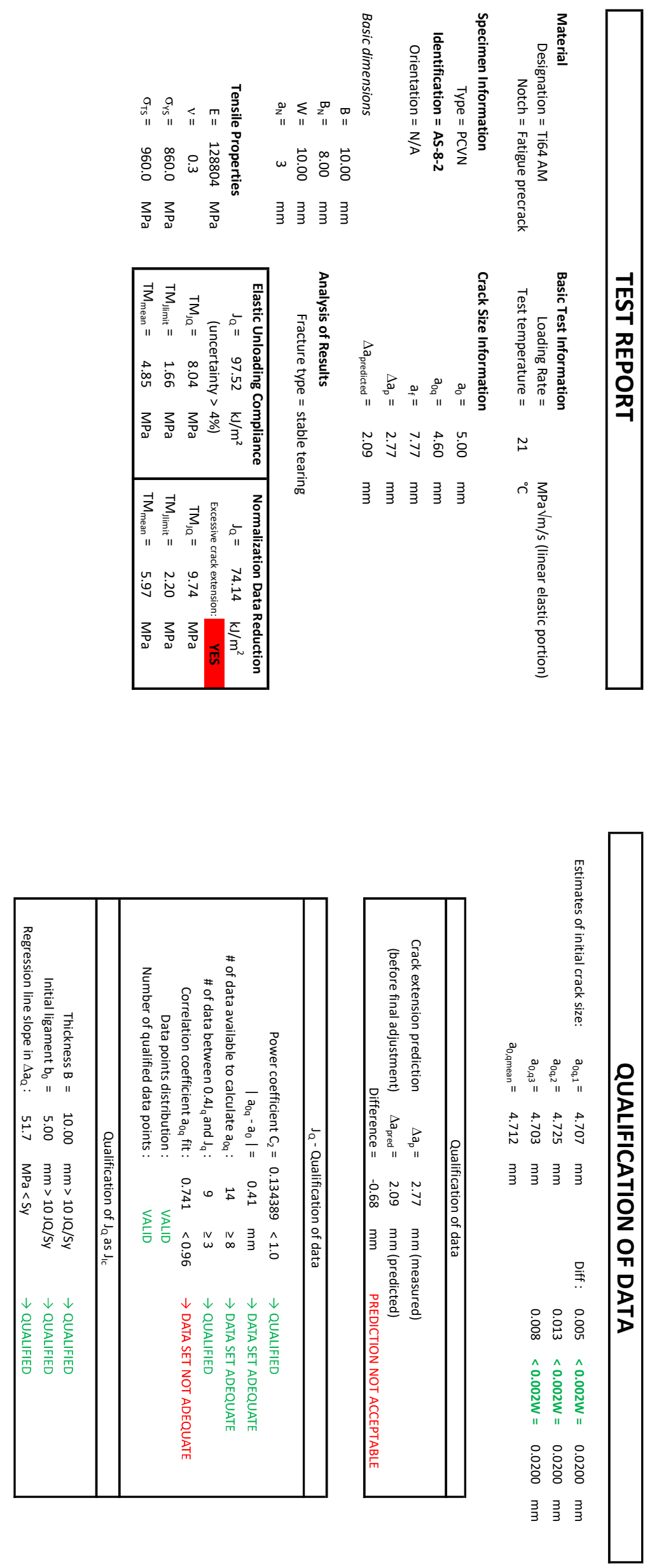

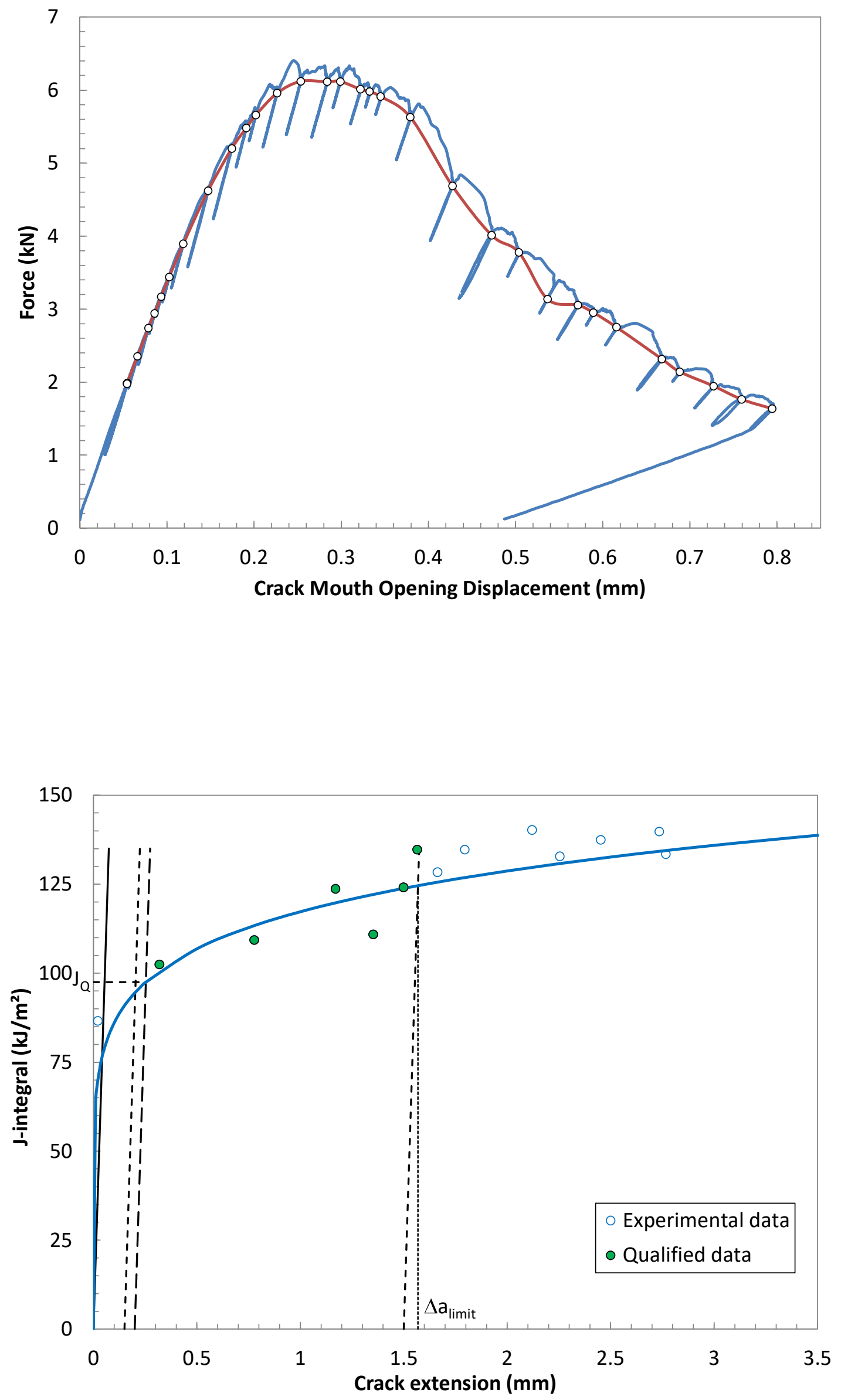

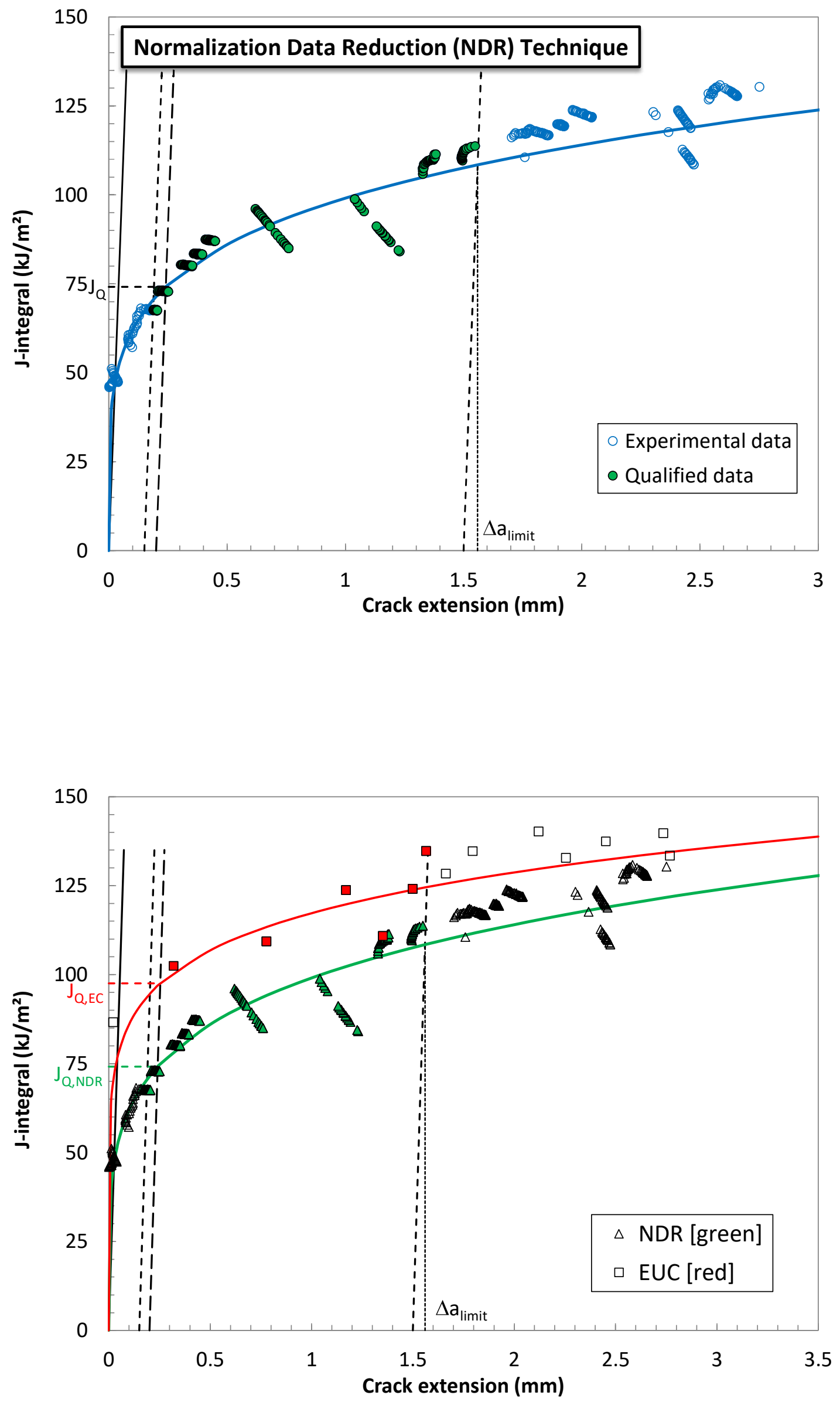

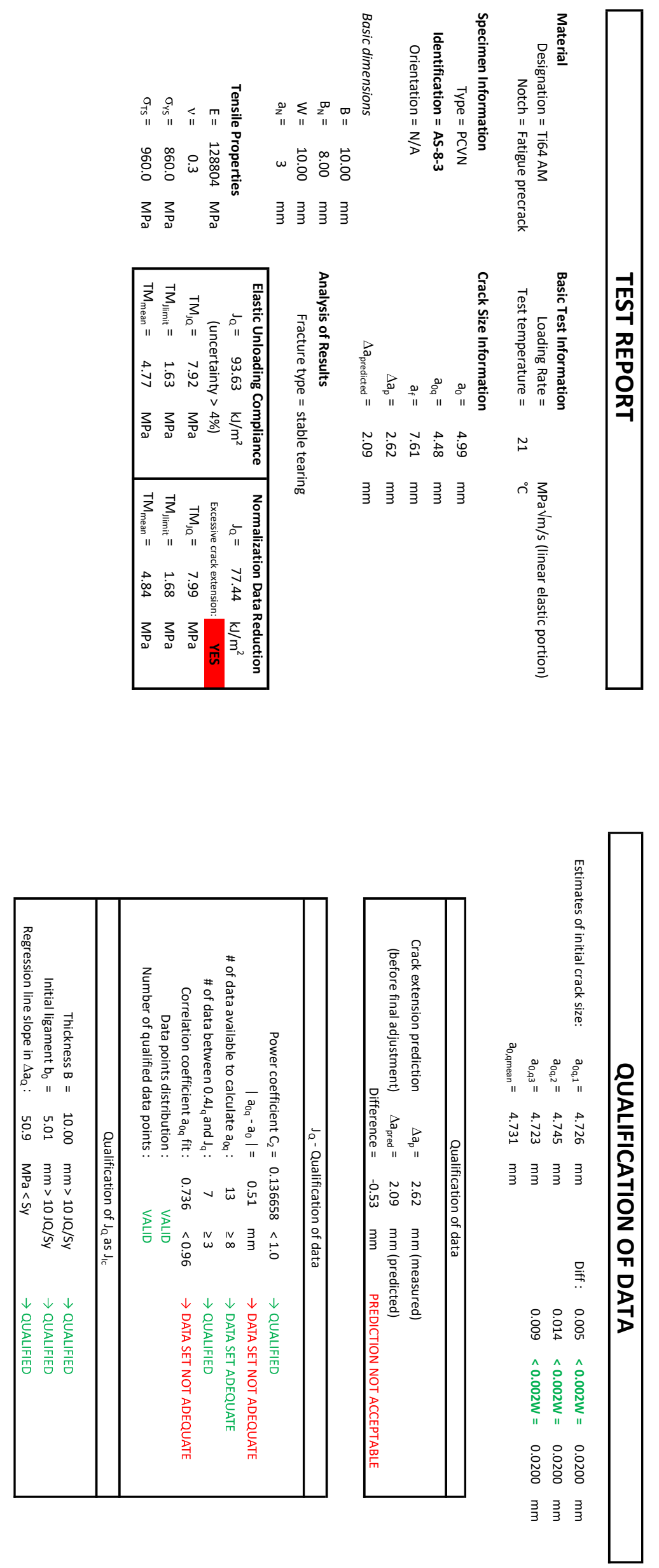

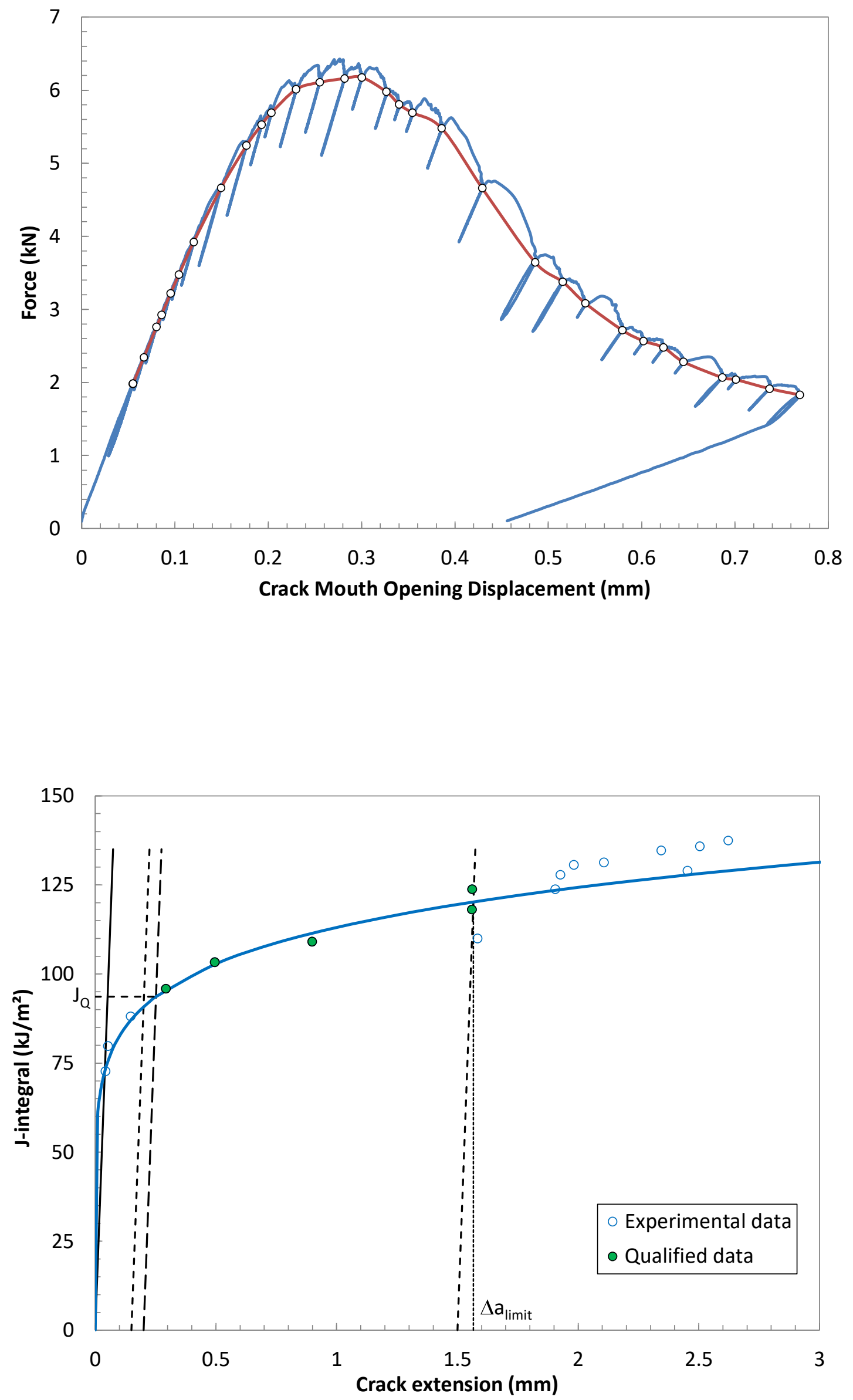

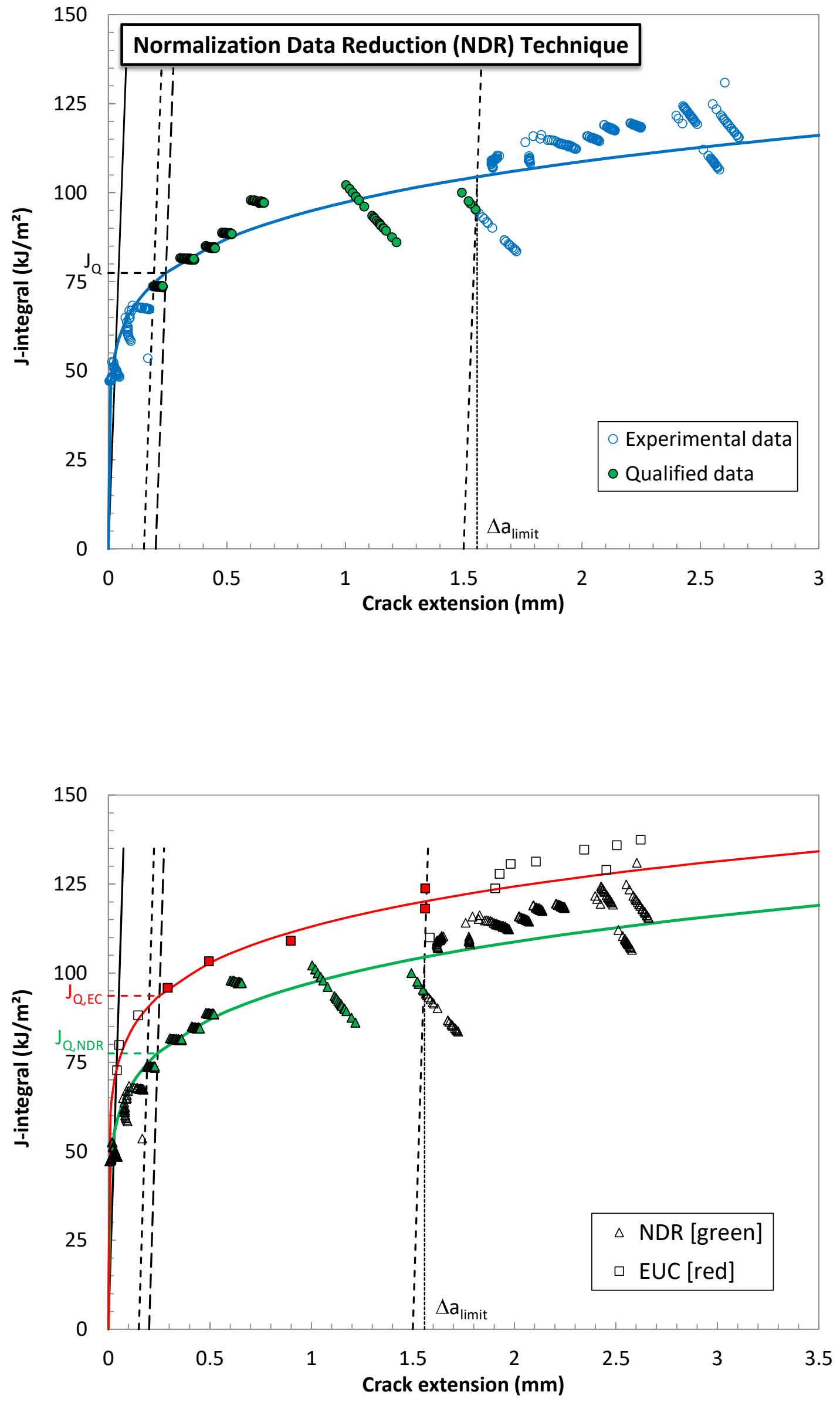

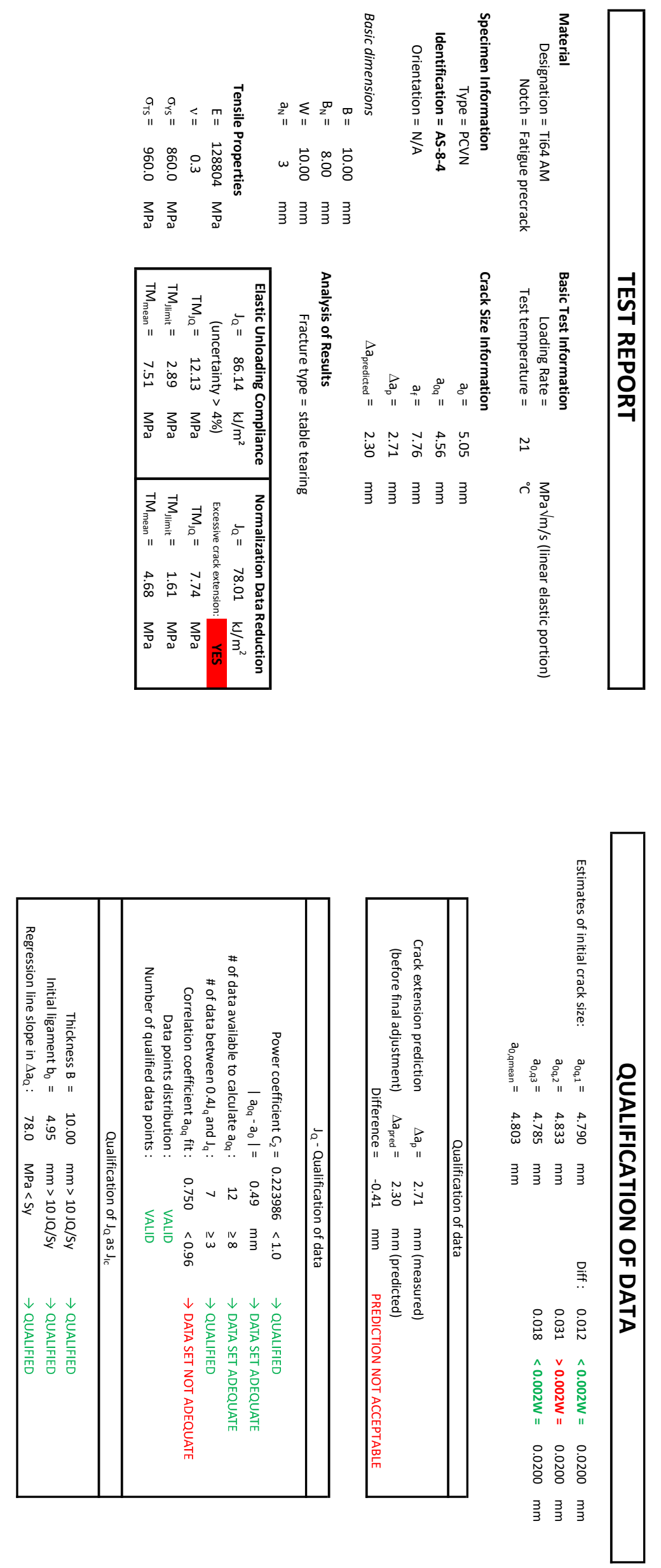

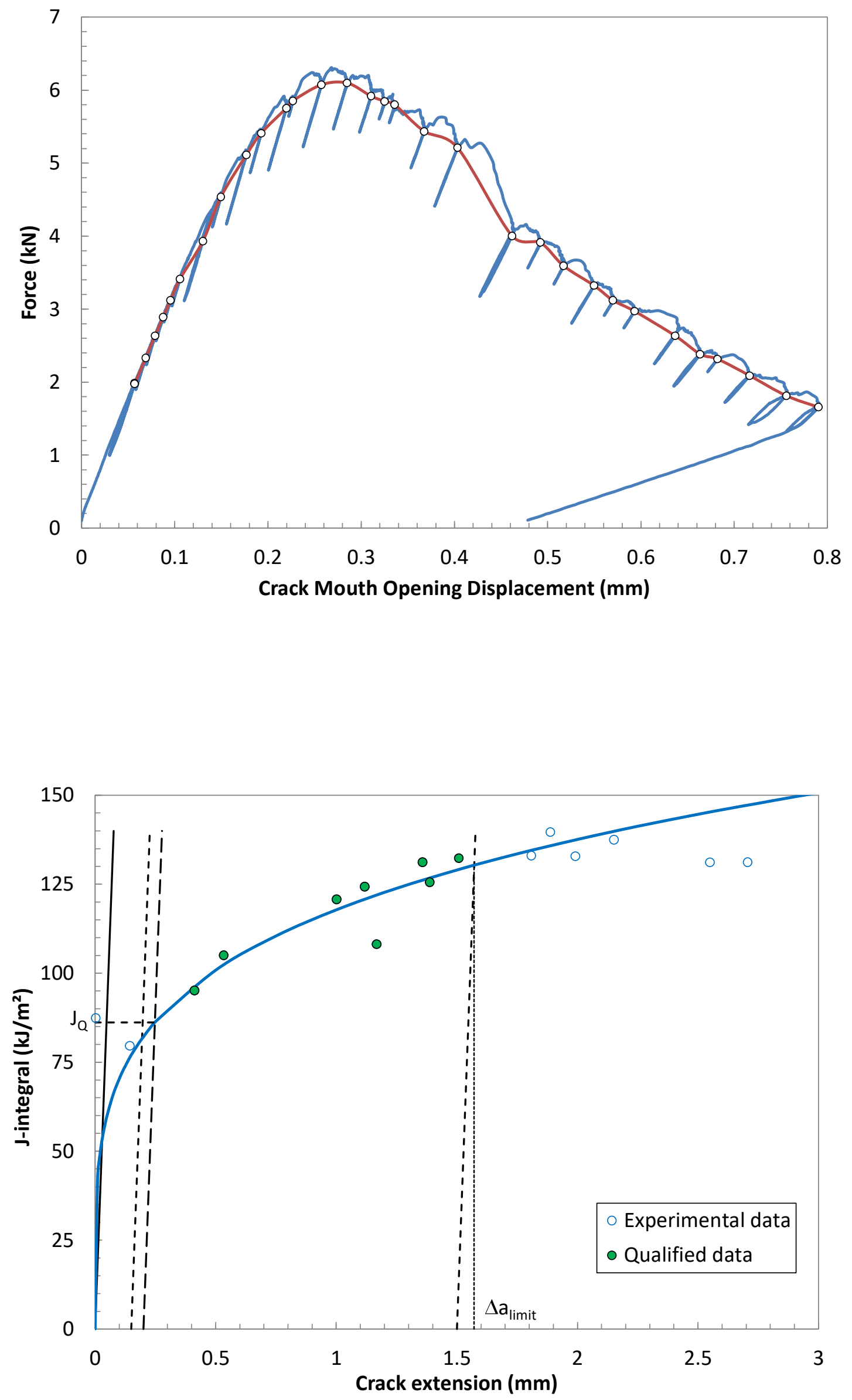

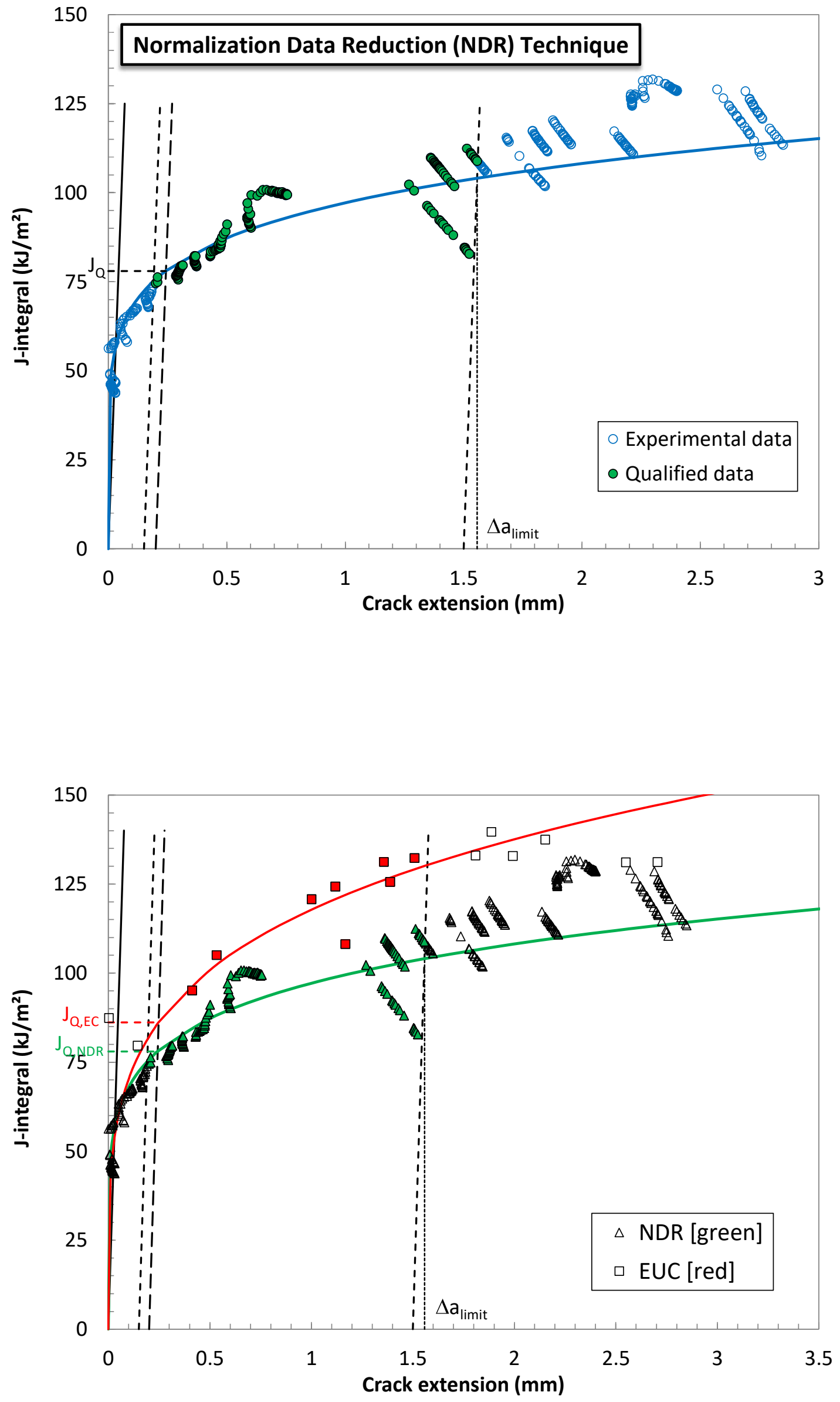

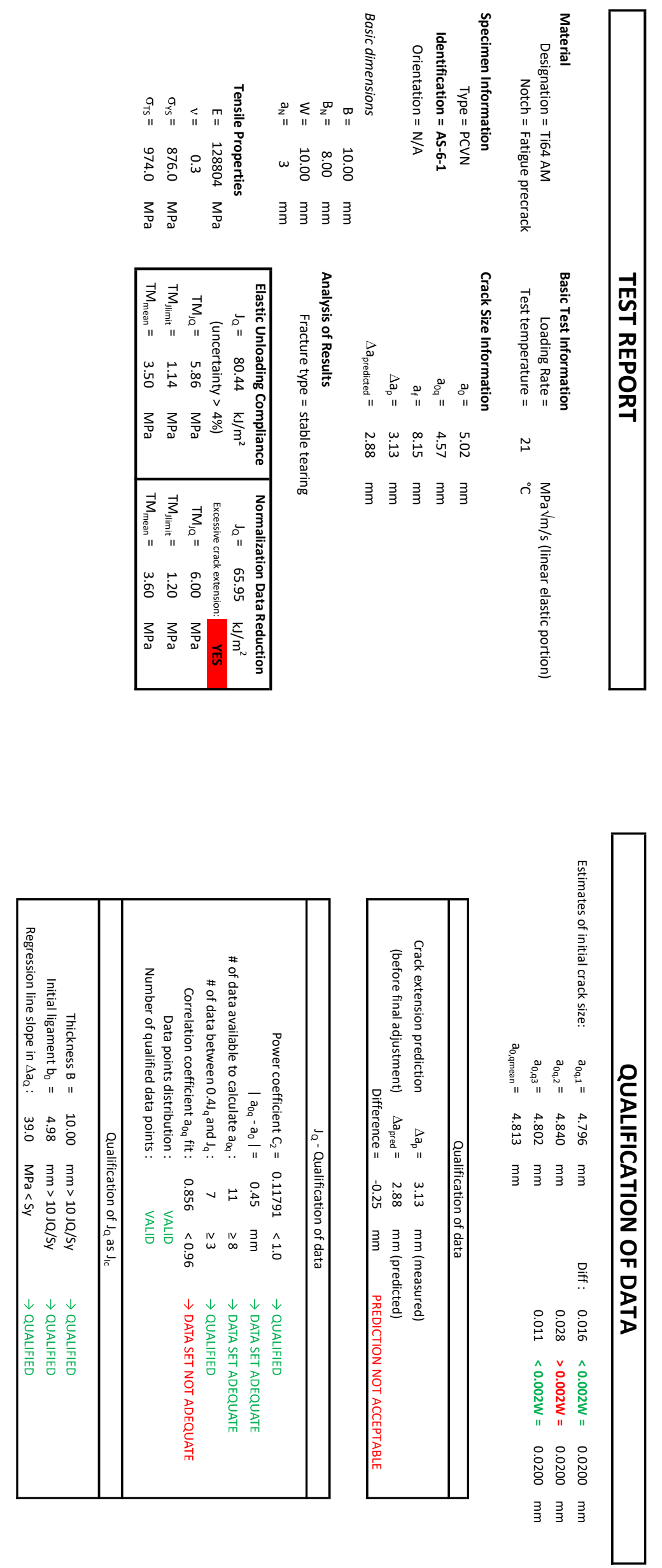

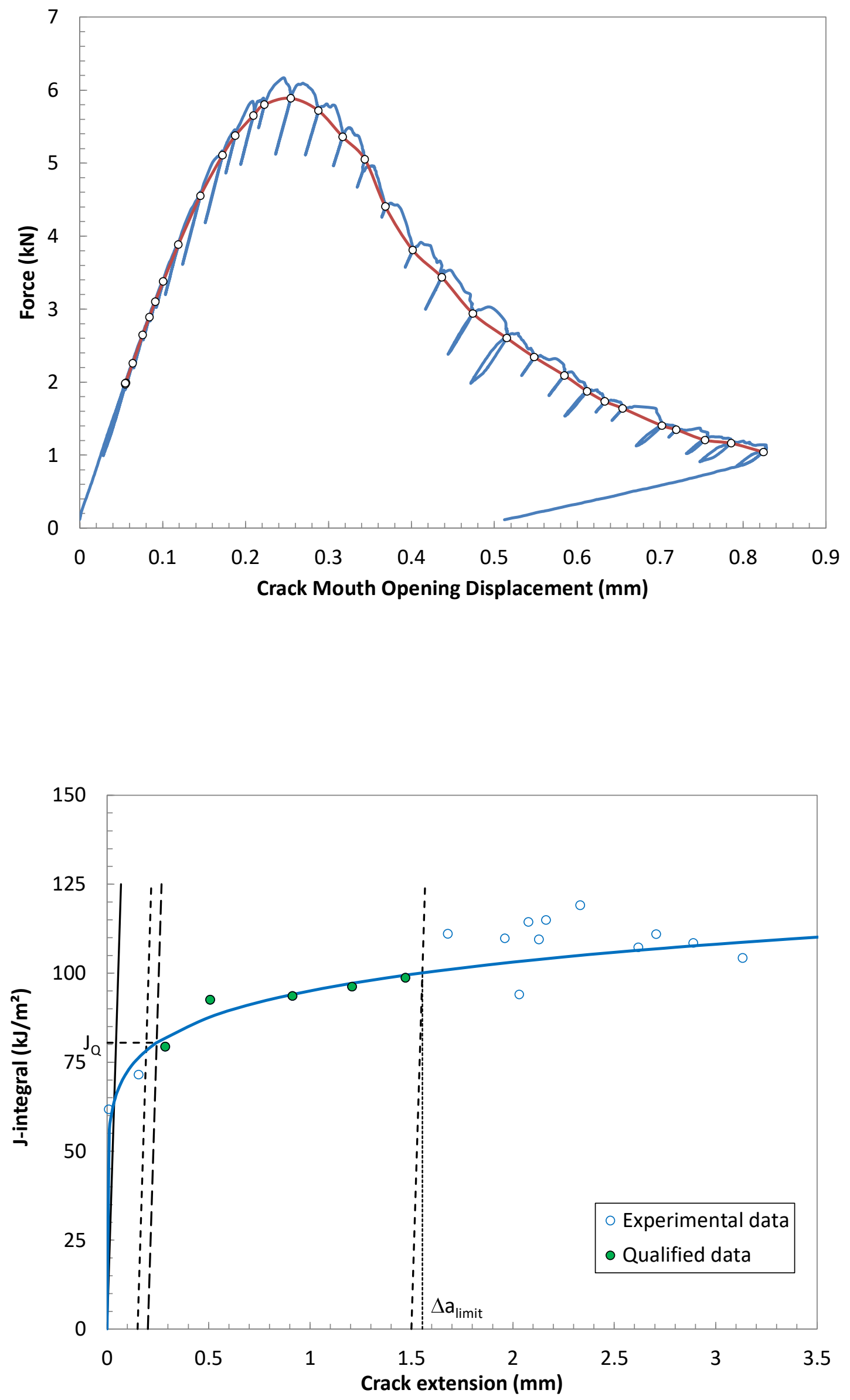

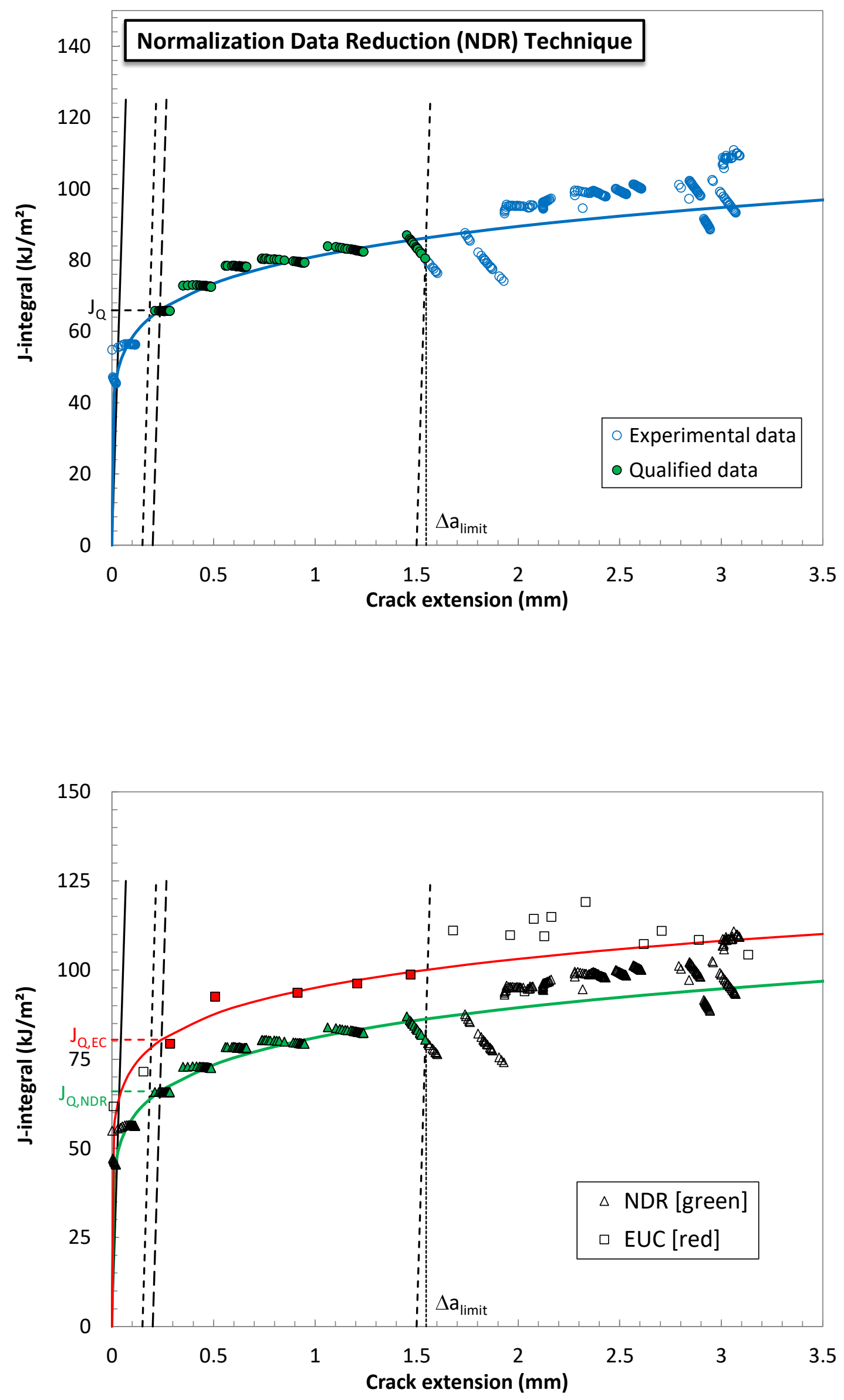

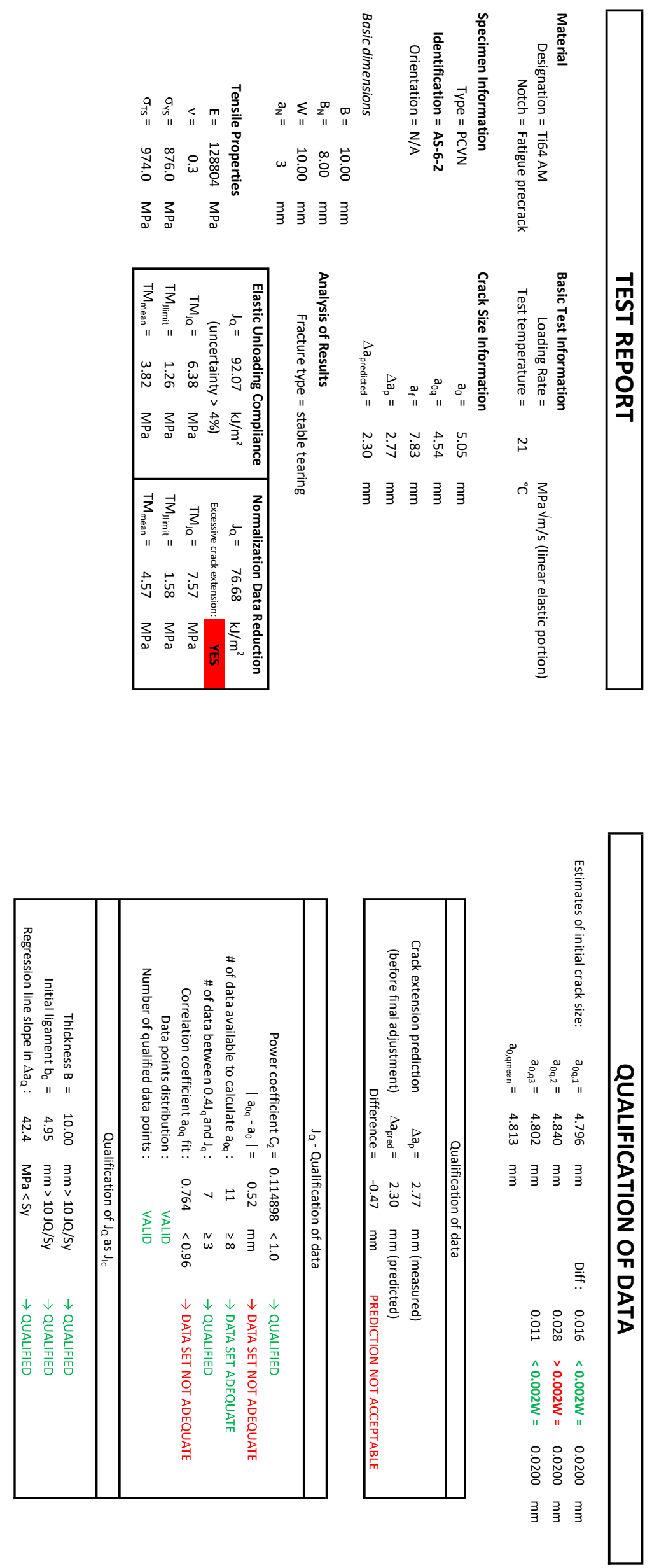

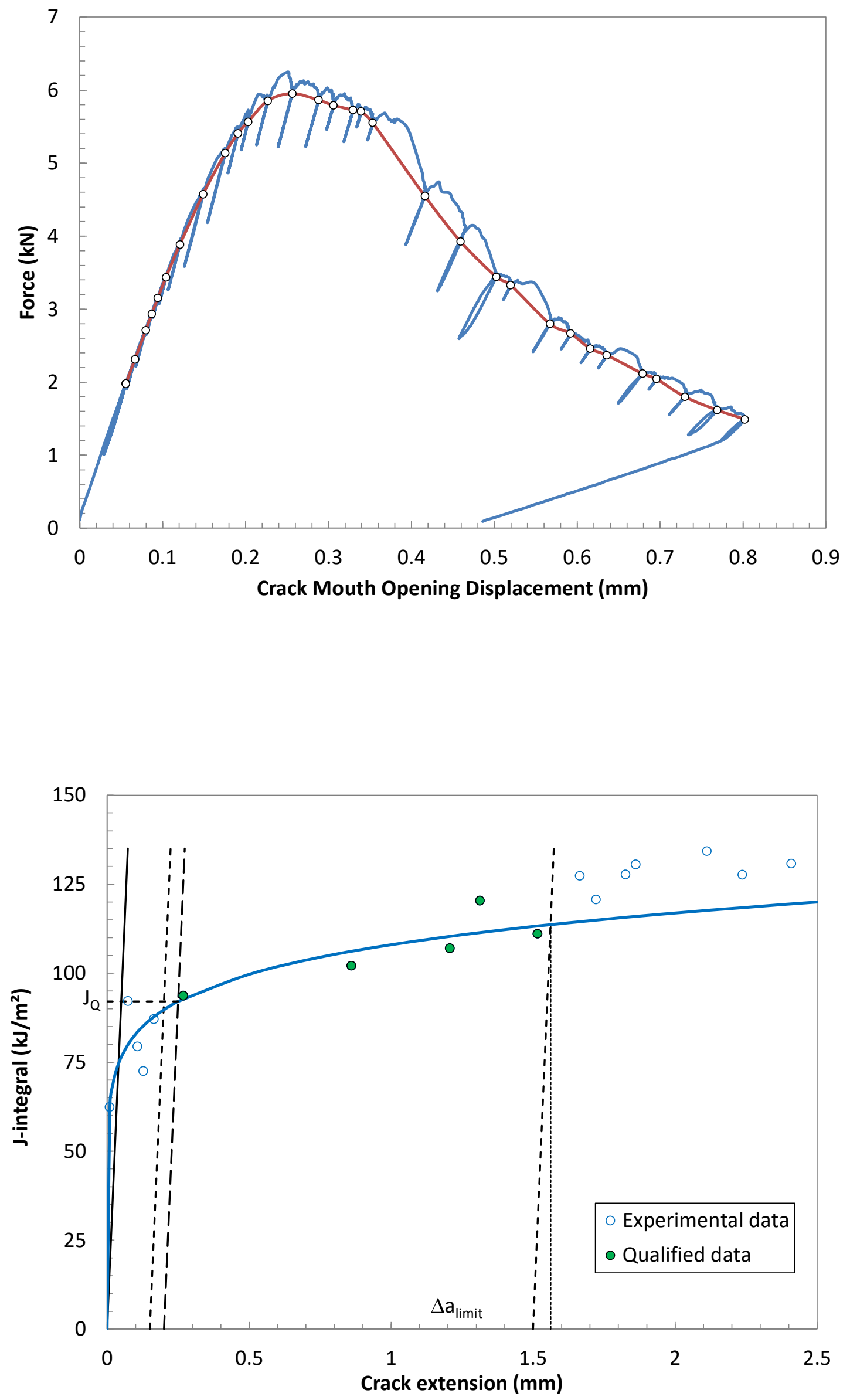

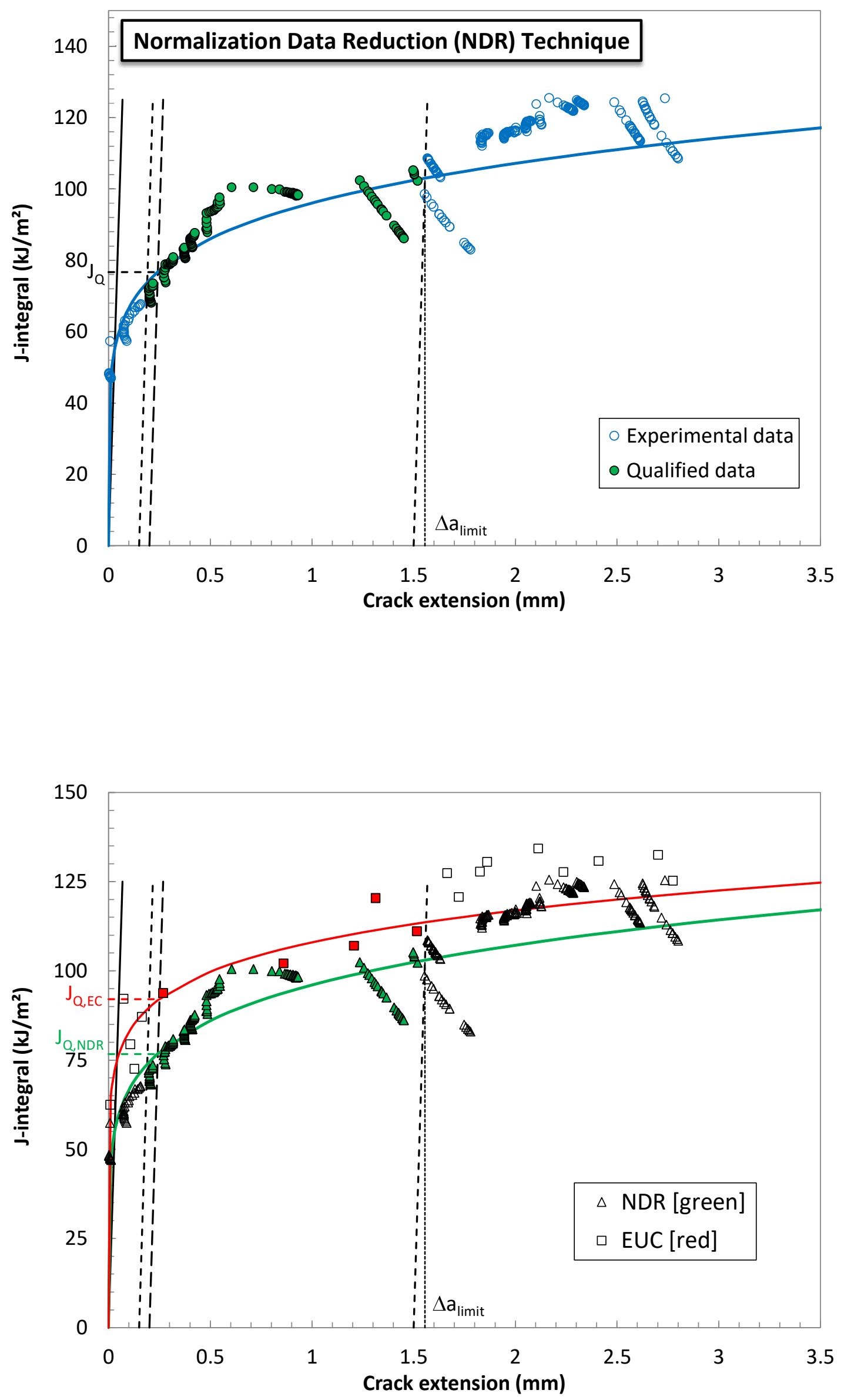

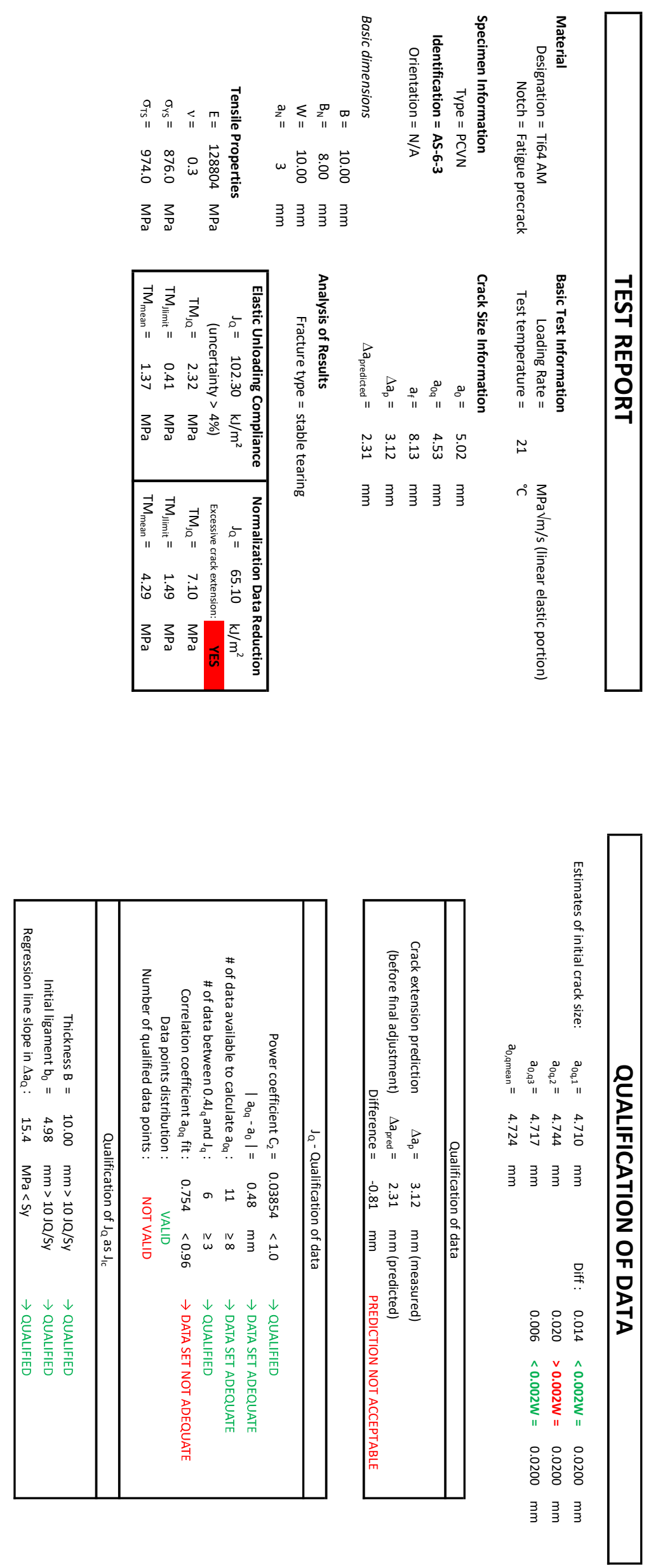

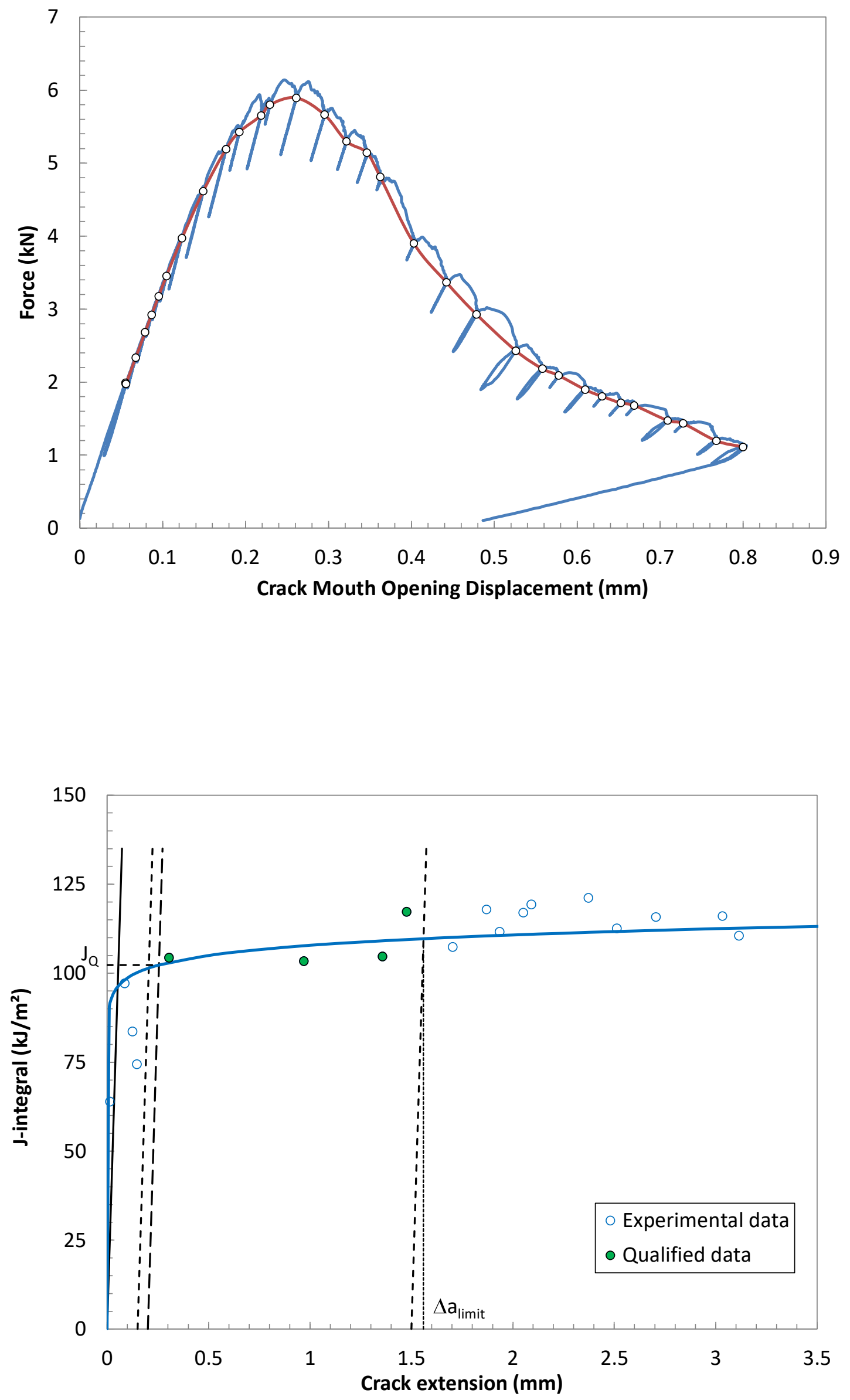

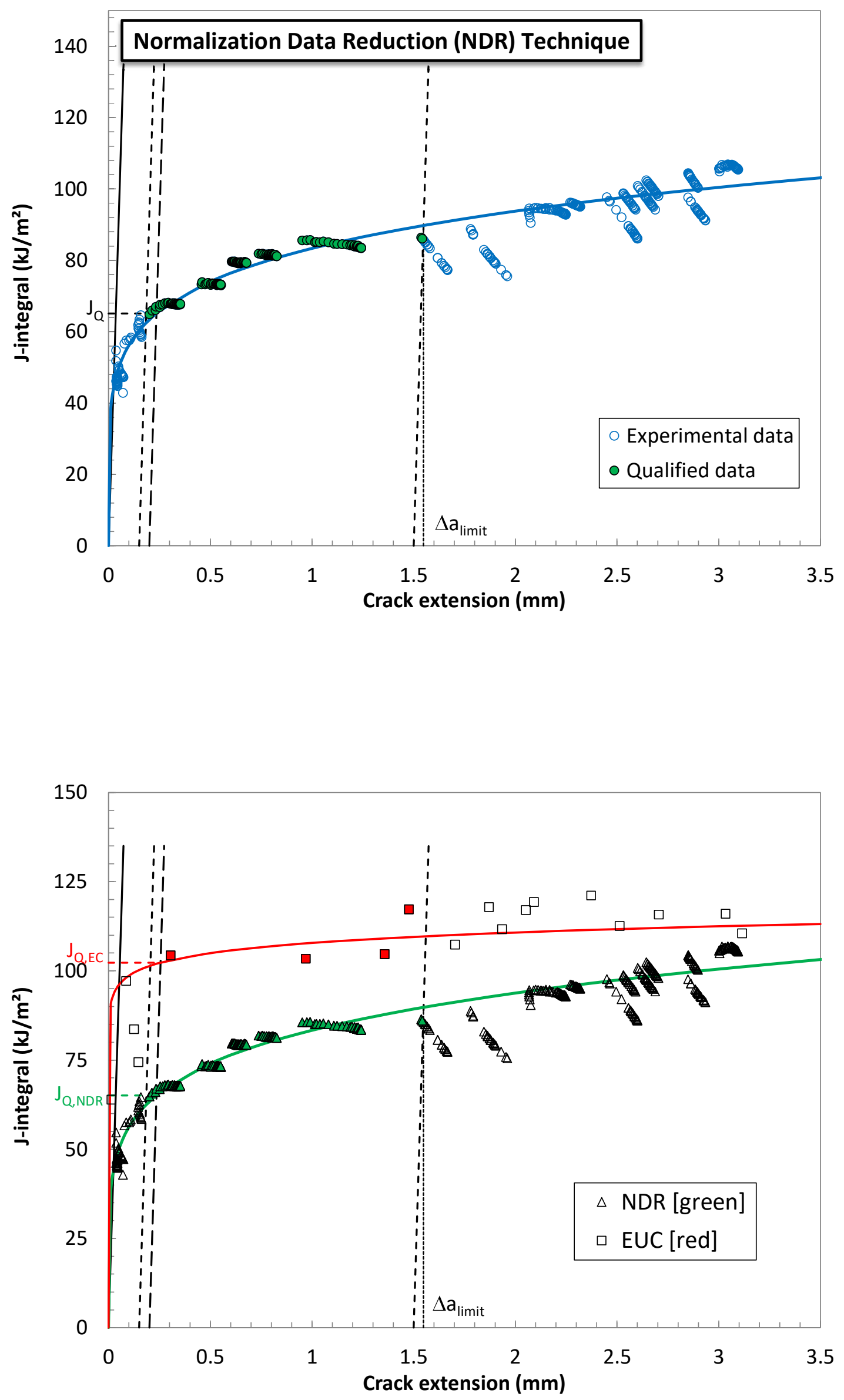

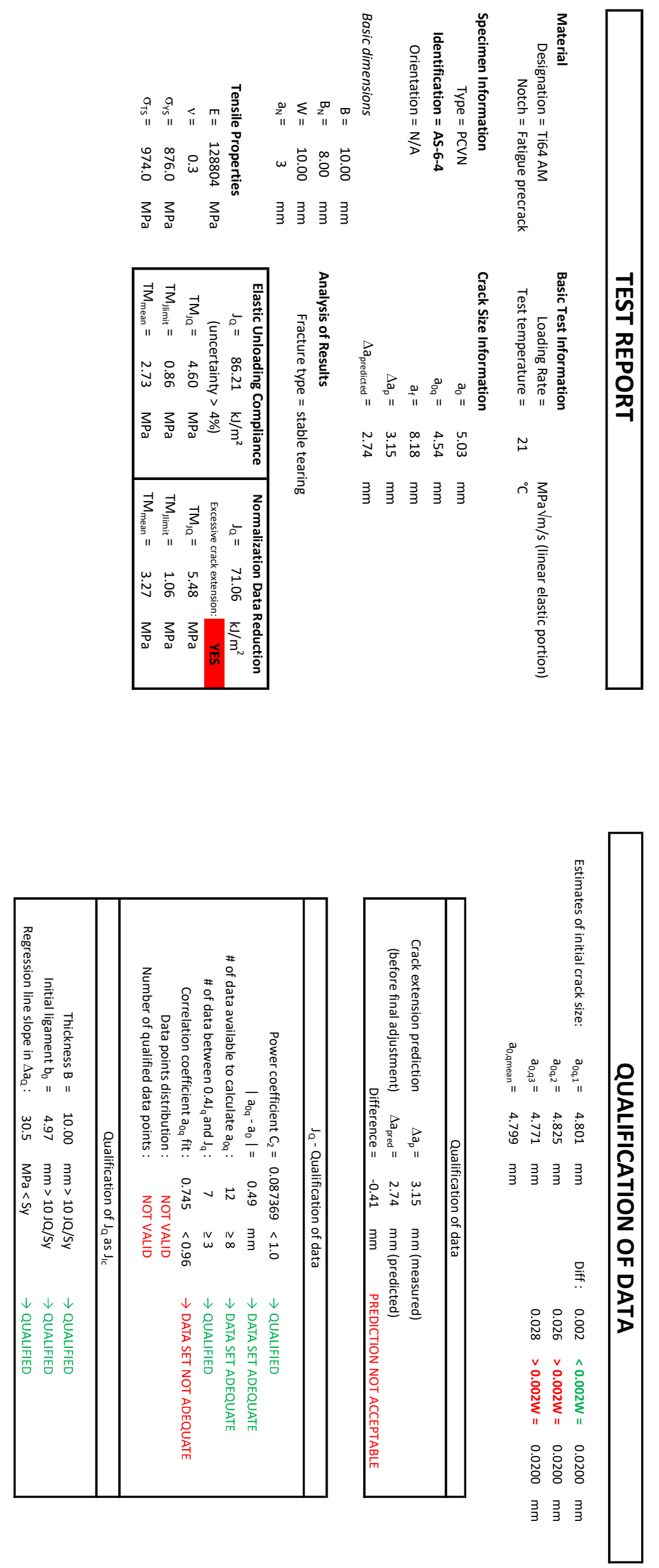

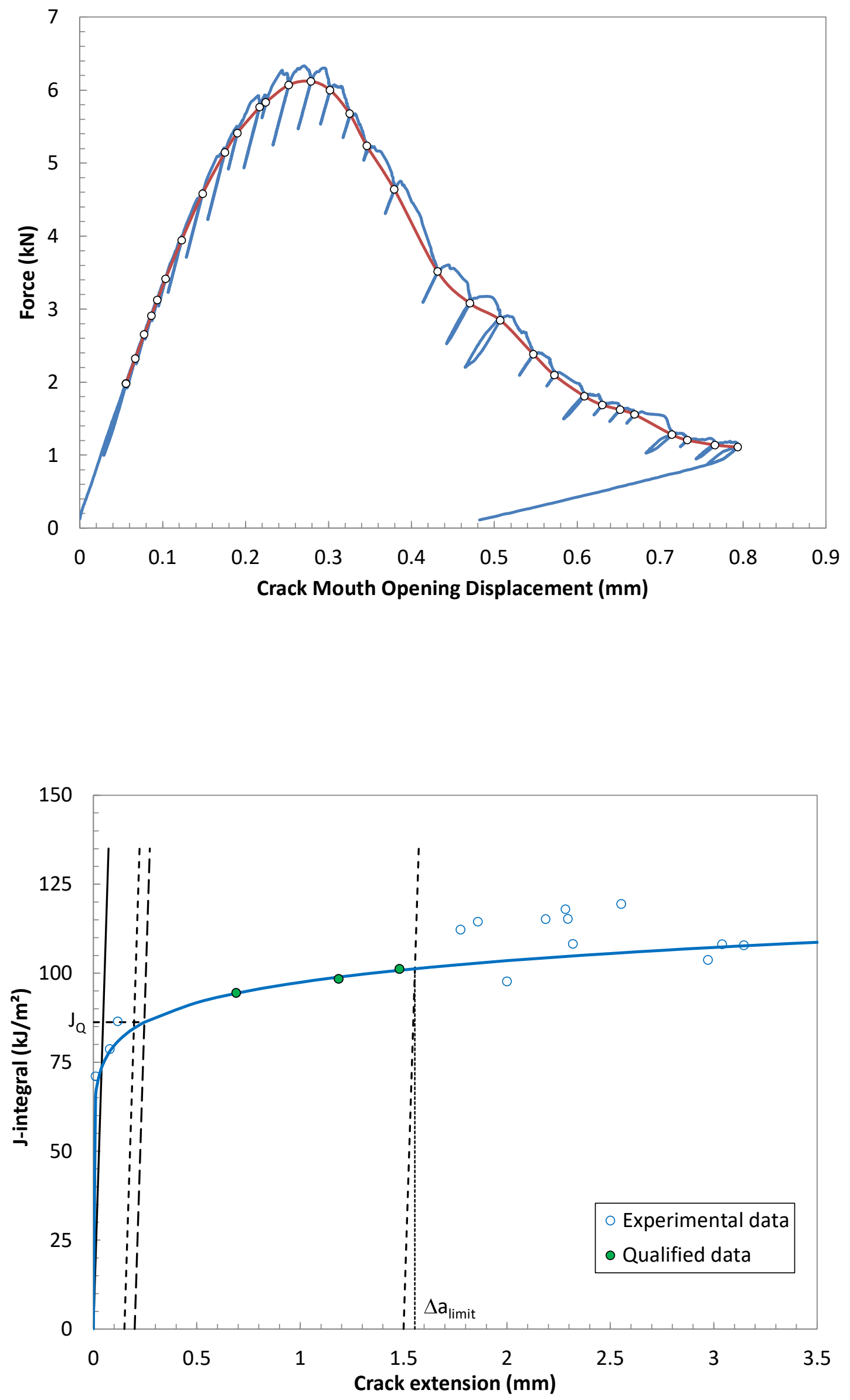

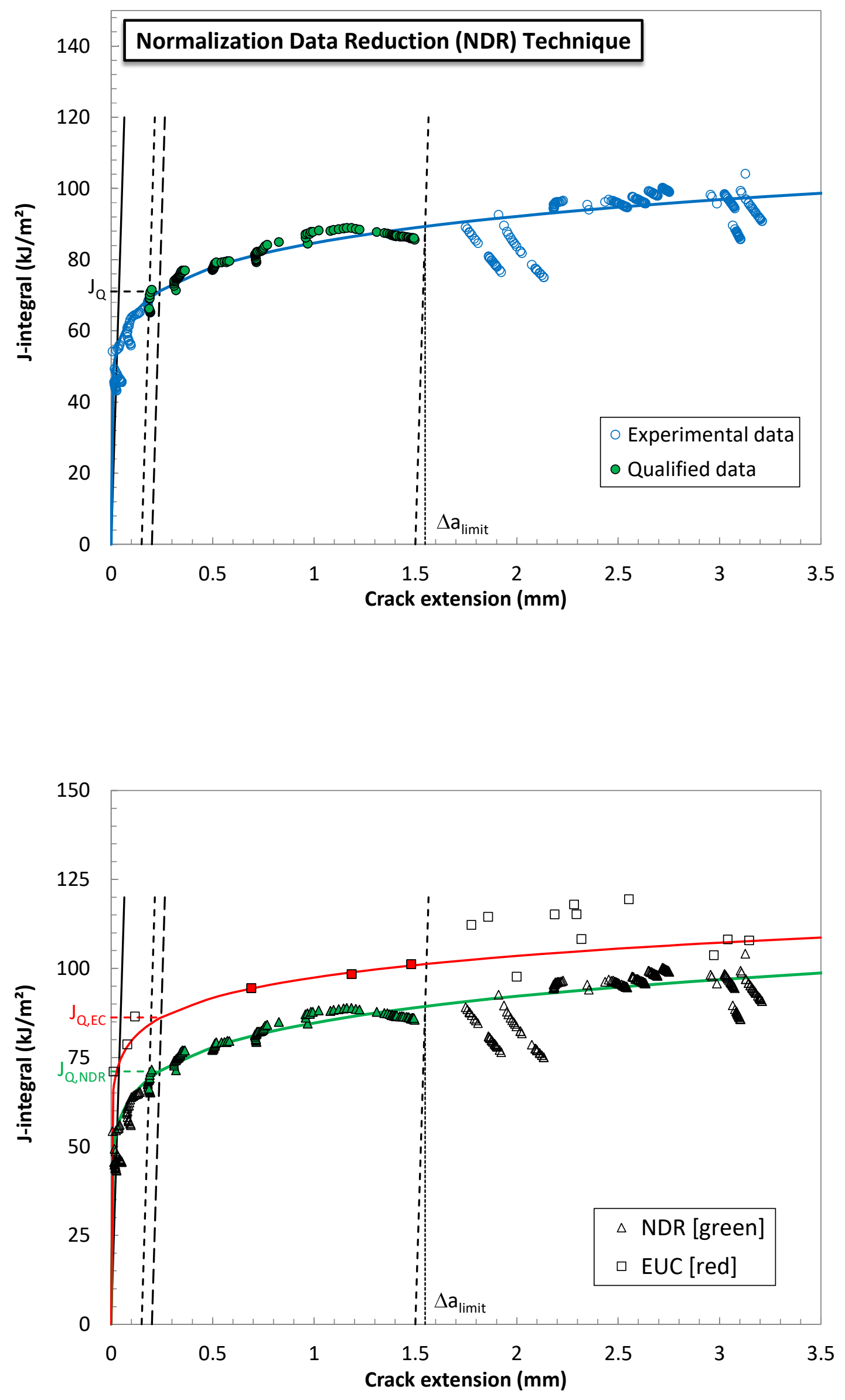

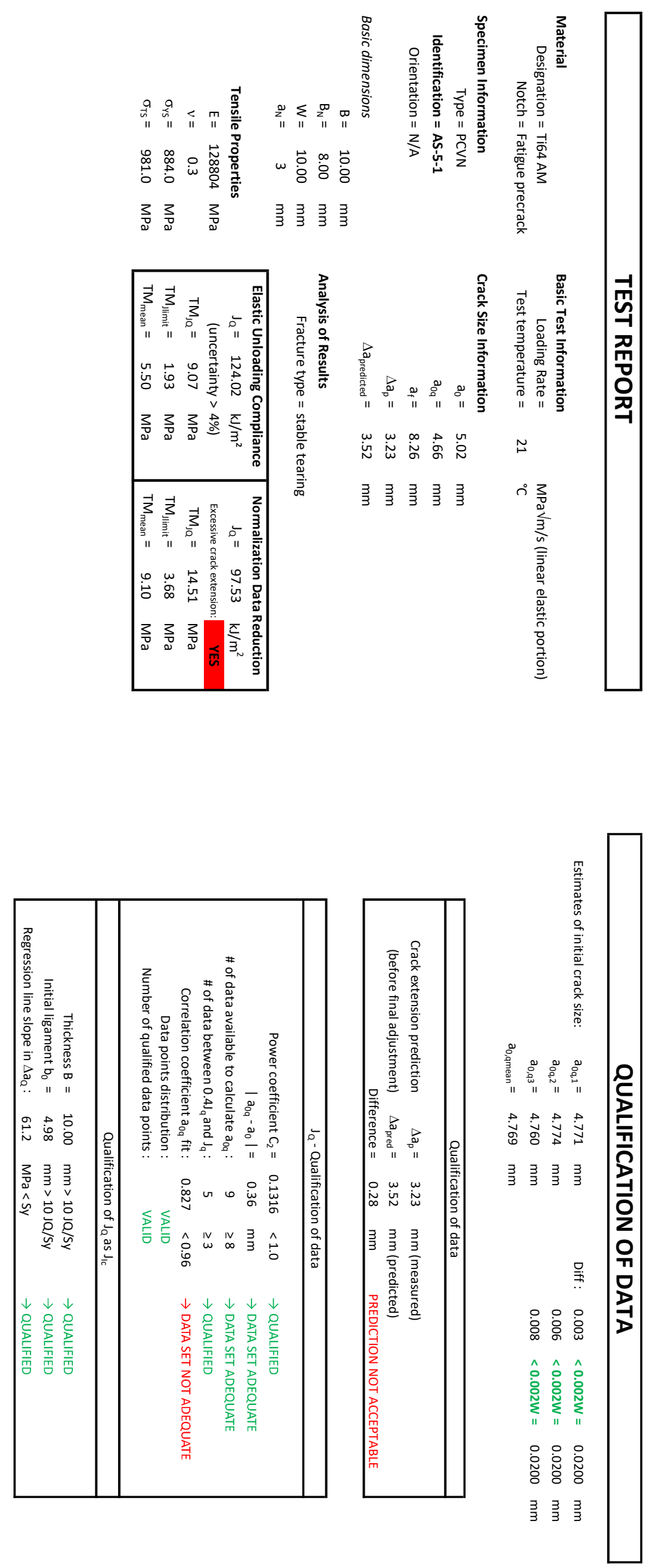

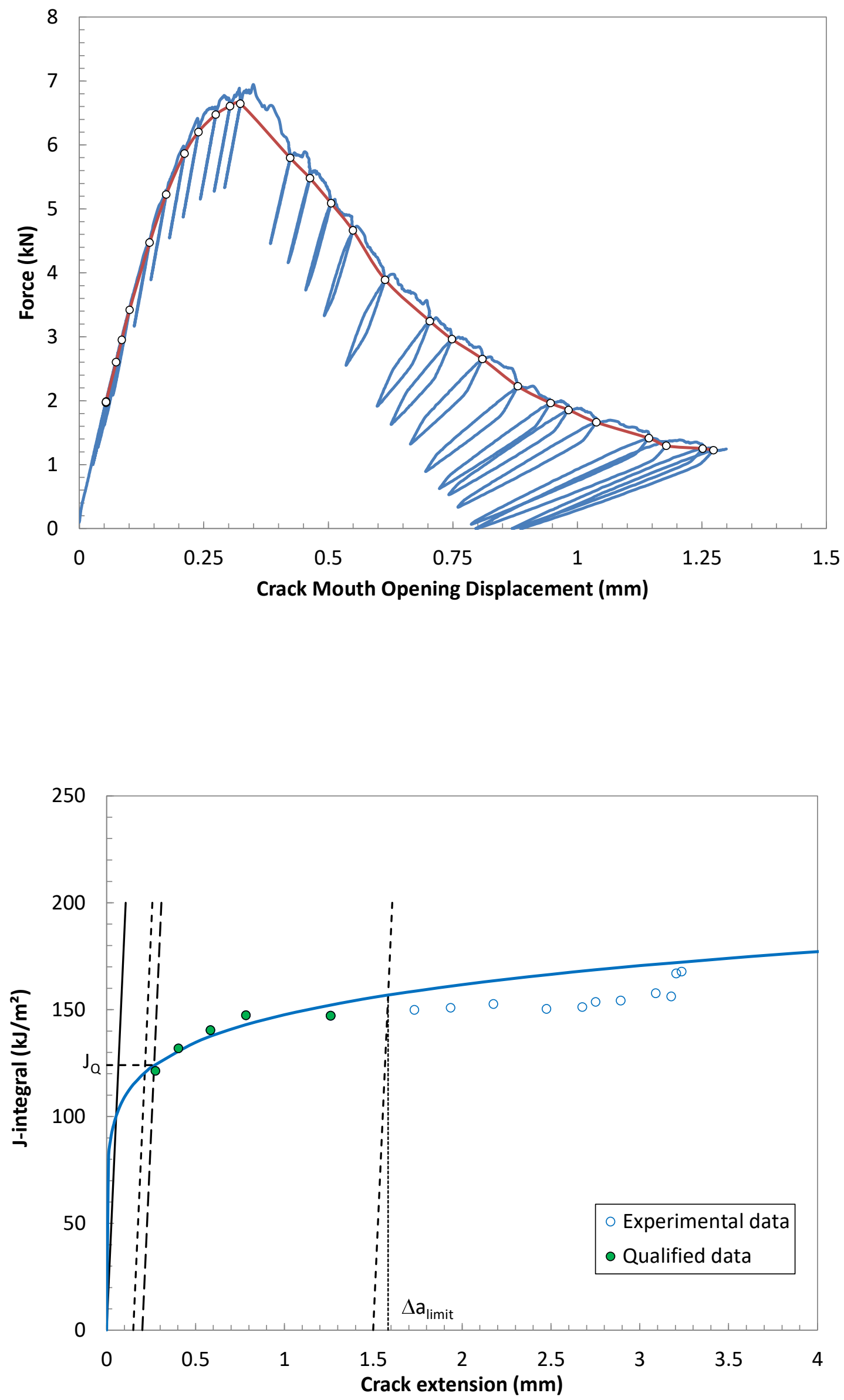

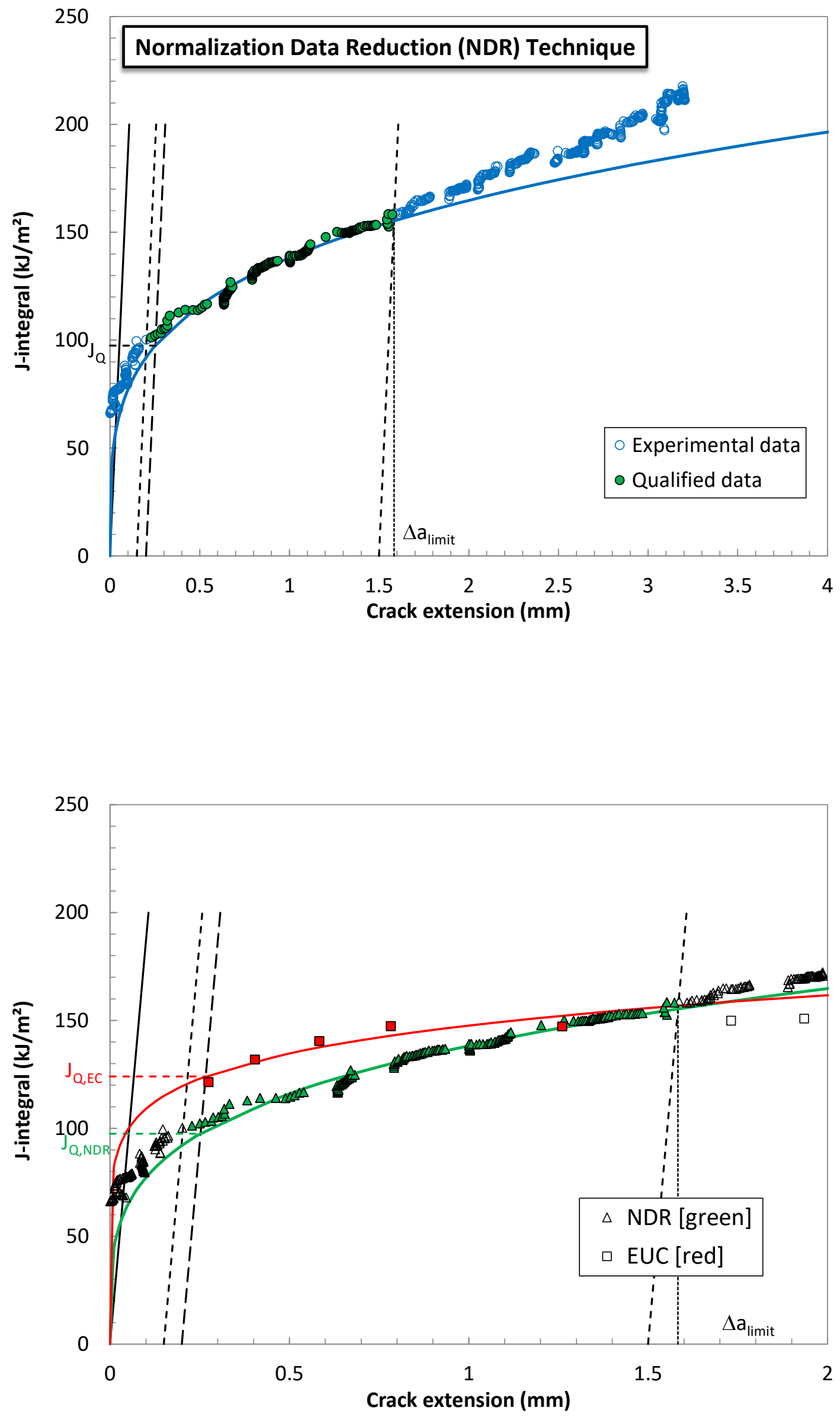

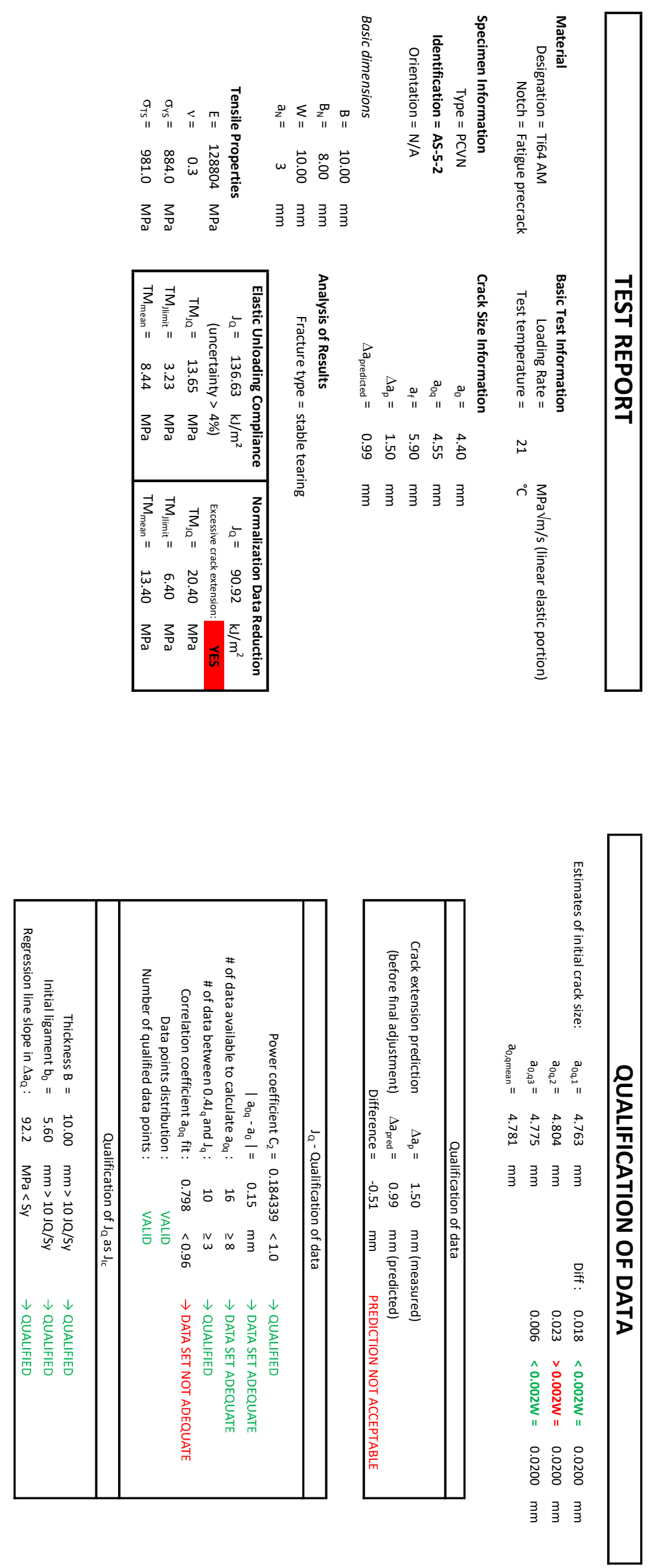

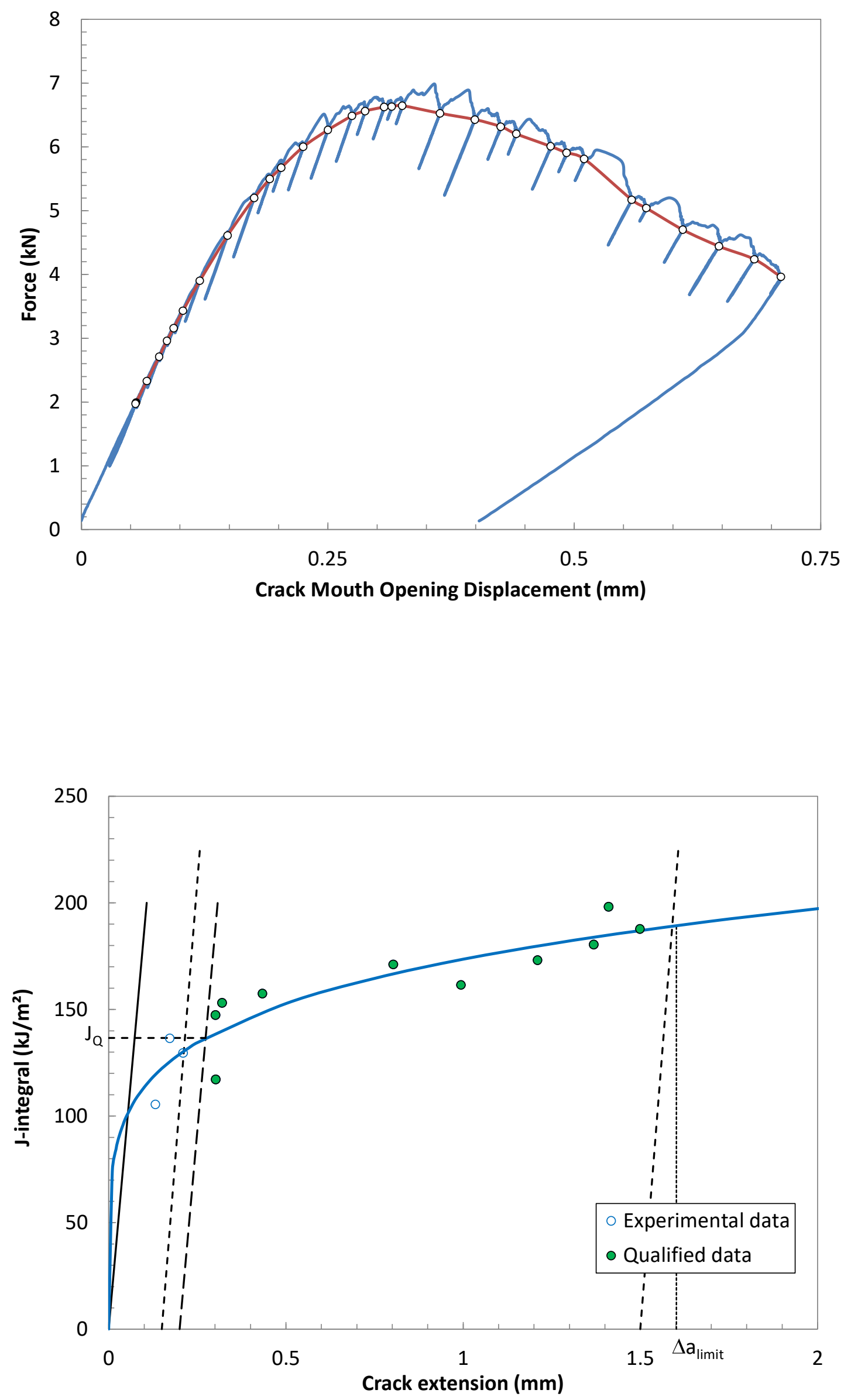

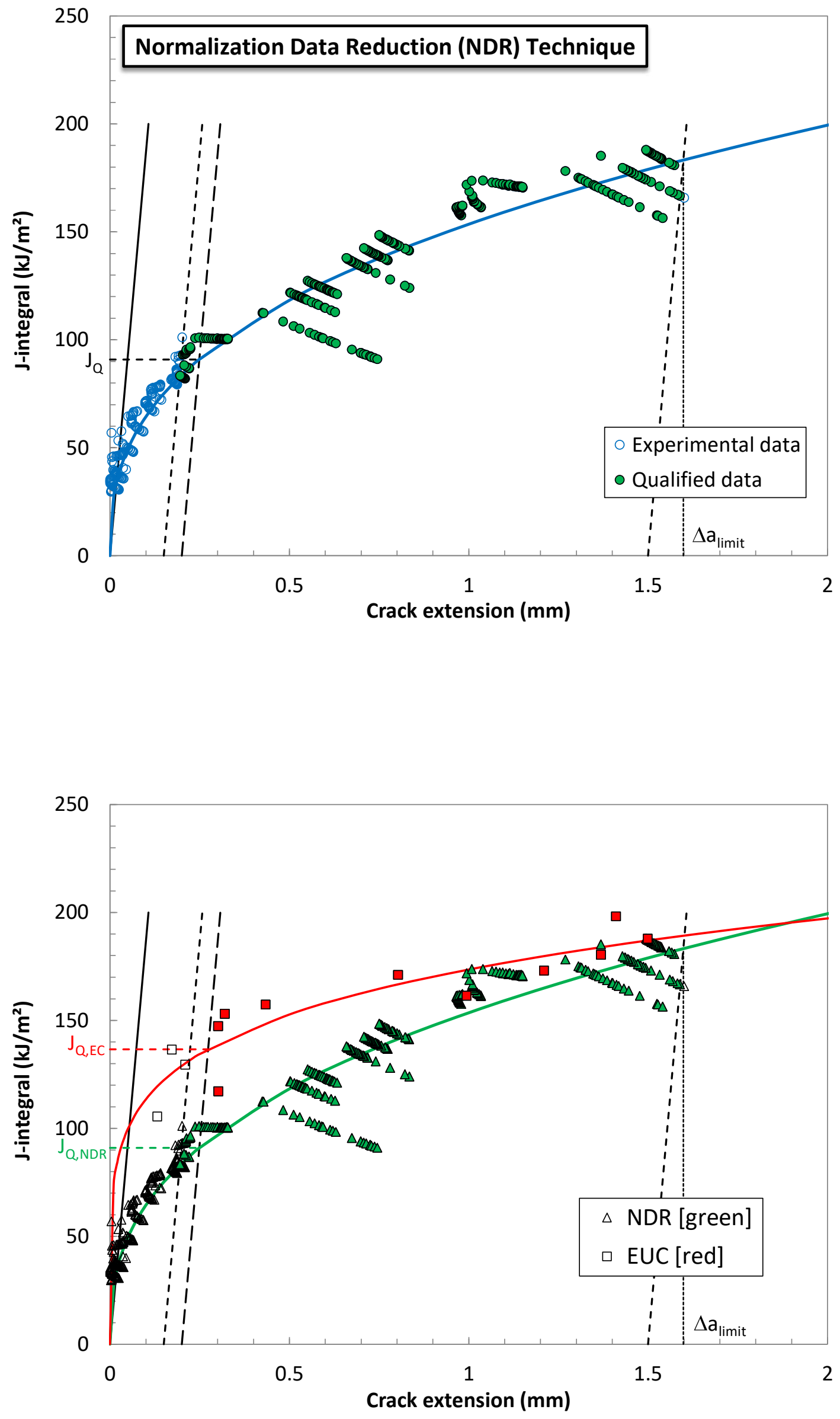

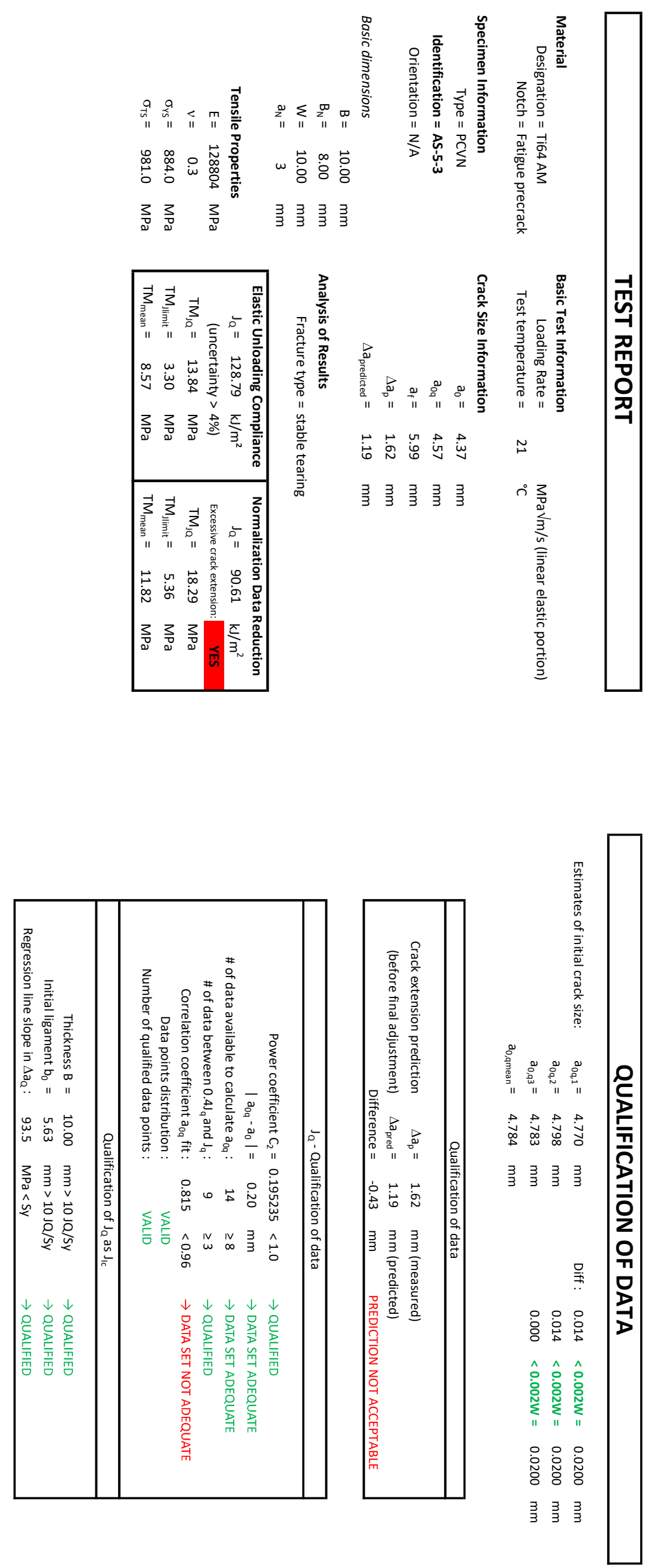

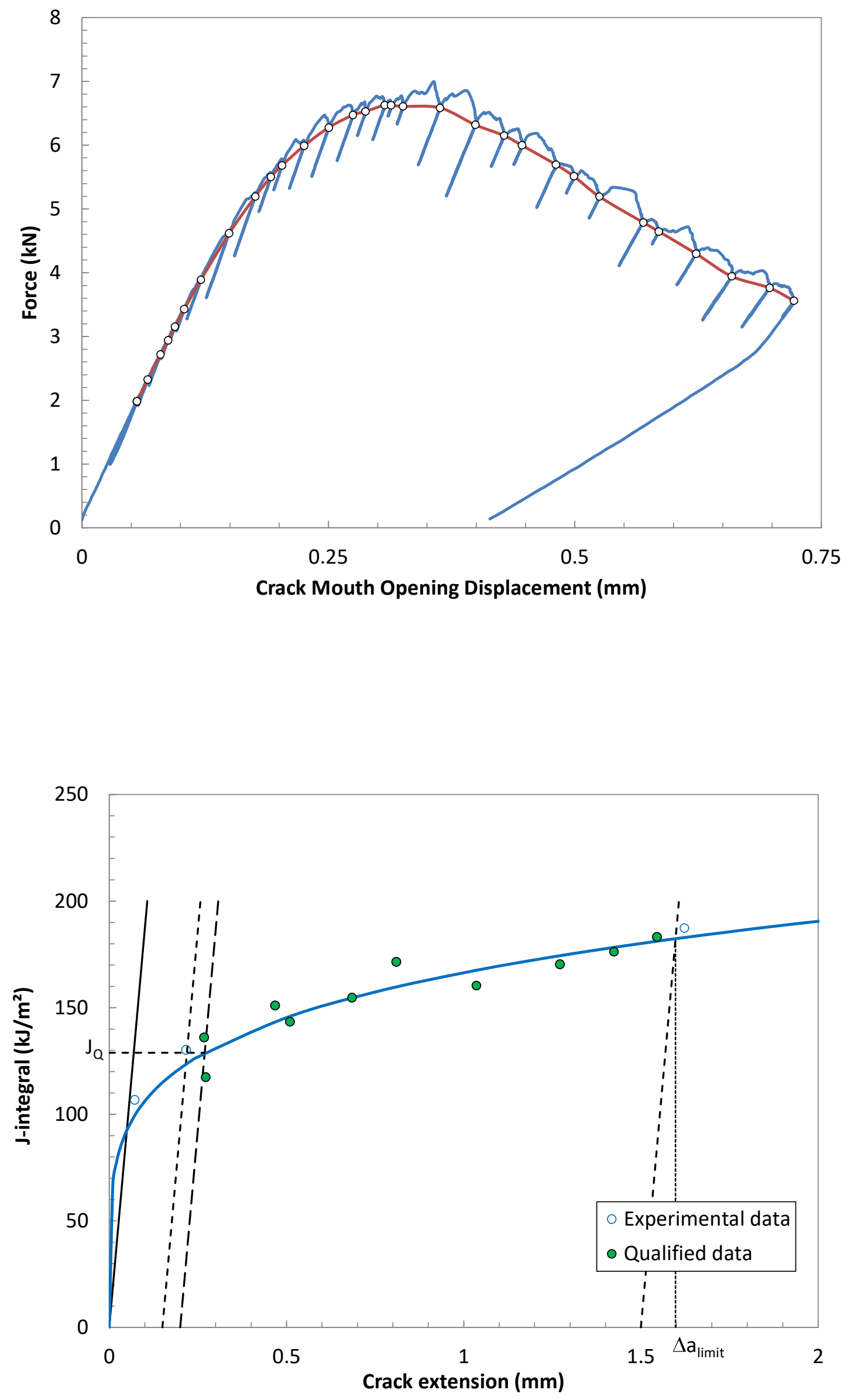

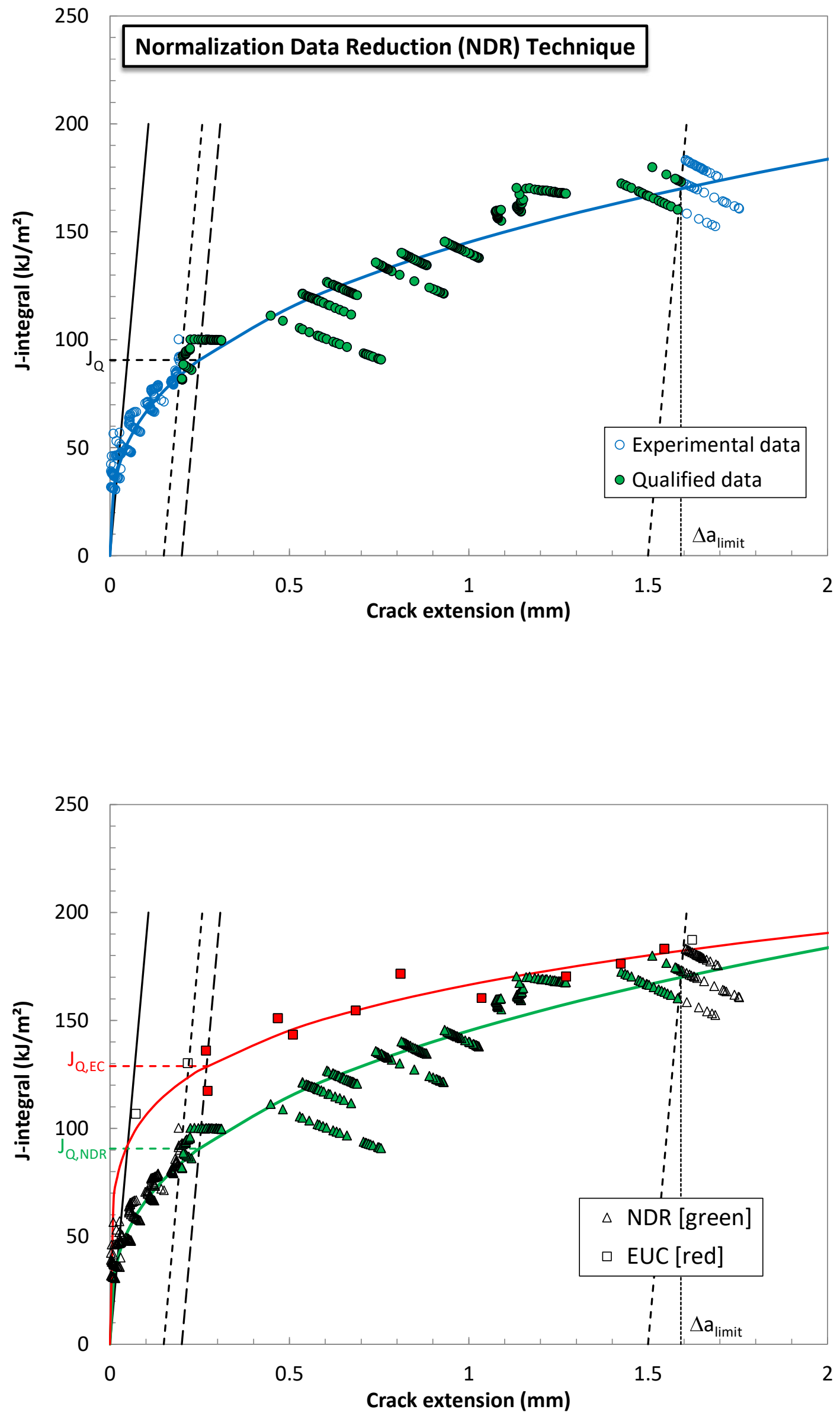

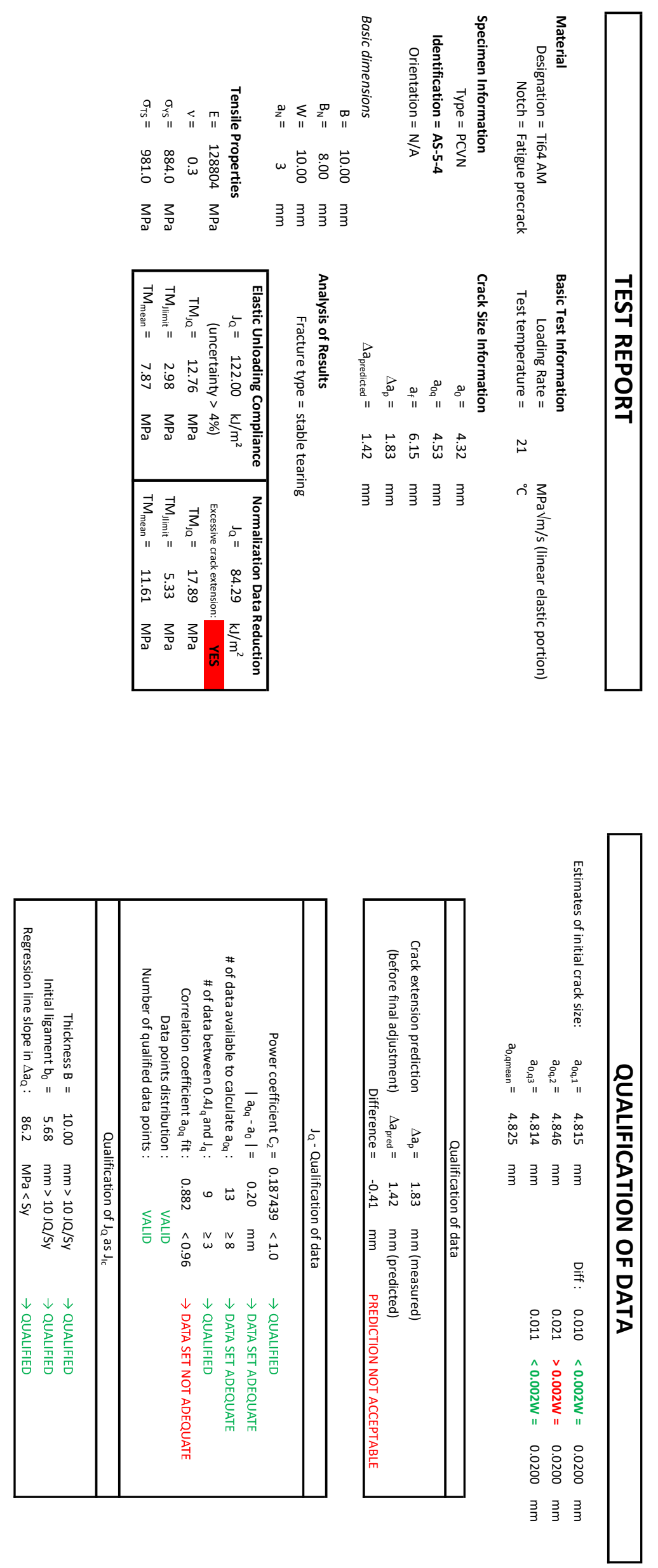

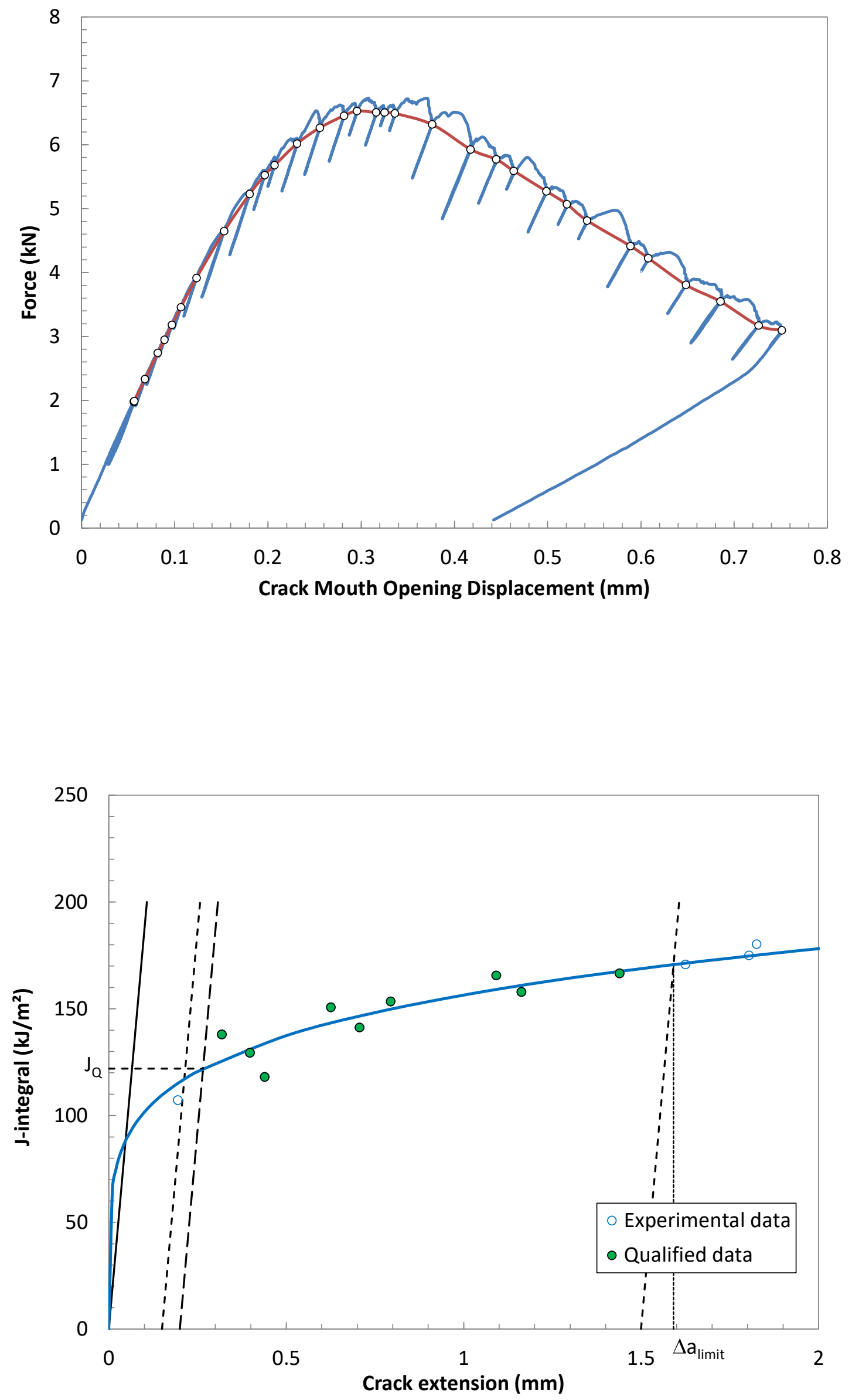

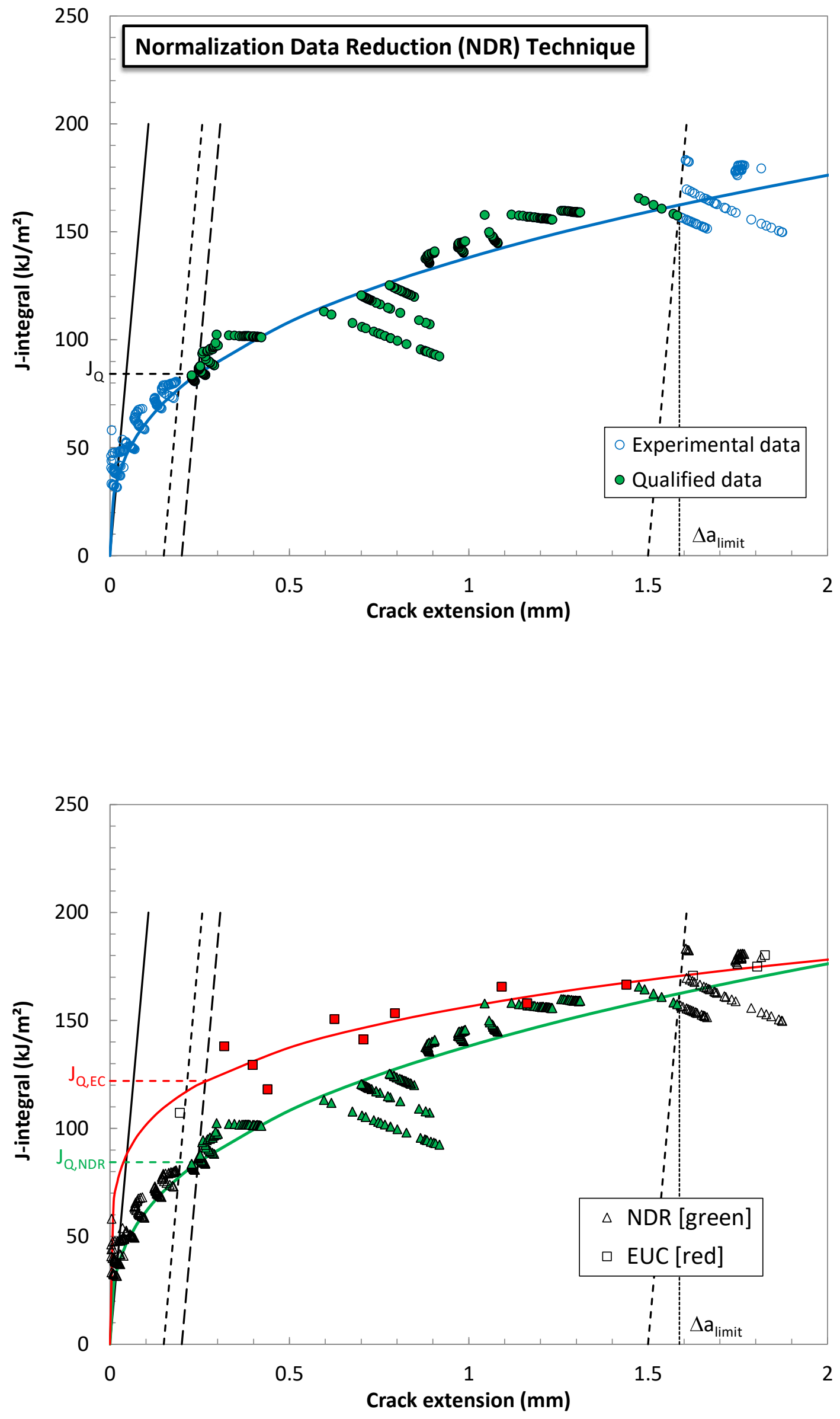

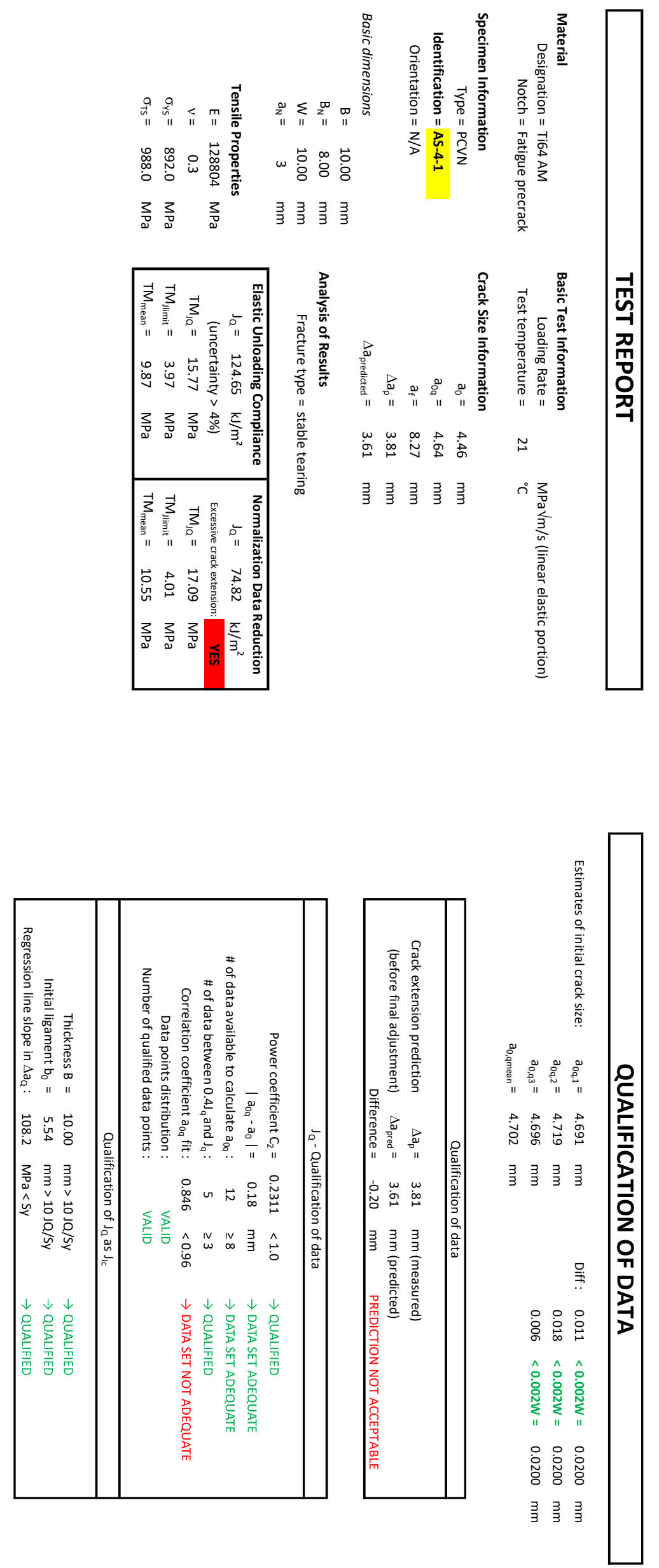

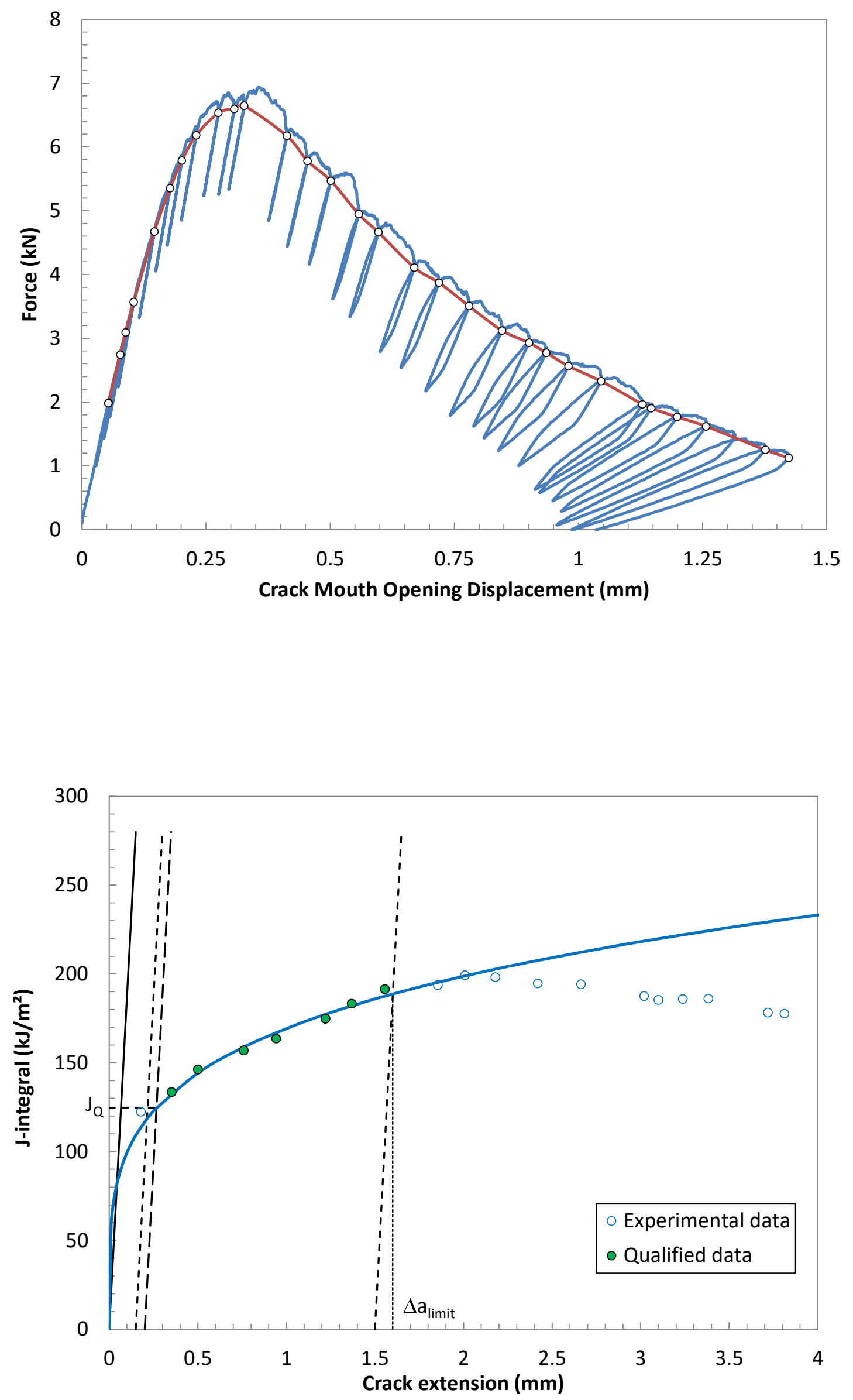

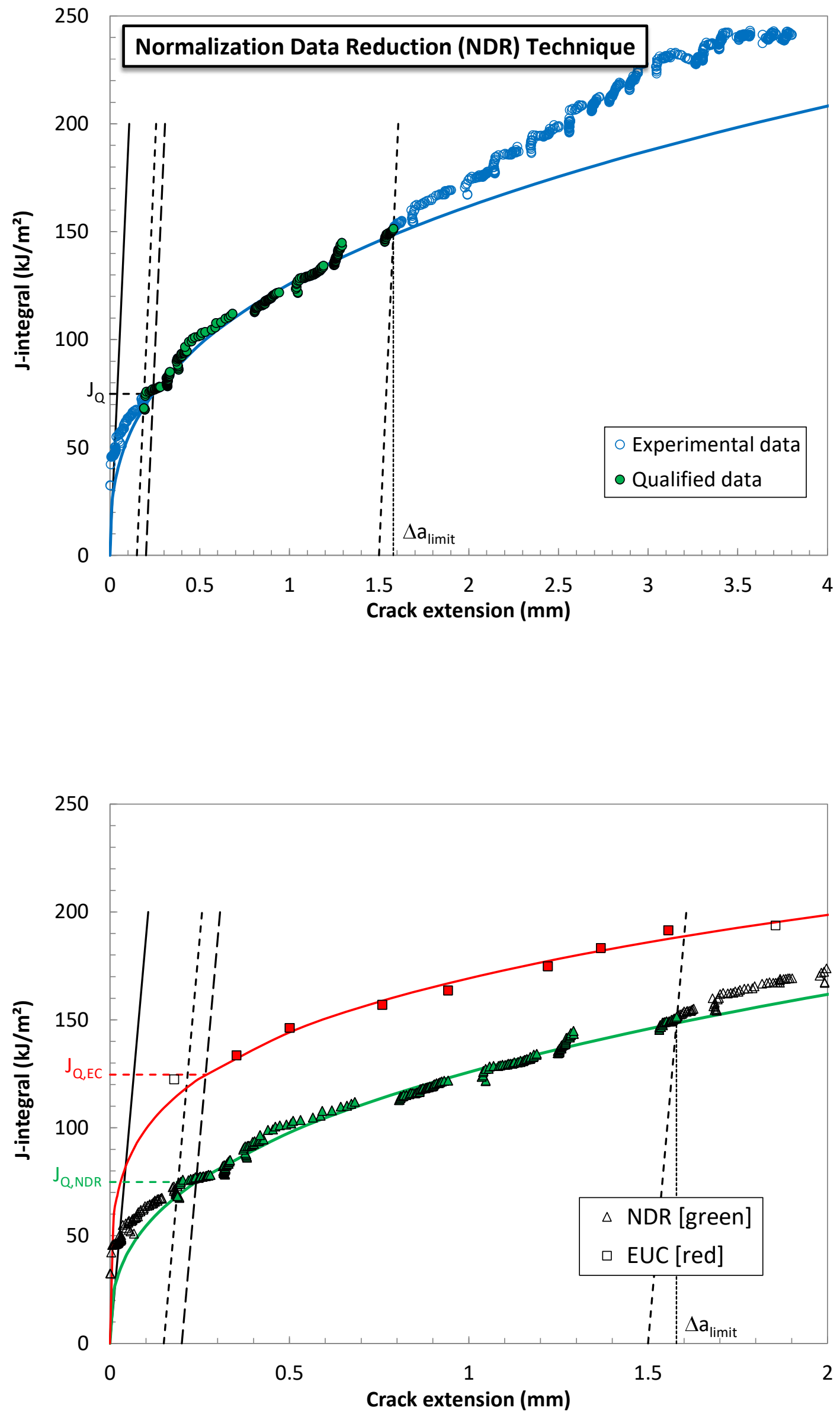

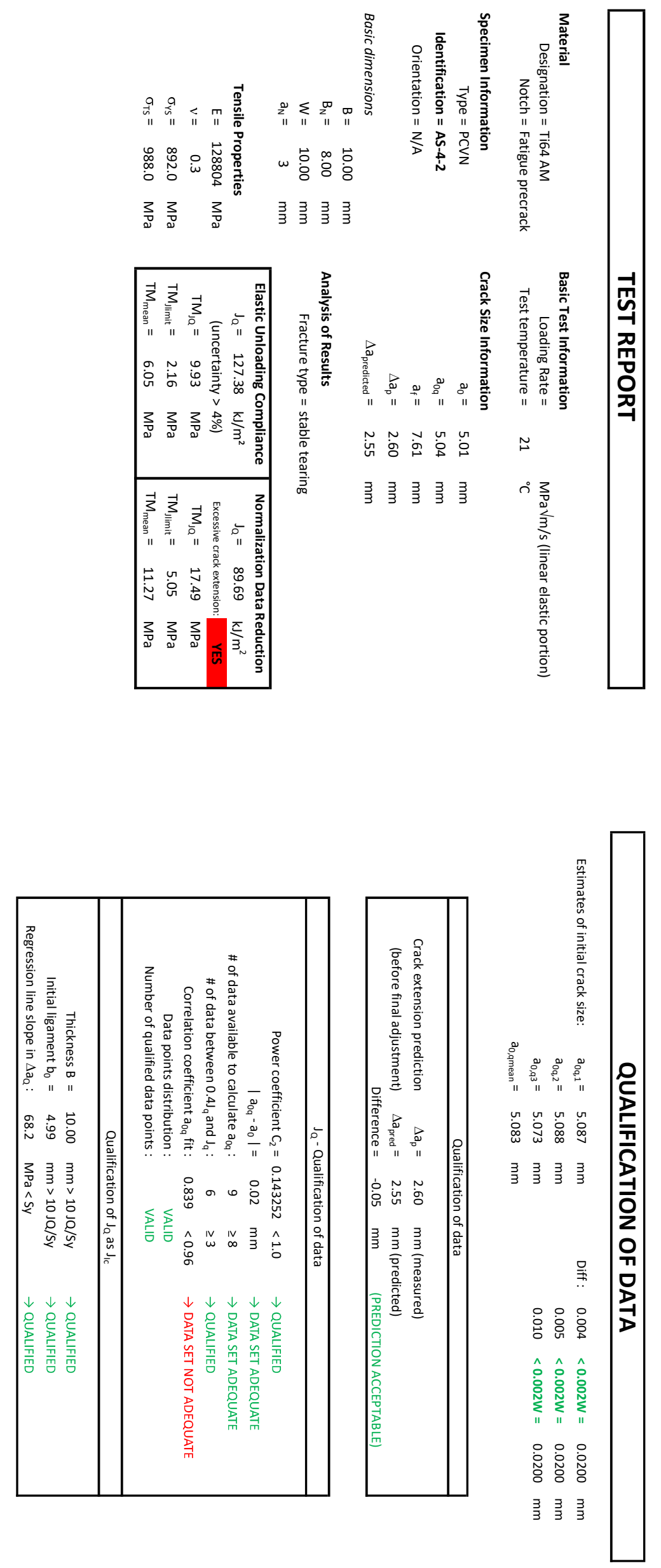

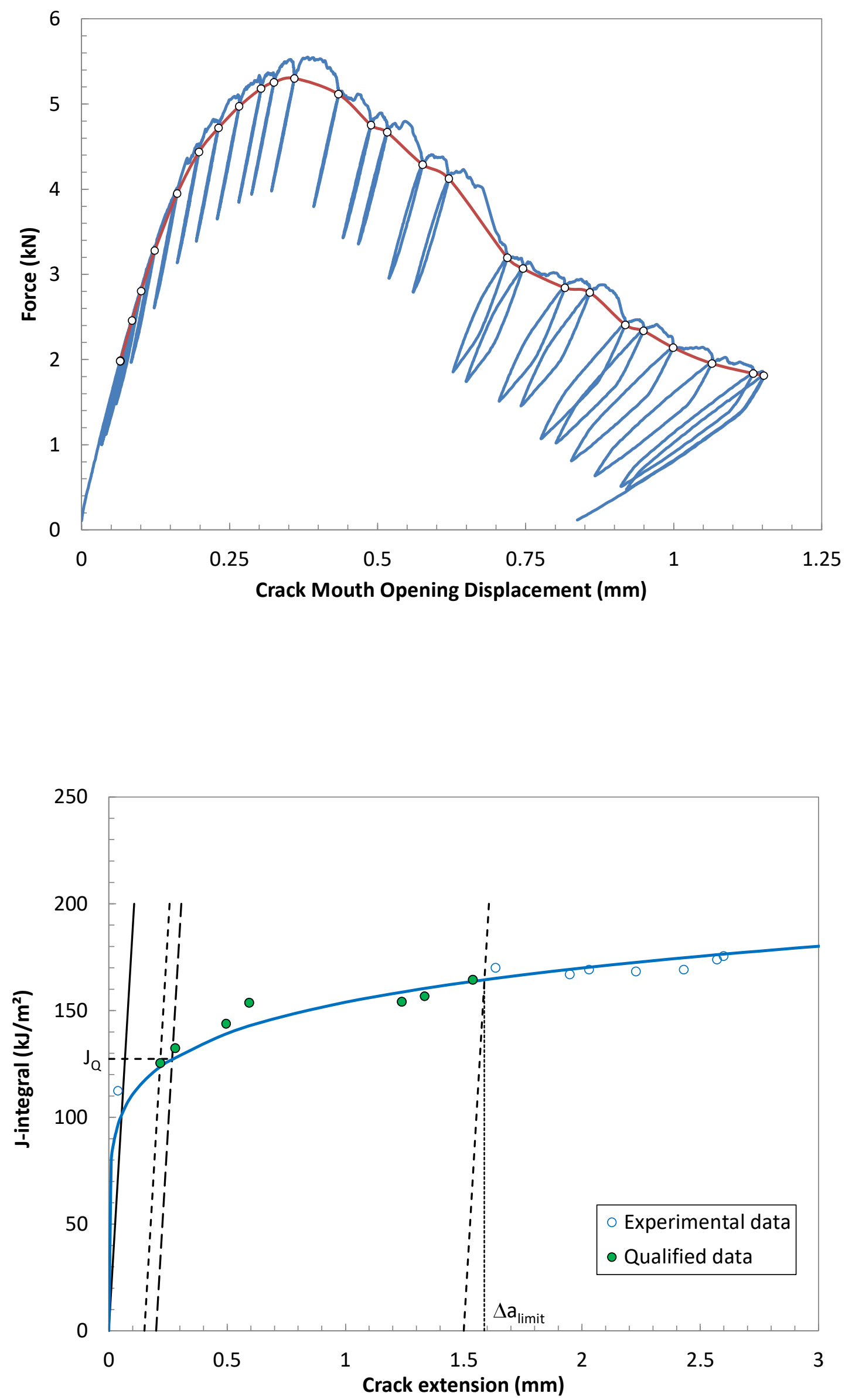

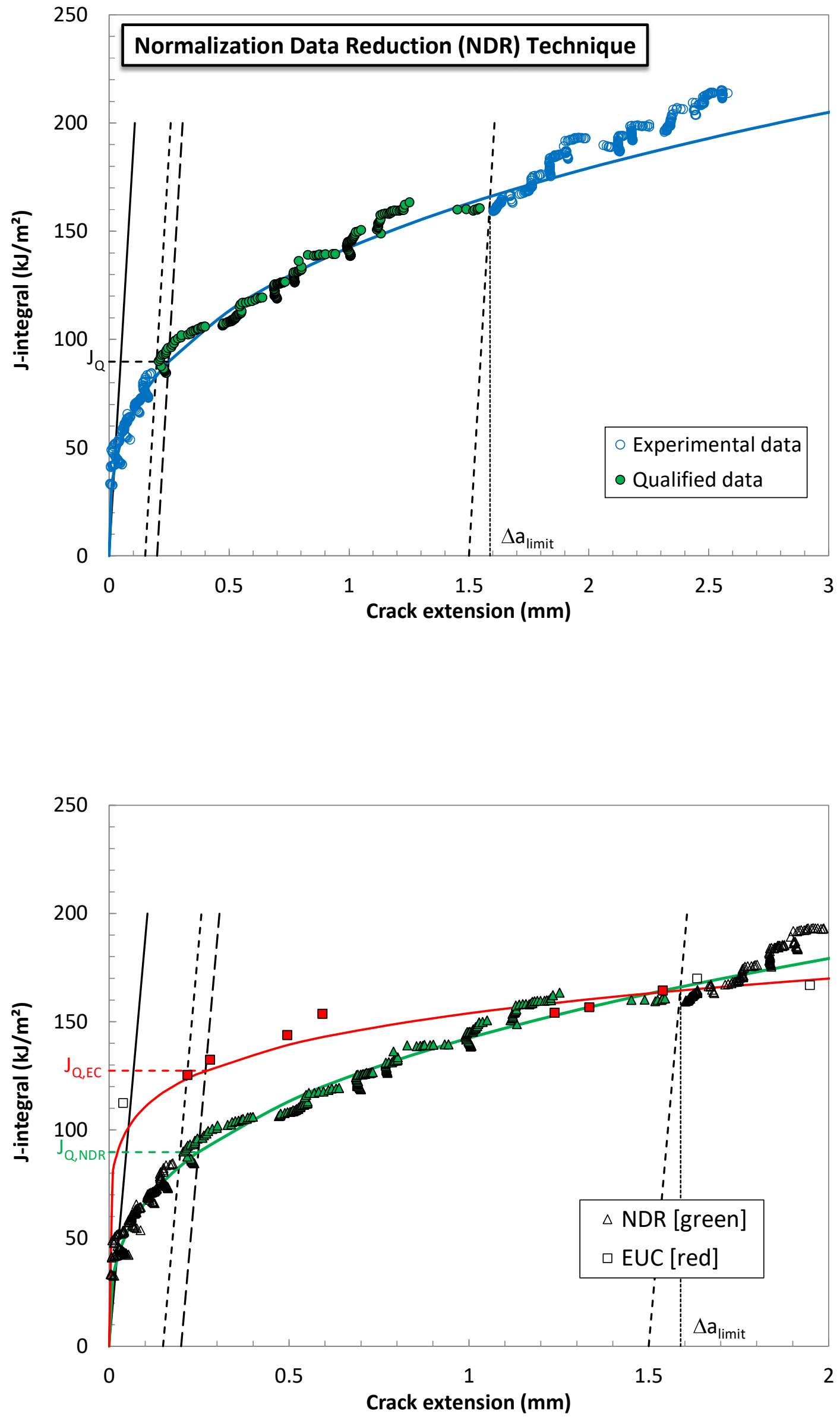

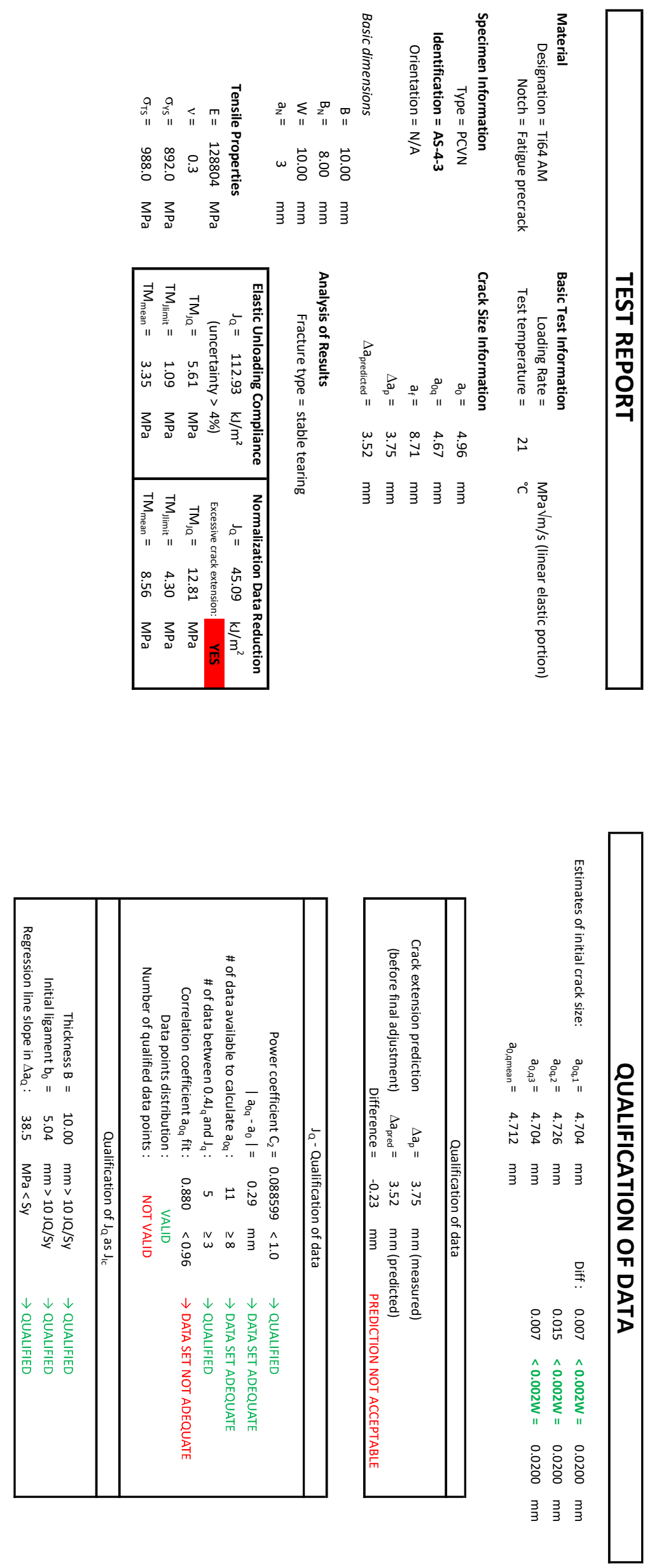

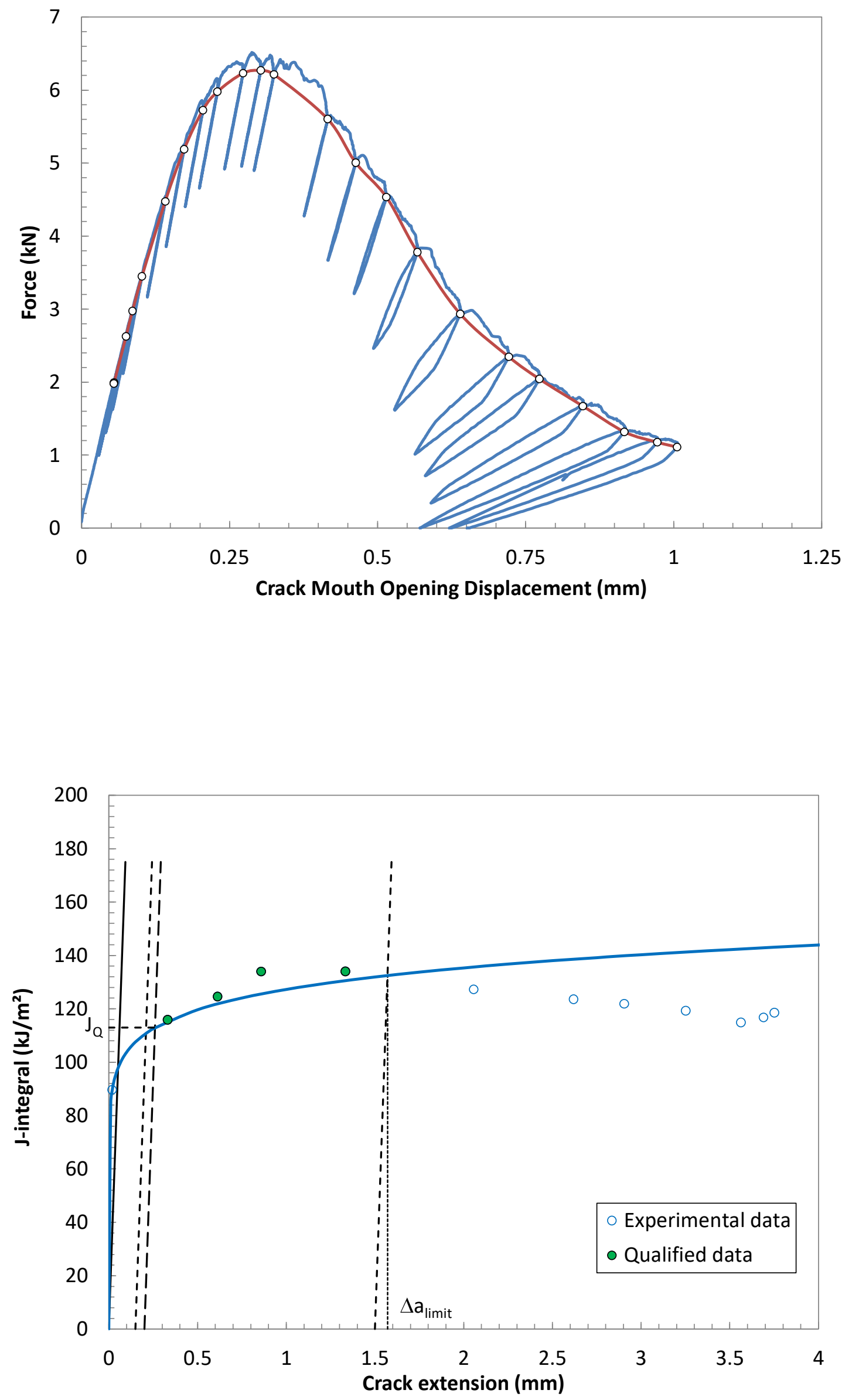

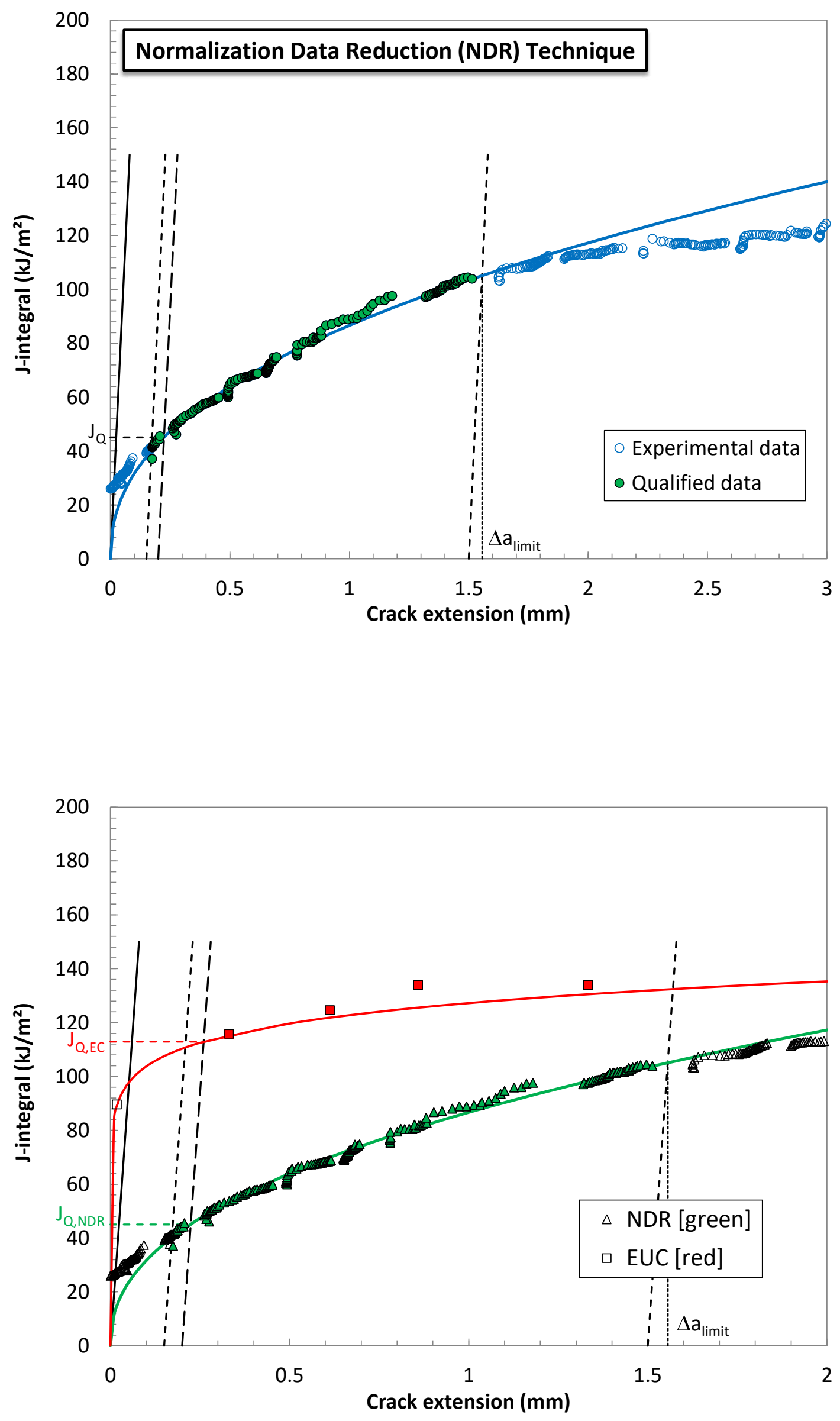

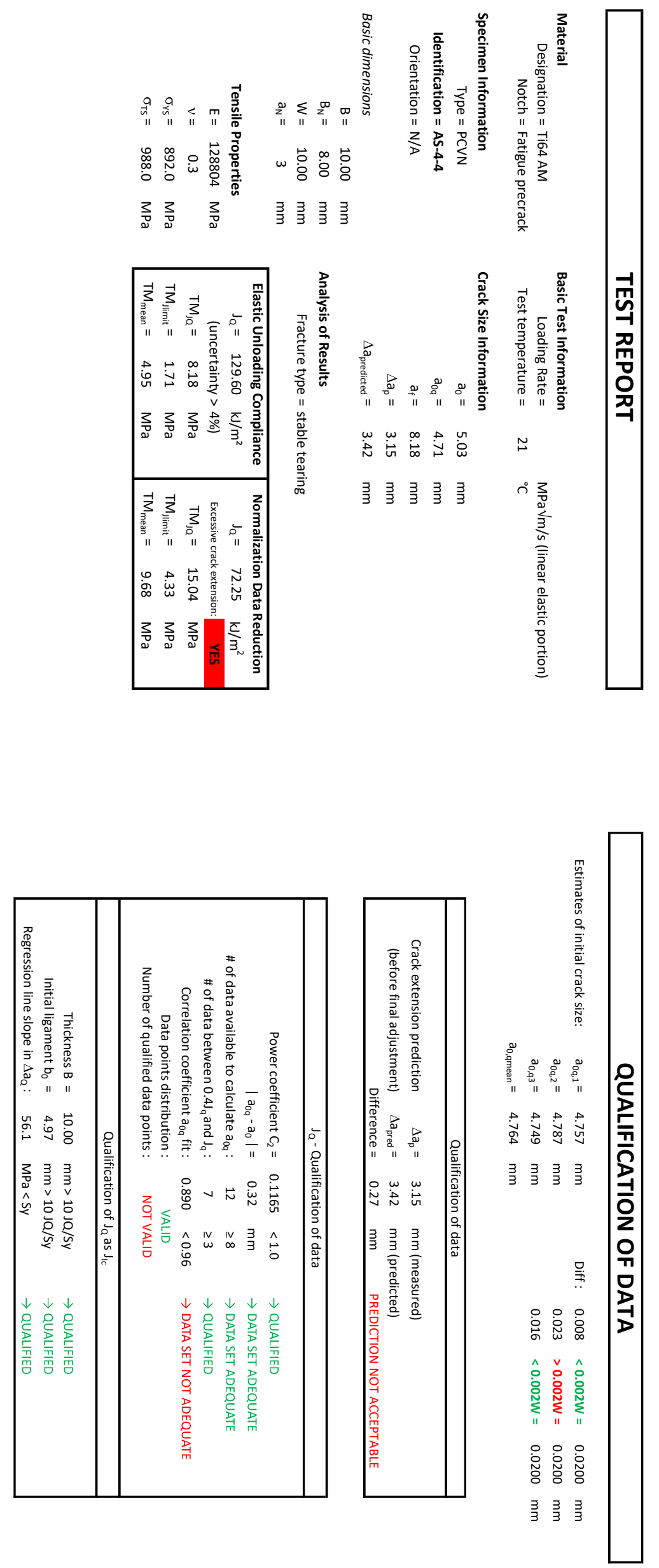

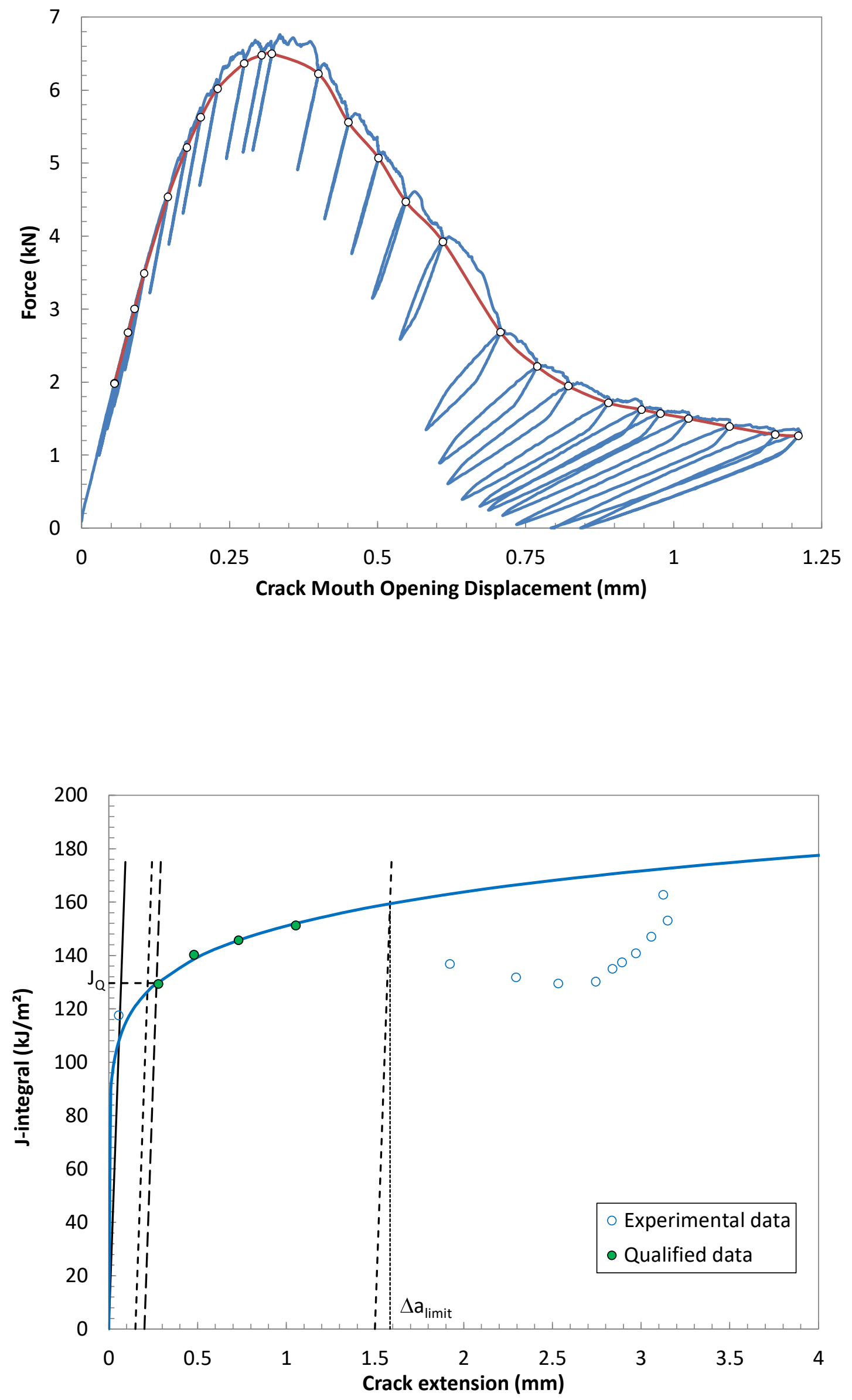

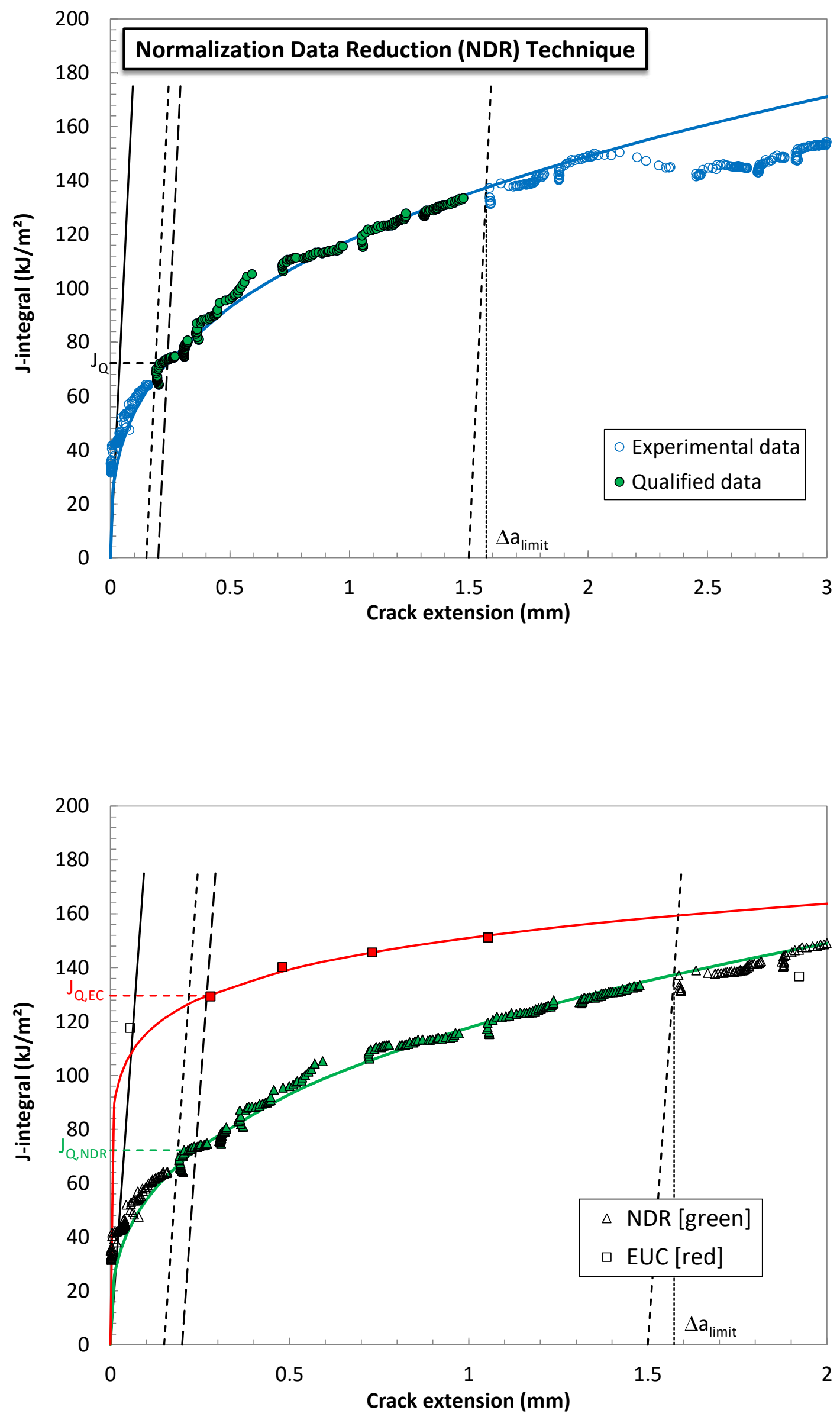

ANNEX 3

Classic HIP, non-supported 

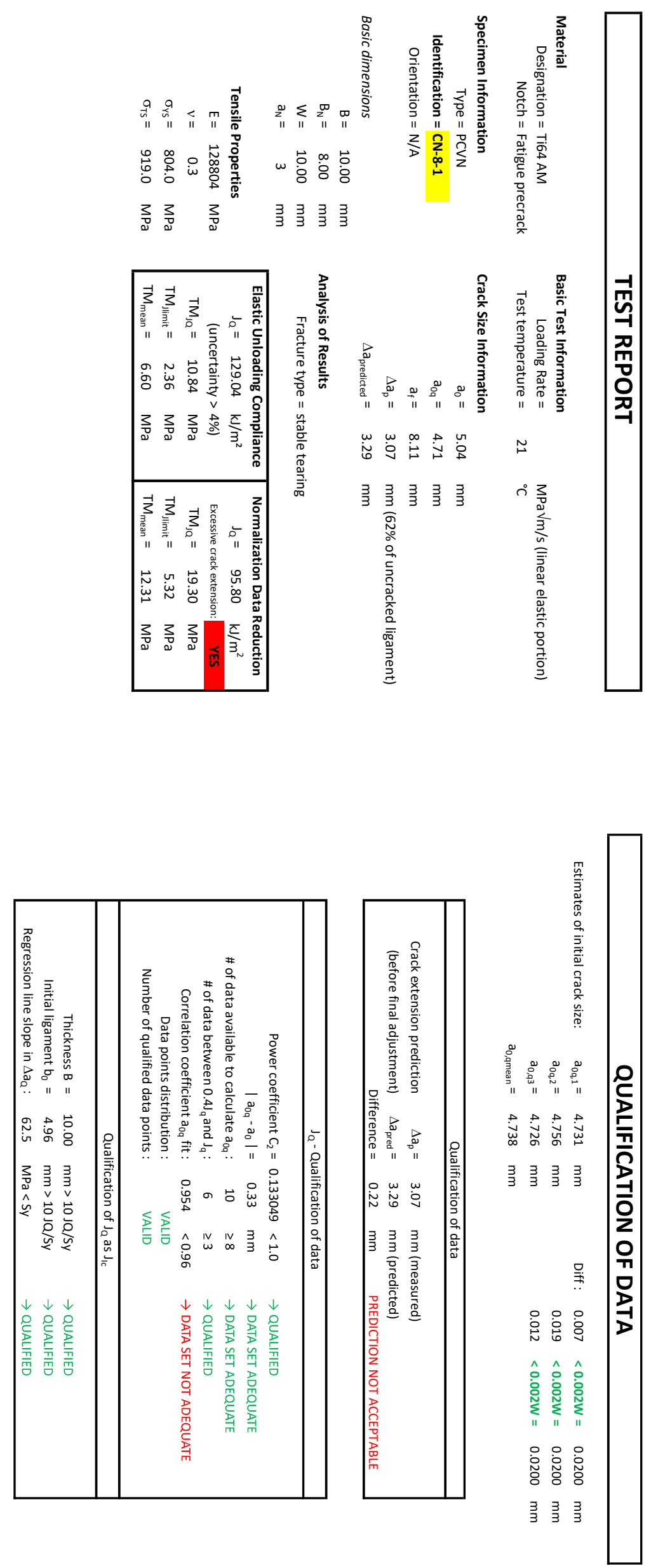

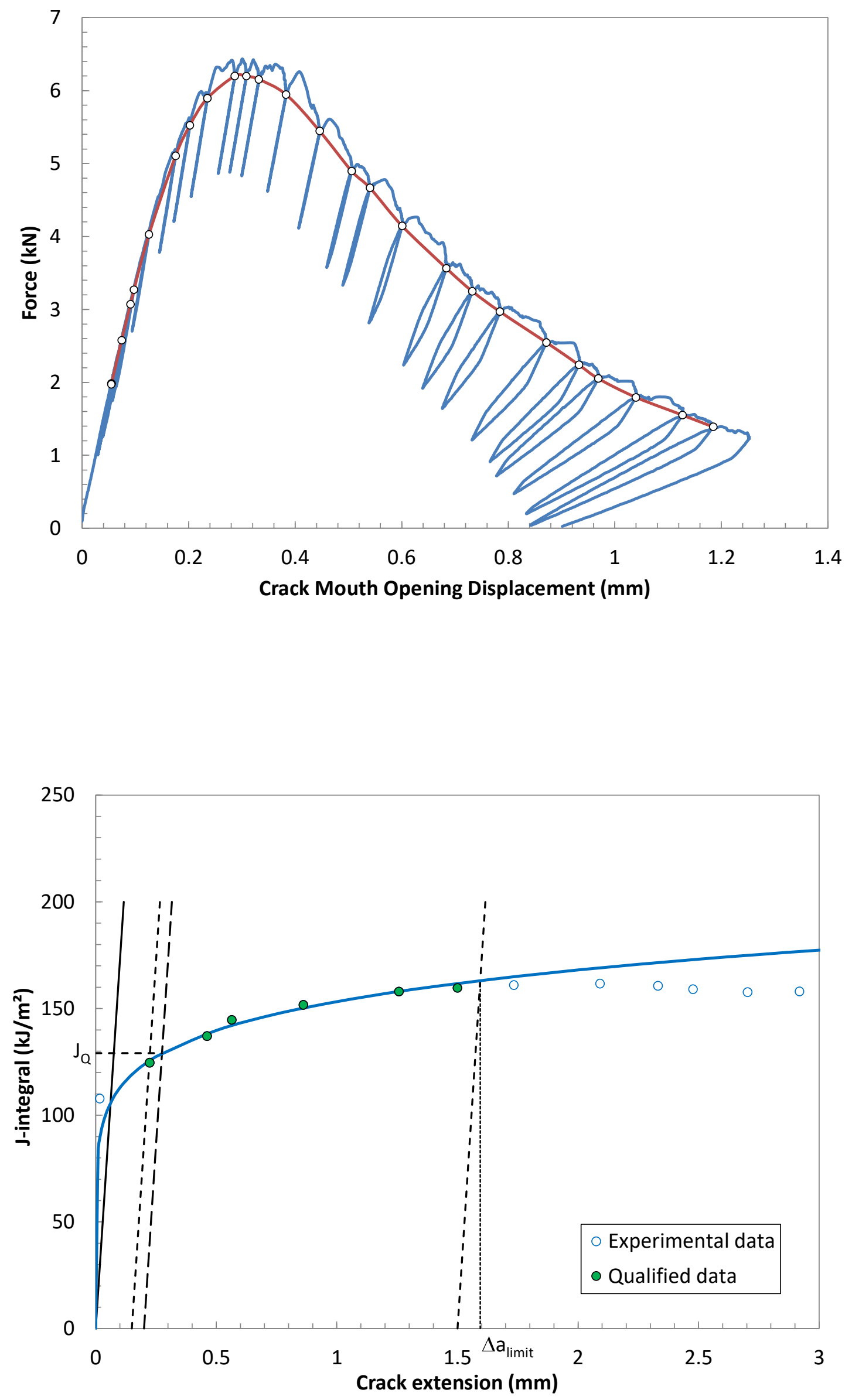

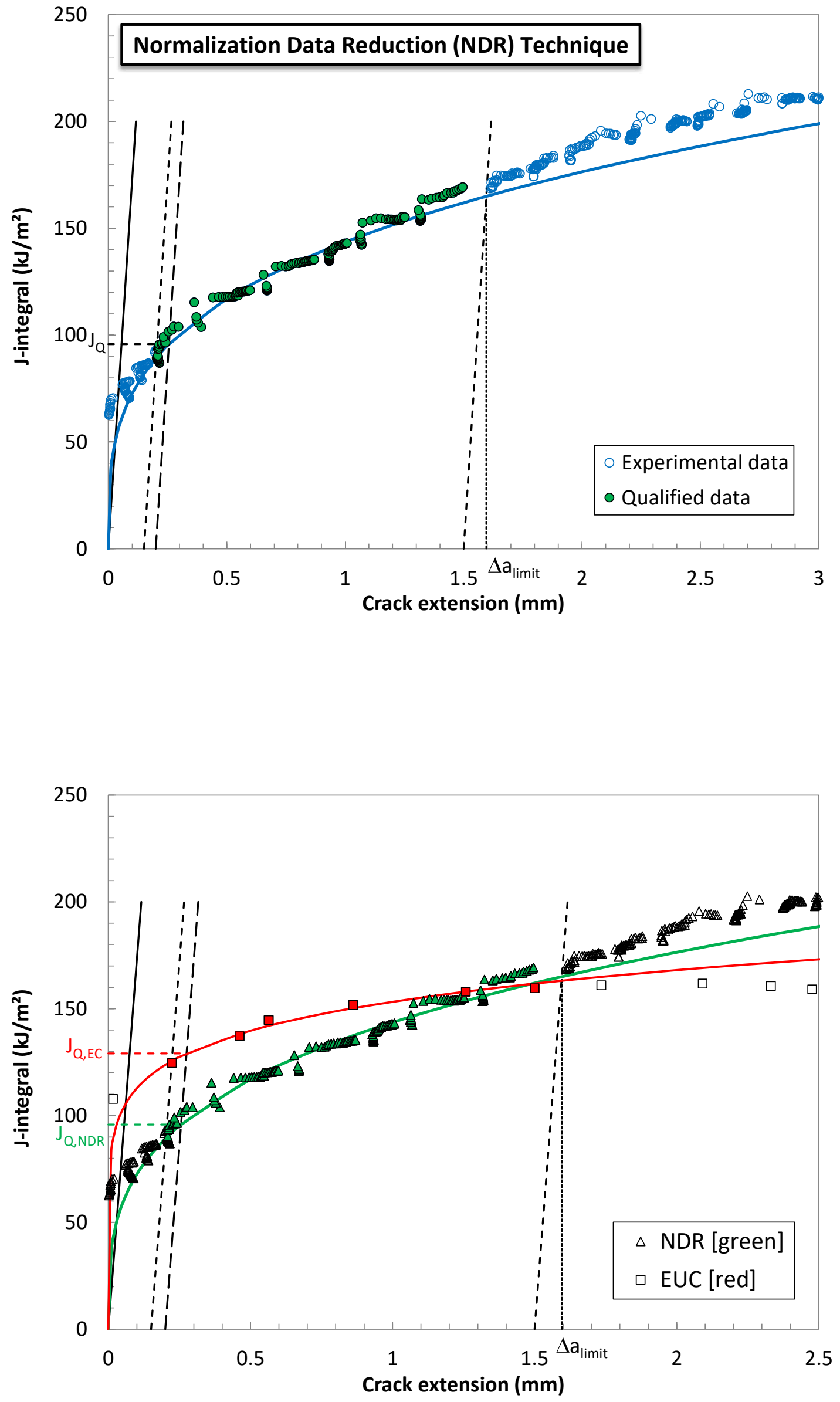

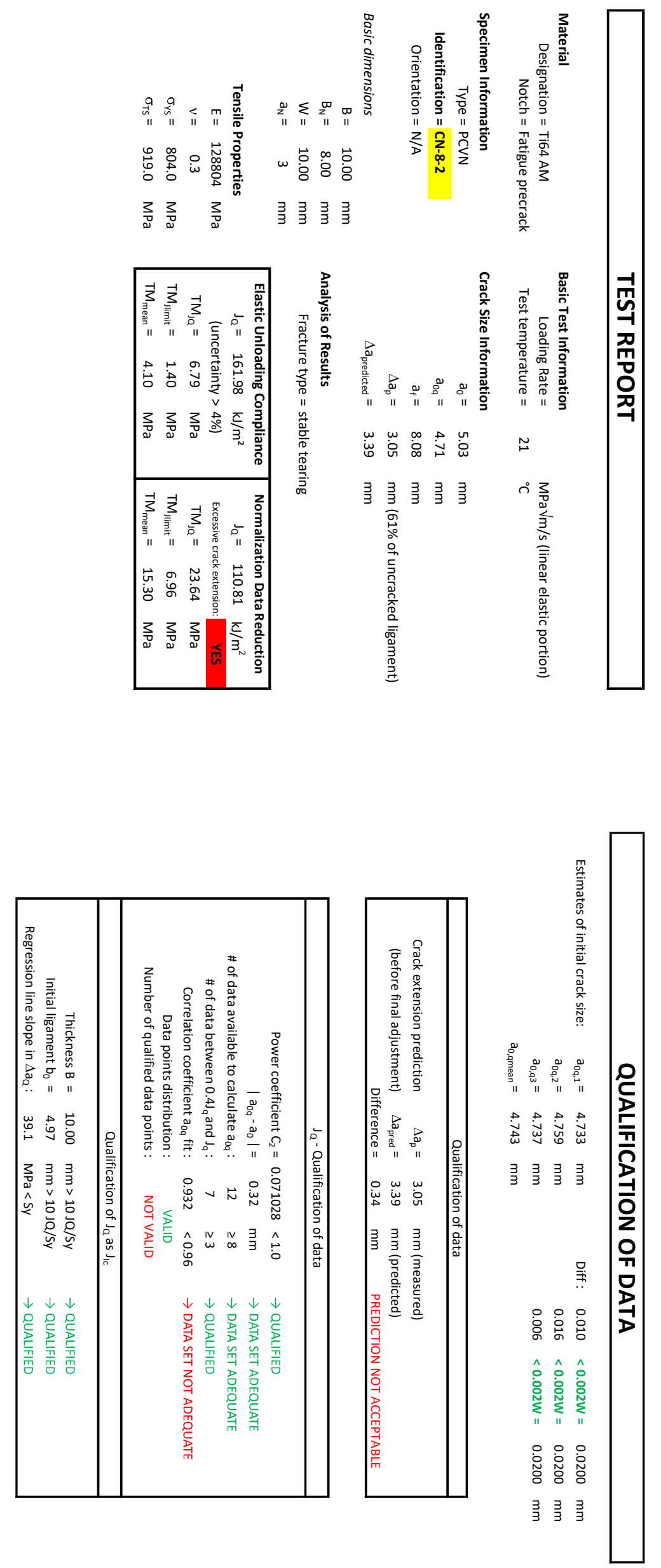

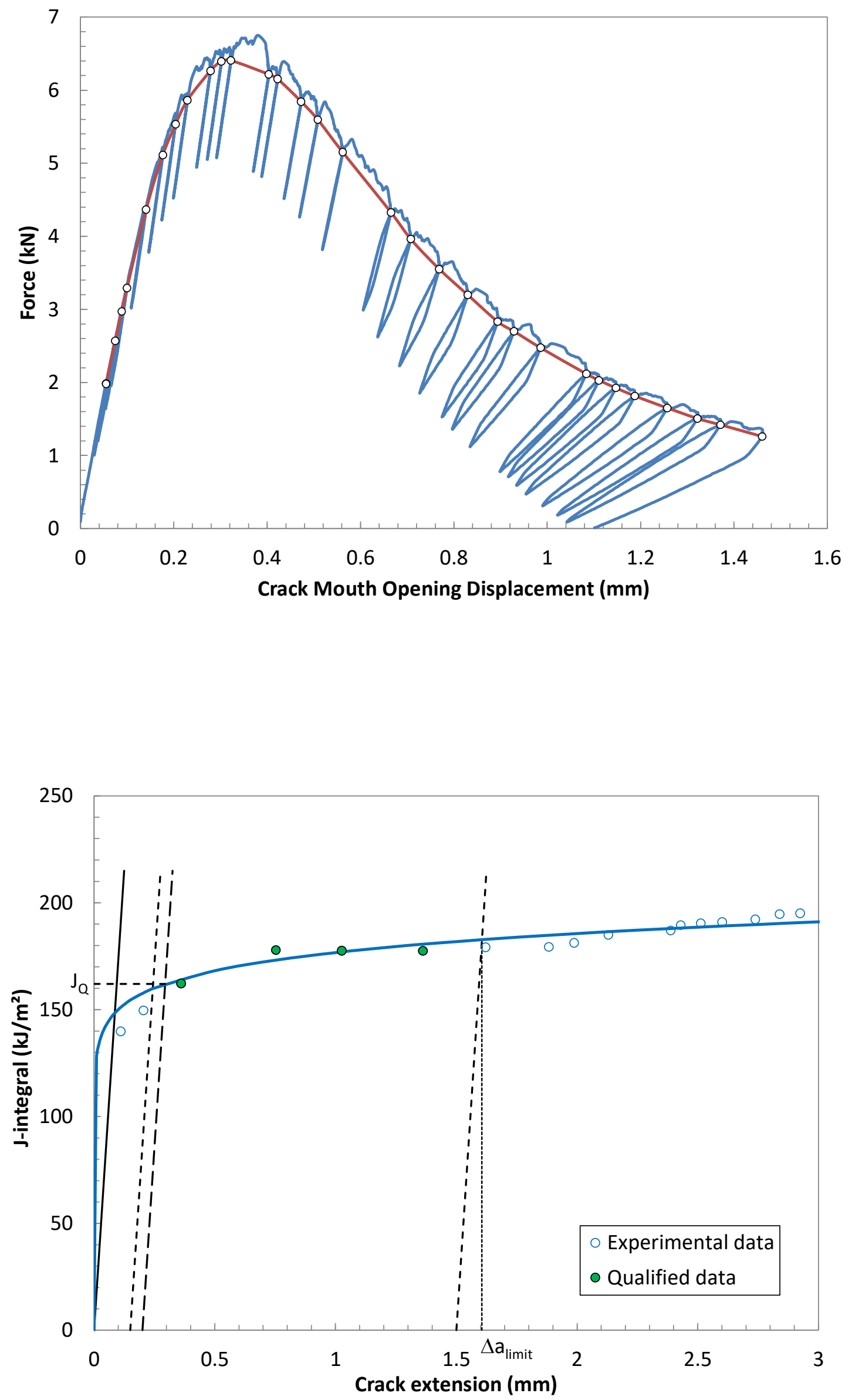

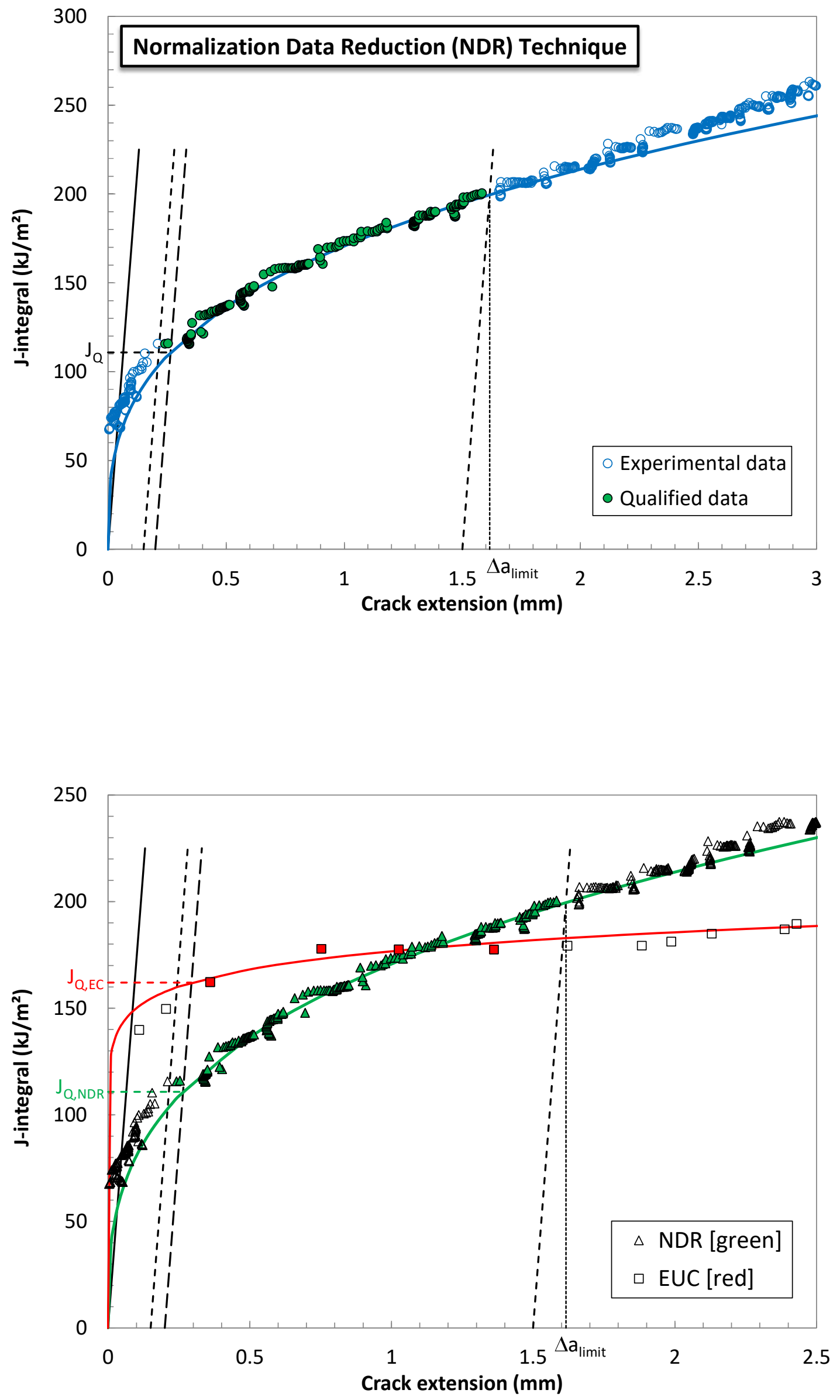

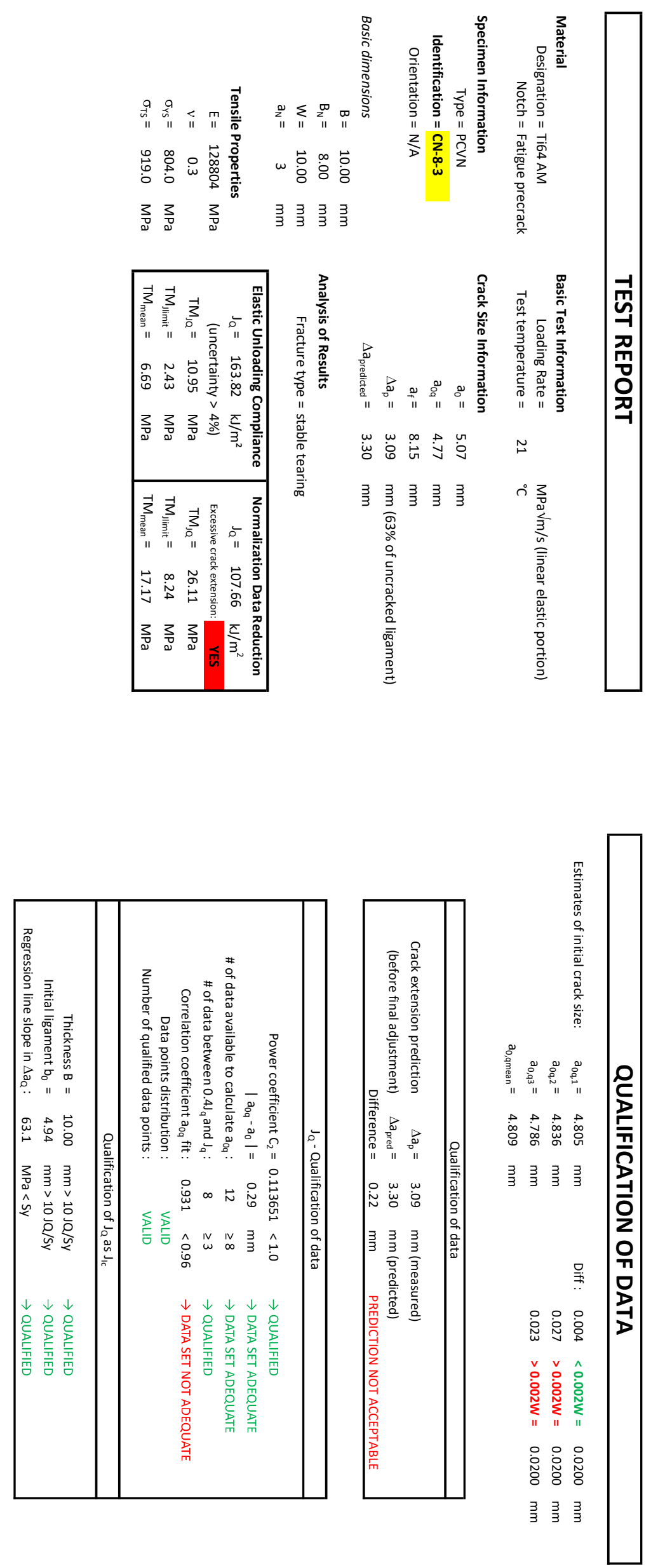

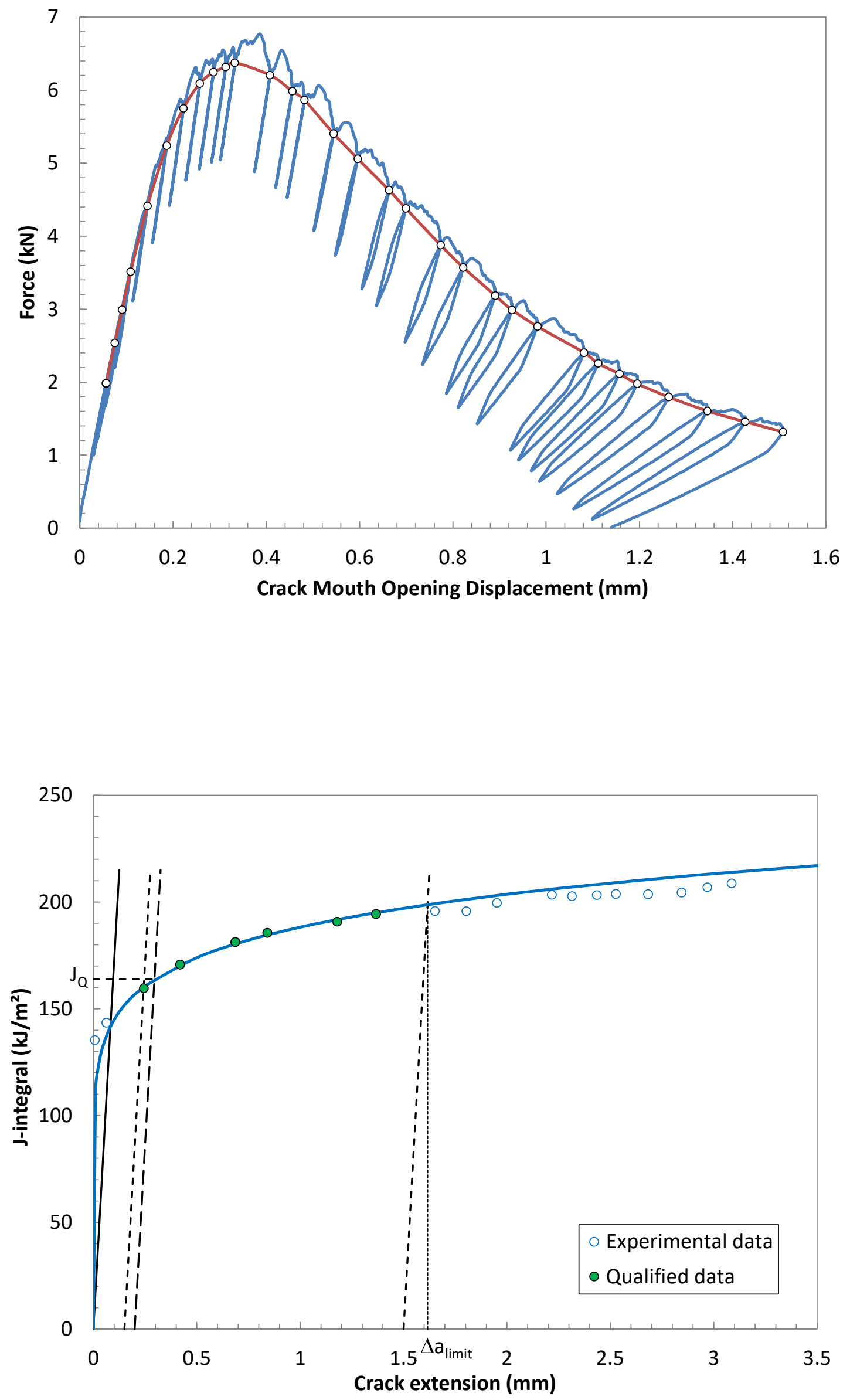

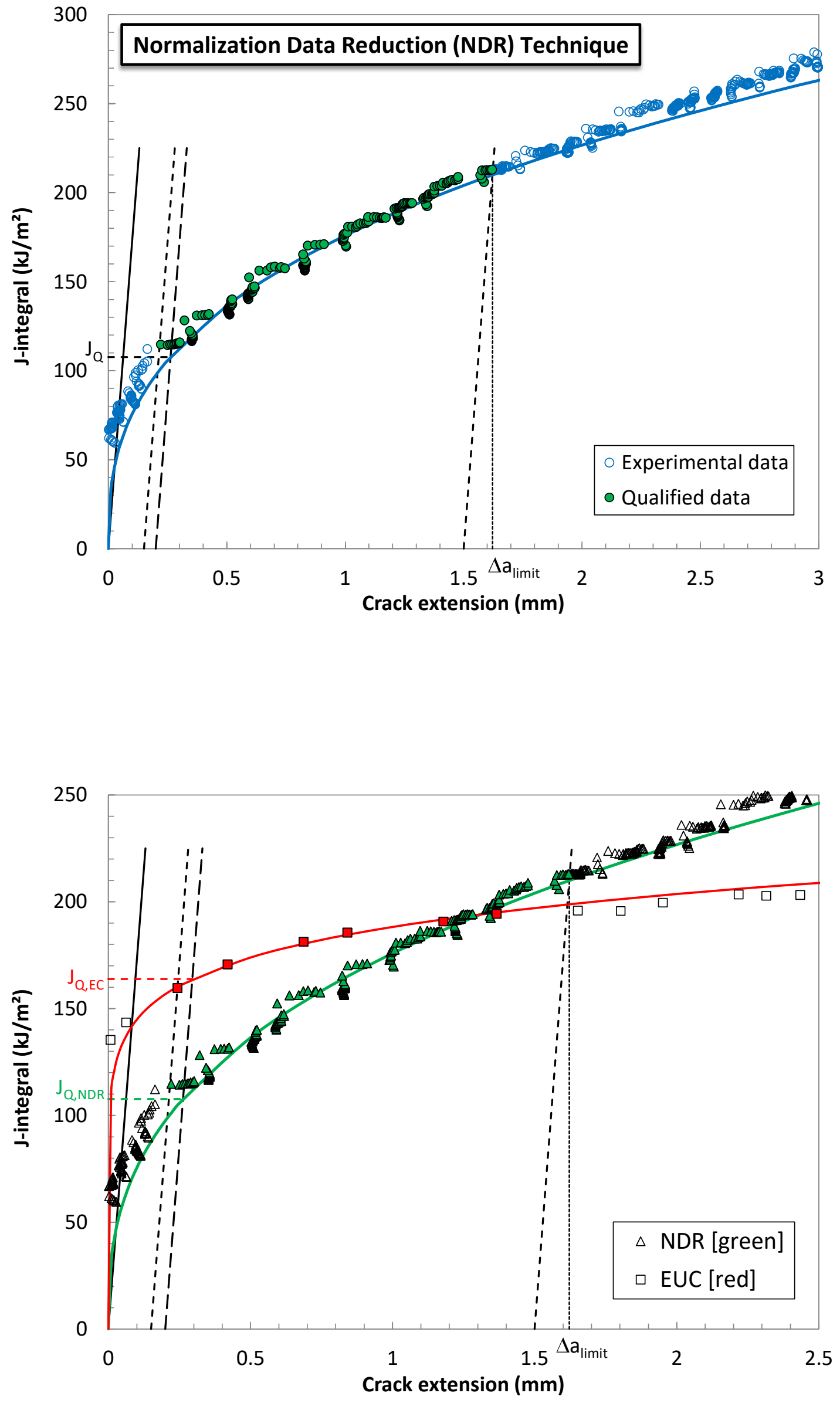

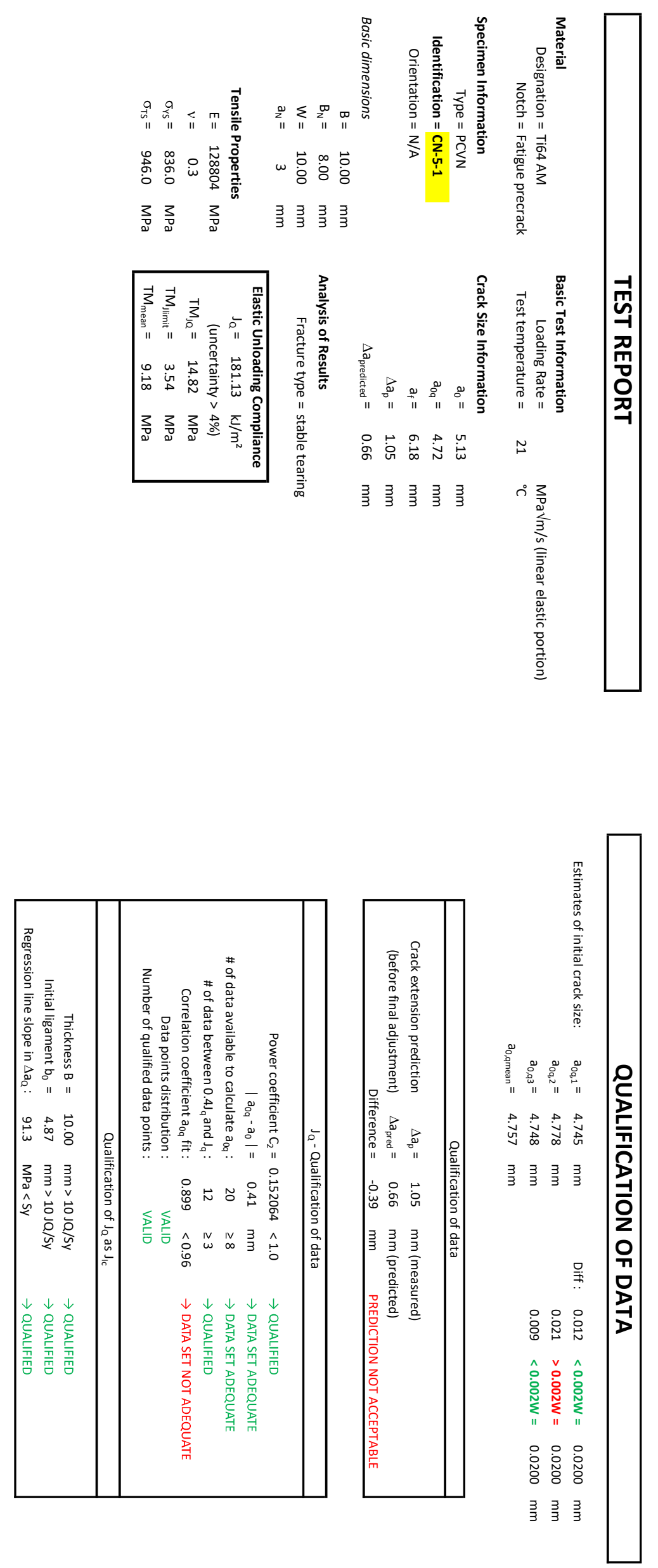

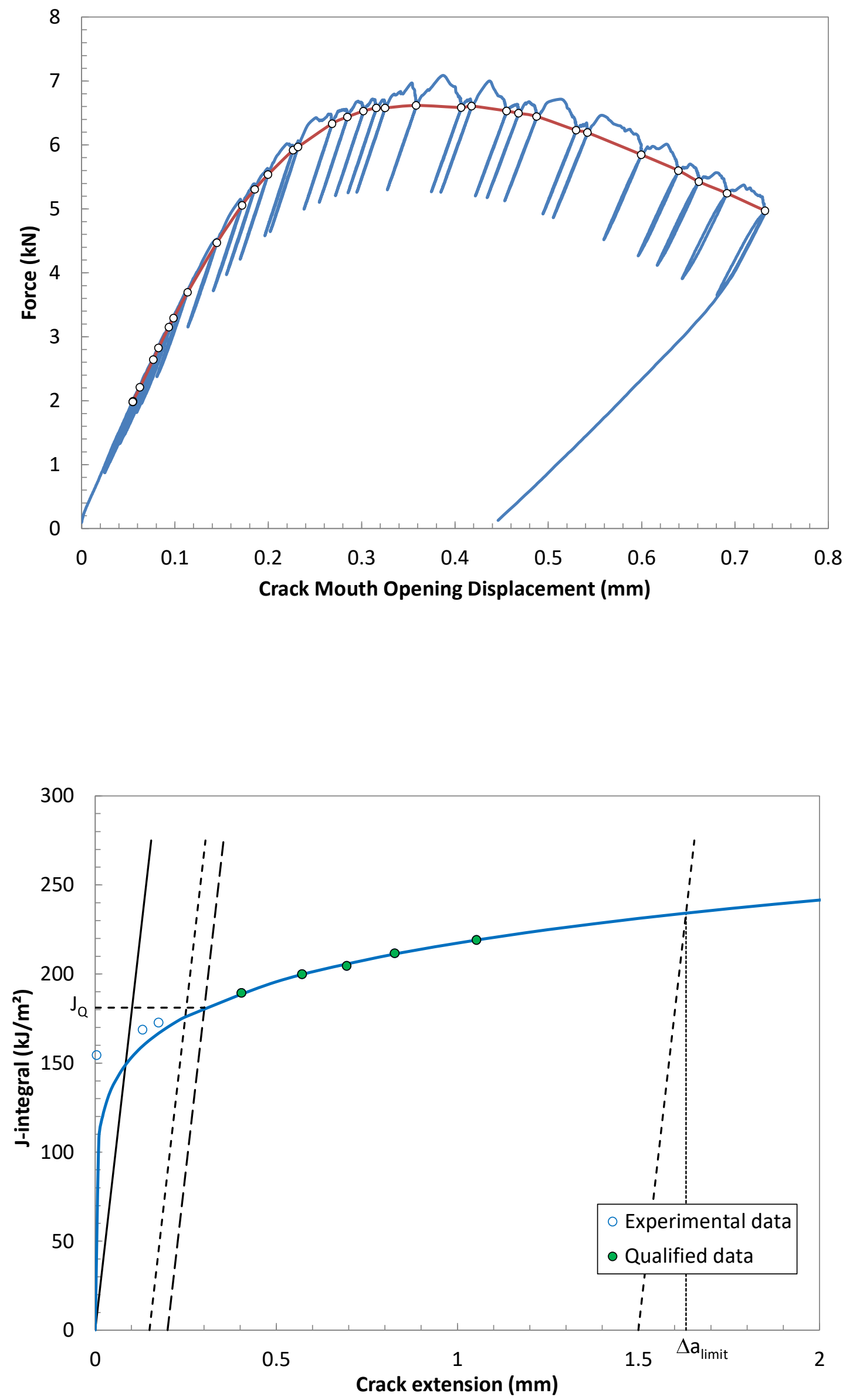

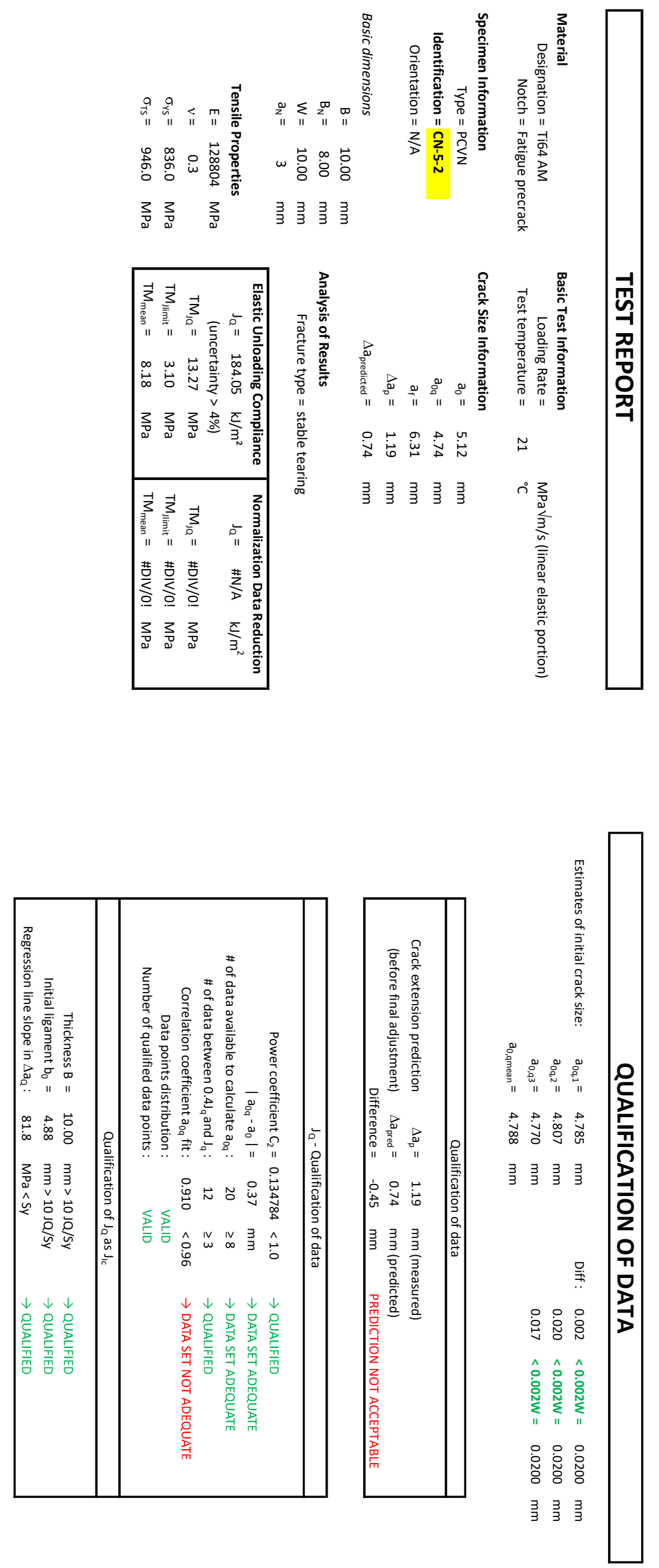

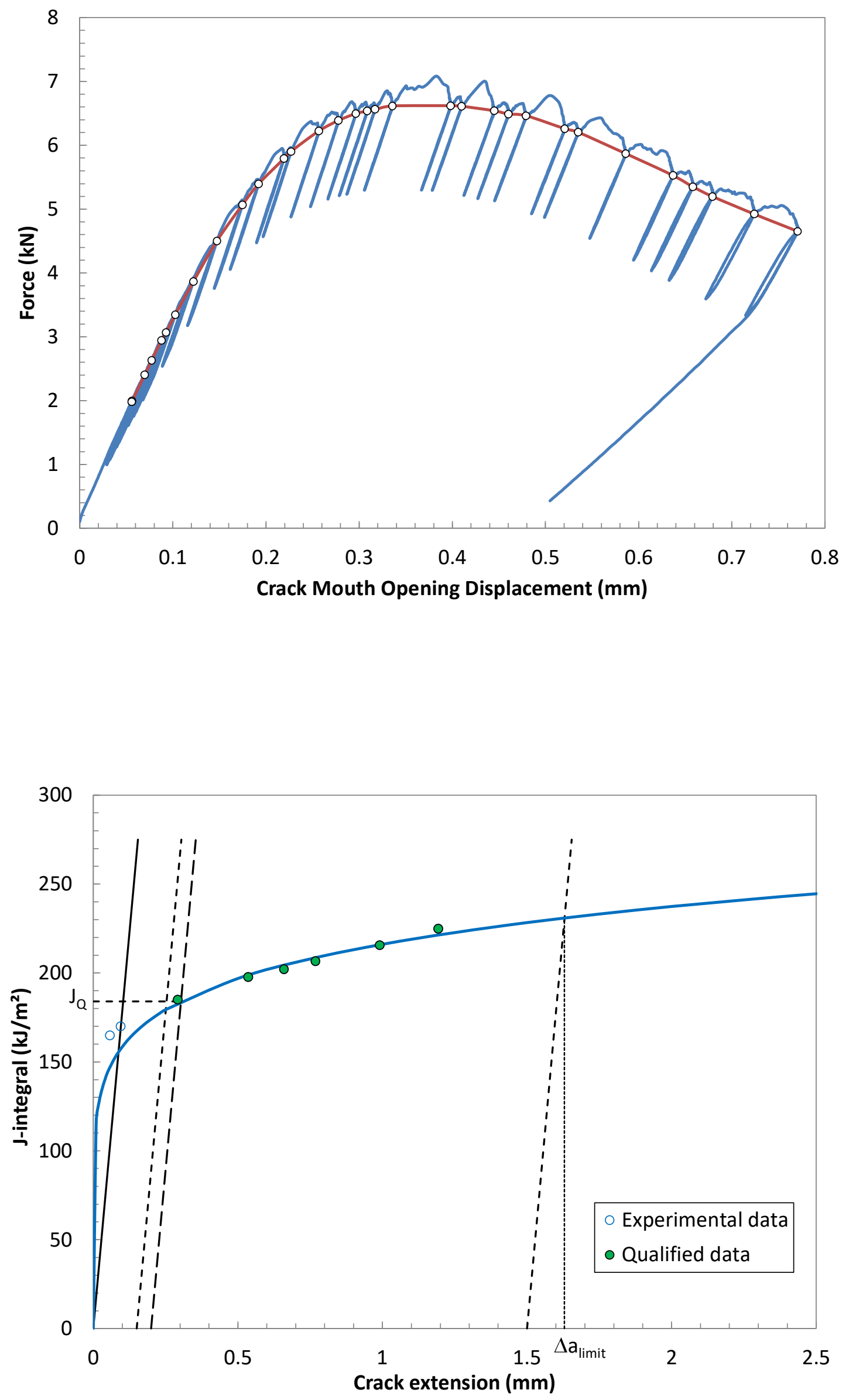

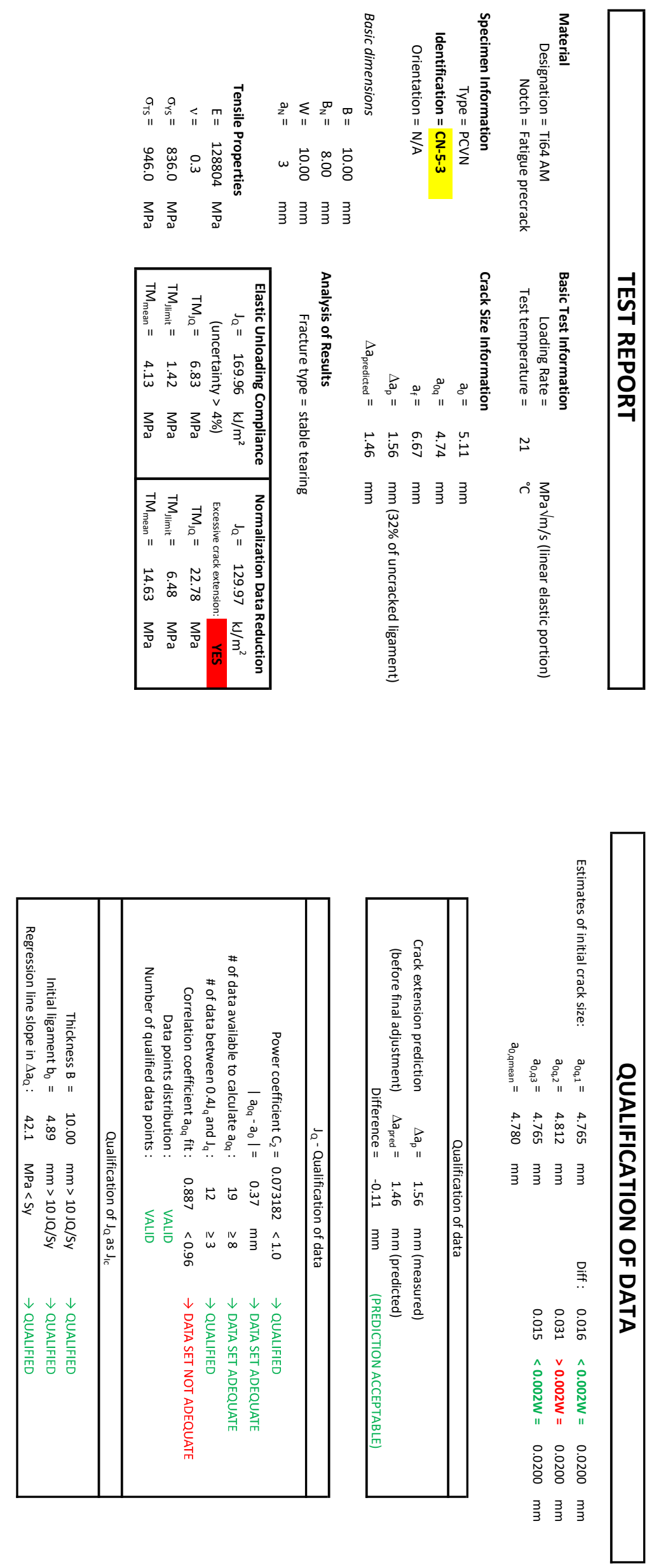

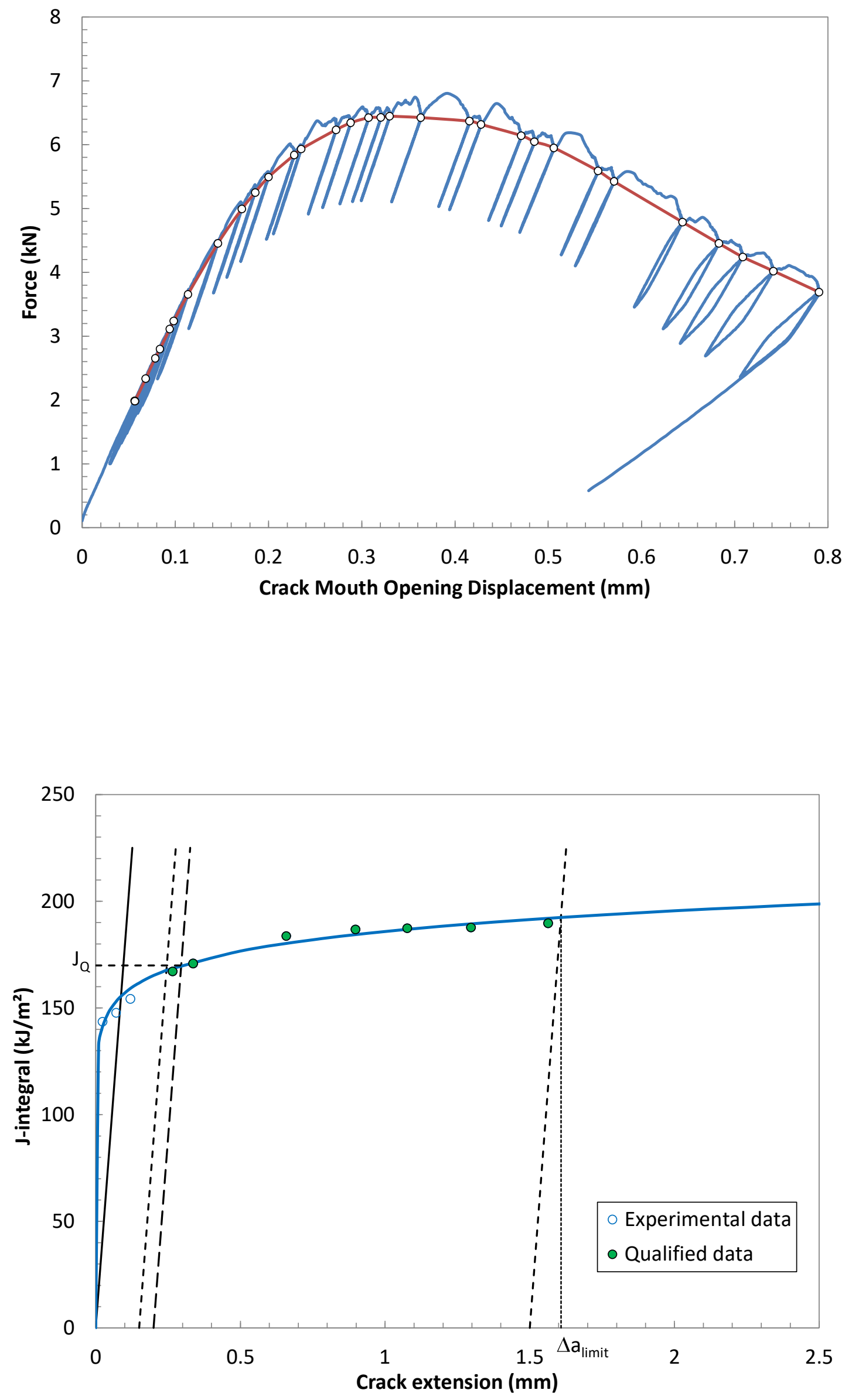

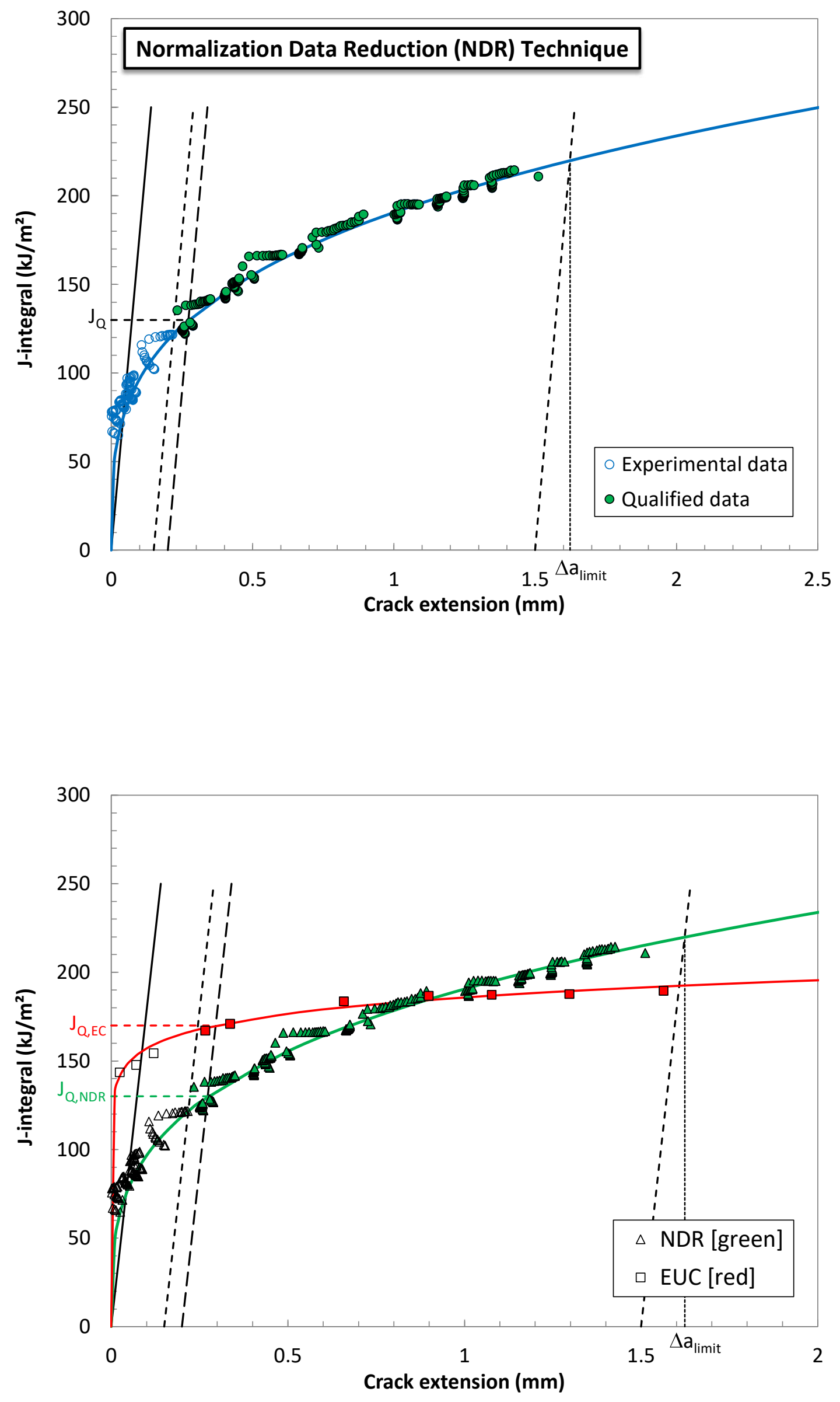

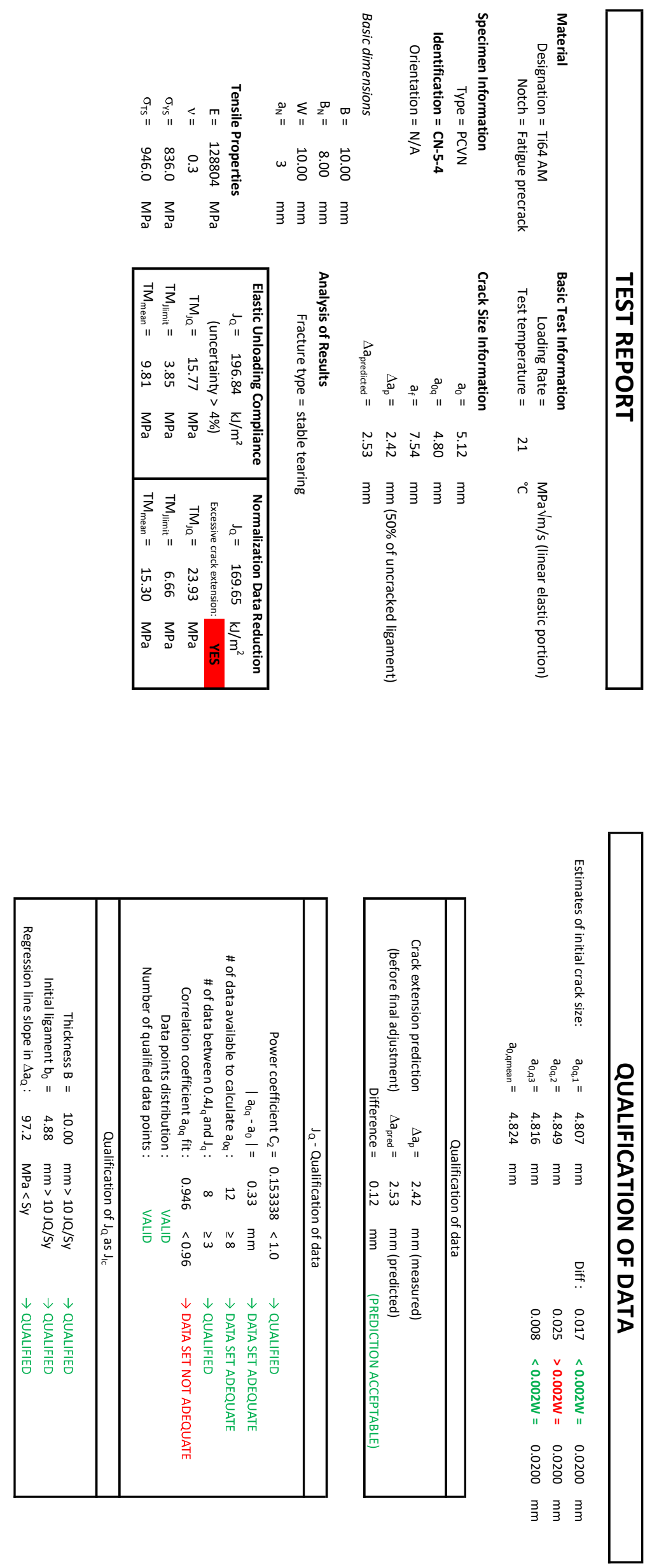

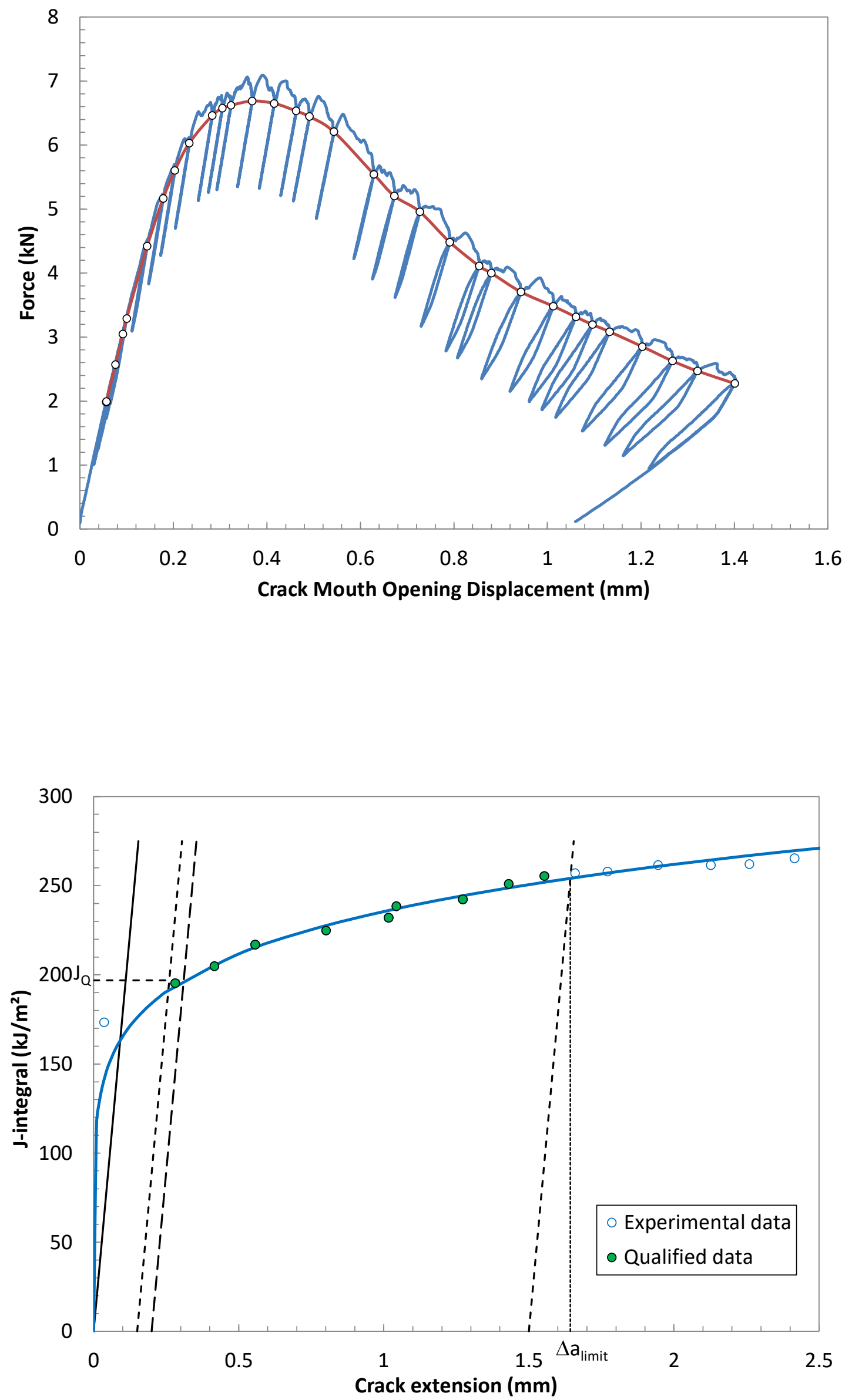

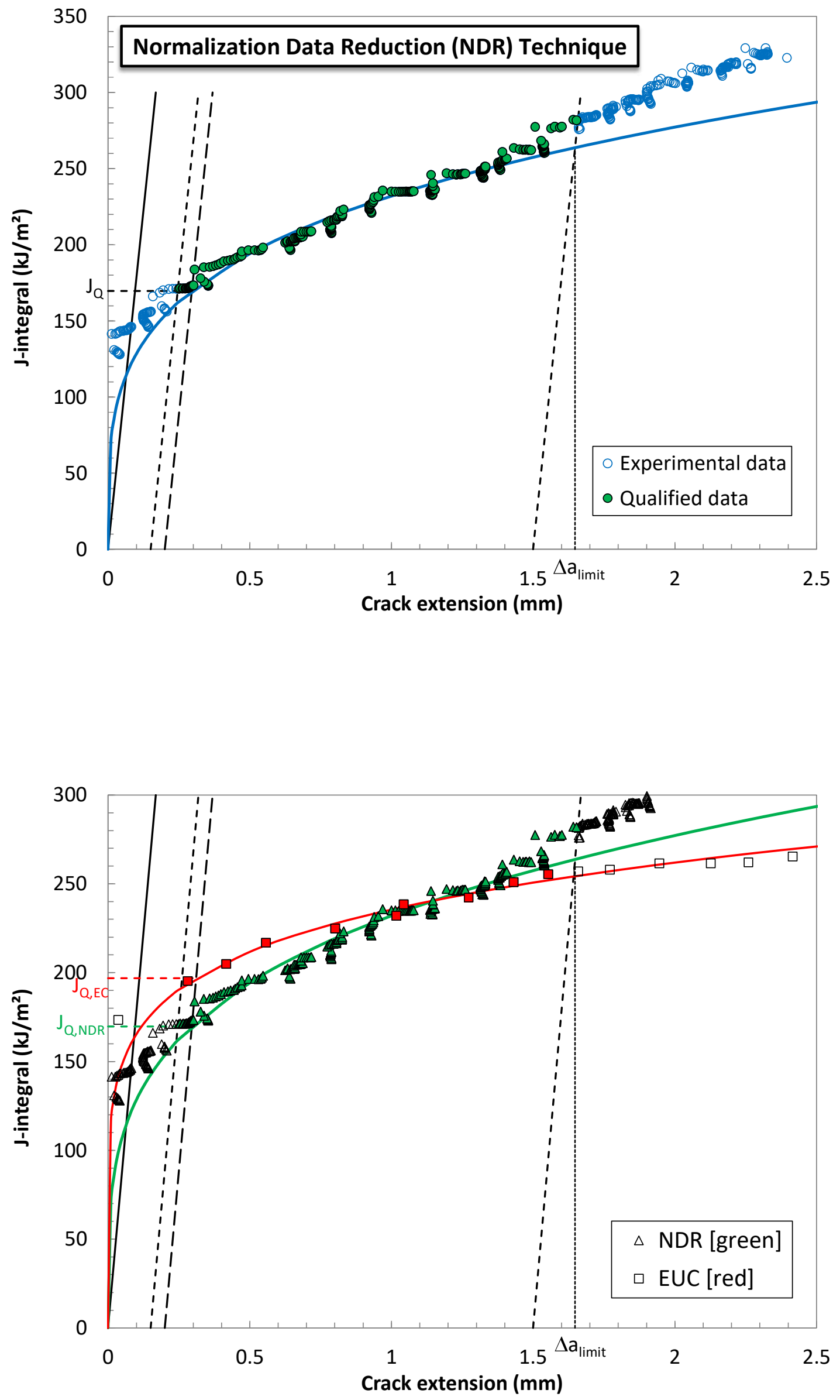

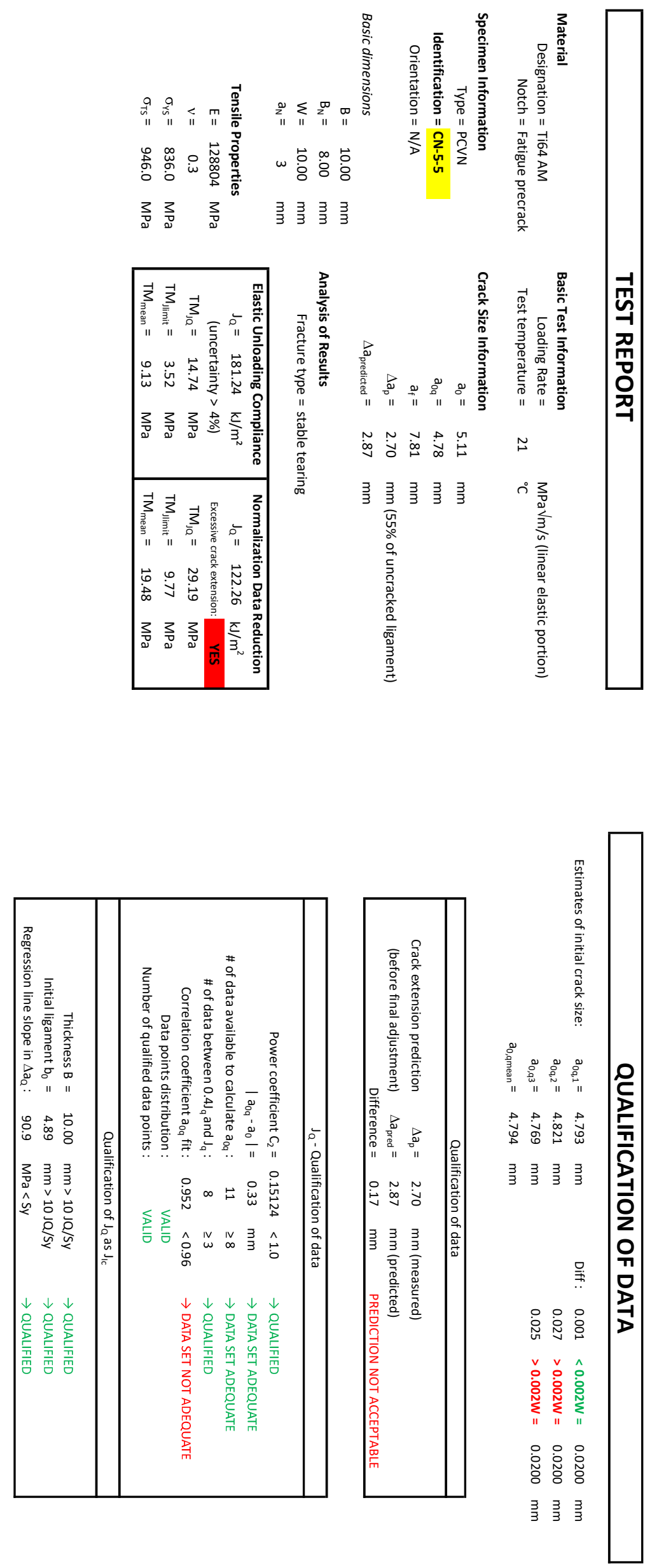

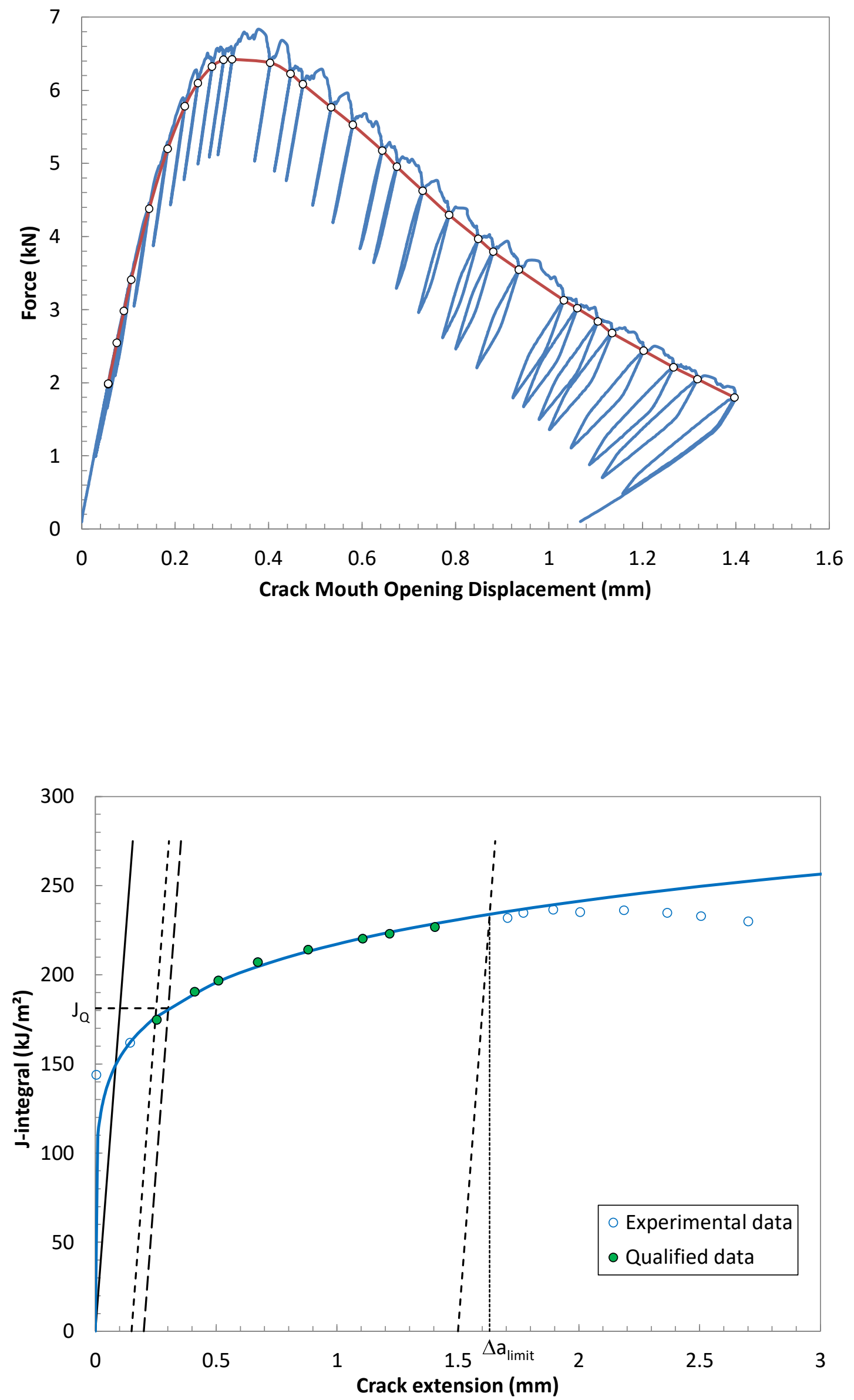

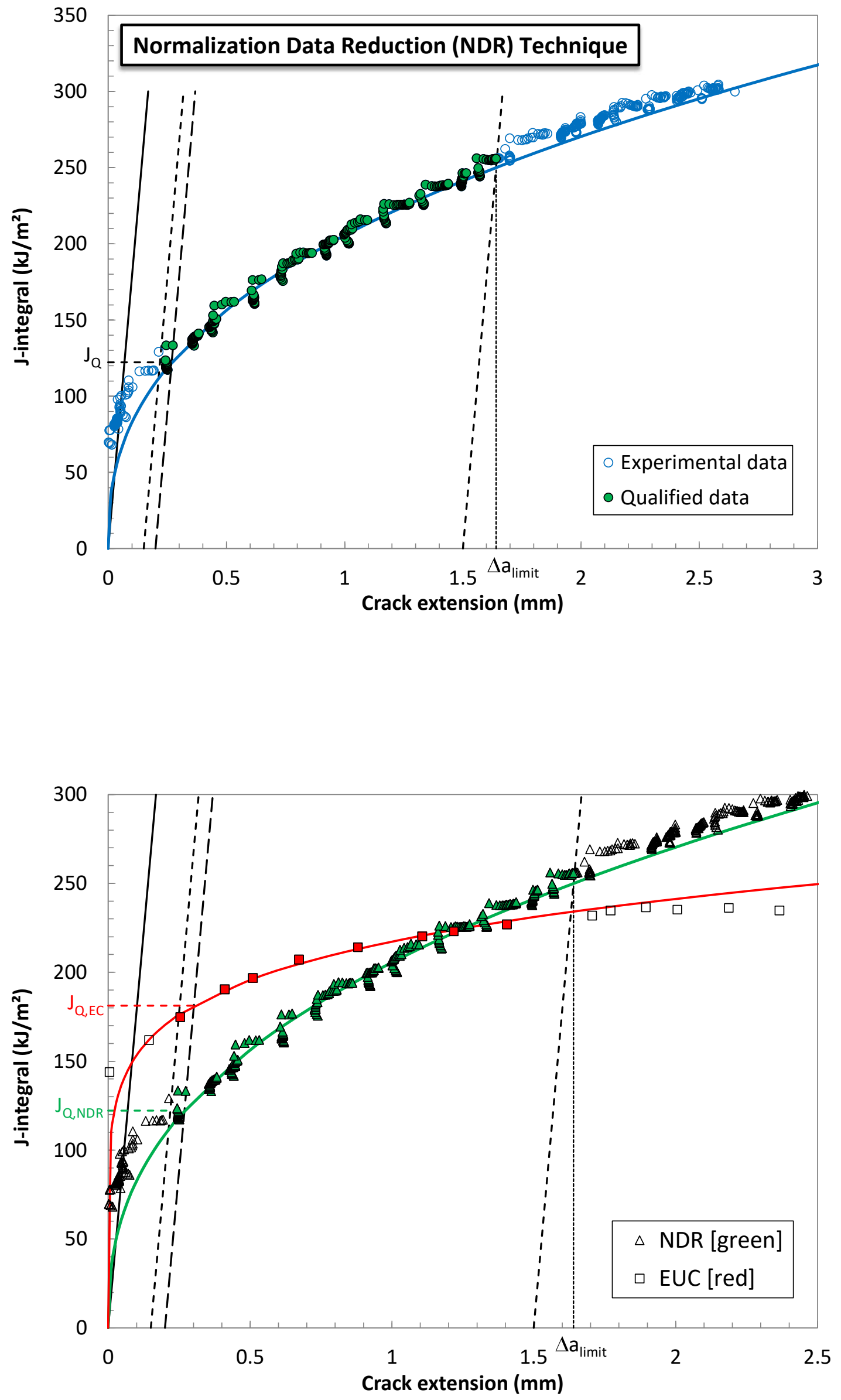

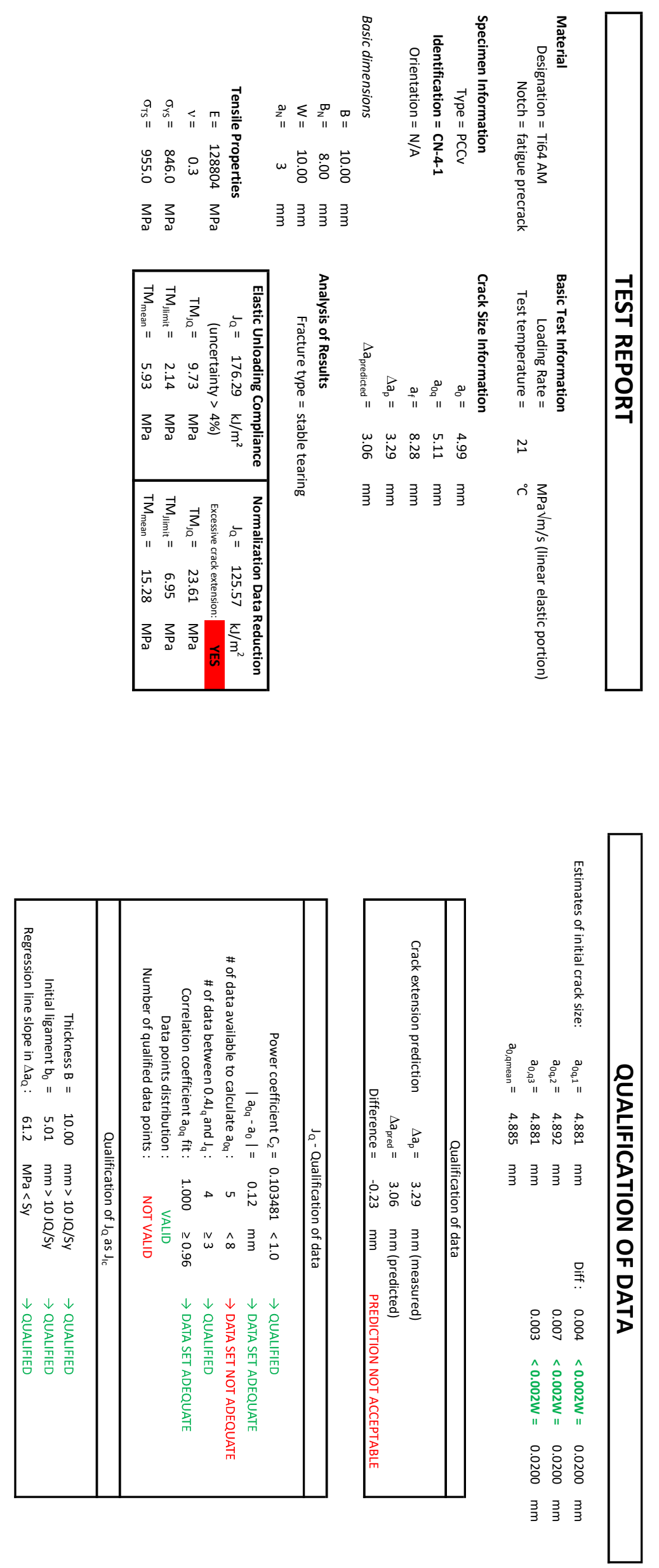

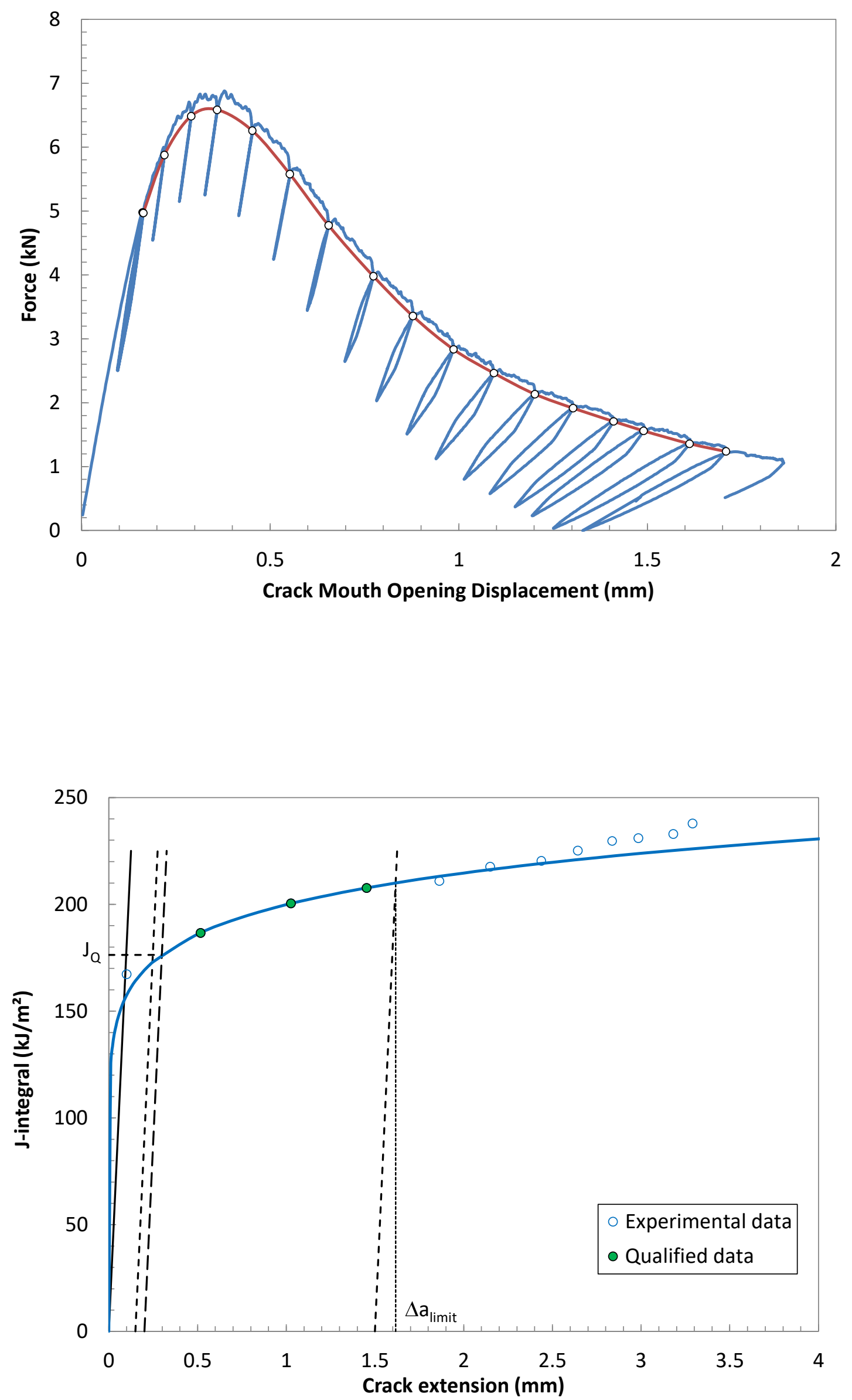

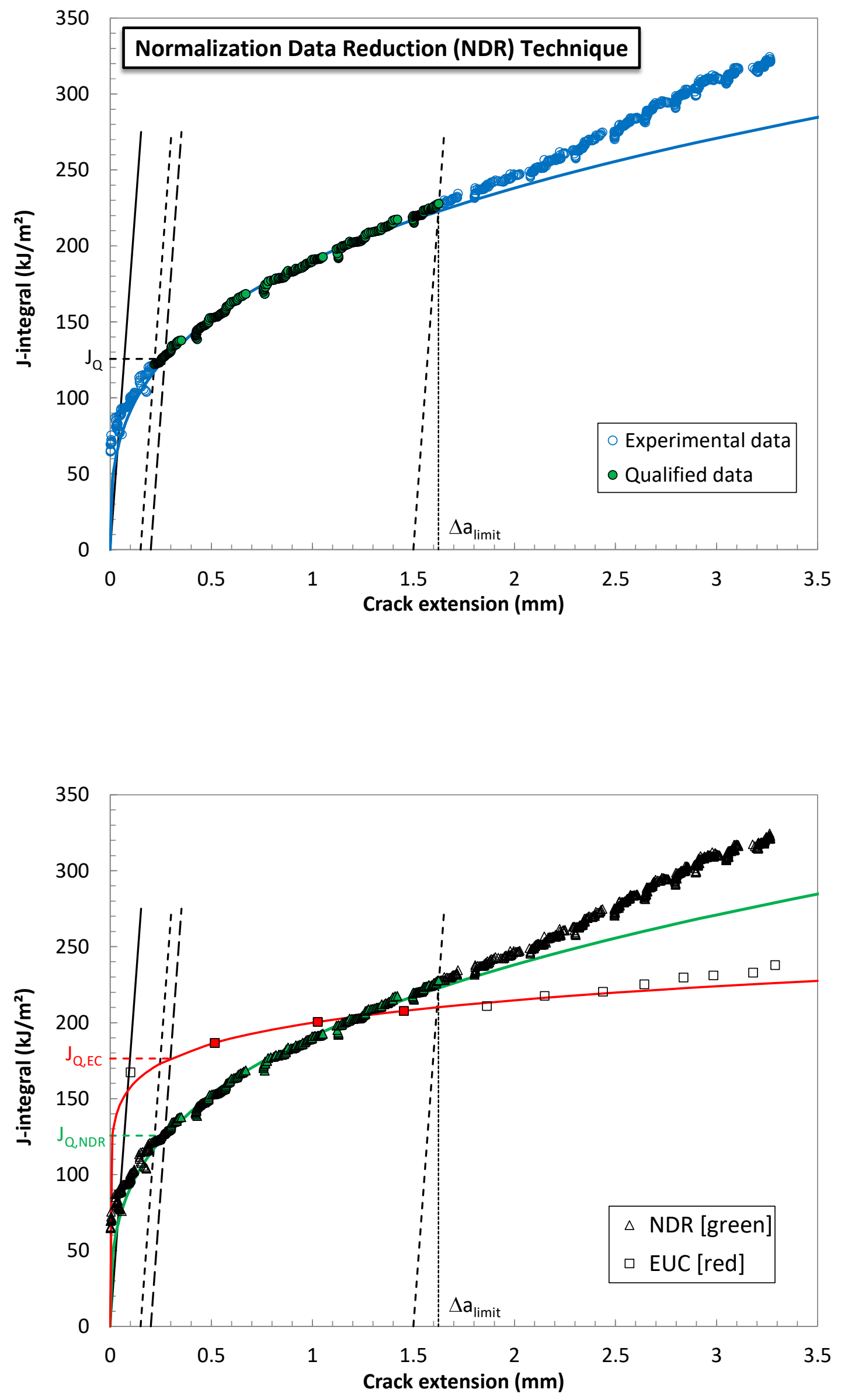

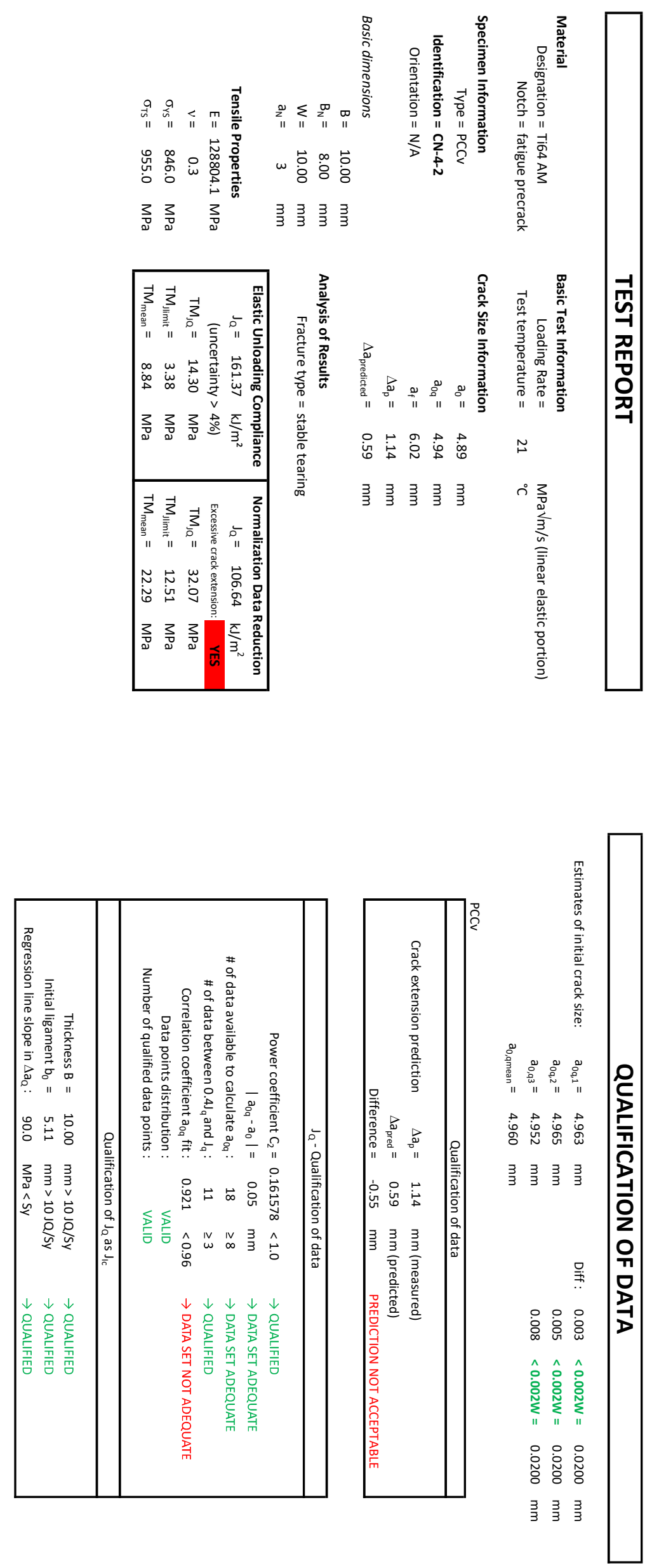

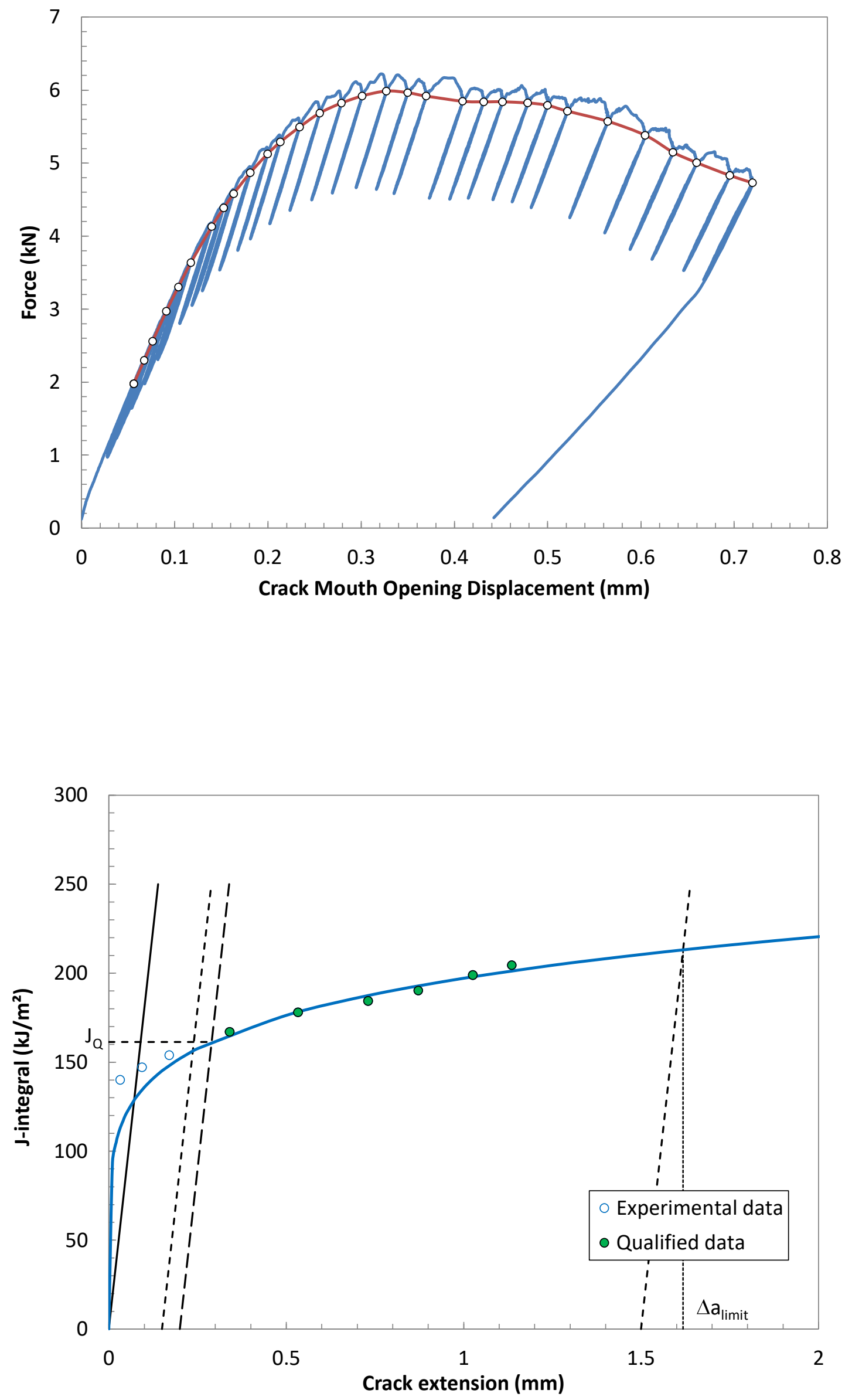

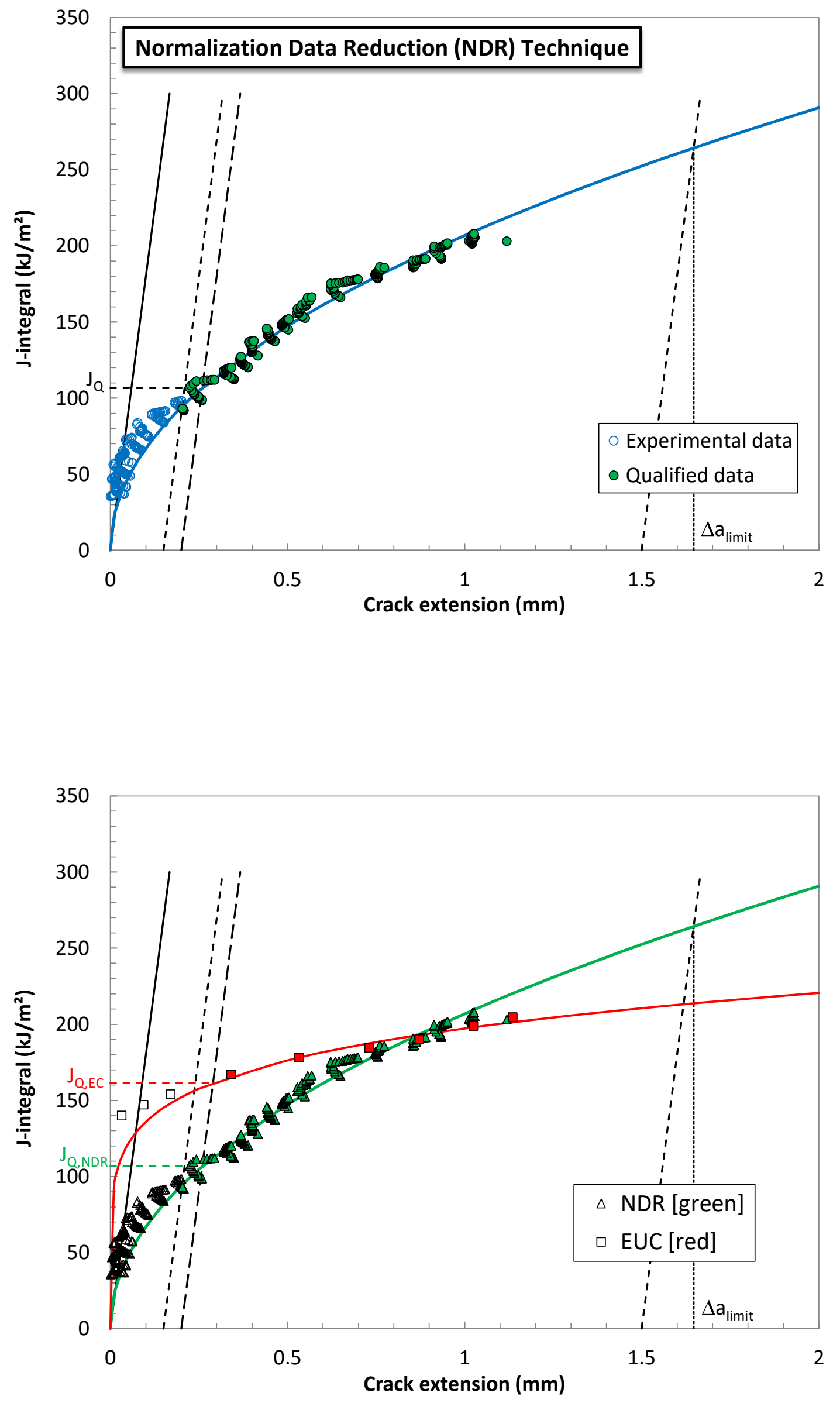

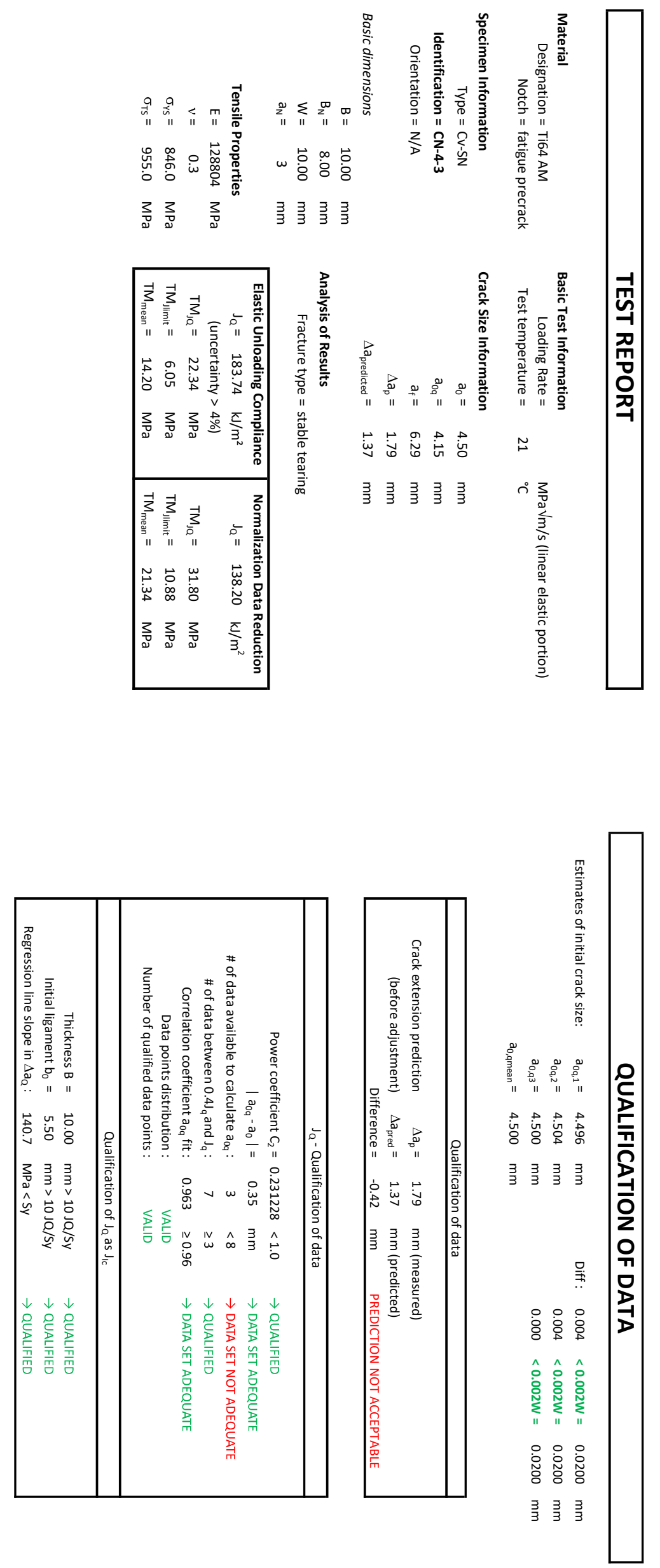

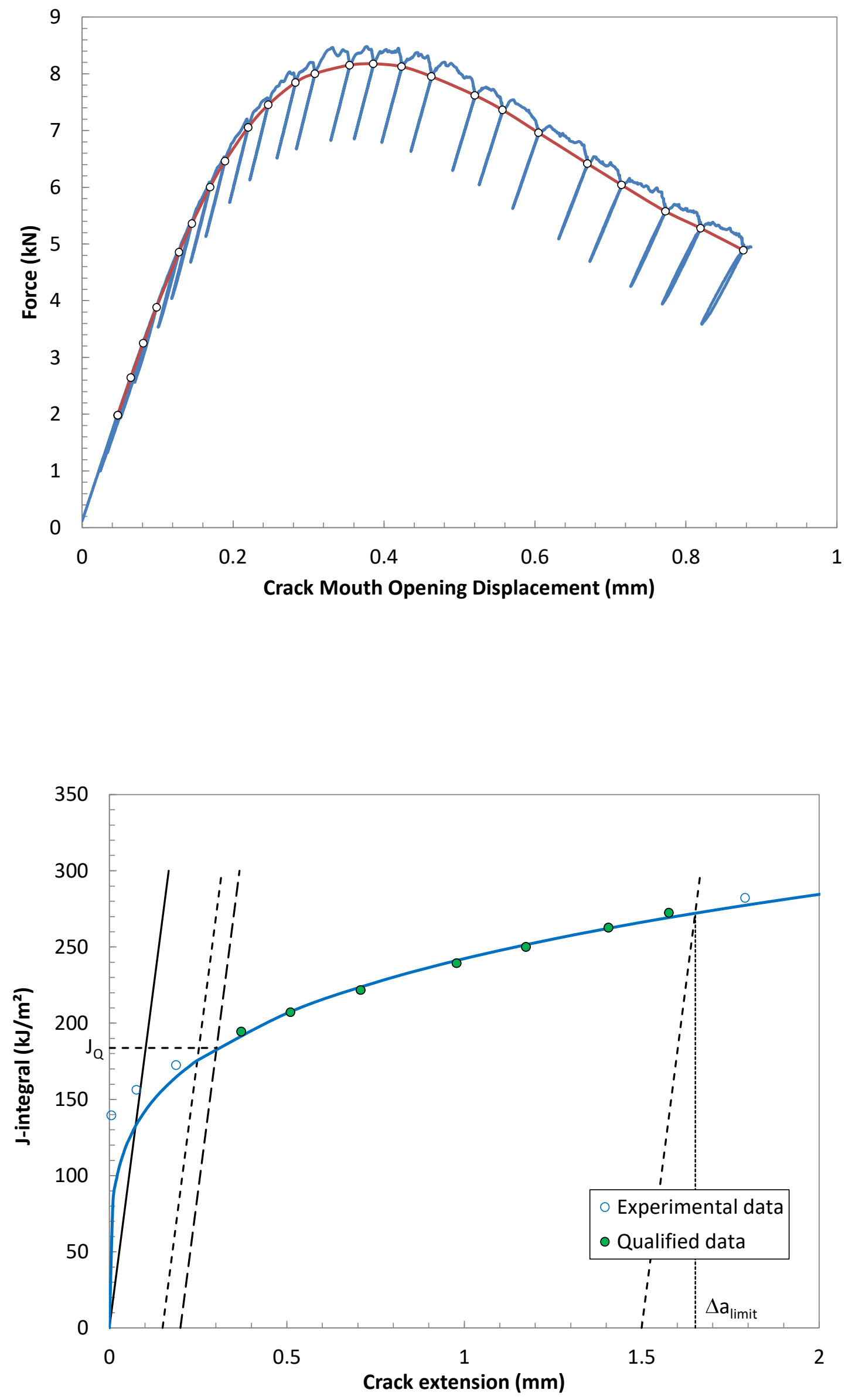

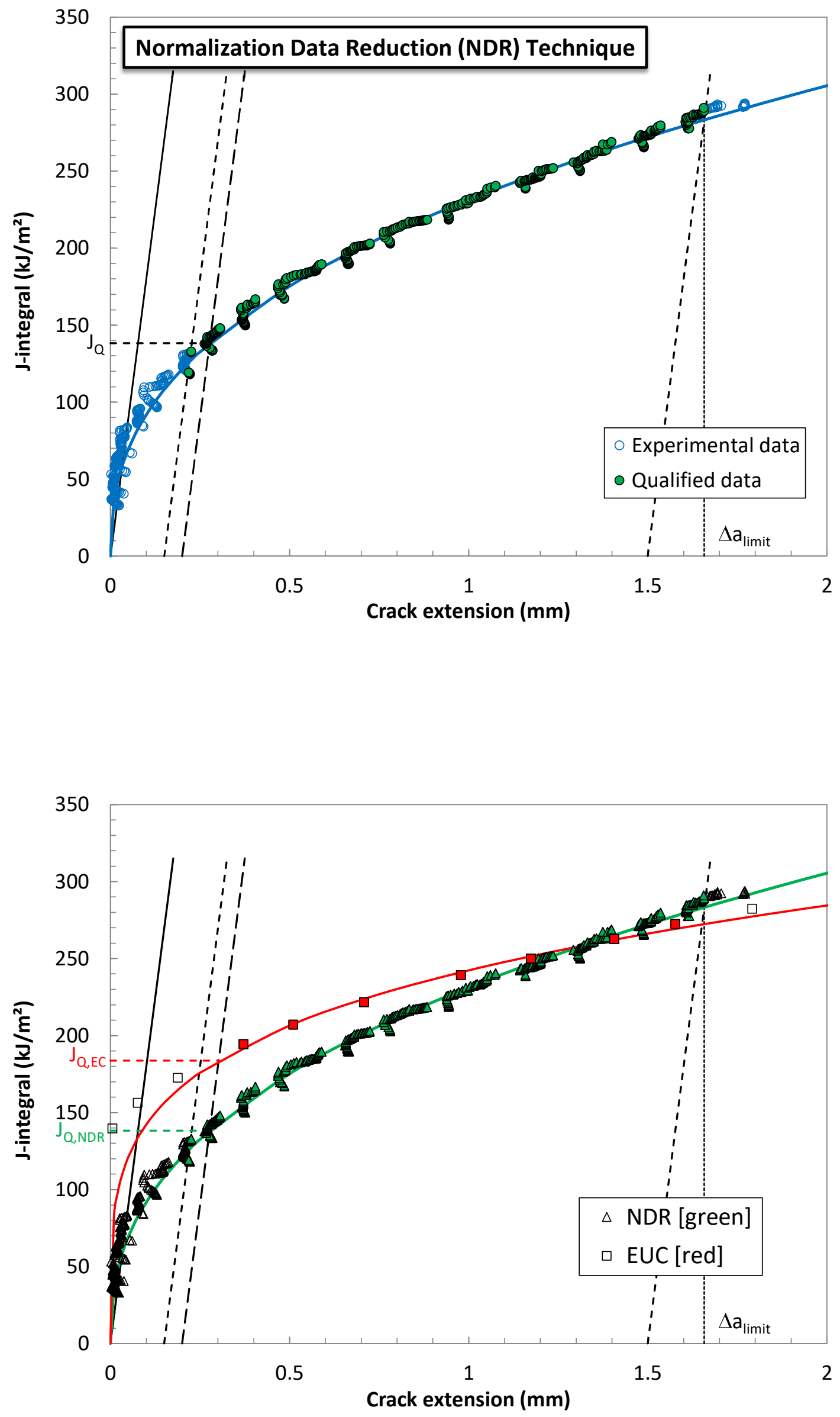
ANNEX 4

\section{Classic HIP, supported}



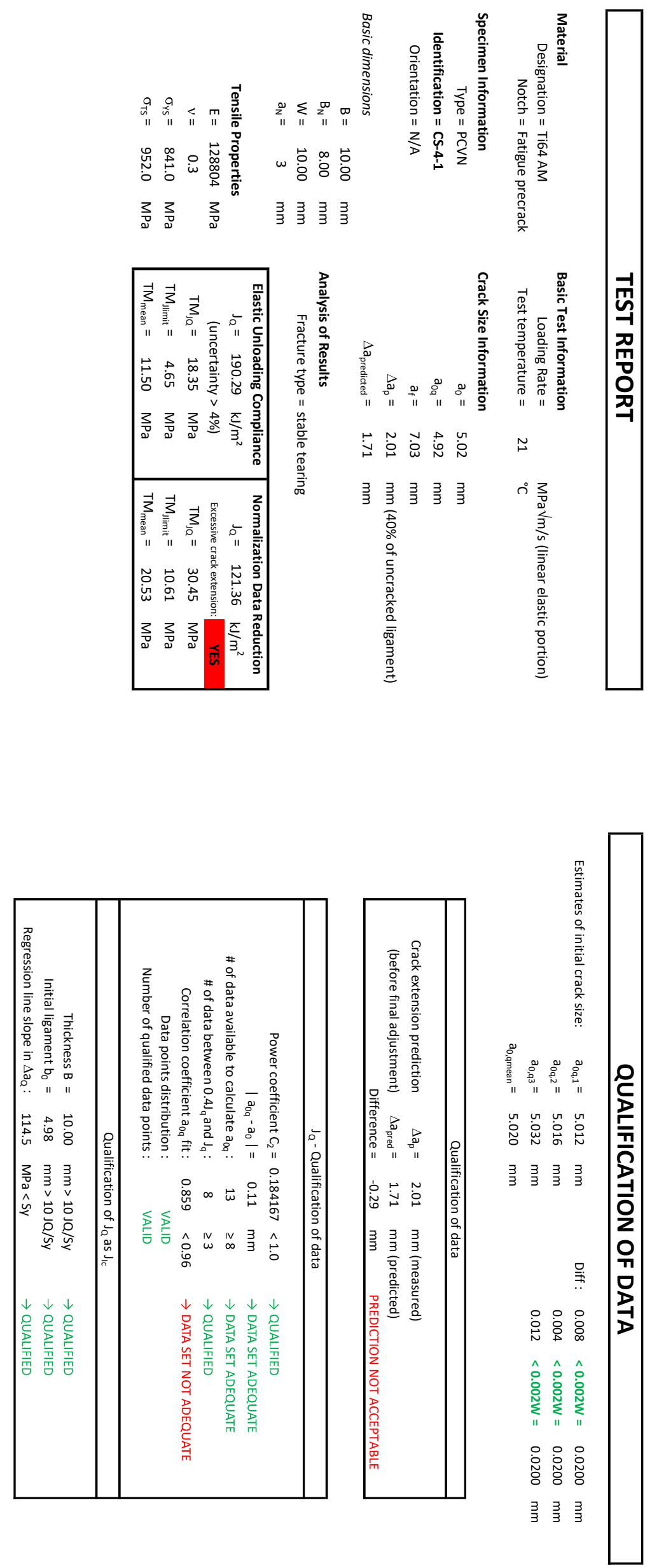

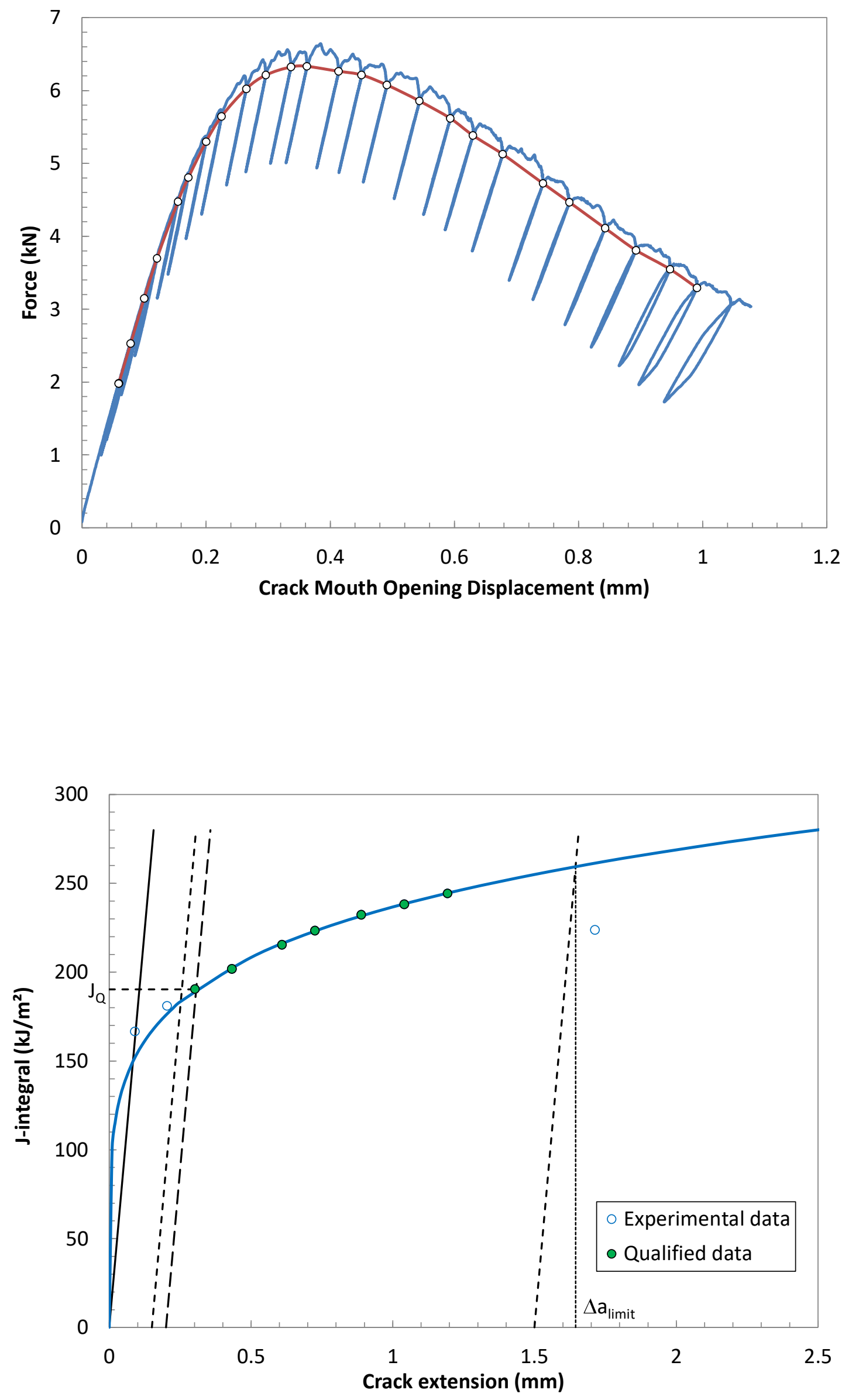

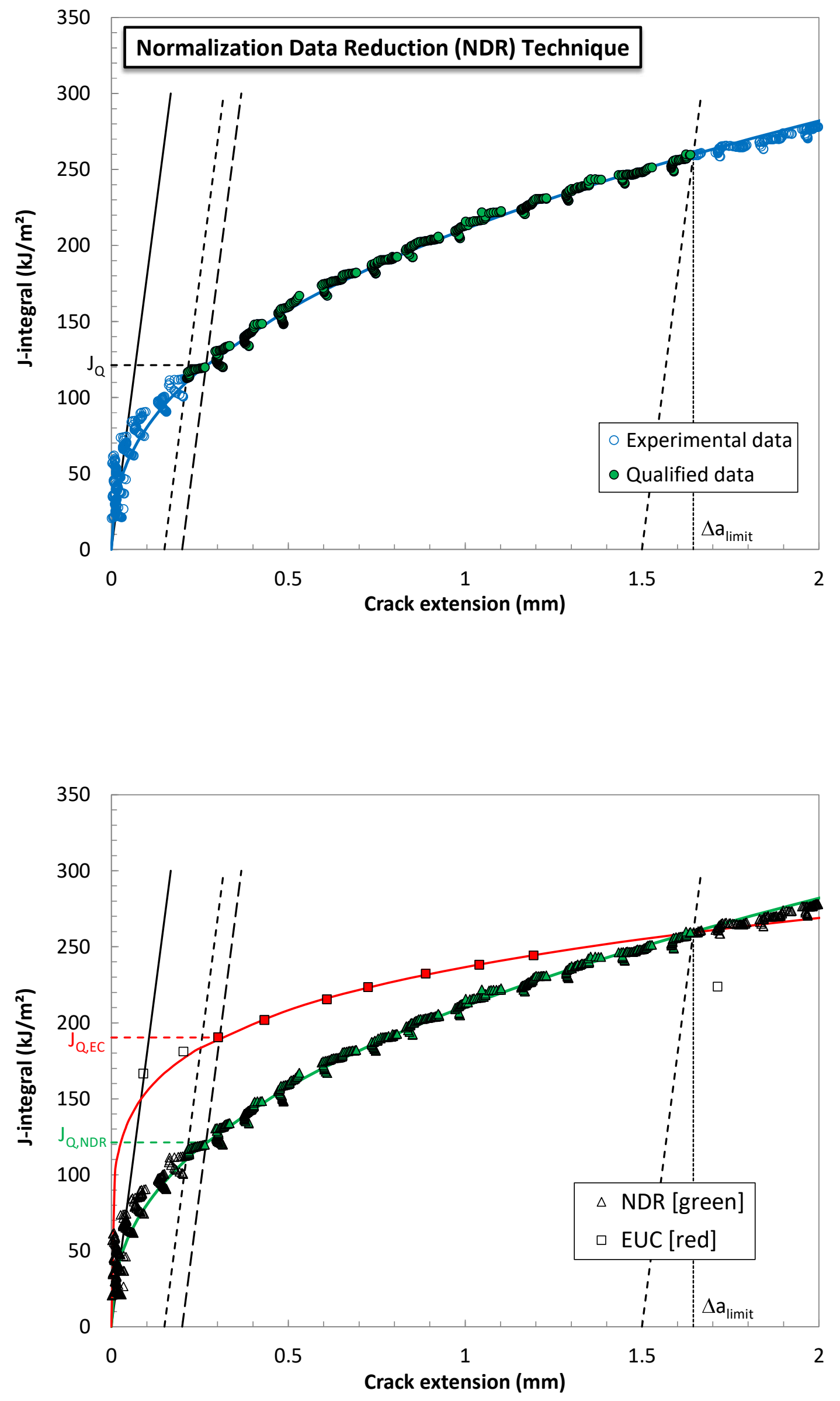

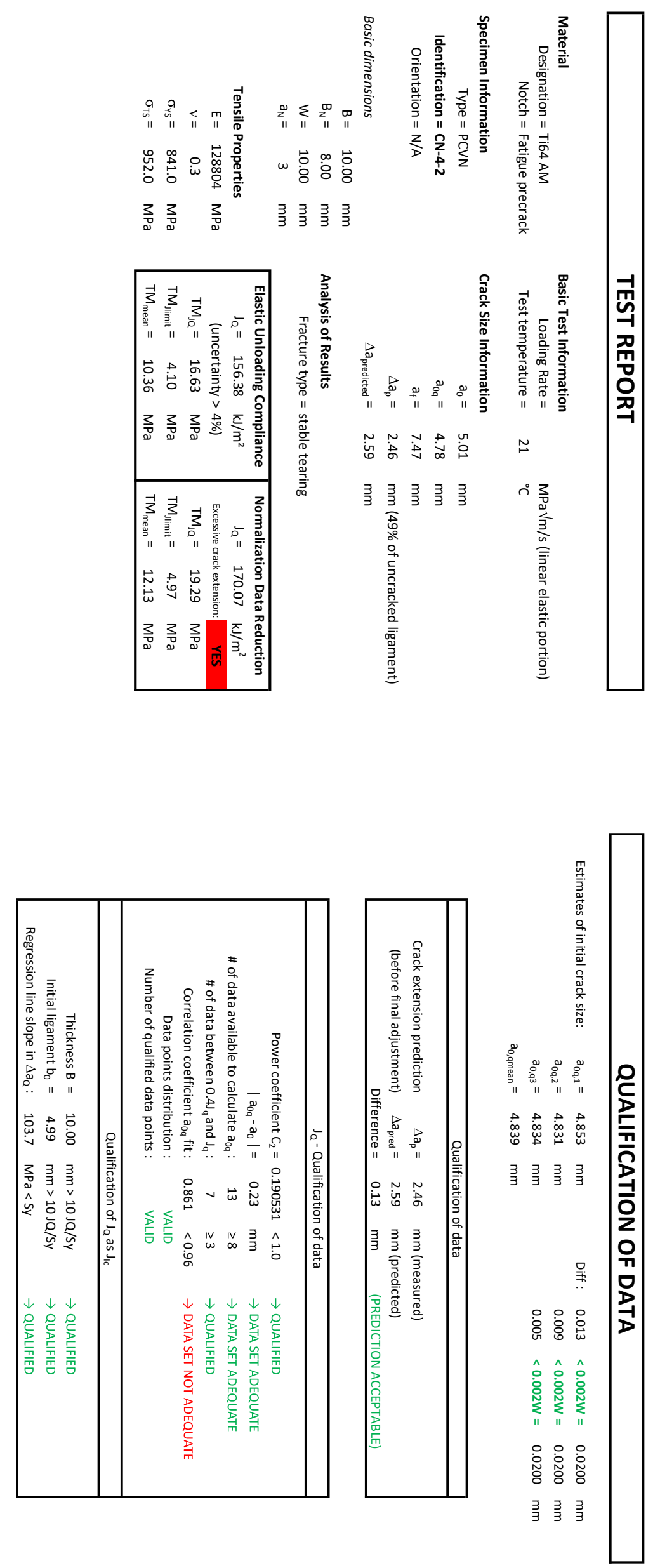

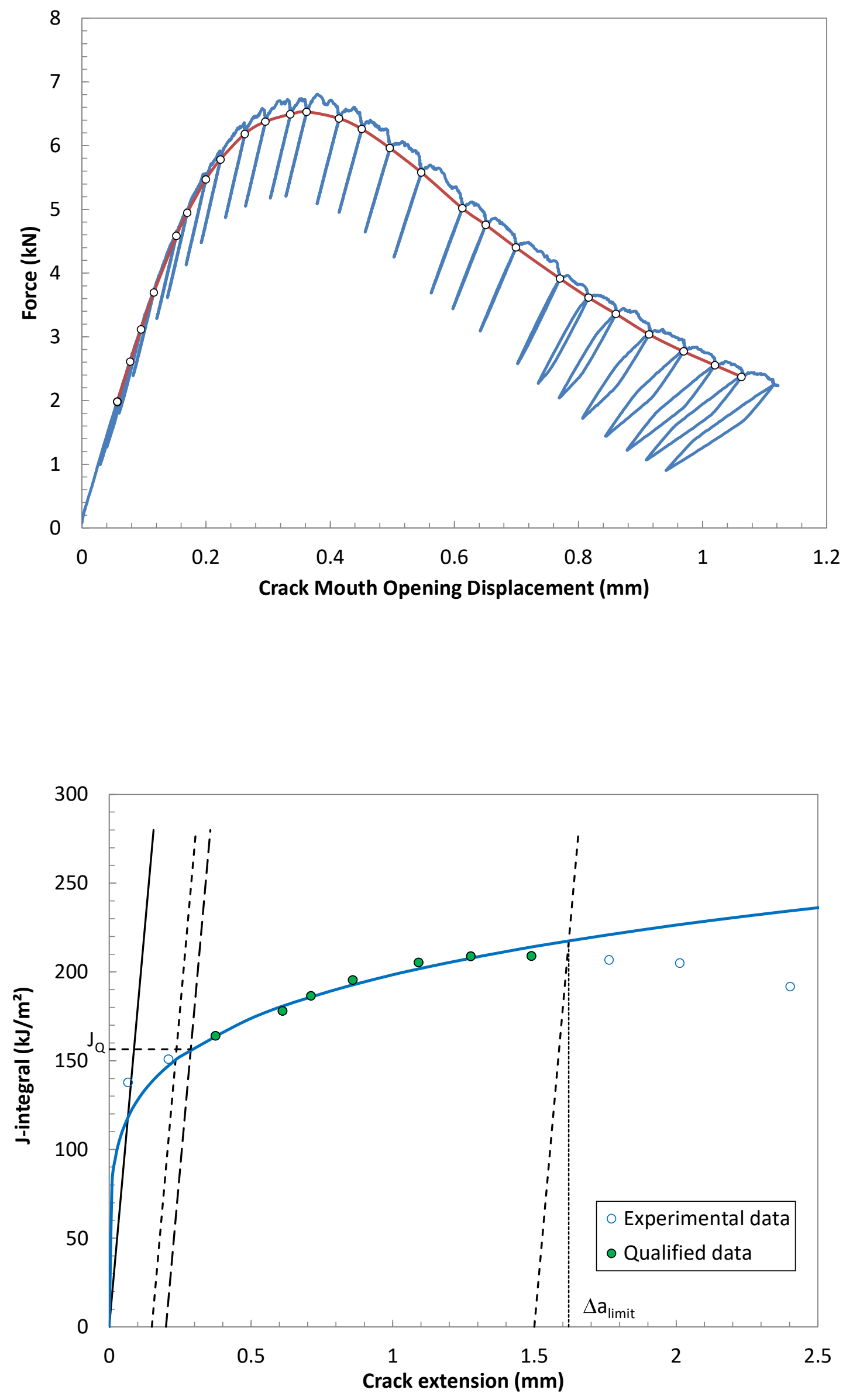

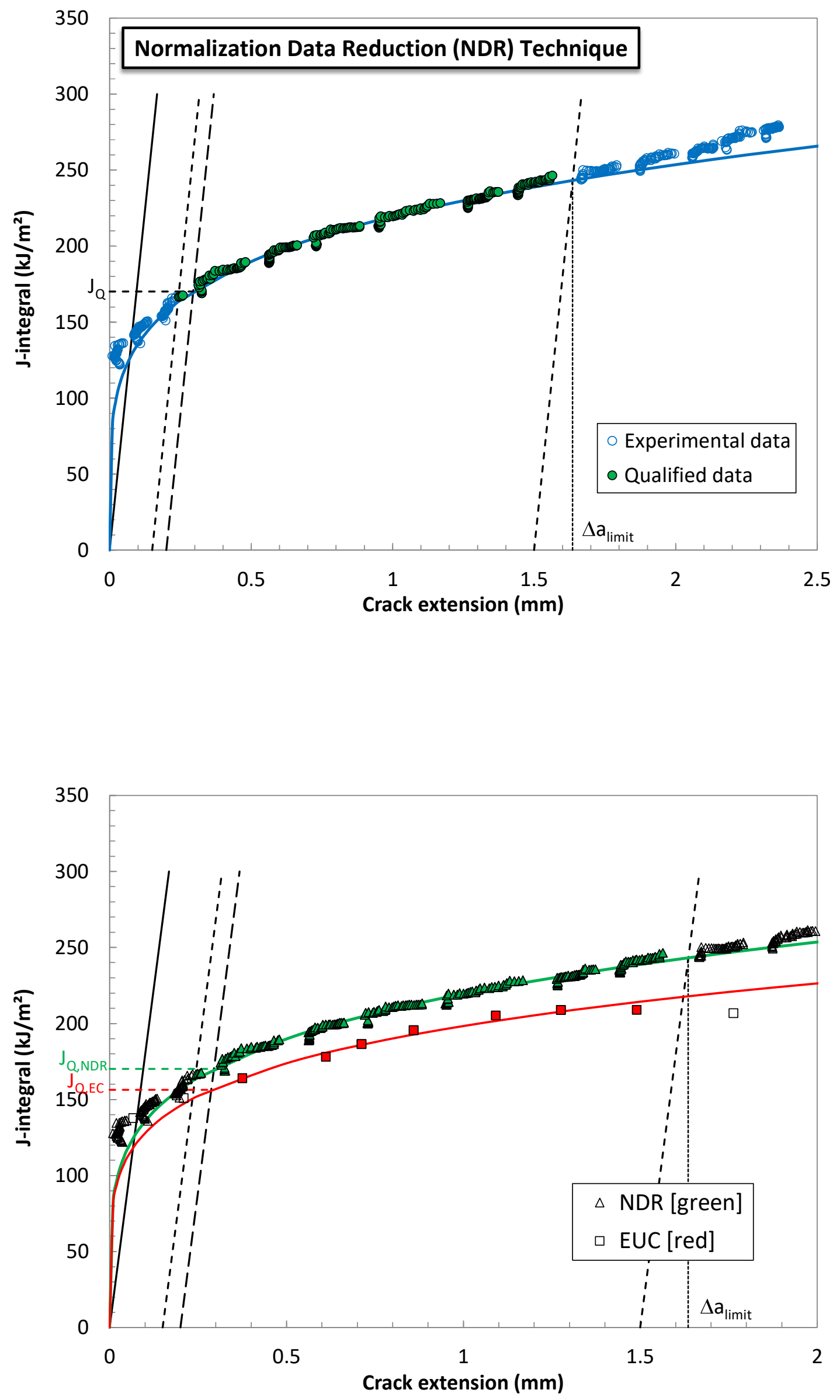

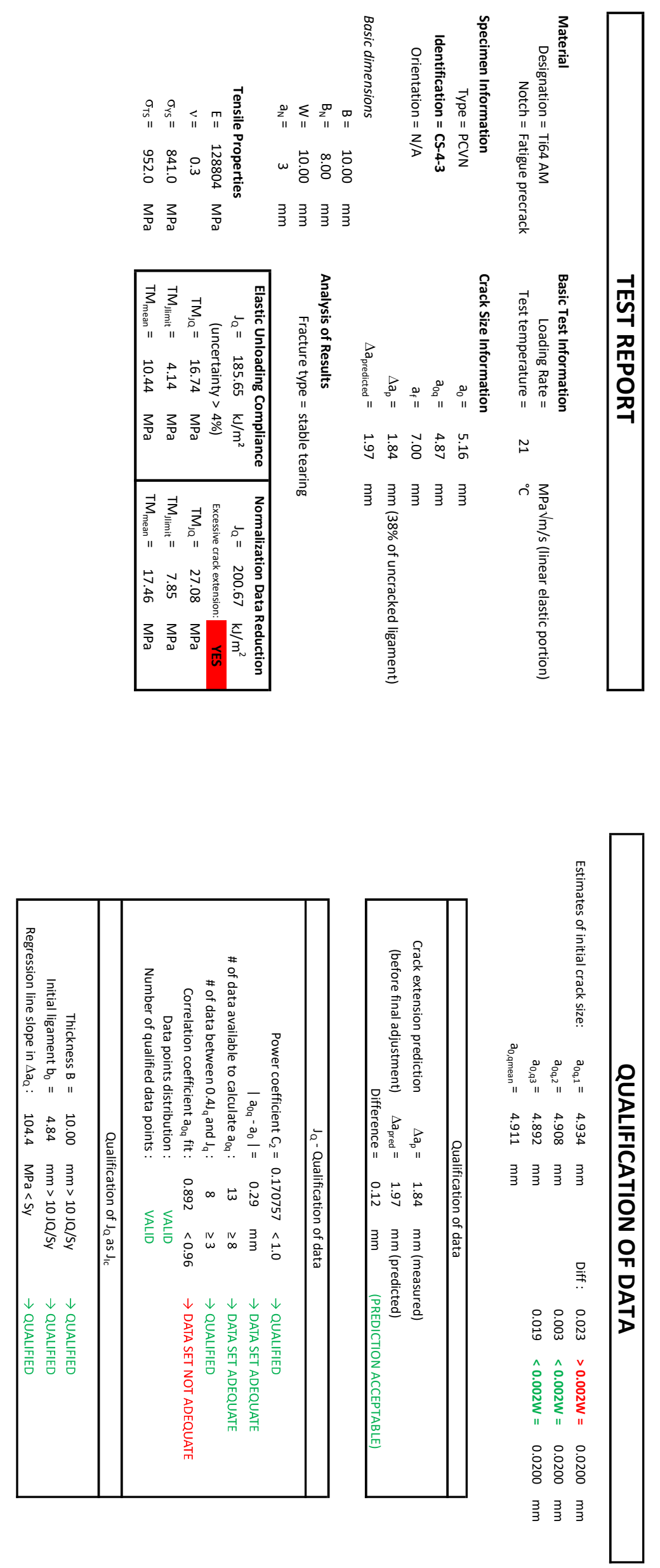

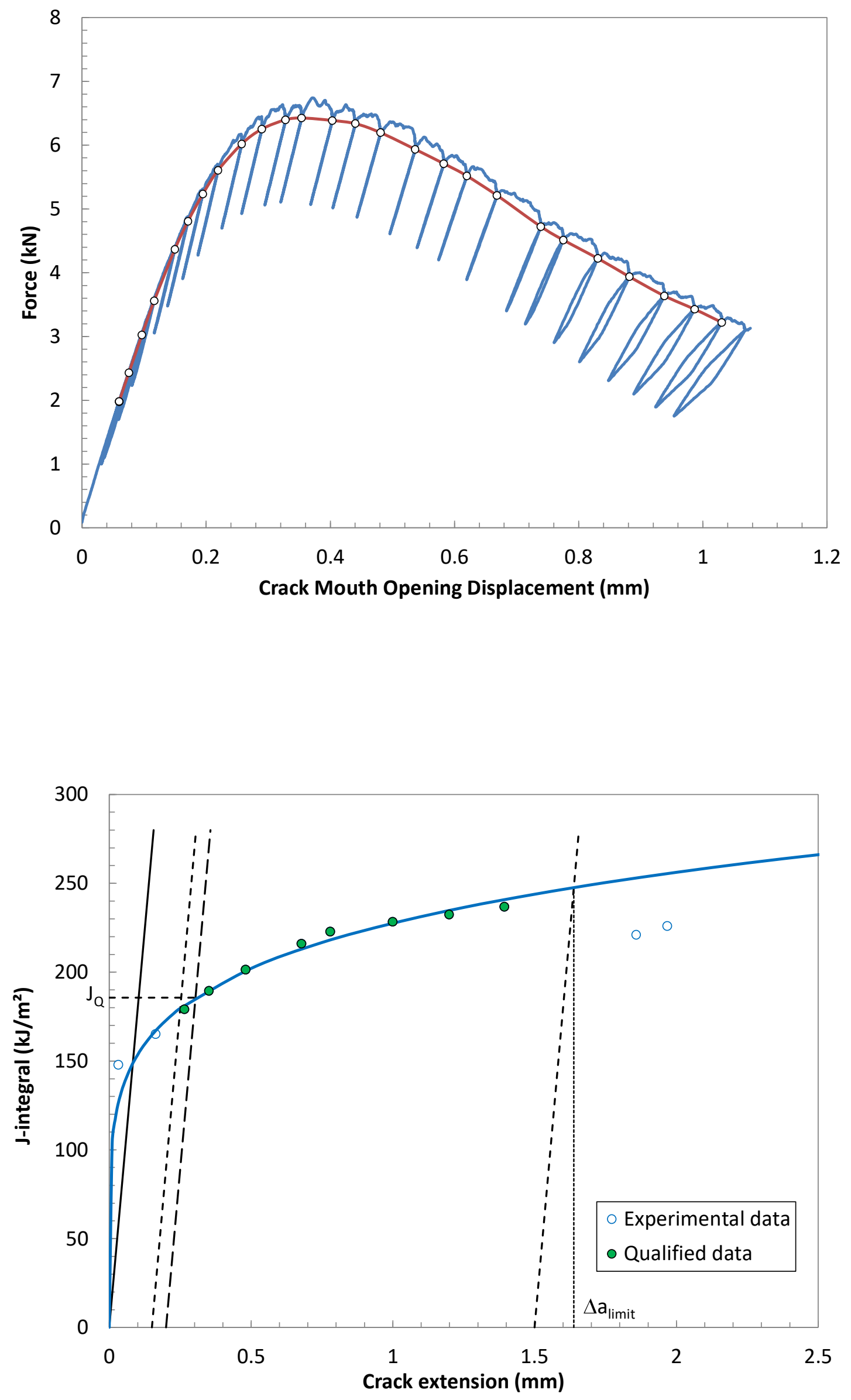

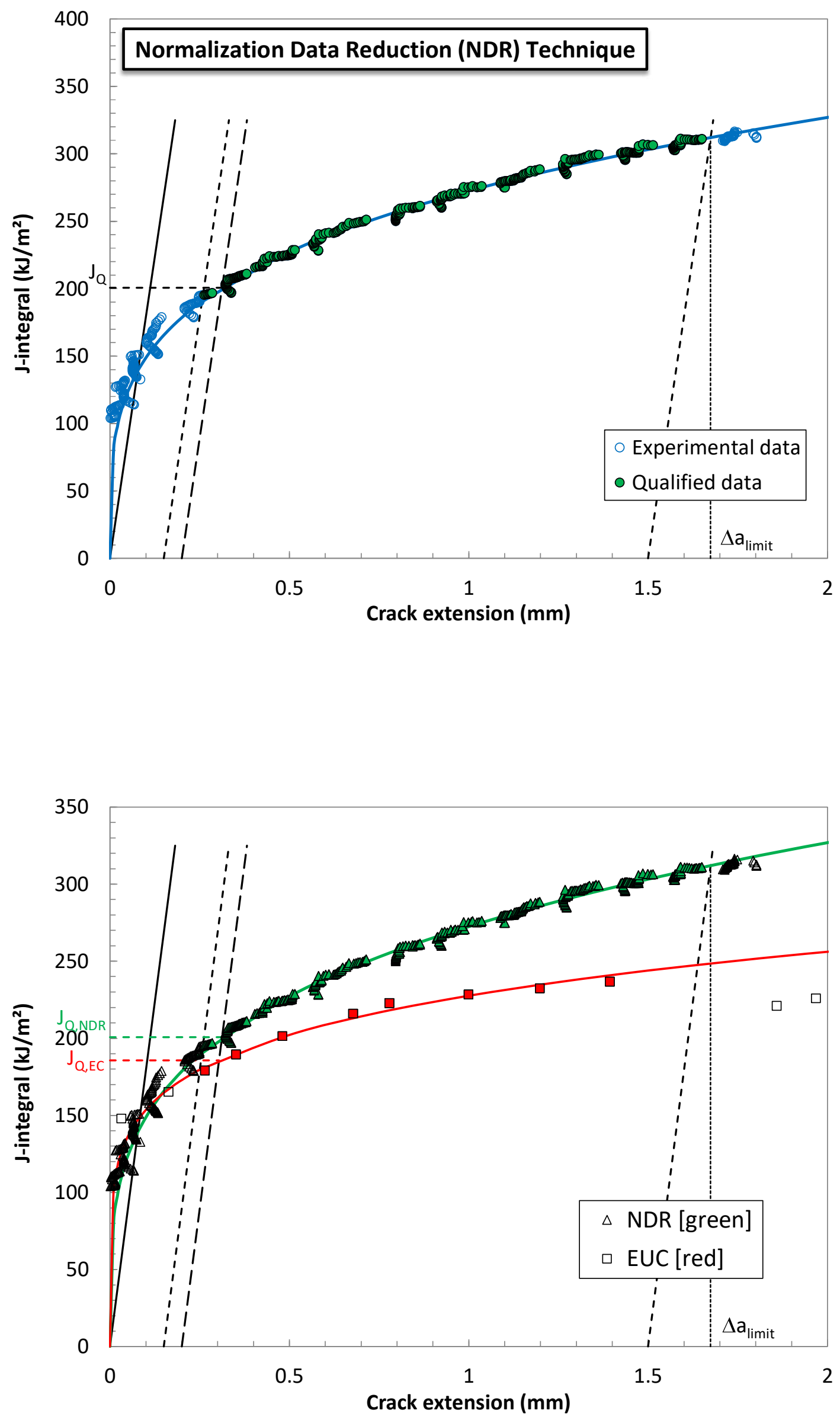


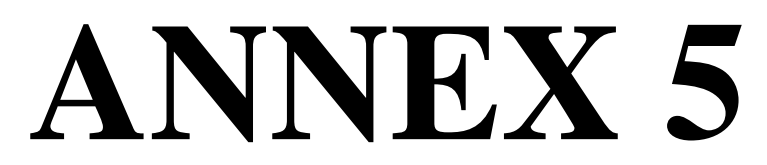

\section{Super- $\beta$ transus HIP, non-supported}



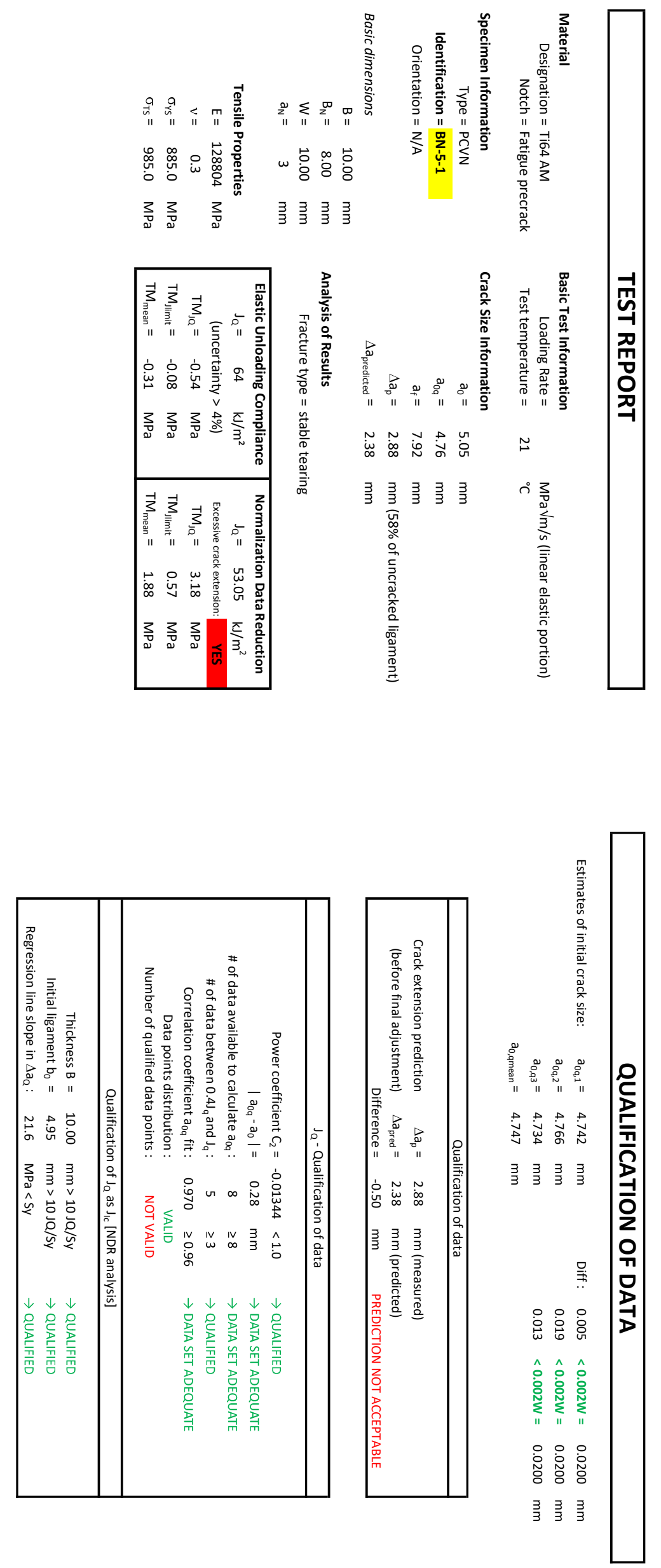

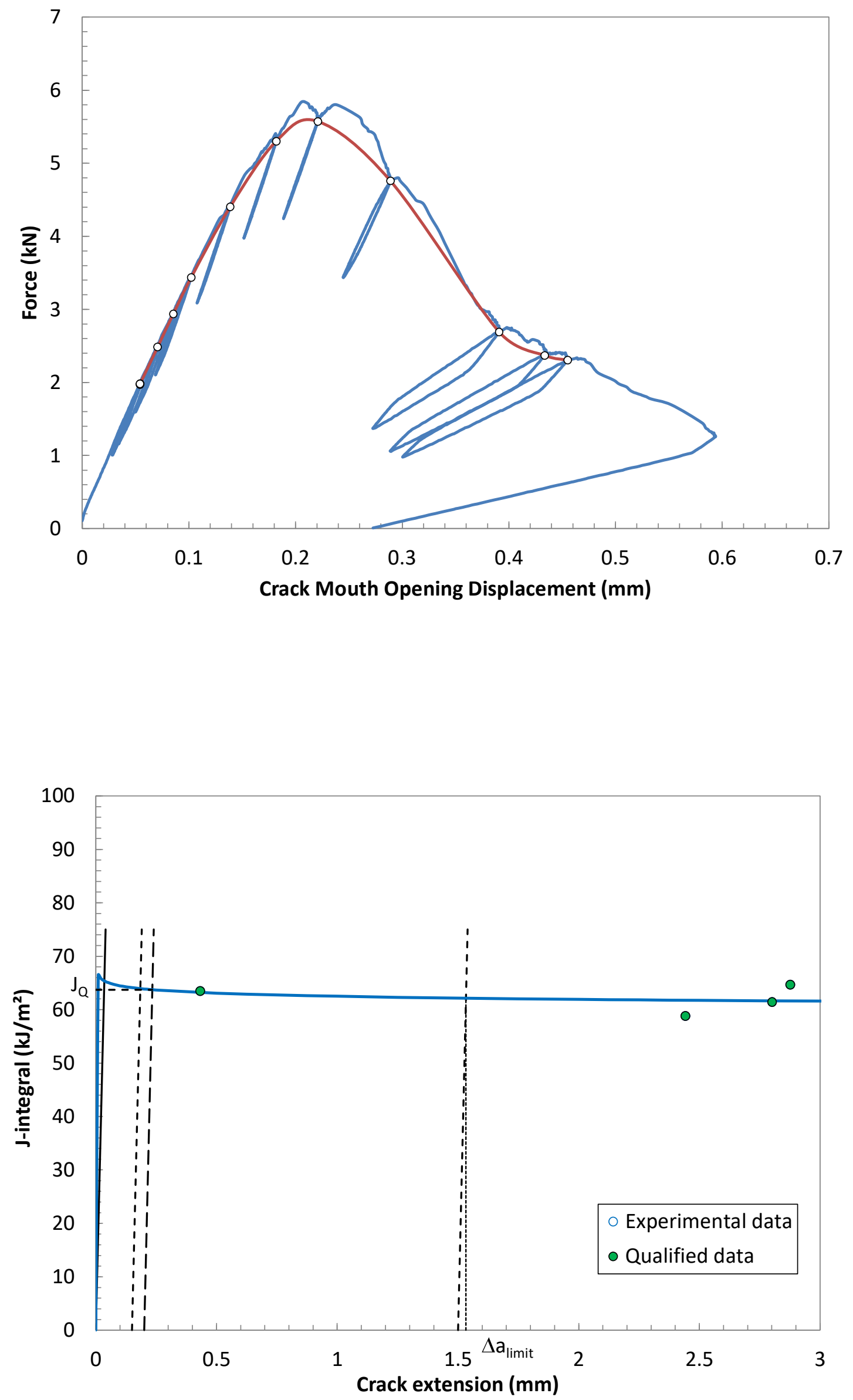

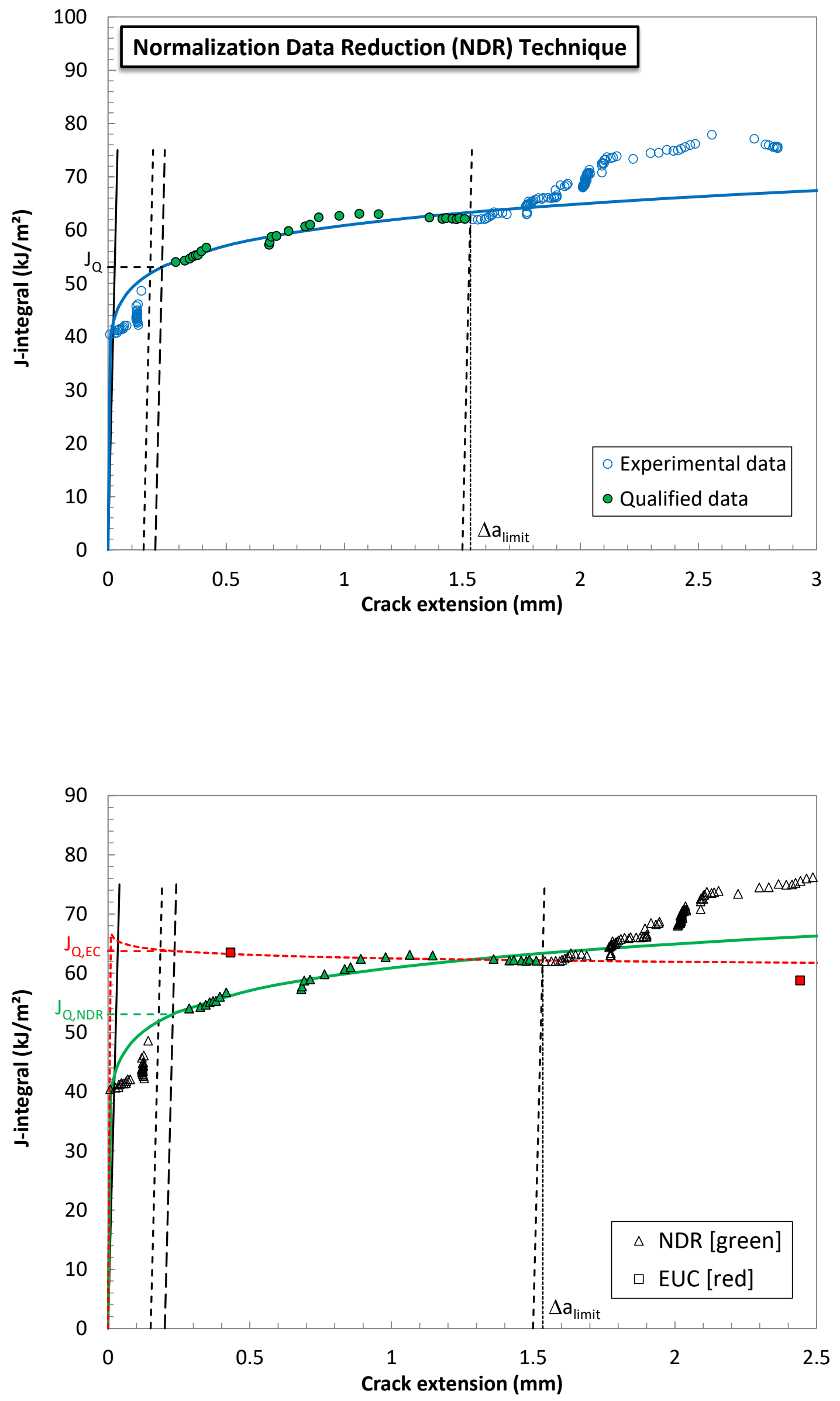


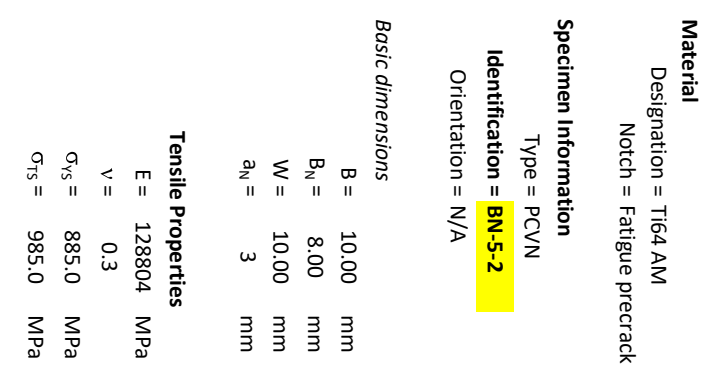

\begin{tabular}{|c|c|}
\hline 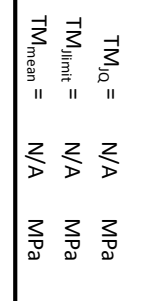 & 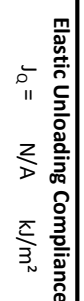 \\
\hline 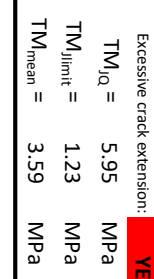 & 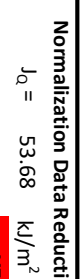 \\
\hline
\end{tabular}
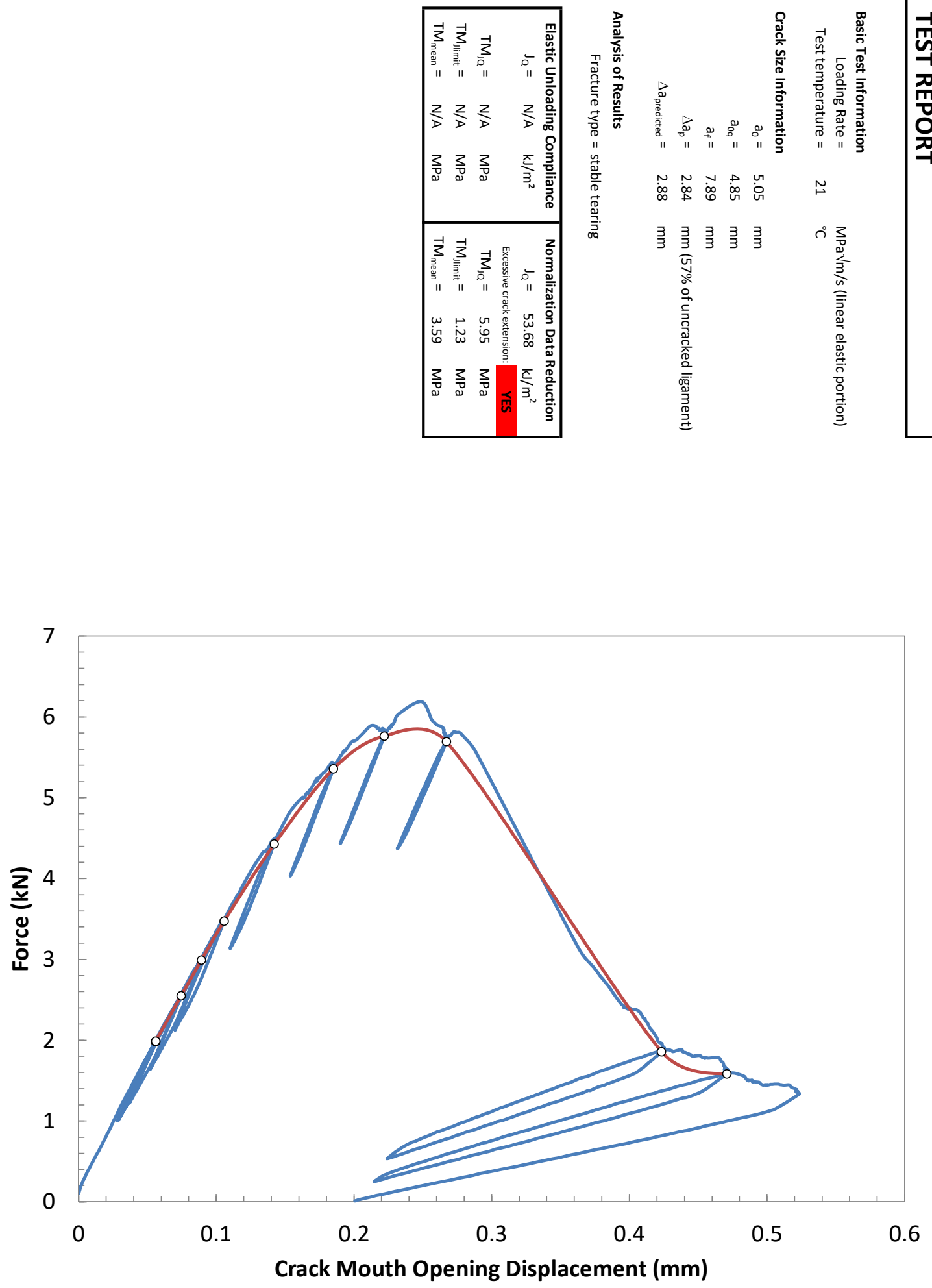

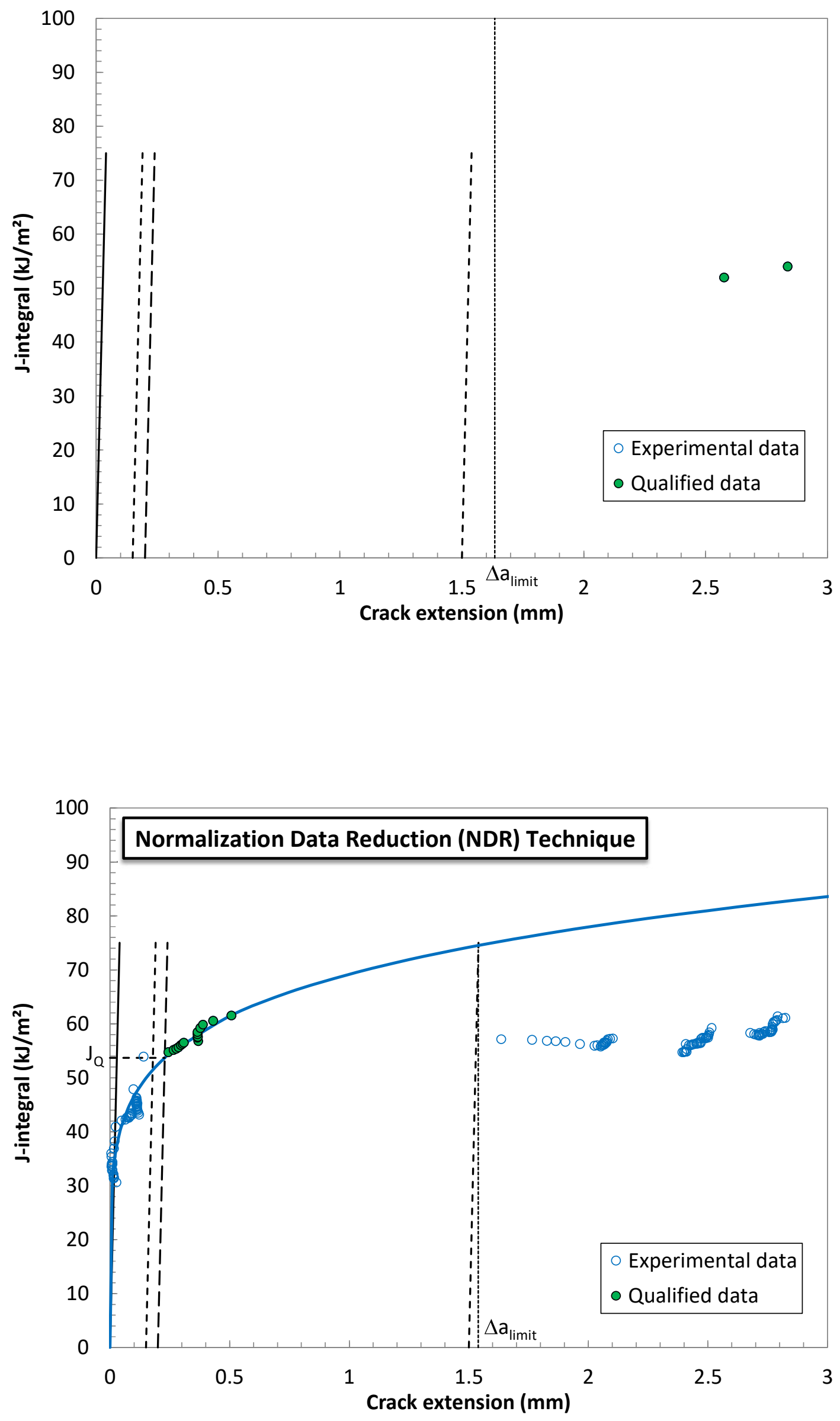


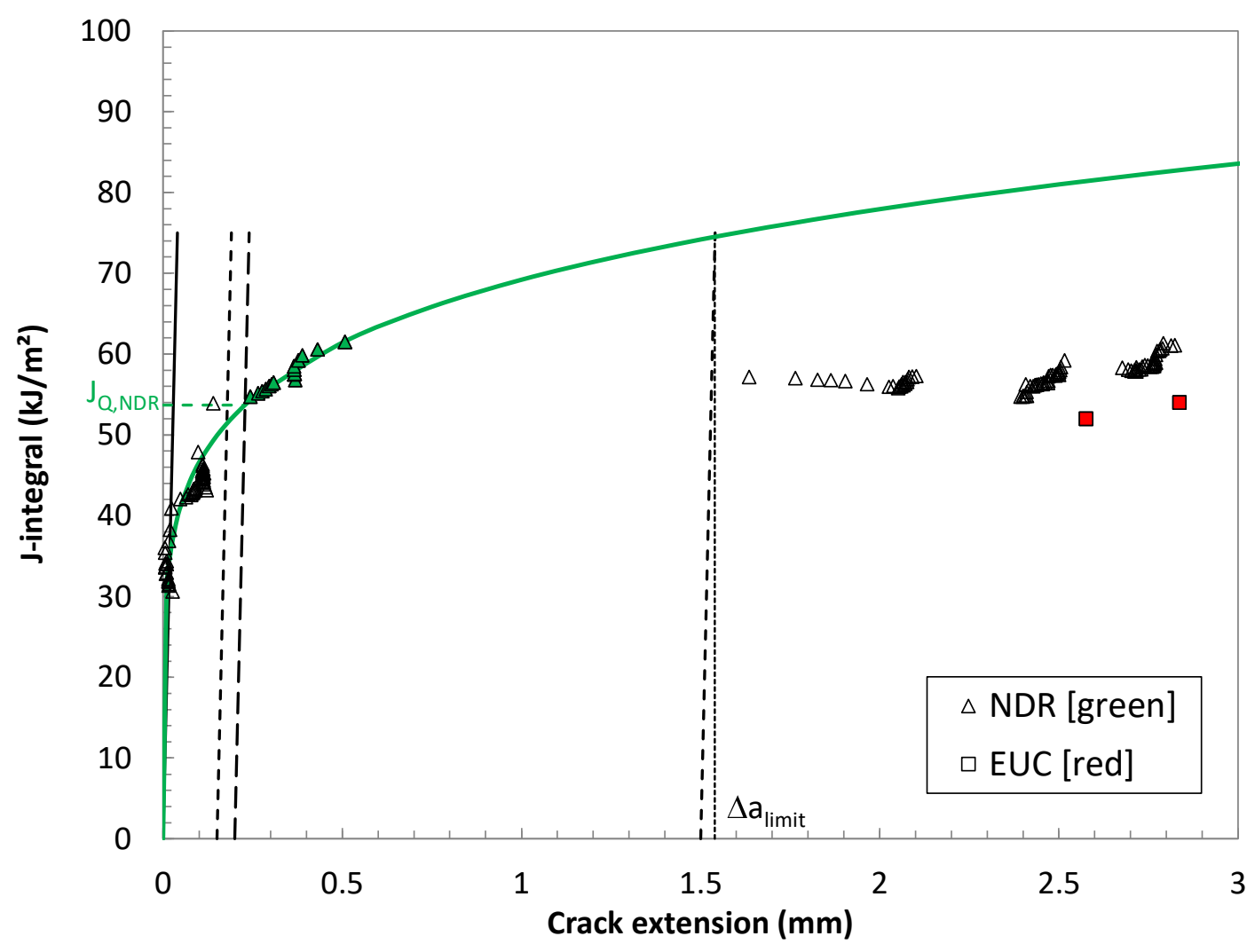

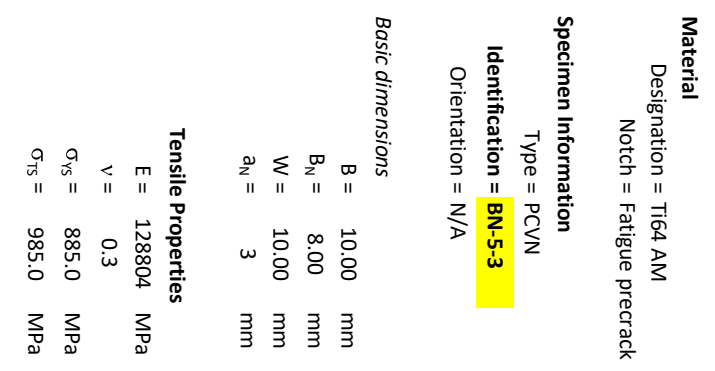

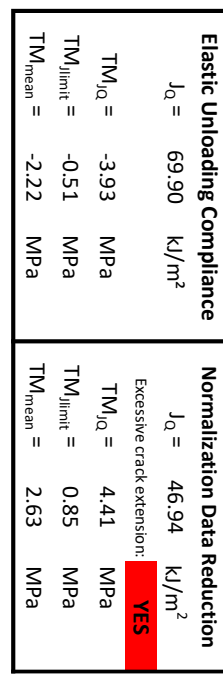
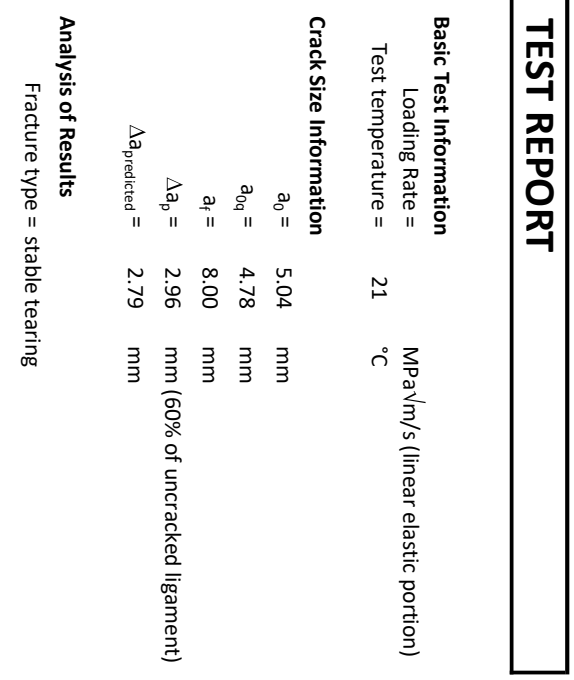

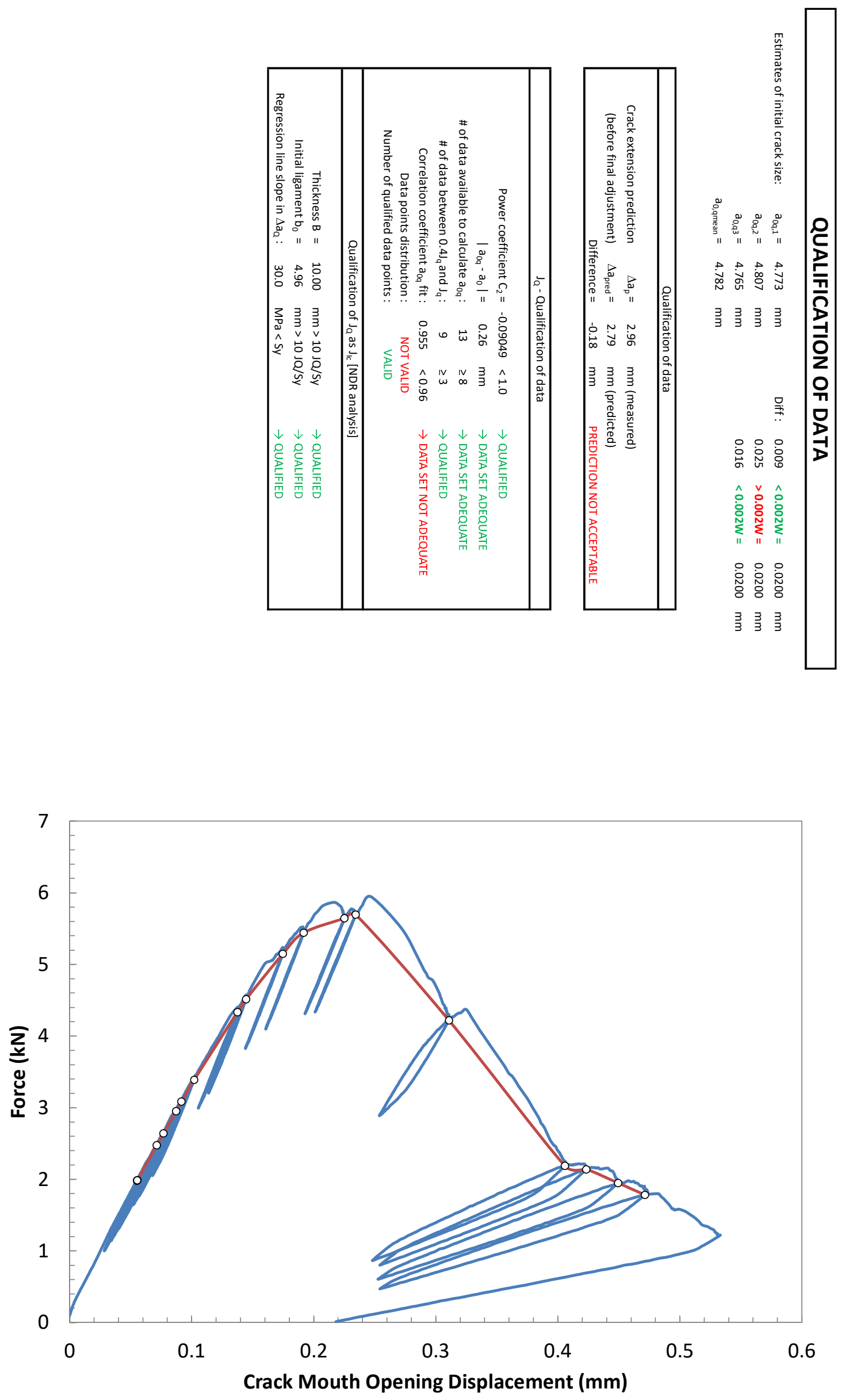

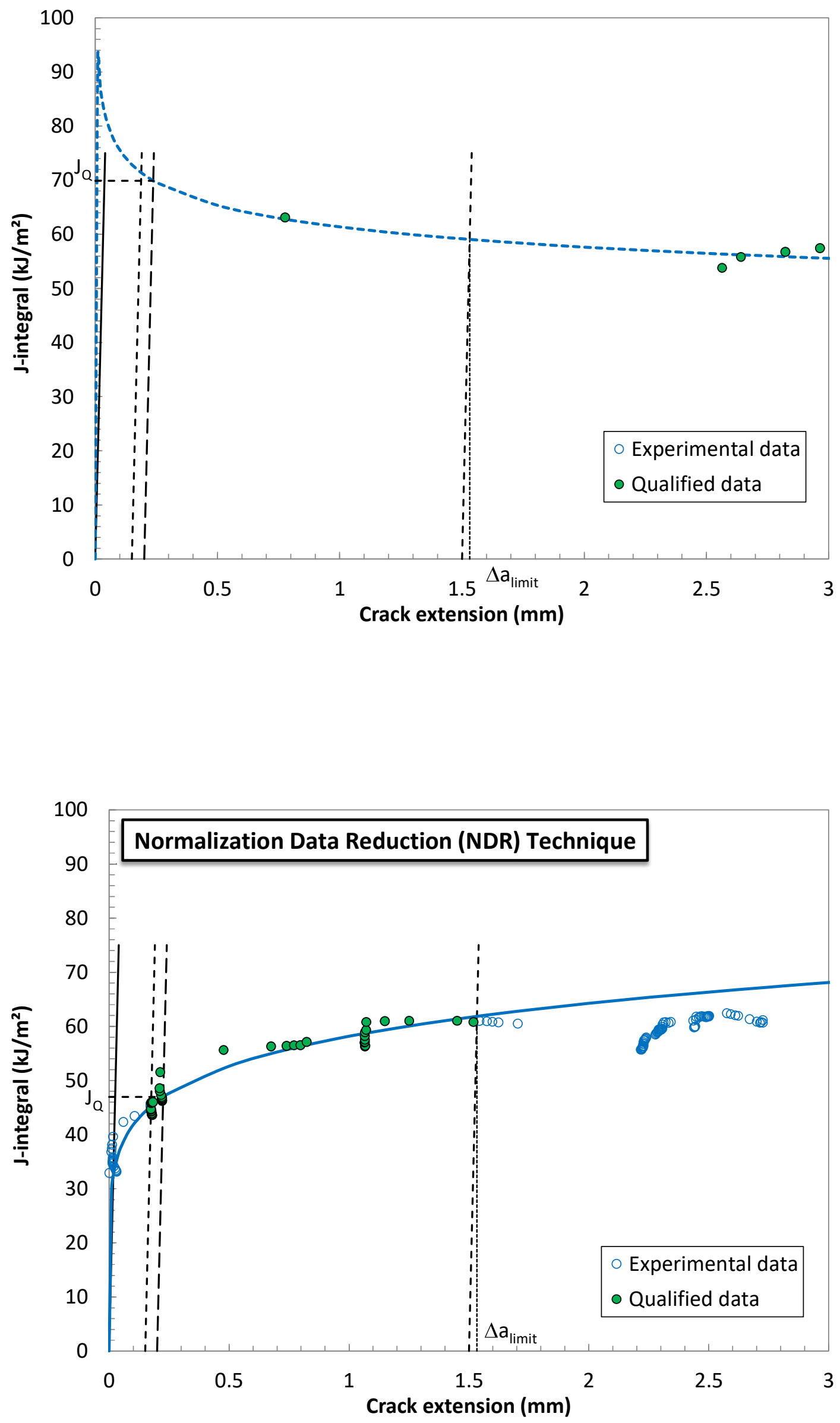

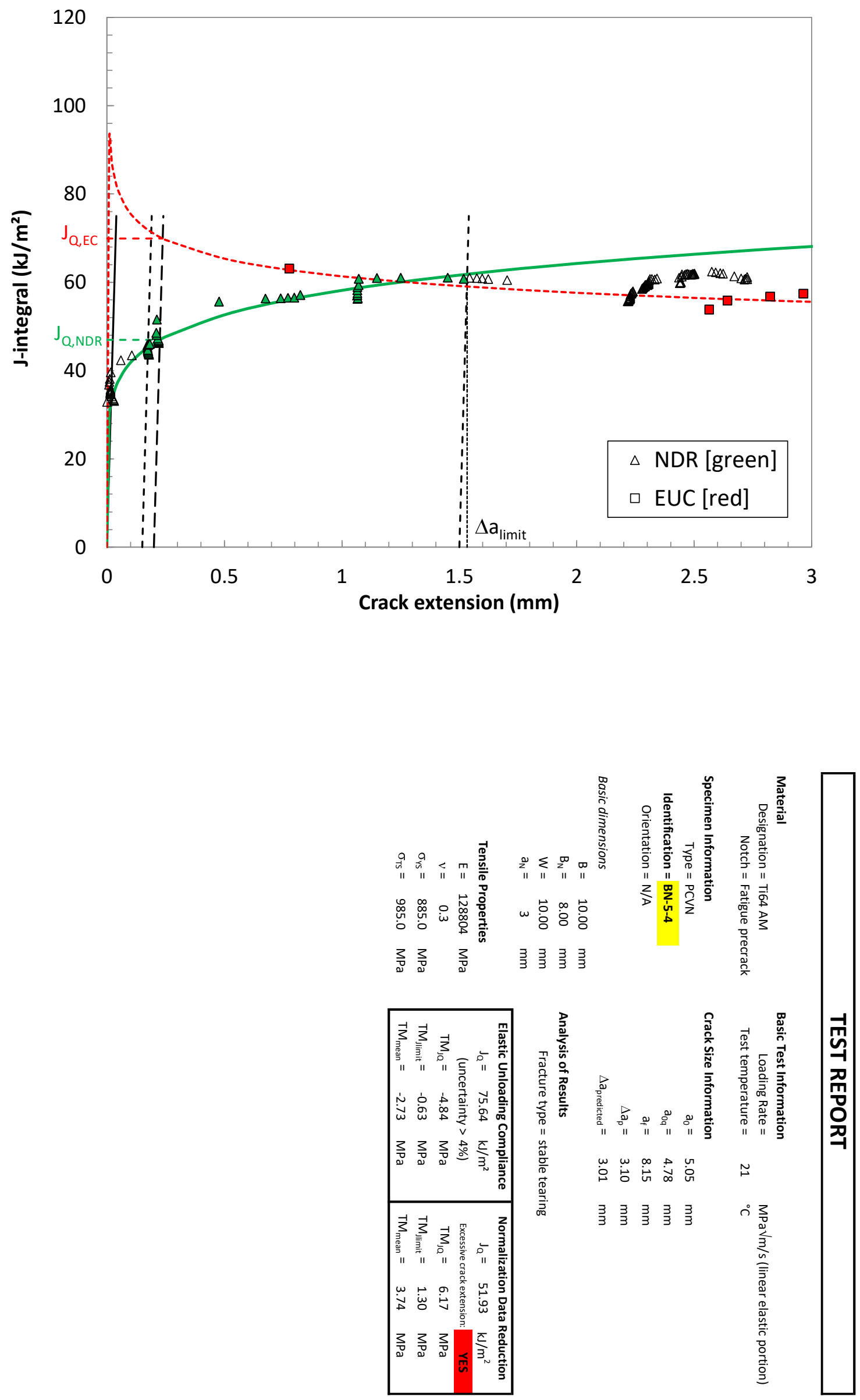

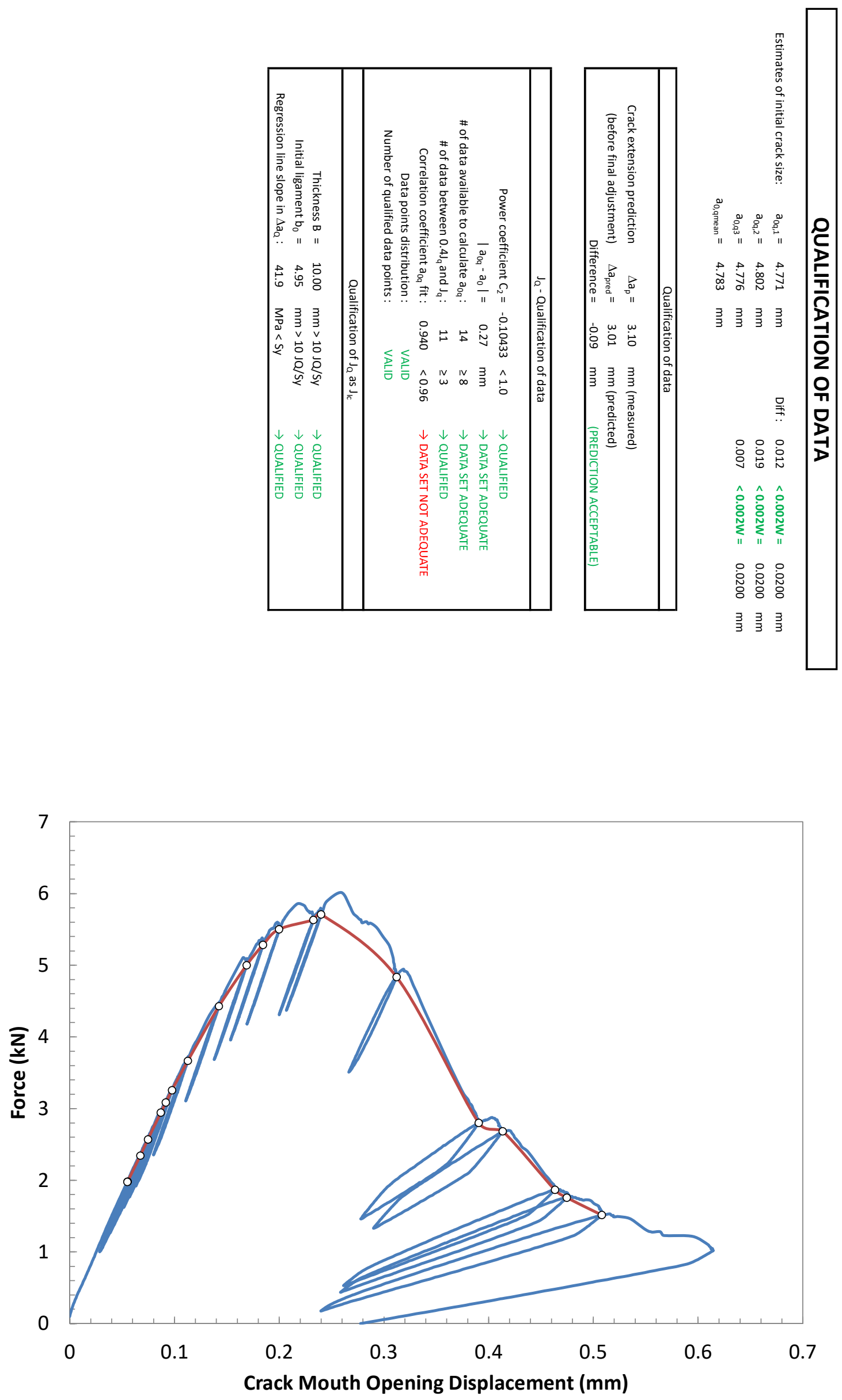

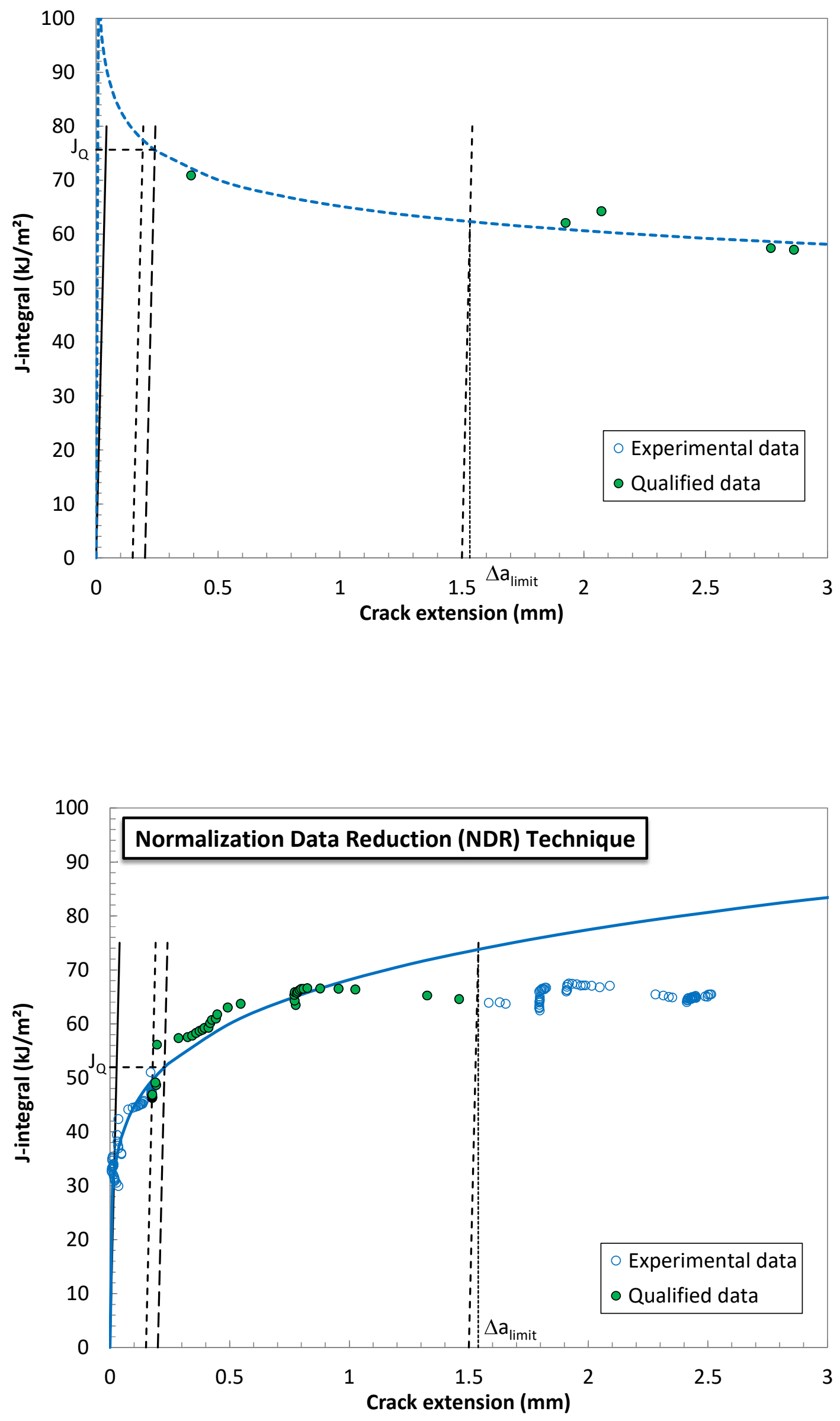


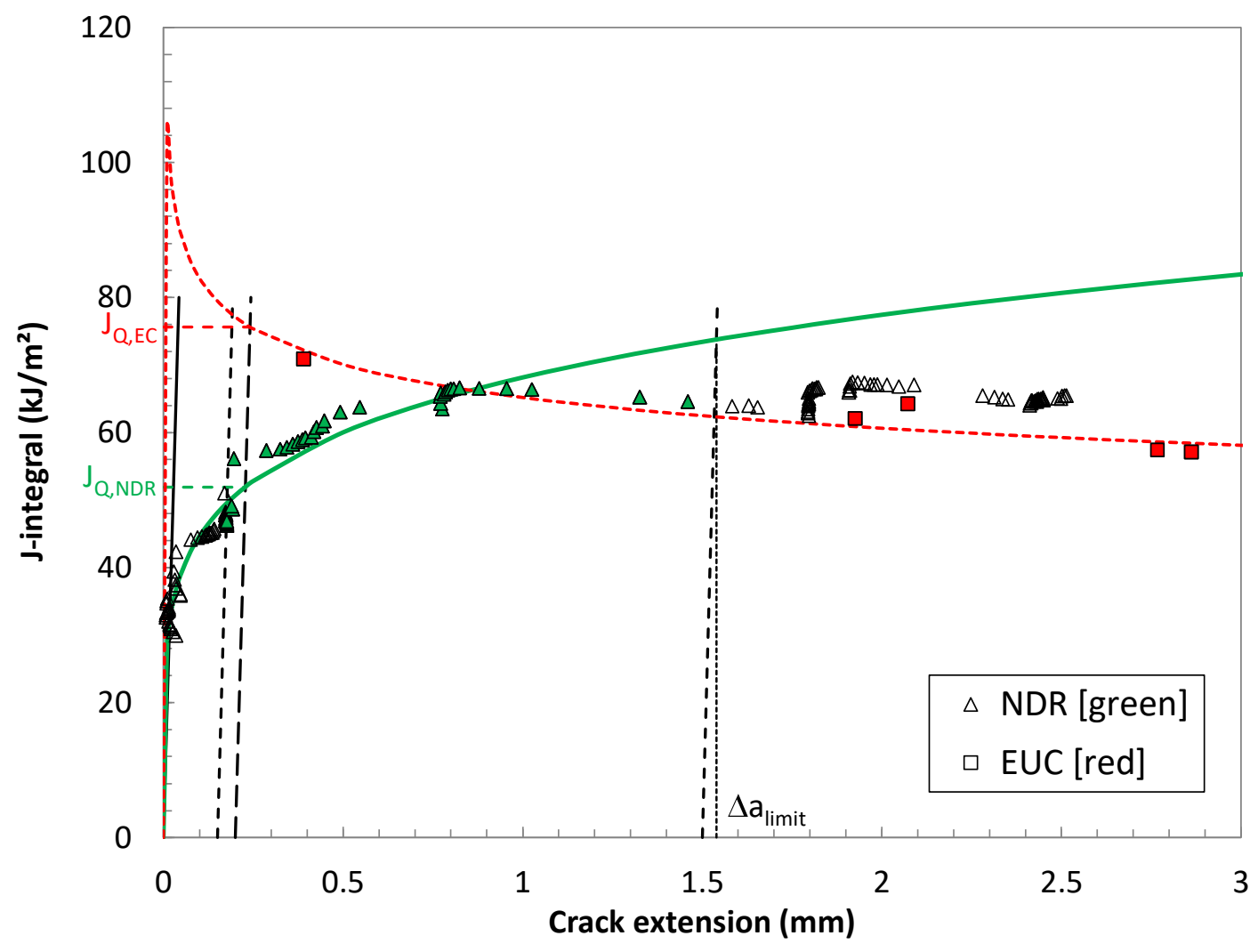

